\title{
LUXURY FASHION ADVERTISING: TRANSITIONING IN THE AGE OF DIGITAL MARKETING
}

$$
\text { by }
$$

Natasha Lamoureux

B.A. Commerce, University of Ottawa, 2011

A Major Research Project presented to Ryerson University

in partial fulfillment of the requirements for the degree of Master of Arts in the Program of

Fashion

Toronto, Ontario, Canada, 2014

(C) Natasha Lamoureux 2014 


\section{AUTHOR'S DECLARATION FOR ELECTRONIC SUBMISSION OF A MAJOR RESEARCH PROJECT}

I hereby declare that I am the sole author of this MRP. This is a true copy of the MRP, including any required final revisions.

I authorize Ryerson University to lend this MRP to other institutions or individuals for the purpose of scholarly research.

I further authorize Ryerson University to reproduce this MRP by photocopying or by other means, in total or in part, at the request of other institutions or individuals for the purpose of scholarly research.

I understand that my MRP may be made electronically available to the public. 


\section{Abstract \\ LUXURY FASHION ADVERTISING: TRANSITIONING IN THE AGE OF DIGITAL MARKETING}

Many luxury retailers fear embracing digital touchpoints, believing it could diminish a brand's integrity. This study explored luxury fashion brands' transition from traditional marketing strategies into the current "digital age" and experiential economy. The research encompassed a 2-phase qualitative content analysis: Phase 1 used an inductive approach that analyzed and categorized print advertisement images from Vogue US 1980 and 2013 into 3 major categoriestypes of product or service, overall presentation, and overall appearance of digital content. Phase 2 consisted of a deductive approach that examined Chanel's and Burberry's online and social touchpoints. Findings showed that both luxury retailers understand the importance of aligning and maintaining a consistent, appealing brand image across all marketing channels to guarantee success. Marketers and managers must pay attention to the aforementioned constructs if they wish to maintain consumer brand loyalty and emotional engagement by transitioning from traditional into digital marketing strategies. 


\section{Acknowledgements}

This major research project would not have been possible without the guidance of my committee members, help from friends, and support from my family.

I would like to express my deepest gratitude to my thesis advisor, Dr. Hong $\mathrm{Yu}$, for her patience, excellent guidance, and of course her advice and unsurpassed knowledge of marketing and retail management. The good advice and support of my second supervisor, Sandra TullioPow, has been invaluable on an academic level, for which I am extremely grateful.

English is not my first language, so I am most grateful to Susan Goldstein, József Szabó , and Mark Poulin for the editing of this major research project. With years of experience and expertise, these editors have been able to provide me with a quality final major research project.

I would also like to thank my parents, Judith Clermont (Mom), Jocelyn Lamoureux (Dad), Sarah Yanchyk (Stepmom), my sister Alyssa, and my two brothers Luka and Maxime who together have always given me their unequivocal support, for which my mere expression of thanks does not suffice.

Last, but by no means least, I thank my friends, you know who you are, for their support and encouragement. And I would like to thank Ryan Jones, who is always there to cheer me up and remains by my side through the good times and the bad. 


\section{Table of Contents}

\section{Page}

Author's Declaration................................................................................. ii

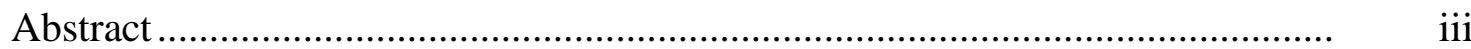

Acknowledgments................................................................................... iv

CHAPTER ONE: INTRODUCTION ...............................................................

The Luxury Fashion Industry: Overview ………………………………....

Research Problem ....................................................................................

Purpose of the Study ................................................................................

Research Questions and Objectives.......................................................... 3

Organizational Structure of the Study ……………………………….......... 3

Key Concepts........................................................................................

CHAPTER TWO: LITERATURE REVIEW …….............................................

Corporate Branding in the Luxury Fashion Industry .................................. 12

Corporate Culture and Corporate Identity .................................................... 13

Brand Image and Identity ....................................................................... 13

Brand Personality and Brand Engagement ................................................ 14

Consistency........................................................................................ 16

Anatomy of the Luxury Fashion Brand ...................................................... 17

Contextualizing Condé Nast Publications .................................................. 20

Vogue Magazine: The Epitome of Luxury Fashion Brands......................... 21

Contextualizing the Advancements of Digital Technology and Media ...... 21

CHAPTER THREE: METHODOLOGY ………….......................................... 25

Phase 1: Traditional Print Media ................................................................. 26

Phase 2: Digital Media ......................................................................... 28

CHAPTER FOUR: FINDINGS AND ANALYSIS .......................................... 30

Phase 1: Traditional Print Media ............................................................... $\quad 30$

Phase 2: Digital Media ........................................................................... $\quad 38$

CHAPTER FIVE: CONCLUSION.............................................................. 61

Summary of Key Findings.................................................................. 61

Implications and Recommendations .......................................................... 64

Limitations and Future Developments ....................................................... $\quad 65$

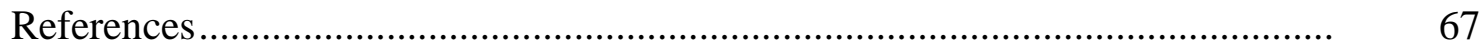

List of Appendices ............................................................................... 


\section{CHAPTER ONE: INTRODUCTION}

\section{The Luxury Fashion Industry: Overview}

Recent studies have shown that the rate of growth and consumption of luxury brands continues to increase annually. In fact, the current market value of the global luxury fashion industry is estimated to exceed US $\$ 317$ billion and that figure is expected to grow by up to $3 \%$ due to the increasing demand for luxury brands (Zargani, 2014). These statistics indicate that exclusive luxury fashion brands have in effect become significantly more accessible to consumers (Fionda \& Moore, 2009). The growth in disposable personal income is one of the factors contributing to the increasing demand for luxury commodities (Nueno \& Quelch, 1998). The well-established luxury markets (i.e., those of North America and Asia) seem to have become saturated. A recent worldwide study of different trends in consumer luxury goods stated that $46 \%$ of wealthy consumers in the United States expect their household incomes will "significantly increase" during the next 5 years; in China, the response to the same question was 74\% (Zargani, 2014, pp. 32-33). Another potential reason why consumers purchase luxury brands is because fashion allows individuals to portray an image or identity to society. Fashion is a form of social communication.

Moreover, consumers have traditionally attributed the concept of luxury with exclusiveness, status, and quality. Luxury, derived from the Latin word luxus, means “indulgence of the senses, regardless of cost" (Nueno \& Quelch, 1998, p. 62). Accordingly, fashion luxury brands convey these attributes as an important component of their brand image. In the past, individuals who purchased luxury goods felt such goods imbued them with social status and appearance; thus, signaling wealth. Vigneron and Johnson (2004) stated that the "consumption of luxury brands may be important to individuals in search of social representation 
and position. This means that [the] social status associated with a brand is an important factor in conspicuous consumption" (p. 489). Therefore, knowing that luxury fashion brands have a strong association with conspicuous consumption, indulging in the purchase of luxury fashion goods as a way to express social standing and success has become widely accepted. Overall, statistics show that the rate of growth and consumption of luxury brands continues to increase annually. When consumers purchase luxury fashion goods, they attach key attributes to the luxury brand (e.g., exclusiveness, status, and quality).

\section{Research Problem}

There are many areas of growing interest in the research literature concerning luxury goods; these include: competition within luxury markets, controversies relating to the democratization of luxury, as well as online and traditional marketing strategies of luxury retailers (Tynan, McKechnie, \& Chhuon, 2010). Specifically, globalization of the luxury fashion industry and rapid technological advancements have "presented luxury consumers with many brand choices, leading to fierce competition of firms" (Sol, Parsons, \& Yap, 2013, p. 403). This fierce competition amongst new luxury and mass prestige brands continues to rise, making it difficult for firms to control and preserve the original image of exclusive high-fashion luxury brands on a global scale (Choo, Moon, Kim, \& Yoon, 2012, 81). Studies have shown that marketing in the luxury goods sector has historically relied heavily on traditional mass media to convey the aforementioned attributes as an important component of their brand image. Marketing has entered a digital era, thus pressuring many luxury fashion firms to adopt new marketing touchpoints, such as in-store, online, social, and mobile. However, many luxury fashion companies are hesitant in adopting these digital touchpoints in fear that it will diminish the brand's integrity and exclusivity. 


\section{Purpose of the Study}

The purpose of this study is (a) to expand the understanding of how traditional marketing strategies of luxury fashion brands transitioned into our so-called Digital Age and experiential economy, and (b) to make implications that marketers and managers should adopt these multiple digital marketing touchpoints and, when doing so, ensure that they are carefully delivering a compelling and consistent shopping experience that continues to build their customers' brand loyalty and emotional attachment. This study will contribute to new marketing literature by integrating traditional marketing with digital marketing initiatives. This study should provide marketers and managers a better understanding of how other luxury providers have successfully adopted these new tools. These new tools (online, social, in-store, and mobile) empower the consumer to become more involved with the luxury brand by reinforcing brand awareness and top-of-the-mind recall. When consumers are engaged with a brand, they not only participate but also feel like they are in control.

\section{Research Questions and Objectives}

The overarching research question is as follows: How have traditional marketing strategies of luxury fashion brands transitioned into our Digital Age and experiential economy? Specifically, the objectives of this study are:

1. To compare and contrast print advertisements featured in Vogue US issues in 1980 and 2013.

2. To identify and describe the major themes of the print advertisements in 1980 and 2013.

3. To explore and investigate the presence of digital marketing strategies of the selected luxury fashion brands: Chanel and Burberry. 
4. To discuss the implications of the study and make recommendations for how to market luxury fashion brands in the Digital Age and experiential economy.

\section{Organizational Structure of the Study}

Chapter 1 provides a brief overview of the luxury fashion industry. Since research in digital marketing is in its infancy, this section frames the research problem and suggests that there is a need for luxury brand retailers to understand the importance of adopting these multiple digital touchpoints and how they impact consumers. Key concepts are defined, and the research question and a series of research objectives are clearly stated.

Chapter 2 outlines theoretical approaches from different disciplines, such as sociology, anthropology, and marketing, and also makes use of existing empirical data. Different academic literatures related to the conceptualizations of corporate branding are reviewed and the main components of corporate branding are defined. Also, because a relevant, clear, and well-defined corporate brand strategy is essentially associated with a solid brand identity, concepts related to brand identity and brand personalities are investigated. The chapter outlines the overarching theoretical framework that supports this study: Principal Luxury Brand Dimensions (Fionda \& Moore, 2009). It states that the principal luxury brand is composed of the following nine dimensions: brand identity, marketing communications, product integrity, brand signature, premium price, exclusivity, heritage, luxury environment and experience, and culture. These nine interrelated luxury fashion brand dimensions are important to the creation and maintenance of the success of a luxury fashion brand. The historical position of the media used for this study (i.e., magazines) and a brief background on Condé Nast Publications and, specifically, Vogue magazine are provided to contextually situate the reader. Lastly, the literature review will include an introduction to the advancements in digital technology and digital marketing. 
Chapter 3 provides the reader with an in-depth understanding of this study's research methodology. It outlines the research process undertaken in this study, specifically using a qualitative approach. Content analysis is used for data collection. Phase 1 of the methodology employed an inductive content analysis on traditional print media. The sample used for the analysis consisted of digital print advertisement images, retrieved through the Vogue archive in the Ryerson University Library. Six published issues were selected from January to June for two different time periods, 1980 and 2013. In total, a combination of 12 issues were analyzed, compared, and contrasted. The rationale for selecting these periods was to identify changes and trends in advertising messages before and after the arrival of the Internet and social media platforms. Phase 2 of the methodology involved a deductive content analysis on Chanel and Burberry, two luxury fashion brands. The theoretical framework selected for coding was the Principal Luxury Brand Dimensions (Fionda \& Moore, 2009), which defines nine principal dimensions that make up a luxury brand. The main sources used for Phase 2 were the Chanel and Burberry websites and social media platforms, specifically Facebook and Instagram.

Chapter 4 presents the results of the study are presented. It is shown that the findings from this study will provide managers with a guide to optimizing their digital branding strategies to effectively retain customer brand loyalty and emotional attachment. In other words, this study is shown to bridge the gap between traditional marketing strategies and digital marketing strategies for luxury firms. By reutilizing a luxury firm's traditional marketing strategies, this study provides insight that will help lead to more conversion and engagement across all channels.

Chapter 5 concludes the study with a discussion of the findings and the implications for luxury fashion marketers and management. 


\section{Key Concepts}

The following key concepts must be defined in order to set the parameters of this study. The vast amount of academic literature and research surrounding branding and media makes it increasingly difficult to find universally accepted definitions of the following key concepts.

\section{Fashion}

The diversity of disciplines and approaches within the literature on fashion are complex. There are many theoretical explanations of fashion that are based on numerous fashion histories such as Veblen, Simmel, and Baudrillard. Fashion also deals with industry, manufacturing, marketing, design and aesthetics, consumption, and lifestyle (Entwistle, 2000). Overall, there are many different viewpoints that stem from a variety of fields. This study defines the term "fashion" according to the two following theorists: Barnard and Entwistle. Barnard (2007) offers different senses of the word "fashion," such as "the action or process of making," "dress," "manner," "a particular shape or cut," "characteristic or habitual practice," and "form" through to "consumer goods in the current mode" and "latest and most admired style" (p. 2). Entwistle (2000) furthers this definition and discusses that fashion is not just about the body but also about the fashioned body; a produced and therefore cultured body (as cited in Barnard, 2007, p. 4). There is no natural body, but rather fashion is to make or produce a body. This cultural phenomenon can be described as "differently cultured bodies communicate different things (meanings), by means of the different things (clothes) that they wear" (Barnard, 2007, p. 4). The added materials of adornment are presented onto the wearer's body that display and stimulate an aesthetic response in which the body now carries a number of messages with social or psychological significance (Barnard, 2007, 110). In other words, fashion is a form of social communication, which allows consumers to express their lifestyle or style of living such as their 
“cultural affiliation, social status, family background, personality, motivation, cognition, and marketing stimuli” (Li, Guoxin, \& Kambele, 2012, p. 1517).

\section{Luxury}

Luxury, derived from the Latin word luxus, means "indulgence of the senses, regardless of cost" (Nueno \& Quelch, 1998, p. 62). Luxury is further defined in this study as material objects, or services that "contribute to luxurious living by providing an indulgence or convenience beyond the indispensable minimum" (Li et al., 2012, p. 1517). Specifically, luxury will refer to a category of prestigious brands and its symbolic values that have a strong connection to socioeconomic and cultural contexts.

\section{Luxury Fashion Brand}

Kapfere defines luxury goods from an economic perspective as "luxury objects are those whose price/quality is the highest of the market" (as cited in Schroeder \& Salzer-Morling, 2006, p. 62); thus, they are an oddity where quality means tangible functions, and intangible represents reputation and image. The core characteristics of a luxury fashion brand is: "exclusivity, premium prices, image and status which combines them more desirable for reasons other than function" (Fionda \& Moore, 2009, p. 2). In other words, the term "luxury fashion brand" throughout this study is defined as being expensive, with exquisite craftsmanship, high-quality, and perceived by the consumer as being "rare, exclusive, prestigious, and authentic and that offers high levels of symbolic and emotional value" (Li et al., 2012, p. 1517). Affordable indulgences and premium versions of mainstream brands are excluded from the definition of luxury brands.

\section{Fast Fashion Brand}

The term "fast fashion brand" in this study refers to "low-cost clothing collections based 
on current luxury fashion trends" that is "by its very nature, a fast-response system that encourages disposability" (Joy, Sherry, Venkatesh, Wang, \& Chan, 2012, p. 275). It also "helps sate deeply held desires among young consumers in the industrialized world for luxury fashion, even as it embodies unsustainability" (Joy et al., 2012, p. 273). Fast-fashion companies succeed on fast-cycles: "rapid prototyping, small batches combined with large variety, more efficient transportation and delivery, and merchandise that is presented 'floor ready' on hangers with price tags attached" (Joy et al., 2012, 275). Fast fashion replaces "exclusivity, glamour, originality, and luxury with 'massclusivity' and planned spontaneity” (Joy et al., 2012, p. 276).

\section{Traditional Mass Media}

David Demers (2005) provides the framework of how traditional mass media is defined in this study. Firstly, mass media is defined as "organizations that produce news or entertainment content and distribute that content to a large number of geographically separated people through a technologically based medium" (Demers, 2005, p. 182). The seven traditional mass media components are books, newspapers, magazines, motion pictures, recording industry, radio, and television (Demers, 2005). Thus, the Internet is somewhat excluded from this definition in this study because it is not a mass medium; "it is a technology and a method of delivering information to people" (Demers, 2005, p. 182).

\section{Experiential Economy}

Experiential economy is referred throughout this study as "the consumption is only a process; the memory of experience will be preserved in the minds of consumers permanently at the end of the process. ... Goods and services become commoditized; customer experiences that companies create will matter most" (Xiao, 2011, p. 26). There are two types of dimensions that a consumer can experience such as passive participation or active participation and the connection 
or environmental relationship that a consumer experiences via an event or performance (Xiao, 2011). This is then further categorized into four subcategories: entertainment, educational, escapist, and aesthetic. Each of these four subcategories is self-explanatory and it is unnecessary and irrelevant to the study to define them in great detail.

\section{Digital Economy}

The digital economy represents the "pervasive use of IT (hardware, software, applications, and telecommunications) in all aspects of the economy, including internal operations of organizations (business, government, and non-profit); transactions between organizations; and transactions between individuals, acting both as consumers and citizens, and organizations" (Malecki \& Moriset, 2007, p. 5). This includes not only the Internet and personal computers, but other technology products like mobile devices, GPS units, PDAs, MP3 players, and digital cameras. It also ranges to "consumer products such as washing machines, cars, and credit cards, and industrial products like computer numerically-controlled machine tools, lasers, and robots" (Malecki \& Moriset, 2007, p. 5), thus, anything that can enable digital functionality and connectivity. This definition is further detailed in the next section.

\section{Multiple Marketing Touch Points}

The online environment allows for marketers via retailers to utilize this opportunity to implement interactive and personalized marketing tools. The marketing tools mentioned throughout this study are defined as follows:

Social media marketing. This type of marketing is a tool that generates word of mouth advertising over the Internet. It is important to differentiate these two terms: social media and social networking. Social media is a strategy used as an outlet for broadcasting information with a broad audience, while social networking is a tool for connecting people with other people who 
share common interests and enable them to build relationships through community (Edosomwan, Prakasan, Kouane, Watson, \& Seymour, 2011). Social networking websites include Facebook, Twitter, LinkedIn, blogs, forums, and YouTube.

Online marketing. A website is not only a tool of the dissemination of corporate identity, but also the platform of internet marketing. This is a marketing tool that allows online retailers to "visually portray their brand, personality and identity via these visual stimuli [which impacts] upon the consumer's emotional response, behavioural reaction and hedonic experience." (Magrath \& McCormick, 2013, p. 116). Marketers and managers are realizing the importance of transforming the consumer's online information search; that is, using a website's interface to create a highly positive Web experience that is capable of delivering intrinsic value in the form of escapism and enjoyment (Mathwick \& Rigdon, 2004). Therefore, consumers' behaviour and attitude towards a brand is further enhanced when they participate in an engaging and enjoyable online experience via a firm's website (Mathwick \& Rigdon, 2004). Some generic online marketing strategies could include "search marketing, display advertising, e-mail marketing and affiliate marketing ... [and] marketing efforts within web sites such as visual merchandising, sales promotion and social media" (Magrath \& McCormick, 2013, p. 116).

In-store marketing. In-store marketing by definition is referred to as retail-based, which consists of the retailers and manufacturers implementing in-store promotional initiatives based on their strategic marketing objectives. There are many factors that influence in-store decisions such as: price markdowns, in-store promotions, displays, store atmosphere, service, stock outs, and store layout (Fam et al., 2011).

Mobile marketing. Marketers and managers have recently started implementing Mcommerce which refers to consumers browsing and purchasing from online retailers with the use 
of mobile devices. Thus, the consumer's experience is no longer limited to E-commerce-a device that provides access to the Internet via a personal computer where the consumer can also browse and purchase from online retailers (Magrath \& McCormick, 2013). Two types of mobile platforms exist: the mobile website and the mobile web app. Mobile website refers to "the online web site viewed on the mobile browser"; and the mobile web app is referred to "the retailer's web site, accessed via the mobile browser which will have been formatted for mobile usage" (Magrath \& McCormick, 2013, p. 117). 


\section{CHAPTER TWO: LITERATURE REVIEW}

\section{Corporate Branding in the Luxury Fashion Industry}

The conceptualization of corporate branding is a noteworthy topic within the academic literature (de Chernatony, 2002; Ewing, 2006; Meierer, 2011). Some suggest that this popularity in the marketing literature is because corporate brands add shared values to not only the products and services that are offered by the company but also to the brand team (Harris \& de Chernatony, 2001). It is important to clarify the definition of corporate branding, as it is a recurring concept throughout this research paper. It is defined as a "holistic brand management approach adopted by firms to craft a unique corporate identity" (So et al., 2013, p. 405; see Appendix 1, Figure 1). Corporate identity and corporate reputation are dynamically interconnected and form integral components to a holistic branding model; within each concept, subcategories include issues related to strategic choices, corporate expression, brand image, and reputation dimensions.

Different academic literatures related to the conceptualizations of corporate branding are reviewed such as corporate culture and corporate identity. The main components of corporate branding are defined, such as brand image and identity. Also, because a relevant, clear, and welldefined corporate brand strategy is essentially associated with a solid brand identity, concepts related to brand identity and brand personalities are investigated. The overarching theoretical framework-Principal Luxury Brand Dimensions' (Fionda \& Moore, 2009)—used for supporting this study is outlined. The historical position of the media used for this study (i.e., magazines) and a brief background on Condé Nast Publications and, specifically, Vogue magazine are provided to contextually situate the reader. Lastly, the literature review will include an introduction to the advancements in digital technology and digital marketing. 


\section{Corporate Culture and Corporate Identity}

The definition of corporate culture may vary according to the theoretical base upon which it is built. While there is not a strong consensus regarding the definition of corporate culture, it may be loosely defined as "the pattern of shared values and beliefs that help individuals understand organizational functioning and thus provide them with the norms for behavior in the organization" (Deshpandé \& Webster, 1989, p. 4). This definition is further formalized through the concept of corporate identity, which includes the core values, philosophy, and strategy of the organization (Meierer, 2011). Corporate identity can be referred to as "the distinct attributes of an organization and as such addresses the questions 'what are we?' and 'who are we?"' (Balmer \& Gray, 2003, p. 979). It is important that there is a mutual understanding that corporate branding endorses the brands of the company's products.

\section{Brand Image and Identity}

Traditionally, firms have used high-status brand names as part of their branding strategy in order to differentiate their brand image from one another (Choo et al., 2012). When referring to the brand image of an organization, it is defined as

the current and immediate reflection that the stakeholders have towards an organisation.

... It is related to the various physical and behavioural attributes of the organisation, such as business name, architecture, variety of products and services, tradition, ideology, and to the quality cues communicated by the organisation's products, services, and people. (Abratt \& Kleyn, 2012, p. 1055)

That is to say, brand image is how the consumer perceives and interprets the brand identity.

Brand identity revolves around the ways the firm presents the brand's meaning to its target audience. Luxury fashion firms can achieve their desired corporate brand identity by 
enabling various corporate branding dimensions. Characteristics of corporate brands include cultural, intricate, tangible, ethereal, and committed (Balmer \& Gray, 2003). However, there are multiple frameworks that theorists have developed to illustrate the dimensions of corporate branding; for example, Harris and de Chernatony (2001) argue that there are six key elements of corporate branding that firms use for brand identity. They summarize them as brand vision, culture, positioning, personality, relationship, and presentation; each component of the model is mutually reinforcing and consistently interacting with one another (Harris \& de Chernatony, 2001).

On the other hand, others have proposed that there are four interrelated dimensions that make up a strong corporate brand: visual identity, brand promise, brand personality, and brand communication (Abratt \& Kleyn, 2012). A strong brand identity can be achieved through the following factors: "impeccable product craftsmanship, innovation, recognizable style, exclusivity, and/or premium pricing" (So et al., 2013, p. 404). Hence, a relevant, clear, and welldefined brand strategy is essentially associated with a solid brand identity (So et al., 2013). Therefore one could assume that the four traditional Ps of marketing — product, place, promotion, price-are no longer sufficient for a brand to succeed in this increasingly customer-focused marketplace (Sullivan, 2009). Nowadays, firms need to pay close attention to two important components of branding: brand personality and brand engagement.

\section{Brand Personality and Brand Engagement}

Thus far, a combination of corporate branding components have been established and each one is critical to strengthening a firm's brand visibility and market positioning of its luxury fashion brands. As a result, a clearly defined corporate brand will provide the firm with "a sustainable competitive advantage that drives loyalty" (So et al., 2013, p. 405). In turn, that loyalty influences consumers to identify themselves with the brand. The concept of brand 
personality refers to the "set of human personality traits that are both applicable to and relevant for brands" (Geuens, Weijters, \& De Wulf, 2009, p. 97). It is how the consumer associates his or her own self, an ideal self, or a specific dimension of the self to a brand by imbuing these brands with human characteristics (Aaker, 1997). This symbolic use of brand in turn allows consumers to consider these brands as if they were, for example, celebrities or historical figures. It follows that brand personality plays a crucial role in the performance of the firm by nurturing consumer engagement; thus, brand engagement allows for consumers to relate to brands in multiple ways, under such categories as brand resonance, brand love, brand commitment, brand loyalty, and brand involvement (Goldsmith \& Goldsmith, 2012).

Many firms in the luxury fashion industry have yet to perceive the importance of brand engagement — "the emotional attachment customers have with a brand"—or simply have neglected it as a priority (Sullivan, 2009, p. 20). Therefore, luxury consumer marketers need to ensure that they are placing more emphasis on the emotional experience. Loyalty drives emotional attachment and, as such, allows firms to truly engage with the premium consumers during their purchasing decisions. This creates a sense of ownership and higher involvement with brands during brand consumption (So et al., 2013). Customers who are emotionally engaged with a brand are one of the leading indicators of a profitable firm (Sullivan, 2009). Revisiting the concept of brand image, one can now see it as a "subjective and perceptual phenomenon, which is formed through reasoned and emotional consumer interpretation and which is affected by marketing activities, by context variables, and by the characteristics of the perceiver" (Meierer, 2011, p. 29).

Corporate reputation, building and maintaining customer loyalty, as well as charging a premium price are three business practices that luxury fashion brands have utilized in their 
corporate branding strategies (So et al., 2013). It is also important for firms to pay greater attention to how they integrate and coordinate these corporate branding strategies on a global level. Firms need to identify with the "coherence of branding decisions across national markets and build an effective international brand strategy that transcend national boundaries" (Douglas, Craig, \& Nijsenn, 2001, p. 98).

\section{Consistency}

Consistency is a key concept to managing brands successfully, as it is intuitively appealing for consumers; however, the brand identity and image also has to stay relevant within the local and international market environments (Ewing, 2006). As previously mentioned, corporate brand includes the name and logo of the company (Meierer, 2011). However, it is much more than that; it is a vehicle for those characteristics to communicate with stakeholdersfor example, consumers, employees, and shareholders (Meierer, 2011). Therefore, it is crucial that the senior management team is developing specific strategies in order to achieve their desired brand identity by defining clear missions and values (de Chernatony, 2002). In other words, consistency is an element that must be present among brand management and the management team in order to have an efficient global communication of the corporate brand across all marketing channels (Meierer, 2011). Therefore, this basic concept must be implemented, maintained, and adapted accordingly, but certain parameters must be adjusted geographically, both locally and globally. This concept must also be applied to a company's online presence, whether it is through their official website or social media platforms.

Most advertised brands found in mainstream North American print media are rarely local brands but rather international brands from Europe and United Kingdom (i.e., Hermès, Chanel, and Burberry). Therefore many luxury firms including the top four conglomerates Louis Vuitton 
Moët Hennessy, Gucci Group, Prada, and Richemont Group ${ }^{1}$ within the fashion industry should "examine branding strategy and formulate the basic principles to guide the effective use of brands in the global marketplace" (Douglas et al., 2001, p. 98). It follows then, in implementing a successful corporate branding strategy, fashion luxury firms can create distinguishable brands in order to gain a customer's brand loyalty and preferences (So et al., 2013). Once again, within the corporation, there must be consistency internally, from its vision and mission to the stakeholders, but also externally, from its manufacturing and sourcing as well as distribution channels. This can be achieved with the cooperation of individuals from top managerial levels who are responsible for the viability of a fashion brand (Moore \& Birtwistle, 2004). Overall, as will be shown, a strong luxury fashion brand is composed of nine key dimensions that are interconnected with all of the aforementioned concepts.

\section{Anatomy of the Luxury Fashion Brand}

A luxury firm's overall marketing strategy, from a local and global perspective, is the anatomy of the luxury fashion brand. There are nine key dimensions inherent to the positioning of luxury fashion (Fionda \& Moore, 2009). Each dimension is composed of subcategories that must all be consistent to the creation and maintenance of a successful luxury fashion brand (see Appendix 2).

Brand identity is the first dimension. A clear brand identity relates to the intangible values and brand differentiation (Fionda \& Moore, 2009). Marketing communications is the second dimension. This refers to the various tactics employed to create brand awareness that must consistently translate the same message across all communication channels, such as fashion shows, advertising (both print and digital), as well as celebrity endorsements (Fionda \& Moore,

\footnotetext{
${ }^{1}$ Created in 1988, Richemont Group "owns several of the world's leading companies in the field of luxury goods [such as] Cartier, Van Cleef \& Arpels, Piaget, Vacheron Constantin, Jaeger-LeCoultre, IWC, Panerai and Montblanc" (Richemont, 2014, para. 1).
} 
2009). Other methods, included in Fionda and Moore's study, are direct marketing, sponsorship, and public relations. These methods are not explored in this current research study. The third dimension is product integrity, which includes various elements: the quality of the product, the craftsmanship, and the attention to detail. Luxury fashion brands achieve their status as a highfashion brand because they are continually investing in innovation and creativity in order to stand out from their competitors (Fionda \& Moore, 2009). The fourth dimension is the brand signature. This refers to iconic products that are closely linked to the company's heritage. The iconic product symbolizes the brand signature. The designers' styles, the designers' typography, and the brand DNA is coherent and consistent throughout the collection and products they sell (Fionda \& Moore, 2009). Product details related to colour, fabric and silhouette are also critical elements because they help the brand be widely recognizable (Nueno \& Quelch, 1998).

The fifth dimension is premium price. By demanding high prices, a barrier of entry further develops luxury brand status. The price is to reflect the aforementioned attributes associated with luxury fashion brands (Fionda \& Moore, 2009). Luxury brand positioning forms the sixth dimension; it is defined as the exclusivity associated with a luxury fashion brand through controlled distribution and accessibility; thus, ensuring that there is a limited production (Fionda \& Moore, 2009). The seventh dimension is heritage. This is related to the history behind the brand and the original creator or current designer of the brand. It allows for luxury brands to adopt a historical positioning strategy where the values of the company are often derived from, and allows the company to maintain its authenticity (Fionda \& Moore, 2009). The eighth dimension indicated is the luxury environment and experience (e.g., flagships, boutiques, wholesale, and licensing). The aforementioned examples provide an experiential environment for the consumer and personalised service (Fionda \& Moore, 2009). Lastly, the ninth dimension is 
culture. This reflects the "management of the internal and external relationships" of the brand; thus, creating the culture of the brand refers to the expertise behind it (Fionda \& Moore, 2009, p. 358).

These nine interrelated dimensions are important to the creation and maintenance of a successful luxury fashion brand. Each adds value to the luxury brand image and positioning, which is then reflected in their brand personalities. Now more than ever, it is important for luxury fashion firms to solidify each dimension by ensuring that communication is consistent and coherent through traditional marketing channels as well as digital marketing touchpoints. In the past decade, changes in marketing mediums have challenged luxury brands to establish consistent emotional connections with consumers.

Luxury fashion brands that are implementing traditional marketing mediums need to understand that the aforementioned concepts are critical strategies that must be integrated into the world of digital marketing. Print advertisements — specifically, image-based advertising-is "the omnipresent signature of corporate culture. Advertisement endorses and legitimates consumerism by saturating the culture with images intended to position commodity purchase at the center of identity" (Hill \& Helmers, 2004, p. 155). Whether it is a print advertisement or an image on a website, luxury fashion brand dimensions should be consistent and coherent through all marketing channels. Condé Nast Publications is the perfect example of a traditional marketing medium that will serve as the foundation for this study. Not only have they implemented digital marketing channels but they have also incorporated much digital-related content throughout a variety of their branded magazines, such as Vogue and its official website. In order to better understand how luxury fashion brands are incorporating digital content into their branding strategies, the print advertisements of Vogue (US) are analyzed. Background information on 
Condé Nast Publications and Vogue are contextualized below to allow the reader to have a historical understanding.

\section{Contextualizing Condé Nast Publications}

Condé Nast, a division of Advance Publications Inc., targets the world's most influential audience (approximately 164 million consumers); it is the face of the industry-leading print and digital media brands: Allure, Architectural Digest, Ars Technica, Bon Appétit, Brides, Condé Nast Traveler, Details, Epicurious, Glamour, Golf Digest, Golf World, GQ, Lucky, Self, Teen Vogue, The New Yorker, Vanity Fair, Vogue, W, and Wired. The company dates back to 1909 when Condé Montrose Nast bought Vogue and established Condé Nast Publications in 1923. Eventually, it became the first company to publish international editions (e.g., British Vogue in 1916). Now they own 18 consumer magazines, four business-to-business magazines, 27 websites, and over 50 mobile and tablet apps. While this covers a wide range of topics (travel, food, home, and culture), fashion is the main focus of the company. Vogue was first created in 1892 as a weekly journal of society and fashion related news in New York. Condé Nast is considered to be the creator of the class publication; "nothing more or less than a publication which looks for its circulation to those only who have in common a certain characteristic marked enough to group them into a class" (Nast, 1923, p. 174) For example, Condé Nast Publications has been able to secure an influential audience of Vogue by targeting those who are the wealthiest, via its ability in selecting and grouping its editorial pages and advertisements. Thus, it is not about having the largest circulation for the masses but rather the cultivation and selection of a discriminating audience who identifies with the brand's values. ${ }^{2}$

\footnotetext{
${ }^{2}$ The "Contextualizing Condé Nast Publications" section is based on the information found on the "Heritage" section of the About Us webpages at www.condenast.com.
} 


\section{Vogue Magazine-The Epitome of Luxury Fashion Brands}

As a leading fashion and lifestyle magazine, Vogue has created a brand identity in which consumers of a specific social class or attitude identify with their advertisements and editorial content. Vogue has come a long way; in a December 2006 edition of the New York Times, book critic Caroline Weber, stated that Vogue is the "world's most influential fashion magazine" (Weber, 2006, n.p.). Anna Wintour became the editor-in-chief of American Vogue in1988, and has established herself as one of the most highly influential figures in the fashion industry. Fashion brands featured as either advertisements and/or editorial content in Vogue magazine were not always like the luxury fashion brands that we see today. This statement will be further explored once the visual content analysis has been completed.

Within the context of brand strategy, advertisements and editorial content in print media, from publications such as Vogue, must adapt to the ever-changing social structures and trends that are present in the macro-environment (e.g., the political, social, technological, legal, and economical). Therefore, it follows that Vogue will likely no longer have the same position within the market as it did 20 years ago. Branding strategies tend to evolve over time, continuously adapting to the environment. Therefore, print media, such as Vogue, continue to be an important medium for luxury fashion brands; as advertisements and editorial content depict a message of a selected brand that they want the targeted audience to decode. The advancements in digital technology and media have gained much popularity over recent years and, thus, must be discussed and utilized.

\section{Contextualizing the Advancements of Digital Technology and Media}

In 1991, the World Wide Web was invented. Since its invention, marketing has been influenced by the tremendous developments in information technology, thus providing new 
media environments. The Internet has been established as a fully-fledged global marketing and communications channel, and can deliver many aspects of any organisation's global marketing strategies ranging from branding, database building and customer acquisition to provide customer service, form relationships, build loyalty and install advocacy in existing customers. (Melewar \& Smith, 2003, p. 363)

In addition, understanding the emotional connections that drive consumers' purchase intentions and how specific marketing touchpoints such as in-store, mobile, and social, can provide the direction for marketing communications (Duboff, 2013). Platt Retail Institute (2013) pointed out that there has been a shift in consumer purchase behaviour. Marketers and management must acknowledge that it is not the buying process that is changing but rather the path to purchase (i.e., the multiple channels through which consumers can execute purchases are changing). The paths can range from a company's website, digital marketplace, catalog, mobile, and other various digital communication devices (Platt Retail Institute, 2013).

However, there are many constraints that the Internet imposes on global marketing strategies, such as the ease of which the Internet can facilitate damage to a firm's global reputation. Eventually, the Internet will replace traditional mass media and many believe that its popularity as marketing potential for organisations will continue to increase in the future (Melewar \& Smith, 2003). The Internet has been perceived by corporations as a major communication tool that allows them to not only promote their products and services but also to build brand awareness. The Internet is a platform that also allows corporations to have access to demographic data and the history of previous interactions, which in turn allows them to create tailored experiences for visitors (Melewar \& Smith, 2003).

A major online challenge is to achieve a balance between "the Internet's ability to be 
customised and the desire to retain coherence, control, and consistency in global marketing strategies" (Melewar \& Smith, 2003, p. 365). On one side, companies govern their own websites; but have little control over social media platforms as content is user-generated. Another challenge is that consumers also expect that they will receive the same desired level of shopping experience regardless of the purchasing channel they pursue (Platt Retail Institute, 2013). In order to support brand consistency and the online experience, companies are adopting omnichannel marketing (OMC) as opposed to an integrated marketing approach. Adopting OMC strategies prevents corporations from having inconsistent messages across channels that can lead to a negative brand impact (Platt Retail Institute, 2013). Digital Signage Expo surveyed 859 respondents of the American Marketing Association, and members and non-members alike were asked about multi-channel and omni-channel marketing; the results were interesting: the majority of the respondents $(88 \%)$ said they are currently using integrated marketing campaigns, which means they are using various complementary methods to market to their consumers (Platt Retail Institute, 2013; see Appendix 3, Figure 2). Among the different marketing channels, participants selected the following three most important current channels as being: the company's website, the physical selling location, and social media (Platt Retail Institute, 2013; see Appendix 4, Figure 3). However, the participants ranked the company website, physical selling location, and direct sales as the three channels yielding the highest return on investment (Platt Retail Institute, 2013; see Appendix 5, Figure 4).

The growth of social media platforms has caused an exponentially large change in consumer behaviors and expectations (Abrams Research, 2011, 2013). Social networking sites emerged in the 1990s but transformed their web presence a decade later with the development of social media like Facebook, a social networking website launched in 2004 (Edosomwan et al., 
2011). In terms of social media, $74 \%$ of the participants ranked Facebook as being the most important marketing channel (Platt Retail Institute, 2013; see Appendix 6, Figure 5). It is important to differentiate these two terms: social media and social networking. Social media is a strategy used as an outlet for broadcasting shared information with a wide audience; while social networking is a tool for connecting people with others who share common interests and build relationships through community (Edosomwan et al., 2011). The number of affluent users on social media reached 57.1 million in 2011 (Abrams Research, 2011). Therefore, corporations, specifically luxury fashion firms, need to understand the importance of social media as an effective marketing communication tool.

To conclude, in the context of the luxury fashion industry, it is argued that "luxury brands must deliver consistent brand experiences online to see continued success"; and by utilizing the power of social media, firms can "directly communicate with their audiences, promote their brands, and further their brand equity" (Abrams Research, 2011, p. 6). The industry must also understand that the power of social networks differs across the world and the use of social media reflects cultural differences (Universal McCann, 2013). Accordingly, analyzing the pre-digital age and the digital age content is essential for developing a contemporary marketing strategy, and will be further explored in the following chapter. 


\section{CHAPTER THREE: METHODOLOGY}

Research is initiated with straight-forward intentions of "careful inquiry...to discover new or collate old facts" ("Research," 1989, p. 884) yet it may become intricate to implement. Combining all facets of research design entails throughout consideration. Given the emerging context of digital platforms and the decline of print media, what must be considered when developing a corporate branding strategy? This research examines the transition from traditional marketing strategies to digital marketing strategies in order to identify how luxury fashion brands effectively retain customer brand loyalty and emotional attachment through multiple touchpoints.

Qualitative approaches enable exploration of a domain to enhance understanding (Creswell, 2009). Sprague (2005) outlines research methodology as "the details of how to conduct a kind of research - how to select what to observe, how to measure and code, how to apply an analytic strategy" (p. 4). Research designs may be structured as qualitative, quantitative, and/or mixed methods. Based on the nature of the issues being addressed in this study, only qualitative methods were utilized. This study's research questions defined why this approach was most appropriate. Quantitative methodologies builds upon applied mathematics and utilize a standardized set of data analysis techniques (Neuman, 2003, 439). This study is not using statistical procedures because it is not "testing objective theories by examining the relationship among variables" (Creswell, 2009, p. 4). A qualitative approach does not have a standardized set of data analysis techniques but it allows for patterns of similarities and differences to be analyzed, which is the aim of this study (Neuman, 2003). The qualitative research process for this study seeks emerging questions related to digital marketing strategies and makes interpretations of collected data (Creswell, 2009). Content analysis is one of several qualitative approaches and it is used to analyze this study's data. Content analysis as a research method is 
used in the form of analysing written, verbal, or visual communication messages (Elo \& Kyngäs, 2008) using inductive and deductive variables. Some issues concerning the use of qualitative content analysis, whether it is inductive and/or deductive, are the procedures taken by the researcher to ensure that the study is reliable. Specific steps were undertaken in order to maintain accuracy throughout this study's research process. Two validity strategies were used in this study to convey the findings; these included triangulation (different data sources of information combined to examined and build coherent themes) and the use of rich, thick descriptions, which provides many perspectives about the theme, allowing the results to become more realistic and richer (Creswell, 2009). The findings and analysis portions of the research were separated into two phases; two types of secondary sources were used such as printed and digital.

\section{Phase 1: Traditional Print Media}

\section{Description of Sample: Advertisement Inclusion Criteria}

Phase 1 of the methodology employed an inductive content analysis on traditional print media. This approach is defined as categories or codes derived from "a systematic reading of a sample set of the materials to be analyzed, gradually establishing the categories that will be used for subsequent analysis of all the materials" (Martin \& Hanington, 2012, p. 40). The research objective was to examine fashion advertisement images that make up a traditional marketing framework. The data sample included digital print advertisement images retrieved through the Vogue archive at Ryerson University Library. Vogue US was chosen for its popularity as a fashion magazine geared towards a female audience and its high volume of fashion advertisement images. Six published issues were selected from January to June for two different time periods, 1980 and 2013. In total, a combination of 12 issues were analyzed, compared, and contrasted. 
The rationale for selecting these periods was to identify changes and trends in advertising messages before and after the arrival of the Internet and social media platforms. According to many authors and historians, it is difficult to pinpoint the exact moment when and how the Internet first began (Banks \& Card, 2008); some argue that it was in the 1950s following the establishment of a US military project. However, the launch of the World Wide Web, a browsing and shared information retrieval system, was introduced in the early 90s (Moschovitis, Poole, \& Schuyler, 1999, p. 162). Since then, the Internet has become a powerful global medium for communication, content, and commerce; specifically, helping to build a relationship between a consumer and the overall organization (O'Callaghan \& Fahy, 2002). Nonetheless, one can argue that this new connection between the consumer and the multiple digital marketing touchpoints (online, mobile, social, and in-store) has created an emotionless relationship (O'Callaghan \& Fahy, 2002). Notwithstanding previous findings, this study also successfully demonstrates that an emotional experience and brand loyalty can be created between consumers and an organization through multiple digital marketing touchpoints.

\section{Content Variables}

For each selected issue, advertisements were cut and pasted into a PowerPoint document. In total, 12 PowerPoint documents were created and then analyzed. Analysis of the advertised images among both timeframes was grouped according to three major categories; types of product or service, the overall presentation, and the general appearance of the digital content. A table was created accordingly for both time periods (1980 and 2013) against each of the variables of analysis (see Appendix 7, Table 1). Each generalization observed in this table allows for comparisons in regards to the similarities and differences in the brand's overall marketing strategies of that time period. Product and service categories ranged from cosmetics, skin-care or 
anti-aging, fragrance, women's accessories (sunglasses, jewelry, headpieces, scarves, and hats), women's apparel, footwear and handbags, cigarette advertisements, and luxury automobile advertisements.

\section{Phase 2: Digital Media}

Phase two of the methodology involved a deductive content analysis on two luxury fashion brands, Chanel and Burberry. Chanel appeared throughout both time periods in Phase 1 of the methodology. Chanel was selected not only because it was declared as the "Luxury Daily’s 2013 Luxury Marketer of the Year" but also because of its impeccable luxury marketing initiatives. The second luxury brand chosen was the Burberry Group, although this brand has existed since 1856, it did not appear in any of 1980s' issues. Burberry Group was selected for its strong market position and status as a global company. Burberry is said to be "among the quickest to adapt to digital marketing” (Burberry Group PLC, 2013, p. 36). Data collection for Phase 2 took place from March 10, 2014 to March 17, 2014. Approximately 40 hours were spent browsing the content of Chanel's and Burberry's official websites and social media platforms (Facebook and Instagram). Both Chanel and Burberry print advertisements from February 2014 Vogue issue were analyzed for the print marketing communication channel. The rationale for selecting this time period was to determine whether or not their print advertisements reflected their official website and social media platforms.

With deductive content analysis, categories or codes are derived prior to investigation. Codes are typically based on a theoretical framework. The use of a codebook, a document containing a list of codes, was created based on the Principal Luxury Brand Dimensions model that guided its structure so that it could appropriately capture data relevant to brands' marketing strategies, both traditional and digital (Moreno, Egan, \& Brockman, 2011). Codebooks are 
essential tools in categorizing images and content-based text (Liu, Hou, \& Karimi, 2014). The theoretical framework selected for coding was the Principal Luxury Brand Dimensions (Fionda \& Moore, 2009); it is defined as the nine principal dimensions that make up a luxury brand. The principal luxury brand is composed of the following nine dimensions: brand identity, marketing communications, product integrity, brand signature, premium price, exclusivity, heritage, luxury environment and experience, as well as culture. From the nine dimensions, only seven (brand identity, marketing communications, product integrity, brand signature, premium price, exclusivity and heritage) were based on empirical research from digital sources. The other two dimensions (luxury environment and experience, and culture) were based on a review of existing literature due to the limitations of this study. In addition, the content analysis of digital sources was supplemented with literature and previous studies (i.e., Wave, Euromonitor International, and Abrahams Research). Each aforementioned dimension is considered the overarching category (see Appendix 8).

With the use of this theoretical framework, the selected brands were analyzed, compared, and contrasted according to the description for each dimension (see Appendix 2). This study explored Chanel's and Burberry's current corporate brand strategies with emphasis on each of their digital marketing branding initiatives such as online and social media. These nine interrelated key luxury fashion brand dimensions are important to the creation and maintenance of the success of a luxury fashion brand. Findings from this study provide managers with a guide to managing their digital branding strategies in order to effectively retain customer brand loyalty and emotional attachment. In other words, this study bridges the gap between traditional and digital marketing strategies within luxury firms. This study should bring more insight to marketers and managers that will help lead to more conversion and engagement across all channels. 


\section{CHAPTER FOUR: FINDINGS AND ANALYSIS}

\section{Phase 1: Traditional Print Media}

Phase 1 of the methodology employed an inductive content analysis on traditional print media. This approach is defined as categories or codes derived from "a systematic reading of a sample set of the materials to be analyzed, gradually establishing the categories that will be used for subsequent analysis of all the materials" (Martin \& Hanington, 2012, p. 40). The research objective is to examine fashion advertisement images that make up a traditional marketing framework. The sample of analysis was digital print advertisement images retrieved through the Vogue archive in the Ryerson University Library. Vogue US was chosen for its popularity as a fashion magazine geared towards a female audience and its high volume of fashion advertisement images. Six published issues were selected from January to June for two different time periods, 1980 and 2013, and 12 issues were chosen, in total, for their print advertisements images to be analyzed, compared, and contrasted. A summary of the findings and analysis of traditional print advertisement images in 1980 and 2013 are presented below.

General assumptions based on an inductive content analysis have been highlighted into three major categories, with subcategories, in order to grasp a thorough understanding of the similarities and differences of overall marketing branding strategies. A conglomerate of advertisements from multiple channels (radio, television, print, digital, and online) are continuously harassing consumers; approximately $\$ 171.7$ billion has been spent in total advertising to date (Plunkett Research, 2013). Considering the sheer volume of media messages targeted at consumers, it is essential that companies develop and communicate a strong and welldefined corporate branding strategy. The firm's brand visibility and a coercive brand image is crucial now more than ever due to the alarming saturation of brands and an overwhelming 
selection to choose from. The brand identity and image ultimately comes down to the consumers' values and social connection toward a particular brand that they wish to embody. This concept has been coined as the theory of symbolic interaction; thus, the self is socially constructed through multiple sources of imagery that influence their self-construct identity but the meanings that he or she may attach to him or herself through mass media (Ballis Lal, 1995). This explanation can be linked with the following three major categories for all print advertisement images: the types of product or service, the overall presentation and the general appearance of digital content. Analysis did not take into consideration the seasons, collections, or fashion trends of each time periods. Observations for all three categories in 1980 and 2013 are presented below.

\section{First Category: Types of Product or Service}

All 12 issues in 1980 and 2013 featured many of the same types of product or service categories such as skin-care, cosmetics, hair-care, fragrance, women's apparel, jewelry, footwear, and handbags. The information in Table 1 (see Appendix 7) allows for comparison between the different types of product or service categories for each time period. Based on the socio-cultural shift in women's lives, cigarette ads, feminine hygiene ads, contraception and pregnancy-testing ads, home goods or lifestyle ads, and alcoholic beverage ads were much more prevalent product or service categories being advertised in 1980. Possible reasons for this relate to the historical, social, ethical, and political issues that were prevalent in this time period and advertisers responded through the types of products or services being advertised in the 1980 issues (i.e. the women's rights movement in the United States, feminist movements, and/or the Pregnancy Discrimination Act in 1978). Therefore, numerous ads seen in the 1980 issues have incorporated feminist themes in order to target women (Kates \& Shaw-Garlock, 1999). The 
published issues selected in 2013 had fewer feminine hygiene ads, contraception and pregnancy testing ads, home goods or lifestyle ads, and zero cigarette and alcoholic beverage ads. Perhaps, one of the reasons that explain the aforementioned statement is because these categories are not considered luxury fashion goods and no longer have the same value as it did in the 1980s. A considerable amount of service print advertisements in 1980 featured exotic travel destinations, hotels, resorts, airlines, cruises, and other vacation deals (see Appendix 9, Figures 6-10). Most of these advertisements were located near the end of a specific magazine issue. Hardly any of these types of brands were featured in 2013 magazine issues. The same can be said about advertisements that included cut-out coupons or "preferred subscription reservation" in magazine issues from 1980 (see Appendix 10, Figures 11 and 12).

Ads in the 1980s usually depicting commodity-based brands while ads in 2013 portrayed luxury-based brands. The brand mix featured in the 2013 issues ranged from high-fashion labels (Celine, Chanel, or Burberry Prorsum) to fast-fashion or contemporary brands (H\&M, J Brand Jeans, or Rag \& Bone), generally, mixing expensive products with more affordable ones in order to reach the multiple target markets (see Appendix 11, Figures 13 and 14). Globalization and rapid technological advancements have "presented luxury consumers with many brand choices, leading to fierce competition of firms" (So et al., 2013, p. 403). This fierce competition amongst new luxury and mass prestige brands continues to rise, therefore making it difficult for firms to control and preserve their traditional exclusive reputation and brand image on a global scale (Choo et al., 2012). It is crucial that the aforementioned examples of high-fashion companies and fast-fashion or contemporary companies have a defined and strong corporate branding strategy as it will allow them to be profitable and gain competitive advantage. Although Vogue US targets the wealthiest consumers through its editorials and print advertisements, one cannot deny that the 
range of brands, from high-fashion to fast-fashion, and premium to affordable prices, also attract middle-class customers to purchase the latest issue. Magazine issues in 1980 and 2013 demonstrated brand promotion by retailers and department store advertisements such as Saks Fifth Avenue, Neiman-Marcus Company, and Bloomingdales. These specific brands were readily available for purchase. The number of retailers and department stores advertising brands in the 1980 issues was significantly higher than in the selected 2013 issues. Each retailer or department store had approximately one to two page(s) per advertisement spread in each selected published issue (see Appendix 12, Figures 15-21). But, in 2013, each retailer and department store featured about 10 to 15 pages per advertisement spread. Furthermore, the number of pages per advertisement spread varied according to the month the issue was published, some had more than 15 pages of advertising and others had less than 10 pages (see Appendix 13, Figure 22). Brand advertisements in 1980 that were promoted, through a retailer or department store, enumerated a number of retailers and/or department store locations (see Appendix 14, Figure 23). In 2013, approximately one or two retailers and/or department store locations would be listed on advertisements. It was more common to find a brand like Anne Klein being promoted by retailer or department store advertisements in 1980, but promoted as a stand-alone advertisement in 2013 (e.g., Louis Vuitton, Chanel, Dior; see Appendix 15, Figures 24-28).

As previously mentioned, Vogue US must adapt to the ever changing social structures and the trends that are present in the macro-environment such as the political, social, technological, legal, and economical issues. The aforementioned results undoubtedly demonstrate that Vogue US currently no longer has the same position within the market as it did in the 1980s. However, it is difficult to pinpoint if the magazine had any influence with overall company marketing strategies or brand promotion (i.e., brands promoted by retailers and department stores or on a 
standalone basis). Thus, evidence is inconclusive regarding whether it was the magazine's branding strategies or those of the luxury fashion brand. Nonetheless, branding strategies clearly evolved over time, continuously adapting to the environment.

\section{Second Category: Overall Presentation}

The number of total advertising pages varied depending on the month's issue; nevertheless, 1980 showed a higher volume compared to 2013 . In the 1980 issues, the majority of the print advertisements for a selected brand were less than a two-page spread, the bulk of the ads being a one page-spread at the beginning of the issue and a half or quarter page-spread near the end of the issue (see Appendix 16, Figures 29-32). In the 2013 issues, the majority of the print advertisements for a selected brand were more than a two page-spread, oftentimes ranging all the way up to a six-page spread (see Appendix 17, Figures 33 and 34). On average, there were about two full one-page spreads at the end of the magazine for each monthly issue. A possible reason why more ads were featured in 1980 was because it was the most effective marketing channel during that time frame. Vogue US, however, continues to be the highest provider of luxury fashion advertisements. Even though there has been a decline in print magazines, the amount of print magazine advertisement spending is still significantly high — approximately US\$15.1 billion in 2013 - publishers such as Vogue US are transforming their magazine into digital formats for different mediums such as tablet, mobile, and online (Plunkett Research, 2014). A projection of approximately US\$3.5 billion in digital magazine advertisement spending represents a more flexible and wider readership (Plunkett Research, 2014).

The colour palette used in print advertisements images have tremendously changed accordingly for both years. In 1980, ads were often featured in black and white or neutral shades such as tan, grey, and brown as well as primary colours like red and blue. Very rich and bright 
colours were common throughout images in 2013 print advertisements. The front covers for all 12 issues in 2013 featured bright and neon hues. Cover images from both time periods showcased a famous model or celebrity; however, their position on the cover page was different. In the 1980 monthly front page covers, only the face of the women was shown and often she was styled wearing a significant amount of bright coloured makeup and oversized colourful earrings (see Appendix 18, Figures 35-40). In the 2013 monthly front page covers, the entire body of the famous model or celebrity was depicted, in bright coloured clothing in shades of yellow, orange and pink as well as metallic hues. A variety of brands and props (clothing, footwear, accessories, and sometimes handbags) were also showcased (see Appendix 19, Figures 41-46).

Observations were also made based on the content and layout of print advertisement images. Print advertisement images in 1980 were usually crowded with heavy written descriptions persuading consumers with the reasons to purchase the product(s) or service(s) or simply telling a story of the feature brand (see Appendix 20, Figures 47-52). Content also included the brand's name or logo written in large text, a detailed list of store locations and phone numbers, both local and international (sometimes with addresses). Print advertisement images in 2013 were usually less descriptive (with the exception of pharmaceutical ads which included required legal disclosures; see Appendix 21, Figures 53-55). Content usually incorporated the brand's name or logo written in large text and nothing else. Occasionally, there would be images that merged small-scale wording of one or more store locations both local and/or international and sometimes phone numbers (see Appendix 22, Figures 56 and 57).

Conclusions were made in regards to the layout of the type of product or service that was being advertised. In 1980, ads featured a product or service with or without a model (see Appendix 23, Figures 58-63) leading to believe that there were possibilities of brands implying 
themes of autonomy due to potential feminist movements of that time period (Kates \& ShawGarlock, 1999). In 2013, many ads showcased the product or service with more than one model in an environment surrounded by props. The purpose of this marketing strategy is to allow the consumer's imagination to interpret the story or message that is being told. Many 2013 cosmetics, skincare, fragrance, and sometimes women's apparel ads, used celebrities or supermodels as product ambassadors (see Appendix 24, Figures 64-69). Print advertisements are a way of saturating the culture with images in order to influence consumers to connect with the brand through their identity (Hill \& Helmers, 2004).

\section{Third Category: Overall Appearance of Digital Content}

There was an absence of digital content in the 1980 magazine issues because the Internet was non-existent to the general public. The 2013 issues did contain digital content and many print advertisement images displayed a Web page and/or main website address, sometimes in minuscule text (see Appendix 25, Figures 70-73). Other brands prompted consumers with digital jargon to "shop the Digital Flagship Store at gucci.com" (Vogue Archive, 2013, pp. 8-9; see Appendix 25, Figure 74). Numerous brands displayed social media icons such as Facebook, Twitter, Pinterest, and Instagram (see Appendix 26, Figures 75 and 76) as well as hashtags (see Appendix 26, Figure 77). Some of Calvin Klein's advertisement images featured in Vogue US were a part of a YouTube advertising campaign (see Appendix 26, Figures 78 and 79). There are many potential reasons for Calvin Klein to implement this marketing strategy—perhaps due to taking on digital marketing initiatives by being innovative and creative than their competing firms. Several advertisements had QR codes, Quick Response Codes, in print advertisement images, usually located at the bottom left or right corner (see Appendix 26, Figures 80-83). Observations regarding Condé Nast Publication's initiatives in adapting to the digital 
environment were made. Many print advertisements included one full-page spread on their online website (Vogue.com), Vogue Online Archive, and Vogue Insiders (see Appendix 26, Figures 24-87). In addition, a variety of contemporary Condé Nast Publications advertisements were often seen coming out of an IPad (see Appendix 26, Figure 88). There were two types of product or services categories that were not seen in any 1980 issues with the exception of one telephone advertisement (see Appendix 26, Figure 89). Such print advertisements in 2013 featured ads such as telecommunication and computer software brands (i.e., iPhone 5 or Microsoft; see Appendix 26, Figures 90-92), as well as only online websites brands (i.e., Net-APorter and Amazon; see Appendix 26, Figures 93 and 94). Lastly, advertisements featured designer brands that were in collaboration with department stores or retail stores such as Target and Gap; both examples demonstrate digital content (see Appendix 26, Figures 95 and 96). Advertised brands, Condé Nast Publications, and Vogue US, are all adapting and incorporating digital media content, enabling "rich information" to be shared and communicated beyond traditional boundaries.

Phase 2 included examination of two iconic luxury brands, beginning with Chanel and followed by Burberry Group. Each brand was compared and contrasted to determine how each respective brand translated into digital branding initiatives. Data sources used for this phase included each company's' official website, as well as their social media platforms such as Facebook and Instagram. Using the principal luxury brand dimensions model, a codebook was created in order to properly categorize each brand. The first seven dimensions were based on empirical research and the last two dimensions were based on a review of existing literature due to the limitations of this study. Each dimension considered the overarching category subsequently followed by relevant subcategories (see Appendix 8). 


\section{Phase 2: Digital Marketing}

\section{First Dimension: Brand Identity}

In theory, the brand identity is created by the company; therefore, it is the "unique set of brand associations that the brand strategist aspires to create or maintain" (Srivastava, 2011, p. 341). Each brand not only possesses an identity but also carries with it an image that is then communicated to the target audience (Srivastava, 2011). The brand image is often defined as how the brand is perceived by the consumer. Brand identity and brand image are often used interchangeably. From a marketer's perspective, both Chanel and Burberry project a favourable image that conveys distinctiveness. These companies have each built a brand that consumers can trust, and in return have been able to reduce the perceived risk and post-purchase cognitive dissonance (Srivastava, 2011). In other words, this refers to the negative attitudes that consumers experience once they have purchased a product or service (Clark \& Das, 2009). Therefore, by examining each of their official websites and social media, one can assume that the consumer's perception of each brand image is exactly the image each brand strategist is striving to maintain. Both Chanel and Burberry are strong brands. This strength is apparent on each of their official website home pages (www.chanel.com and www.burberry.com), as well as on social media: Facebook and Instagram.

The assumptions below are based on observations from Chanel's official website (see Appendix 27, Figure 97A) and Facebook page (see Appendix 27, Figure 97B). Chanel does not have an official Instagram account but Burberry does. And the analysis throughout this phase is complemented with existing literature in order to connect the reader back to key concepts.

One assumption in relation to Chanel's brand identity is that the brand values of the Chanel company are derived from Gabriel Coco Chanel herself, the founder who pioneered the 
brand in 1909. These values are reflected through the brand vision, brand culture, positioning, personality, relationship, and presentation (Harris \& de Chernatony, 2001). Evidence supporting this statement was identified throughout Chanel's website where two overarching brand values were identified while browsing the website and social media: timelessness and elegance. On the website, one of the videos ("Chapter 8: Coco by Karl") has Karl Lagerfeld, the chief designer for Chanel who took over in 1983, stating that "[Chanel] created an image and she liked the idea that posterity was held in this image" (see Appendix 27, Figures 97C and 97D). To this day, the Chanel brand has recognized that one of its successful traits is being able to continually re-create the existing iconic products over time. For example, Chanel's iconic perfume invented in 1921, Chanel $\mathrm{N}^{0} 5$, continues to reinvent itself through different marketing initiatives (see Appendix 27, Figures 98A and 98B) without having to continuously formulate completely new fragrances every couple of years like most competitors. It can also be interpreted through Coco Chanel's style. In "Chapter 9: Chanel by Karl," Karl noted that "If I had to define Chanel, I would say that she was the first stylist to give women a modern attitude that didn't exist before," associating her work with the historical liberation of women (see Appendix 27, Figures 99A and 99B). He goes on to define Chanel's style "It is timeless, but it is also in style. Her style belongs to another period but it has survived, and adapted itself, to the modern world and all the following decades ... Chanel elegance" (see Appendix 27, Figures 99C-G). This quote is unquestionably a part of Chanel's Mission Statement. The Chanel company's mission statement is designed to ensure that the brand will stay true to its past and to its founder, Coco Chanel, and that its legacy will remain in the future. Timelessness and elegance is used interchangeable in that it is expressed consistently through every brand communication channel.

The assumptions below are based on observations from Burberry's official website, 
www.burberry.com (see Appendix 27, Figure 100A), and social media, Facebook Page (see Appendix 27, Figure 100B). Unlike Chanel, Burberry does have an official Instagram account. According to its website, Burberry, founded in 1856, has remained to this day quintessentially British. Burberry's overall brand value stems from its symbolic Britishness, elegance, innovation, and creative talent, which has not only been able to cultivate a cultural capital but has gained a great deal of success in doing so. The performance of the British fashion brand Burberry has not always been what it is today. Burberry has long since left behind its impoverished image and poor company performance. Burberry's successful achievement of realigning its business model and integrating the physical with the digital has exceeded consumers' expectations and the company's performance. As a result, since 1997, the company has gained momentum worldwide in the luxury goods industry. This change of direction reflects the company's identity and their core values.

It was rather easy to identify what Burberry's core values were-Protect, Explore, and Inspire - because it is written on its website. Unlike Chanel, who is privately owned, Burberry is publicly owned; therefore, access to the Burberry Group PCL was rather easy. However, making the connection between these core values and the brand's identity was rather challenging. One way that connects these values to the brand is how passionate the company is about its Foundation. The Burberry Foundation is a philanthropic organization that gives back to communities by partnering with other charitable organisations from the Americas, Europe, and Asia. This organization builds off its historical roots; for instance, when Thomas Burberry invented gabardine. Gabardine became a synonym of the brand Burberry to anyone who wore it, like adventurers and aviators (see Appendix 27, Figure 101). Once again, these assumptions are made by observing the company's website and social media accounts for a long period of time. 
Overall, both Burberry and Chanel are explicitly telling their stories from a variety of different angles.

\section{Second Dimension: Marketing Communication}

In the pre-digital age, luxury brands used traditional marketing strategies such as print and TV in order to attract their target audience. In today's Internet era, successful fashion brands are embracing both traditional and new media in order to communicate a consistent and authentic message across multiple touchpoints. With the proliferation of digital and social media, it has become even more important for brands to ensure that they are attracting consumers with the necessary content and service that in turn creates long-term brand value. One way that both Chanel and Burberry do this is by uploading their most recent Fashion Shows onto their website and social media Facebook page providing consumers with digital touchpoints. This allows the consumers to experience the Collections of the brand anytime and anyplace. However, each company promotes their online marketing strategies differently.

Fashion shows. Fashion shows are an important marketing communication channel that highlight the luxury status of the brand and emphasizes the fashion credibility of the brand, thus attracting international press coverage (Moore \& Birtwistle, 2004). Chanel's “Fashion" webpage is composed of a black background with white text and has four different categories: Haute Couture, Collections, Products, and Chanel News (see Appendix 28, Figure 102). Each of these categories is subsequently divided into subcategories (see Appendix 28, Figure 103). Interactive images of all different sizes are laid out across the interface; by clicking and dragging the background in all directions, consumers can view more images (see Appendix 28, Figure 104). Each image not only comes to life in a virtual video activated by the cursor, along with the title representing that image (e.g., Spring-Summer 2014 Collection Details; see Appendix 28, Figure 
105). This is how the latest runway shows are exemplified. By clicking on any of the images, the consumer will be redirected to a new page to see further details or to a specific video in regards to each theme. By clicking on the "Haute Couture," a video appears featuring its most recent Fashion Runway Show; the Fall-Winter 2014/15 (see Appendix 28, Figure 106). The "Collections" tab also offers consumers videos of the latest Fashion Shows such as Fall-Winter 2014/15, the Paris-Dallas 2013-2014 Métiers d'Art Fashion Show, the Spring-Summer 2014, the Spring-Summer 2014 Pre-Collection and Cruise 2013/2014 (see Appendix 28, Figure 107). Videos and images of Chanel's Fashion Shows are also uploaded onto their Facebook platform and their "Chanel News" website, a website where consumers can experience behind-the-scenes footage (see Appendix 28, Figure 108).

One can assume that Chanel's interface is more digitally engaging but it can also be overwhelming. Burberry is rather less complex than Chanel. Burberry's webpage is composed of a black background with a large image of its most recent haute couture campaign (see Appendix 28, Figure 109). The company's website features Burberry Fashion Shows in womenswear and menswear for both Autumn/Winter 2014 and Spring/Summer 2014 under the "Shows and Events" tab (see Appendix 28, Figures 109 and 110A). Users can "Shop The Runway" looks, share by saying that the user "love this" and follow the latest from the show via social media, Twitter and Instagram (see Appendix 28, Figures 110B-D). Burberry is constantly setting new British music trends on its runways-Burberry acoustic musicians can be heard playing in the background during the fashion shows. Burberry's website has one designated place that users can view these Fashion Runway Shows, unlike Chanel. One can assume that it is less creative to have it in one place but more practical for users to navigate the website, and, with Chanel, there appears to be more creative content but a less intuitive interface to navigate all the content. 
Advertising channels: Print. Whether it is Chanel or Burberry, both brands use two main advertising channels: print and digital. Chanel's print advertisements appeared twice within the recent February 2014 Vogue issue. The rationale for selecting this time period was to determine whether or not their print advertisements reflected their official website and social media platforms. The first Chanel advertisement was a two page-spread image of its SpringSummer 2014 Ready-To-Wear Collection (see Appendix 28, Figure 111). The model is seen lying across the floor surrounded by mirrors, wearing an asymmetrical cotton tweed jacket embellished with jeweled buttons and paired with a matching tweed dress. The look is complemented with a long multi-strand glass pearl necklace and a small black calfskin bowling bag embellished with an interlaced chain. All advertisement images, whether print or digital, play on the idea of ambiguity between masculinity and femininity (see Appendix 28, Figures 111 and 112).

In the upper left corner of the first page, "Chanel" is written in large white text, with small text written alongside the advertisement; location, telephone number, website, the copyrights, and the logo. The second image was a two page-spread of Chanel's fragrance, Coco Mademoiselle (see Appendix 28, Figures 113A-B). The first page is an image reflecting the young irresistible spirit of the young Coco Chanel; in this case, Keira Knightley's face, who is holding the perfume bottle close to her mouth. Keira's facial composition expresses a sensual and elegant look that is both daring and bold, all done in a neutral pink and earth tones (see Appendix 28, Figure 113A). Once again the "Chanel" brand name is written in large white text in the top-right corner and the "Coco Mademoiselle" signature writing is laid out across the bottom of the image. The second image is the featured product, a bottle of Coco Mademoiselle perfume, with same text layout but in opposite, black colours (see Appendix 28, Figure 113B). In 
fine print at the bottom of the advertised image is the website, chanel.com and the name of a department store, Saks Fifth Avenue, followed by its website, saks.com. All of which are clear signals that Chanel is prominently integrating digital content into their print advertisements.

Burberry is also featured twice within the February 2014 Vogue issue. However, the first advertisement is on the Vogue cover page, where actress Lena Dunham is wearing a Burberry Prorsum white linen shirt with red polka-dots from their Burberry Prorsum Spring/Summer 2014 Collection (see Appendix 28, Figure 114). The second advertisement image is a two-page spread of Burberry Prorsum Spring/Summer 2014 Collection (see Appendix 28, Figure 115). A bold pastel palette in petal pink and lavender hues reflects the inspiration for the Burberry Spring/Summer 2014 Campaign: "English Rose." The advertised image, artists and roses, aims to provoke an effortless and romantic English air by casting an all-British group of models, three females and two males, with relaxed silhouettes and what seems to be a luxurious stage-like atmosphere (see Appendix 28, Figure 116).

Advertising channels: Digital. These featured advertisement images are then transposed and brought to life via each of their official websites and social media platforms. Both Chanel and Burberry advertising strategies are consistently expressed in a digital context through their websites and social media platforms. Each of their websites allows the consumer to be immersed in a variety of interactive experiences that are related to each of their brand products.

Chanel's homepage used a clean layout, with a white background and black text. This, in return, allows for the four slideshow images (see Appendix 28, Figures 117A-D) to stand out, as it is the first thing consumers will see; two of the four images were in black and white, making the other two colourful images of the products stand out even more. However, the images are constantly being updated by the company. The basic black and white colours used throughout the 
website portray an image of elegance, whilst being minimalist and classy. The style of the website is a reflection of Gabriel Coco Chanel herself. Chanel's official website is a very interactive touchpoint that focuses on displaying the Chanel brand culture. An example where the user is prompted to interact with the brand is with their "Fragrance" category, in which a video appears that features multiple bottles of perfume, Chanel Chance (see Appendix 28, Figure 118). The user watches the video and, as they watch, they are urged to select one of the featured bottles by navigating the cursor to the desired location (see Appendix 28, Figures 119A and 119B). This allows the consumer to interact with the brand and be engaged by continuously participating, as they anticipate their next move until the video ends. The user is then able to "Share the Experience" via social media or mail (see Appendix 28, Figure 119C). Throughout the website, mid-tempo classical music and/or a woman speaking English in a thick French accent attracts the user's attention by allowing themselves to be a part of another world, an imagined Paris, France.

Burberry's homepage is designed in a way that reflects a refined and traditional British quality, as easily seen in the font or the images presented on the website. The background is black with off-grey lettering. The brand name is depicted in the top-left corner of the website, and remains there throughout the entire website's interface; unlike Chanel's website, where it is moving around constantly (see Appendix 27, Figure 100A). The images presented throughout the website, give an air of nostalgia and heritage. A general practice that sets Burberry apart from its competitors in terms of marketing innovation is how the company leverage the brand's content to connect and engage with audiences from around the world. One of the ways it does this is through its "Acoustics" webpage (see Appendix 28, Figure 120). On this page, you have a collage-type image layout that features Burberry's acoustic artists. By navigating the web page, 
users can click on an image and view a music video of the artist (see Appendix 28, figure 121). Regent Street, Burberry's most comprehensive and innovative flagship store to date, situated in London, is also a venue for Burberry's acoustic artists to perform live. This can be seen in its "Shows and Events," where users can view live music performance at Regent Street by artists like Kaiser Chiefs and Jake Bugg (see Appendix 28, Figure 122). Burberry has found a unique way of connecting consumers to Burberry's digitally-enabled culture. One method that Burberry incorporates quite often throughout its website is the use of Instagram (see, e.g., "Art of the Trench" or "Womenswear S/S14"), a webpage feed where consumers can follow and view Instagram images of behind-the-scene footage, and famous British musicians, fashion bloggers, magazine editors, and celebrities (see Appendix 28, Figure 110D). If users like a photo, they can share it via Facebook, Twitter, Google + and Pinterest. Adding these social media icons to a website not only allows the user to become engaged and connect with the brand through their personal social media accounts, but it spreads the word and attracts other followers to become part of these two worlds, Chanel and Burberry.

Lastly, one of the company's most recent collaborations was with Google in 2013, called "Burberry Kisses" (see Appendix 28, Figure 123A). There is no direct link from its website, however, on its Facebook page, one could find images of Burberry Kisses with the following caption: "Burberry Kisses—letters sealed with your kiss http://kisses.burberry.com/" (see Appendix 28, Figures 123B-D). By clicking on the link, consumers are taken to an external webpage. Consumers can either "capture your kiss" or "explore the world of kisses" (see Appendix 28, Figure 124). This digital initiative, Burberry Kisses, allows anyone in the world to capture and send, via the Internet, an impression of their lips in the form of a kiss. Or consumers can view a map of the world that shows "live kisses" or "all kisses" (see Appendix 28, Figure 
125). Burberry's Art of the Trench, Acoustic, Bespoke, and Burberry Kisses were designed to engage the consumer and increase awareness of the brand.

As previously mentioned Burberry has an official Instagram account, whereas Chanel does not. The company has 1.35 million followers and counting, with a total of 1,094 photos that have been posted to date. The photos and video clips reflect the brand's Britishness: from views of London, to behind-the-scenes sneak peeks, to fashion runway shows, to British Models, especially supermodel Cara Delevingne, and celebrities.

\section{Third Dimension: Product Integrity}

Product quality. It does not come as a surprise that both Chanel and Burberry are two brands that are targeted by counterfeiters and products are frequently copied and reproduced. For this reason it is critical to have full control of the operational side of the business including the supply chain and distribution processes. One way that Chanel preserves the integrity and quality of its product is by incorporating a serial number into each one of its products in order to identify the given Chanel product as an authentic and genuine piece. Often it happens that Burberry's signature tartan plaid products, first used in 1924 to line the infamous trench coat, are replicated, making it difficult for those who want to purchase authentic merchandise via consignment stores, vintage shops, and discount sites. Authentic Burberry products do not have serial numbers; however, each product can be easily identifiable by inspecting the tartan plaid pattern, the knight logo, interior labels, hardware, materials, and stitching. Unlike Chanel, Burberry manufactures its products from across the globe in order to meet consumer demand. This information is from personal experience and from observing both Chanel and Burberry website and social media platforms.

Product craftsmanship. When it comes to the product's craftsmanship, Chanel strives to 
ensure that the users are a part of every step from the very beginning to the final product via an informational video. For example, Chanel's jewelry expertise video allows users to view how fine jewelry is made: from the creation, selecting the stones, the model, casting, and setting the stones (see Appendix 29, Figures 126A and 126B). This experience is enhanced further with sound as a classical harmonized orchestrated music is playing in the background. This also goes for Chanel's informational videos on each one of their exceptional timepieces: "grandes complications," "haute horlogerie," "haute joaillerie," and "artistic crafts" with a 360-degree view of that watch (see Appendix 29, Figures 127A and 127B). These informational videos allow the viewers to see exactly how each piece is carefully crafted (see Appendix 29, Figures 128A-D). This in return adds value to the timepiece, hence, the high price.

Burberry does not excel in this dimension. There are no informational videos on how the Burberry Mill in London creates and produces the trench coat. There was, however, one area on its website where users can view the craftsmanship of their Burberry Flagship store in London. The "Live At 121 Regent Street" webpage is a video that engages the consumer to be part of a virtual tour of the 'Burberry World Live' concept store. A segment of the video featured "a celebration of British design and craftsmanship" where artists and labourers, are seen creating exquisite mouldings or hand painting the Burberry's brand name by paying a great deal of attention (see Appendix 29, Figures 129A-D).

\section{Fourth Dimension: Brand Signature}

Both Chanel and Burberry have iconic products, some of which were ground-breaking during the time they were invented, and therefore set new standards in the fashion industry in terms of quality, function, features, and style. Chanel's $\mathrm{N}^{\mathrm{0}} 5$ fragrance, the Chanel Suit, the Little Black Dress, Chanel's two-toned shoes, and Burberry's iconic plaid trench coat, are all designs 
that have stood the test of time, remaining popular today. Since then, each one of the aforementioned iconic products have adapted and evolved since their creation by remaining innovative and aesthetically pleasing. Each one of the iconic products has a place in history, and some have even helped change history. On a side note, each iconic product has certain properties of the brand such as fabrics, colours, and shapes. The selected two iconic products, Chanel's $\mathrm{N}^{\mathrm{0}} 5$ Fragrance and Burberry's Trench Coat, were closely observed and analyzed via each of their website and social media platforms.

Iconic product: Chanel $\mathbf{N}^{\mathbf{0}} \mathbf{5}$ fragrance. Chanel excels a great deal in this dimension. Chanel $\mathrm{N}^{0} 5$ fragrance, the Chanel Suit or even the Little Black Dress reflects Chanel's history through videos such as "Chapter 1: $\mathrm{N}^{\circ}$ 5"; "Chapter 2: Marilyn and $\mathrm{N}^{\circ}$ 5"; "Chapter 3: The Diamond"; or even "Chapter 4: The Jacket" (see Appendix 30, Figure 130). Historical video clips and images are combined to create a stimulating, interactive user experiences. Customers gain knowledge on the historical product and therefore solidify their emotional attachment. For example, a consumer now wants to purchase the Chanel $\mathrm{N}^{\circ} 5$ perfume after viewing "Chapter 2 : Marilyn and $\mathrm{N}^{\mathrm{o}}$ 5." Chanel was able to successfully construct a brand personality to this fragrance. The brand Chanel enables consumers to express her own self, an ideal self, or a specific dimension of the self via the Chanel $\mathrm{N}^{0}$ fragrance (Aaker, 1997). Therefore, brand personality attributed to the fragrance serves a symbolic or self-expressive function that allows consumers to associate human characteristics with the product. Often times, in this instance, consumers will think about this fragrance as a famous historical figure (e.g., Marilyn Monroe), and feel a kinship with that celebrity. Thus, Marilyn Monroe's endorsement of the iconic fragrance is constantly in the back of the mind of viewers (see Appendix 30, Figure 131). The Chanel $\mathrm{N}^{0} 5$ fragrance was created in 1921 . The design of the fragrance bottle is presented with 
simple lines and a stark-white label. It is presented in a simple laboratory flagrant so that its sobriety ensures its timelessness. A chiseled stopper was cut like a diamond reflecting the geometry of the place Vendôme in Paris, France. Since then, the packaging design of the Chanel $\mathrm{N}^{0} 5$ has been slightly adapted through the passing years (see Appendix 30, Figure 132). This ultimate feminine scent is composed of top notes like aldehyde, the heart of jasmine, rose, lily, and iris — just to name a few — and to this day has remained unchanged.

Iconic product: Burberry trench coat. The same qualities regarding brand personalities can be said about Burberry's iconic trench coat, a true symbol of Britishness. It was first designed for British troops during War World I (see Appendix 30, Figure 133). The military details such as the D-rings used to hold grenades, epaulettes, and gun flaps are properties of the brand that are still featured on today's Burberry trench coat, which permeate a sense of posterity. In 1888, Thomas Burberry patented gabardine; this type of fabric used for the trench coat was not only waterproof but lightweight, breathable and highly durable. The famous tartan plaid check was first used in 1924 to line the trench coats, and is now seen on Burberry's handbags, scarves, and other apparel. One way that Burberry engages consumers to be a part of the brand is through specific marketing initiatives, such as the "Art of the Trench" interface and "Art of the Trench Events." Firstly, Burberry's Art of the Trench is a user-based online platform that encourages wearers of the Trench Coat to upload an image of themselves wearing their favourite look using the website or the mobile Instagram app (see Appendix 30, Figures 134A-C). This project is a collaboration between Burberry and some of the world's leading image makers. The purpose is to create a body of images that reflects wearers of the Trench Coat from all over the world. Again, acoustic music from British artists is playing in the background while the user filters and browses photographs by liking, commenting, or sharing via social media icons (see 
Appendix 30, Figures 135A and 135B). Lastly, the Art of the Trench Events features videos of different countries (e.g., Turkey, Eastern European countries, Seoul, Shanghai, Chicago, Brazil, and India) that mark the launch of Art of the Trench campaign that celebrates the diverse cultures and communities with a collection of street style image from each of the aforementioned countries (see Appendix 30, Figure 135C).

\section{Fifth Dimension: Premium Prices}

These well-established companies can certainly charge their loyal customers premium prices. Unlike Burberry, Chanel does not display the prices on its website for Haute Couture and Collection pieces, and the same goes for its entire product line which includes: handbags, small leather goods, shoes, costume jewelry, eyewear, camellias, belts, scarves, hats, gloves, and other accessories. Only the name, the item number, and a brief description are shown (see Appendix 31, Figures 136A and 136B). However, Burberry displays the prices for all three product labels, Burberry Prorsum (haute couture label), Burberry London (Ready to Wear label), and Burberry Brit; thus, they are listed in descend order from limited distribution premium prices to wider distribution, more accessible prices (see Appendix 31, Figures 137A-E). The fragrance, makeup, and skincare products for both brands display price labels and a detailed description of the products (see Appendix 31, Figures 138A and 138B).

One of the reasons why Chanel does not display the prices for the fashion apparel section is to reflect its exclusiveness that only the wealthiest socialites and aristocrats can actually afford it. (This is better reflected in the sixth dimension: exclusivity.) Perhaps another reason why Chanel does not advocate its prices online is the fear that e-commerce (of the Fashion apparel only) will diminish the brand's integrity or that consumers will come to prefer seeing such expensive items in a Boutique rather than online. Thus, one could assume that Chanel is 
perceived as being more exclusive as it does not advocate its fashion apparel prices through ecommerce. However, it appears that Burberry acknowledges the importance of e-commerce as a digital marketing strategy, which could potentially result in generating more profit.

\section{Sixth Dimension: Exclusivity}

The countries of origin for both brands are easily identifiable throughout their respective websites and social media. The French House of Chanel originated in Paris, France while the British brand Burberry was originated in London, England. The accessibility of purchasing an item from the Chanel and Burberry website is simple and user friendly. Once again, only the fragrance, makeup, and skincare products can be ordered online; and Chanel's apparel, handbags, and accessories can be accessed via a Chanel Boutique. A store locator is readily available for users who wish to find the closest Boutique or department store location (see Appendix 32, Figure 139). However, all of Burberry's products, whether it is womenswear, menswear, handbags, and accessories, can be purchased via their online e-commerce platform. Customizable options of the Trench Coat are also available to customers who wish to personalize their Trench coat via Bespoke (see Appendix 32, Figure 140).

\section{Seventh Dimension: Heritage}

Chanel's heritage is reflected throughout the entire website and social media platforms. "Inside Chanel" is divided into two sections — "Chapters" and "Timeline" — that each represent a historical look at Chanel. The history of Chanel was not only summarized through a timeline (see Appendix 33, Figures 141A and 141B), but was also illustrated through 10 videos, each representing a chapter reflecting Gabriel Coco Chanel's identity (see Appendix 30, Figure 130). Each chapter can be seen as a piece of marketing communication, connecting to form the "Chanel Story." It is worth mentioning that these videos were released after substantial build-up 
as is indicated throughout Facebook's timeline. Viewing each one of these Chapters, one could summarize that Coco wanted to be different and independent, beginning with how she dressed herself. Gabriel Coco Chanel revolutionized the world of fashion and empowered femininity through the simplicity of dress. Her first store opened in 1910 at 31 rue Cambon in Paris, France. The Chanel brand draws upon its inspirations: from Coco's lifetime experiences, her sense of austerity, her taste for the black-and-white style (likely originating from the Aubazine nunnery where she spent 7 years of her life), her fascination with baroque style, gold, and coloured gems all serve to this day as inspiration for collections. Her inspiration of masculine attire and the simplicity of the styles, fabrics, and articles of clothing that she appropriated from men transformed the feminine silhouette and launched a new century of fashion during that time period. The House of Chanel's brand is indebted to its fruitful heritage. The two black-andwhite, interlocked, opposing letter Cs (see Appendix 33, Figure 142)-standing, of course, for “Coco Chanel"-were designed by Gabriel Coco Chanel herself in 1925. It has remained unchanged ever since, symbolizing, once again, elegance and timelessness.

Burberry' heritage stems from its trench coat and it is reflected throughout the entire website and social media platforms. For over 150 years, Burberry has not only endured style and quality but the brand name, trademark, and signature trench coat has been recognized as a global luxury brand. The history of Burberry is represented in one section of the website under the "Timeline" tab (see Appendix 33, Figure 143A). But on Facebook, Burberry's timeline is incomplete (see Appendix 33, Figure 143B). It is composed of photos, advertisement images, and videos with content dating as far back as 1856. Once again, Burberry's heritage is presented in one location rather than multiple locations on the website. People of importance are seen wearing Burberry articles of gabardine clothing from 1910 and onward (see Appendix 33, Figure 
144). The legendary brand dates back to 1856 when Thomas opened its first store in Basingstoke on Winchester Street (see Appendix 33, Figure 145). It was not until 1891 that the brand opened its first store in London. The Burberry "equestrian knight" logo is one of the most identifiable iconic emblems in the luxury fashion industry. Trademarked in 1901, the logo carries the word prorsum, which means "forward" in Latin, which reflects Burberry's fabrics and styles (see Appendix 33, Figure 146). Indeed since its foundation, the brand has constantly been innovating and setting itself apart from competitors. The findings reported above are based on the online website and social media platforms.

\section{Eighth Dimension: Luxury Environment and Experience}

Many studies have stated that the number of flagship retail stores has been on the rise (Kent \& Brown, 2009; Manlow \& Nobbs, 2012). Luxury fashion brands are opening flagships in the world's major cities as a way for them to strengthen and maintain "control of their image, to shape it in the eyes of consumers, to promote an identity that enhances the brand, and to provide customers with an enjoyable experience on both a personal and interpersonal level in a branded environment" (Manlow \& Nobbs, 2013, p. 59). The design of Burberry's and Chanel's flagship stores are a manifestation of their brand identity (Manlow \& Nobbs, 2013; see appendix 34, Figure 147). Riewoldt (2002) refers to this as a "brandscape" (p. 50); these elements of design, such as its architecture and placement of merchandise, reflect the brand's identity (Manlow \& Nobbs, 2013). Information on Chanel's flagship store, located in Paris, France, was limited. Most of the information retrieved on the Internet was either reviews or blogs describing personal experiences of Chanel's flagship store in Paris. The reason for discussing and analyzing both Chanel's and Burberry's London flagship stores is because it allows for comparisons to be made.

Chanel's recently new London Flagship Store opened in June 2013 (see Appendix 34, 
Figure 148). It is the largest Chanel shop in the world and it is located at 158-159 New Bond Street. This location is known as the Mayfair District, which is London's most luxurious district (Beckman, 2013). The three-storey, 12,600 square-foot space was designed by renowned New York architect Peter Marino to reflect the brand's French roots. It is said to be devised to feel like the "abode of Chanel's indomitable founder Coco Chanel" (Pithers, 2013, para. 1), that is to say its main inspiration was Coco Chanel's famous Rue Cambon apartment. It took approximately 15 to 18 months to build. The layout of this flagship store begins with a sculpture reminiscent of Coco Chanel's iconic pearls, created by French Artist Jean-Michel Othoniel (see Appendix 34, Figure 149). Suspended from the ceiling from the third floor and hanging down to the ground, this sculpture is entirely fabricated from hand-blown Venetian glass. This store centrepiece adds a luxurious touch to the space. The first floor of the flagship store features an area solely dedicated to Chanel's handbags, from classical to seasonal, called the Bag Bar. The first floor also includes ready-to-wear fine jewellery, beauty accessories, and custom rooms dedicated to collection-specific products (see Appendix 34, Figures 150A-E). The second floor has a more intimate feeling to it, reflecting Madame Coco Chanel's apartment, and features Haute Couture pieces. The store detailing truly represents luxury and is like no other:

Glass and mirrored walls feature gold ribbon encased within (an original feature devised by Coco Chanel and inspired by her collection of Coromandel screens), curtains feature hand-stitched pearls and the chandeliers real crystals (Madame Chanel was very superstitious, you see. Everything had to be real). Each piece of furniture-from the tweed chairs that line the undoubtedly popular handbag bar to the inviting recliners and sofas - has been specially made for the store, while each piece of artwork - of which there are many_was commissioned by Marino. (Karmali, 2013, para. 5) 
Not to mention, that when you first walk in, you are greeted by the Mark Swanson sculpture of a deer that is covered in 200,000 silver rhinestones (see Appendix 34, Figure 151). If there is one thing that Chanel does exceptionally well, it is creating luxurious retail environments that become industry standards that other competing luxury brands aspire to.

Burberry's flagship store on Regent Street in London strategically provides the consumers with multisensory experiences of the brand's products (see Appendix 34, Figures 152A-H). Luxury flagships are designed to engage and connect with consumers by creating an emotional response; thus, meaningful relationships between the luxury shopping and the need to fulfill status and desire to indulge in pleasurable experiences are created amongst Burberry's consumers via multisensory experiences (Manlow \& Nobbs, 2013). Chanel's luxurious aesthetic and appearance are the utmost priority and, thus, perhaps it does not feel the need to engage and connect with the consumer via multisensory experiences. Here is a quote by Christopher Bailey, Chief Creative Officer and soon-to-be CEO of Burberry, that clearly illustrates the importance of flagships and brand image:

Burberry Regent Street is one of the most architecturally and culturally significant projects we have undertaken. ... In renovating this iconic London building we have worked with some of the UK's finest craftsmen to restore a wealth of historic features, at the same time as pushing the boundaries of digital technology. The result is a space defined by contrasts: at once imposing and intimate, its juxtaposition of craft and innovation is designed to delight surprise and entertain. It is a reflection of how we approach everything at Burberry—revealing the different layers of the brand's heritage within a modern context, and forever celebrating design and expert craftsmanship. (Alexander, 2012, para. 2) 
Burberry's global flagship on Regent Street in London has a strong in-store digital presence. Burberry's flagship has integrated digital trunk shows, and 24/7 click-to-chat customer support (Burberry Group PLC, 2013). Over 160 iPads are distributed among employees (Burberry Group PLC, 2013). The use of iPads in store informs them on product knowledge. In 2012, Burberry opened its largest and most technologically advanced store; "a multi-media experience combining the label's physical and digital achievements" (Alexander, 2012, para. 1). The 44,000 square-foot space is designed to reflect Burberry's website and is divided into rooms for Bespoke, Acoustic Artists, and Experiences. The store is equipped with mirrors that transform into screens that allow consumers to view Burberry runway shows, such as womenswear Spring/Summer 2013 and Autumn/Winter 2013 runway shows. The mirrors also demonstrate the making of certain Burberry products. The product tags communicate with the store's wireless WIFI system in order to display product information on screens inside the dressing rooms. Burberry current CEO Angela Ahrendts stated that "Burberry Regent Street brings our digital world to life in a physical space for the first time, where customers can experience every facet of the brand through immersive multimedia content exactly as they do online. ... Walking through the doors is just like walking into our website" (Alexander, 2012, para. 4). This concept is called "Burberry World Live” (Burberry Group PLC, 2013). Burberry's new flagship is a must-stop shopping destination. The store's theatre-like facilities also host a number of events as well as an innovation hub.

\section{Ninth Dimension: Culture}

Within the literature, two luxury brand models coexist, each are based upon opposing cultural assumptions about luxury. Both Chanel and Burberry are European luxury brands that are deeply rooted in history, rarity, and craftsmanship; thus, representing the luxury pyramid 
where its fame stems from historic designers. The other, which was omitted from this analysis, was luxury brands that are "based upon stories, image, and marketing finesse, often linked to American success [like Ralph Lauren and Diane Von Furstenbers]" (Kapfere, as cited in Schroeder et al., 2006, p. 68). Chanel's and Burberry's brand identity and brand image are communicated differently. The same can be said about their corporate culture. Once again, the reason for this is that Chanel is privately owned company, while Burberry is a publicly owned company. Therefore, Chanel does not need to advocate any information on activities related to the corporation's ethical views, a corporation's socially responsible standpoint to even the corporation's brand management culture. Chanel does not openly communicate any of its charitable organizations on its website or social media. Nonetheless, the Chanel brand has undertaken different routes to ensure that its own culture is represented vividly around the world. One way Chanel does this is by featuring many editions of "Culture Chanel" exhibits around the world, such as Pushkin State Museum of Fine Arts, and in Beijing at both the National Art Museum of China and in the Opera House in Canton. The " $\mathrm{N}^{\circ} 5$ Culture Chanel" exhibition was also featured as part of the Palais de Tokyo Guest Program, which were all curated by JeanLouis Froment from May 5th to June 5, 2013 (see Appendix 35, Figure 153). Many children and adult workshops were included as well as multi-media library, audio guide, and booklet. Perhaps, there will be another "Culture Chanel" exhibition that will be featured this year. The exhibit's concept and inspiration is defined to project the following amongst its visitors:

$\mathrm{N}^{\circ} 5$ is a perfume that travels afar. It crosses countries, gardens, books, poems and artistic movements, where it's taken as a source for the modernity of its composition. It's a perfume born of a love story, which its base note very subtly evokes at precisely the same instant time grasps it and carries it to us; so close and never fugitive, revealing even our 
most secret failings. Indefinable, the words that speak of it are abstract and the images which accompany it superposed on the thick layer of an artistic memory without time. The cultural effect which accompanies $\mathrm{N}^{\circ} 5$ and the unique aura that encircles it, bring continuity to this perfume and enable it to span all periods with knowing assurance. And this journey has no end; it continues to merge and mix with an irreversible movement onward through time. Like a work of art which is renewed with each visitor's gaze at every exhibition, $\mathrm{N}^{\circ} 5$ recomposes its history with each encounter and time it traverses. Sustained by a set of references attached to the adventures of Modernity's artistic forms and with Gabrielle Chanel's very singular and romantic story as a backdrop, the $\mathrm{N}^{\circ} 5$ perfume has gained the status of creation. (Palais de Tokyo, 2014, para. 4)

Unlike Chanel, it was easier to assess Burberry's corporate responsibility because it publically shares everything one needs to know about the brand (e.g., annual reports, investor relations, share prices, etc.). Burberry's corporate responsibility is strengthened on its "Burberry Beyond" webpage, where Burberry clearly states its commitment to driving positive social, cultural, and environmental changes that have impact on a global scale (see Appendix 35, Figure 154). Three pillars establishes Burberry's initiatives such as "Burberry Impact" ("leveraging our creative thinking culture to inspire sustainable action"), "Burberry Engage" ("harnessing the passions and talents of Burberry associates"), and "Burberry Invest" ("supporting and inspiring the next generation of creative thinkers"; see Appendix 35, Figure 155).

One of Burberry's corporate responsibilities is to recognize the importance of its people through "Burberry Impact," along with product, process, and property. Burberry does this by recruiting the best talented people from across the world at its locations. Thus, Burberry's community exudes energy, vibrancy, and connectedness. Interestingly enough with the last point, 
one thing that was repeatedly observed with Burberry was the company's connected culturebalancing "creativity, commerce and culture" (Ahmed, 2013, para. 5). Another way that Burberry ensures its culture to remain consistent throughout the company is through their retail teams. Thus, retail associates are to learn the Burberry culture and values through "international networking opportunities, global strategy off-sites, mentoring from senior executives, and leadership training workshops" (Burberry Group PLC, 2013, para. 6) - and one must include their Retail Management Program that was launched in order to ensure a high retention rate. Burberry also rewards all of their employees, regardless of the hierarchy, through bonuses or incentives as well as the "All Employee Free Share Plan." 


\section{CHAPTER FIVE: CONCLUSION}

This paper seeks to increase awareness of the importance of digital marketing tools including online social, mobile, and in-store. Adoption of these multiple digital marketing strategies ensures that compelling and consistent messages are delivered to customers, enhancing the customer experience and building brand loyalty and emotional attachment. Both Chanel and Burberry are successful international digital luxury retailers. These two luxury retailers understand the importance of aligning and maintaining a consistent brand identity and brand image that is appealing across all marketing channels-whether it is traditional or digital platforms - in order to have a successful and competitive brand. Hence, both luxury fashion brands demonstrate strong brand values that are measured by the consumers brand loyalty, perceived quality, brand awareness, and brand engagement. This area of luxury fashion marketing has remained largely unexplored. Due to the nature of this exploratory research, a summary of the key findings, implications, limitations, and future developments are presented below.

\section{Summary of Key Findings}

Prior to analyzing the digital marketing strategies utilized by Chanel and Burberry, preliminary research examined print advertisements featured in six Vogue US issues in 1980 and 2013. Through content analysis three major traditional marketing strategies were identified. The first category identified was the types of product or service. Numerous observations were made and each of the time periods featured many of the same types of product or service categories, such as skin-care, cosmetics, hair-care, fragrance, women's apparel, jewelry, footwear, and handbags. However, variances in the social, economic, technological, political, and cultural environments between 1980 and 2013 clearly influenced the types of recurring advertisements 
published within each time period. In 1980, ads were geared towards commodity-based brands. As opposed to 2013, ads were displaying a larger portion of luxury-based brands, but also adding a few fast-fashion brand advertisements. The second category established was the overall presentation of the advertised images from both time periods. This looked at the number of total advertising pages, the number of advertising pages per brand being featured, the commonly depicted colours on the front-page cover, as well as print advertisement images, to the content and layout of the print advertisement images. This last theme resulted in interesting findings. In 1980, ads were commonly crowded with heavy descriptions of reasons why consumers should purchase the brand because it was one of the few mediums for consumers to get information about a brand. In 2013, advertisements were less descriptive, with the assumption that consumers should purchase based on the story that is being told in the image. Today, most consumers have access to the Internet. Therefore, by having the brand name and a website present on the advertisement, consumers are redirected to the official website where they will have access to a lot of information. In 2013, a great deal of print advertisement images displayed a webpage, while others displayed digital jargon as well as social media icons and QR codes. Observations were also made on some of Condé Nast Publications' initiatives towards adopting digital marketing strategies. With the use of the principal luxury brand model, results were categorized into each dimension.

Findings in Phase 2 demonstrated that both Burberry and Chanel have strong and clear brand identities through each of their official websites and social media Facebook accounts. Each depicted strong marketing communication ties to print and digital channels. Fashion shows were significantly present across all marketing channels. Traditional print advertisements reflected the digital content. Chanel and Burberry equally featured many interactive touchpoints throughout 
their websites and social media platforms depicting the brands' heritage and culture. The layout of each website gave an air of nostalgia and heritage that was illustrated differently through each of the firms' brand identity and values. Chanel's basic black and white shading used throughout the website portrays an image of elegance whilst being minimalist and classy. On the other hand Burberry's homepage is designed in a way that it reflects a refined and classic traditional Britishness through the font and the images presented on the website. Each website allowed consumers to share via Facebook, Twitter, Google +, and Pinterest. Adding these social media icons to a website not only allows the user to become engaged and connect with the brand through their personal social media accounts, but also spreads the word and attracts other followers to become a part of these two worlds, Chanel and Burberry.

The foundation of each brand is dependent on the brand signature, thus, a consumer can automatically pinpoint the brand's iconic products in which the product's integrity is emulated. Simply by observing, assumptions were made in regards to each brands' iconic products; Chanel's $\mathrm{N}^{0} 5$ fragrance and Burberry's Trench Coat which in turn reflected the companies' heritage. These well-established companies can certainly charge their loyal customers with premium prices. Findings suggest the reason that Chanel does not advocate its prices online is due to concerns that e-commerce (of the Fashion apparel only) will diminish the brand's integrity or that consumers prefer seeing such expensive items in a boutique rather than online. Burberry acknowledges the importance of e-commerce as a digital marketing strategy and in turn this is potentially translated into generating more profit. Overall, the use of a more complex interface, combining informational videos and images, was more apparent throughout Chanel's official website and social media platforms, as opposed to Burberry. However, in the past, Burberry 
resulted in having more interactive initiatives and digital projects such as "Acoustics," "Art of The Trench," and "Burberry Kisses," as opposed to Chanel.

\section{Implications and Recommendations}

This study has shown that there is a need for luxury firms to implement digital marketing strategies through multiple touchpoints, such as online, social, mobile, and in-store. Marketers and managers must pay attention to the aforementioned constructs if they wish to maintain and improve consumers' brand loyalty, perceived quality, brand awareness, and brand engagement. To achieve increasing profits, luxury fashion brand retailers must transition their current traditional marketing platform to a digital marketing platform. Following Condé Nast Publications' marketing initiatives, it is important for luxury brand retailers to also adapt to the ever changing social structures and trends that are present in the macro-environment (e.g., the political, social, technological, legal, and economical). Thus, there is a greater need for luxury fashion retailers to incorporate digital platforms to stand out in the world of luxury fashion.

Before luxury fashion brands transition their traditional marketing strategies into digital marketing strategies, it is important that the marketers and managers thoroughly analyze and define their luxury fashion brand according to the nine luxury brand dimensions. Once this step is completed, luxury fashion retailers can then implement various digital marketing strategies through multiple touchpoints, such as online, social, mobile, and in-store. Findings from this study related to the luxury fashion brands' official websites demonstrates the importance for practitioners to implement the following recommendations. Having a clean and professional interface that reflects the brand's identity and brand values ensures that the luxury fashion brand remains consistent throughout all digital platforms. Interactive touchpoints such as informative videos and images about the brands' identity are important because it adds value and should not 
be excluded throughout the digital platforms. Social media icons prompting a user to share their online experiences (e.g., videos and images) externally via Facebook, Twitter, Google +, Pinterest, and Tumblr not only allow the user to become engaged and connect with the brand through their personal social media accounts, but also to spread the word and attract other followers to become part of that selected luxury fashion brand world. Overall, the digital content from the official website should reflect social media platforms and other digital platforms but also traditional media platforms, such as print advertisements.

There are numerous opportunities for luxury fashion brands to implement multiple digital marketing tools (e.g., online, social, mobile, in-store) based on each of their strengths and weaknesses in order to attract and persuade a greater number of consumers to purchase luxury fashion brands that are more expensive. For example, Burberry continuously launches digital initiatives at least 2 to 3 times a year in order to ensure that the consumers are digitally engaged and connected with the brand. Many luxury fashion retailers are not utilizing these new digital tools in fear that it will diminish the brand's integrity. Evidence provided throughout this study strongly points that both Chanel's and Burberry's brands' integrity has not diminished and that they still remain exclusive luxury fashion brands in this digital age and experiential economy.

\section{Limitations and Future Developments}

The main setback that arose was with the last two dimensions: the luxury environment and experience and culture in Phase 2. This part of the study involving the last two dimensions was solely based on secondary data or empirical research. Future research might incorporate a qualitative approach through observation of a selected number of in-store luxury environments and perhaps interviews of key personnel of the company that, thus, solidify the aforementioned findings observed in phase two. However, using qualitative content analysis, whether it is inductive 
or deductive resulting in this study's findings, is deemed adequate to provide good insight and allows for future studies to be made. Although this research paper has made some preliminary assumptions of luxury fashion retailers' digital marketing strategies, a more thorough comparative study using other multiple touchpoints, such as mobile and in-store, can provide marketers and managers with a deeper understanding. With this in mind, different perspectives from other areas of research would provide a more detailed context for this investigation.

As previously mentioned, consumers are bombarded by numerous fashion brands and, in turn, luxury retail marketers must control and preserve the original image of exclusive high-fashion brands by implementing marketing strategies, traditional and digital, based on the aforementioned nine principal dimensions of luxury brands. A major difference that played a role in how much information about each company was divulged was whether they are privately or publically owned. Chanel is the privately owned company and Burberry is the publicly owned company. Practitioners could further this study by comparing and contrasting these two successful digital luxury fashion brands with two unsuccessful luxury brands, with little to no digital touchpoints, in order to further validate the importance of implementing digital marketing platforms. On a side note, in regards to Phase 1 which explored traditional print media strategies, future research could consider exploring two solely traditional marketing mediums such as magazines by comparing and contrasting how they are transitioning into the new digital era. From a practical perspective, the results from this paper provide recommendations of various digital marketing strategies through multiple touchpoints, such as online, social, mobile, and in-store, for luxury fashion retailers all over the world. Gaining a better understanding of the importance for luxury fashion brands to transition their traditional marketing platforms to digital marketing platforms should benefit the fashion industry by providing them with valuable information. 


\section{References}

Aaker, J. L. (1997). Dimensions of brand personality. Journal of Marketing Research, 34(3), 347-356.

Abrams Research. (2011). Social media guide for luxury brands: Content, strategy, optimization. Retrieved from www.abramsresearch.com

Abrams Research. (2013). Social media guide luxury: 2013 spring/summer. Retrieved from www.abramsresearch.com

Abratt, R., \& Kleyn, N. (2012). Corporate identity, corporate branding and corporate reputations. European Journal of Marketing, 46(7/8), 1048-1063.

Ahmed, I. (2013, September 3). CEO talk: Angela Ahrendts on Burberry's connected culture. The Business of Fashion. Retrieved from http://www.businessoffashion.com/2013/09/burberry-angela-ahrendts.html

Alexander, E. (2012, September 13). Burberry opens Regent Street flagship. Vogue UK News. Retrieved from http://www.vogue.co.uk/news/2012/09/13/burberry-regent-streetflagship-opens

Ballis Lal, B. (1995). Symbolic interaction theories. American Behavioral Scientist, 38(3), 421441.

Balmer, J. M. T., \& Gray, E. R. (2003). Corporate brands: What are they? What of them? European Journal of Marketing, 37(7/8), 972-997.

Banks, M. A., \& Card, O. S. (2008). On the way to the Web: The secret history of the Internet and its founders. Retrieved from http://www.apress.com/9781430208693

Barnard, M. (Ed.). (2007). Fashion theory: A reader. London, UK: Routledge. 
Beckman, T. (2013, June 13). Chanel opens largest flagship store in London (sneak peek inside). Women's style. Examiner.com. Retrieved from http://www.examiner.com/article/chanelopens-largest-flagship-store-london-sneak-peek-inside

Burberry Group PLC. (2013). Brand business culture. Retrieved from www.burberryplc.com

Burberry Group PLC in luxury goods (world): Global company profile. (2013). Euromonitor International. Retrieved from http://www.euromonitor.com/burberry-group-plc-inluxury-goods/report

Choo, H. J., Moon, H., Kim, H., \& Yoon, N. (2012). Luxury customer value. Journal of Fashion Marketing and Management, 16(1), 81-101.

Clark, P. W., \& Das, N. (2009). Exploring the use of E-CRM elements and effective website design as tools for reducing consumer post-purchase cognitive dissonance. Journal of Technology Research, 1, 1-8.

Condé Nast. (2014a). About us. Retrieved from www.condenast.com

Condé Nast. (2014b). Heritage. Retrieved from www.condenast.com

Creswell, J. W. (2009). Research design: Qualitative, quantitative, and mixed methods approaches (3rd ed.). Thousand Oaks, CA: Sage.

de Chernatony, L. (2002). Would a brand smell any sweeter by a corporate name? Corporate Reputation Review, 5(2/3), 114-132.

Demers, D. (2005). Dictionary of mass communication \& media research: A guide for students, scholars \& professionals. Spokane, WA: Marquette Books.

Deshpande, R., \& Webster, F. E., Jr.. (1989). Organizational culture and marketing: Defining the research agenda. Journal of Marketing, 53(1), 3-15. 
Douglas, S. P., Craig, S. C., \& Nijssen, E. J. (2001). Integrating branding strategy across markets: Building international brand architecture. Journal of International Marketing, 9(2), 97-114.

Duboff, R. S. (2013). Making better marketing decisions: A left-brain argument for the right brain. Marketing News, 47(6), 18-24.

Edosomwan, S., Prakasan, S. K., Kouane, D., Watson, J., \& Seymour, T. (2011). The history of social media and its impact on business. Journal of Applied Management and Entrepreneurship, 16(3), 79-91.

Elo, S., \& Kyngäs, H. (2008). The qualitative content analysis process. Journal of Advance Nursing, 62(1), 107-115.

Entwistle, J. (2000). The fashioned body: Fashion, dress, and modern social theory. Oxford, UK: Blackwell.

Ewing, M. T. (2006). Brands, artifacts and design theory: A call to action. Journal of Product \& Brand Management, 15(4), 255-256.

Fam, K-S., Merrilees, B., Richard, J. E., Jozsa, L., Li, Y., \& Krisjanouset, J. (2011). In-store marketing: A strategic perspective. Asia Pacific Journal of Marketing and Logistics, $23(2), 165-176$.

Fionda, A. M., \& Moore, C. M. (2009). The anatomy of the luxury fashion brand. Brand Management, 16(5/6), 347-363.

Geuens, M., Weijters, B., \& De Wulf, K. (2009). A new measure of brand personality. International Journal of Research in Marketing, 26(2), 97-107.

Goldsmith, R. E., \& Goldsmith, E. B. (2012). Brand personality and brand engagement. American Journal of Management, 12(1), 11-20. 
Harris, F., \& de Chernatony, L. (2001). Corporate branding and corporate brand performance. European Journal of Marketing, 35(3/4), 441-456.

Hill, C. A., \& Helmers, M. H. (2004). Defining visual rhetorics. Mahwah, NJ: Lawrence Erlbaum.

Joy, A., Sherry, J. F., Jr, Venkatesh, A., Wang, J., \& Chan, R. (2012). Fast fashion, sustainability, and the ethical appeal of luxury brands. Fashion Theory, 16(3), 273-296.

Karmali, S. (2013, June 10). Inside Chanel's new London flagship. Vogue UK News. Retrieved from http://www.vogue.co.uk/news/2013/06/10/chanel-london-flagship---new-bondstreet---largest-chanel-boutique-store

Kates, S. M., \& Shaw-Garlock, G. (1999). The ever entangling Web: A study of ideologies and discourses in advertising to women." Journal of Advertising, 28(2), 33-49.

Kent, T., \& Brown, R. (Eds.). (2009). Flagship marketing: Concepts and places. New York, NY: Routledge.

Li, L., Guoxin, L., \& Kambele, Z. (2012). Luxury fashion brand consumers in China: Perceived value, fashion lifestyle, and willingness to pay luxury fashion brand consumers in China: Perceived value, fashion lifestyle, and willingness to pay. Journal of Business Research, 65(10), 1517-1522.

Liu, W-X., Hou, J., \& Karimi, H. R. (2014). Research on vocabulary sizes and codebook universality. Abstract and Applied Analysis, 1-7. Retrieved from http://www.hindawi.com/journals/aaa/2014/697245/

Magrath, V., \& McCormick, H. (2013). Marketing design elements of mobile fashion retail apps. Journal of Fashion Marketing and Management, 17(1), 115-134. 
Malecki, E. J., \& Moriset, B. (2007). The digital economy: Business organization, production processes, and developments. New York, NY: Routledge.

Manlow, V., \& Nobbs, K. (2013). Form and function of luxury flagships: An international exploratory study of the meaning of the flagship store for managers and customers. Journal of Fashion Marketing and Management, 17(1), 49-64.

Martin, B., \& Hanington, B. (2012). Universal methods of design: 100 ways to research complex problems, develop innovative ideas, and design effective solutions. Beverly, MA: Rockport.

Mathwick, C., \& Rigdon, E. (2004). Play, flow, and the online search experience. Journal of Consumer Research, 31(2), 324-332.

Meierer, M. (2011). International corporate brand management: Evaluating standardized corporate branding across countries. Wiesbaden, Germany: Gabler Verlag.

Melewar, T. C., \& Smith, N. (2003). The Internet revolution: Some global marketing implications. Marketing Intelligence \& Planning, 21(6), 363-369.

Moore, C. M., \& Birtwistle, G. (2004). The Burberry business model: Creating an international luxury fashion brand. International Journal of Retail \& Distribution Management, 32(8), 412-422.

Moreno, M. A., Egan, K. G., \& Brockman, L. (2011). Development of a researcher codebook for use in evaluating social networking site profiles. Journal of Adolescent Health, 49(1), 2935.

Moschovitis, C. J. P., Poole, H., \& Schuyler, T. (1999). History of the Internet: A chronology, 1843 to the present. Santa Barbara, CA: Moschovitis. 
Nast, C. M. (1923). Features: Class publications. Vogue, 61(1), 174, 176.

Neuman, W. L. (2003). Social research methods: Qualitative and quantitative approaches (5th ed.). Needham Heights, MA: Allyn \& Bacon.

Nueno, L. J., \& Quelch, J. (1998). The mass marketing of luxury. Business Horizons, 41(6), 6168.

O’Callaghan, D., \& Fahy, J. (2002). Is the Internet dumbing down marketing? Irish Marketing Review, 15(2), 59-70.

Pithers, E. (2013, June 10). First look inside the new Chanel flagship. Telegraph UK. Retrieved from http://fashion.telegraph.co.uk/news-features/TMG10110339/First-look-inside-thenew-Chanel-flagship.html

Palais de Tokyo. (2014). No 5 culture Chanel. Retrieved from http://www.palaisdetokyo.com/en/exhibition/ndeg5-culture-chanel

Platt Retail Institute. (2013). Corporate attitudes and adoption trends of multi-channel and omnichannel marketing. Hinsdale, IL: Author.

Plunkett Research Ltd. (2013). Advertising \& branding industry overview. Retrieved from http://www.plunkettresearch.com/advertising-branding-market-research/industrystatistics

Research. (1989). Oxford English dictionary (2nd ed.). Oxford, UK: Clarendon Press.

Richemont Group. (2014). About Richemont. Retrieved from www.richemont.com

Schroeder, J. E., \& Salzer-Morling, M. (2005). Brand culture. New York, NY: Routledge.

So, J. T., Parsons, A. G., Yap, S-F. (2013). Corporate branding, emotional attachment and brand loyalty: The case of luxury fashion branding. Journal of Fashion Marketing and Management, 17(4), 403-423. 
Sprague, J. (2005). Feminist methodologies for critical researchers: Bridging differences. Walnut Creek, CA: Altamira Press.

Srivastava, R. K. (2011). Understanding brand identity confusion. Marketing Intelligence \& Planning, 29(4), 340-352.

Statista. (2014). Number of advertising pages in Vogue from 2006 to 2013. Retrieved from www.statista.com

Sullivan, E. A. (2009). Engage your target. Marketing News, 43(4), 20.

Tynan, C., McKechnie, S., \& Chhuon, C. (2010). Co-creating value for luxury brands. Journal of Business Research, 63(11), 1156-1163.

Universal McCann. (2013). Wave 6: The business of social-Social media tracker 2012. Retrieved from http://www.universalmccann.de/wave6/downloads/wave6_insights_international.pdf

Vanthournout, A. (2013, June 10). First look inside Chanel's new Bond Street flagship [Web log post]. Retrieved from http://alexloves.com/2013/06/first-look-inside-chanels-new-bondstreet-flagship/

Vogue archive. (2014). Toronto, ON: Ryerson University Library \& Archives.

Vigneron, F., \& Johnson, L. W. (2004). Measuring perceptions of brand luxury. Journal of Brand Management, 11(6), 484-506.

Weber, C. (2006, December 3). Fashion-books [Review of the book In Vogue: The illustrated history of the world's most famous fashion magazine, by N. Angeletti \& A. Oliva]. The New York Times. Retrieved from http://tiny.cc/gknrfx 
Xiao, Y. (2011). Research on experiential marketing strategy in corporate websites. Management \& Engineering, 4, 24-27.

Zargani, L. (2014, February 2). By the numbers: All around the world in stats. WWD Collection, 32-33. 


\section{List of Appendices}

\section{Appendix}

Page

Appendix 1: CORPORATE BRAND: AN INTEGRATION .77

Appendix 2: FRAMEWORK: THE NINE PRINCIPAL LUXURY BRAND DIMENSIONS ....................78

Appendix 3: RETAIL PRATT INSTITUTE ……………………………………………………....

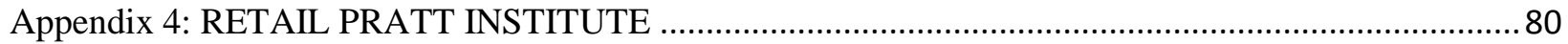

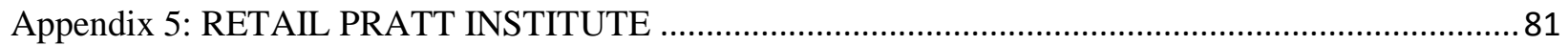

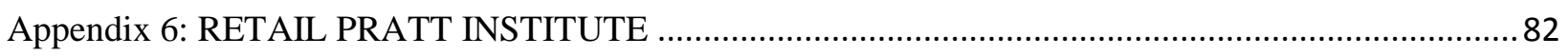

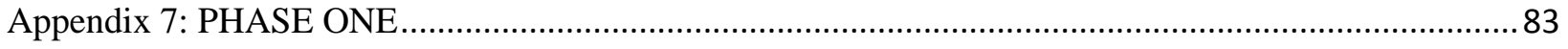

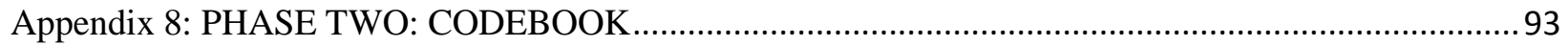

Appendix 9: FIRST CATEGORY: TYPES OF PRODUCT OR SERVICE: TRAVEL ADVERTISEMENTS 1980 .

Appendix 10: FIRST CATEGORY: TYPES OF PRODUCT OR SERVICE: EXAMPLES OF PRINT ADVERTISEMENTS WITH COUPONS OR 'PREFERRED SUBSCRIPTION RESERVATION’ 1980

Appendix 11: FIRST CATEGORY: TYPES OF PRODUCT OR SERVICE: HIGH-FASHION PRINT ADVERTISEMENTS AND FAST-FASHION PRINT ADVERTISEMENTS 2013.

Appendix 12: FIRST CATEGORY: TYPES OF PRODUCT OR SERVICE: RETAILER OR DEPARTEMENT STORE PRINT ADVERTISEMENT SPREADS 1980.

Appendix 13: FIRST CATEGORY: TYPES OF PRODUCT OR SERVICE: EXAMPLE OF A 10 TO 15 AGE ADVERTISEMENT SPREAD OF A DEPARTEMENT STORE 2013

Appendix 14: FIRST CATEGORY: TYPES OF PRODUCT OR SERVICE: EXAMPLE OF A TWOPAGE ADVERTISEMENT SPREAD OF A BRAND LISTING DEPARTEMENT STORE LOCATIONS 106

Appendix 15: FIRST CATEGORY: TYPES OF PRODUCT OR SERVICE: EXAMPLE OF ADVERTISED BRANDS 2013 (WITHOUT DEPARTEMENT STORES).

Appendix 16 SECOND CATEGORY: THE OVERALL PRESENTATION: EXAMPLES OF HALF OR QUARTER PAGE ADVERTISING SPREADS 1980.

Appendix 17: SECOND CATEGORY: THE OVERALL PRESENTATION: EXAMPLES OF 4 TO 6 PAGE ADVERTISING SPREADS 2013.

Appendix 18: SECOND CATEGORY: THE OVERALL PRESENTATION: VOGUE FRONT PAGE COVERS (JANUARY TO JUNE 1980) 
Appendix 19: SECOND CATEGORY: THE OVERALL PRESENTATION: VOGUE FRONT PAGE COVERS (JANUARY TO JUNE 2013) 115

Appendix 20: SECOND CATEGORY: THE OVERALL PRESENTATION: THE OVERALL PRESENTATION: EXAMPLES OF PRINT ADVERTISING CONTENT 1980 116

Appendix 21: SECOND CATEGORY: THE OVERALL PRESENTATION: EXAMPLES OF PRINT ADVERTISING CONTENT 2013 118

Appendix 22: SECOND CATEGORY: THE OVERALL PRESENTATION: EXAMPLES OF PRINT ADVERTISING CONTENT WITH STORE LOCATIONS 2013 120 Appendix 23: SECOND CATEGORY: THE OVERALL PRESENTATION: EXAMPLES OF PRINT ADVERTISING LAYOUT OF MODEL-PRODUCT OR AD-PRODUCT PLACEMENT 1980 122

Appendix 24: SECOND CATEGORY: THE OVERALL PRESENTATION: EXAMPLES OF CELEBRITY ENDORSEMENT PRINT ADVERTISEMENTS 2013. 124

Appendix 25: THIRD CATEGORY: THE OVERALL APPEARANCE OF THE DIGITAL CONTENT: EXAMPLES OF WEBSITES PRESENT ON PRINT ADVERTISEMENTS 2013. 125 Appendix 26: THIRD CATEGORY: THE OVERALL APPEARANCE OF THE DIGITAL CONTENT: EXAMPLES OF DIGITAL CONTENT ON PRINT ADVERTISEMENTS 2013. 128 Appendix 27: PHASE TWO: FIRST DIMENSION: BRAND IDENTITY ..... 137 Appendix 28: PHASE TWO: SECOND DIMENSION: MARKETING COMMUNICATIONS 145

Appendix 29: PHASE TWO: THIRD DIMENSION: PRODUCT INTEGRITY 163

Appendix 30: PHASE TWO: FOURTH DIMENSION: BRAND SIGNATURE. 169 Appendix 31: PHASE TWO: FIFTH DIMENSION: PREMIUM PRICES 174 Appendix 32: PHASE TWO: SIXTH DIMENSION: EXCLUSIVITY 179

Appendix 33: PHASE TWO: SEVENTH DIMENSION: HERITAGE 180 Appendix 34: PHASE TWO: EIGHT DIMENSION: LUXURY ENVIRONMENT AND EXPENRIENCE. 184 Appendix 35: PHASE TWO: NINTH DIMENSION: CULTURE. 193 


\section{Appendix 1: CORPORATE BRAND: AN INTEGRATION}

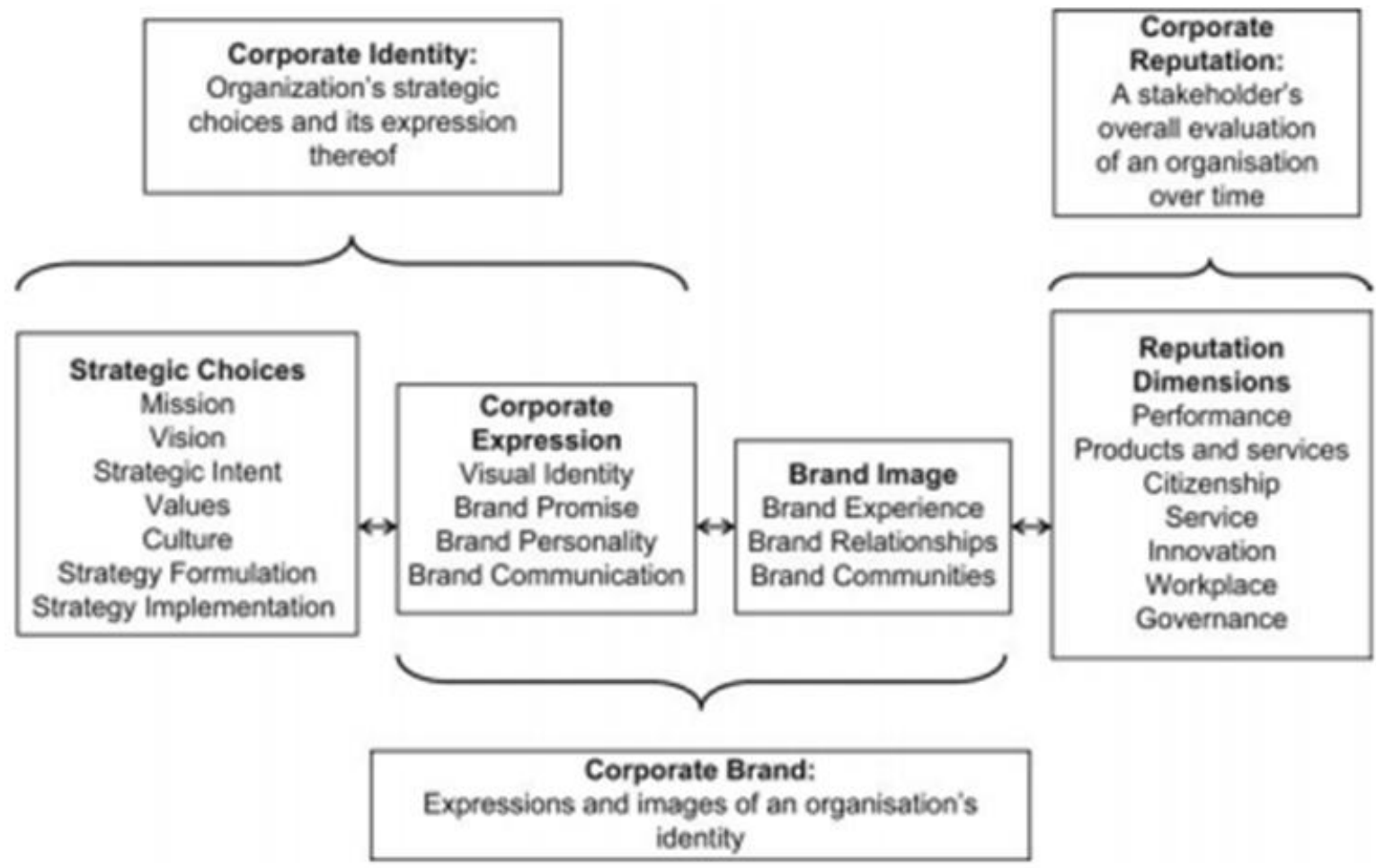

Figure 1: Corporate identity, corporate brand and corporate reputation: an integration

Source: Abratt, Russell \& Nicola Kleyn. "Corporate identity, corporate branding and corporate reputations." European Journal of Marketing 46. 7-8 (2012): 1048-1063. Scholars Portal Journals. Web. 11 Nov. 2013. 


\section{Appendix 2: FRAMEWORK: THE NINE PRINCIPAL LUXURY BRAND DIMENSIONS}

1. Clear brand identity: Clear understanding of brand values \& brand differentiation (distribution, awareness and positioning of the brand).

2. Marketing communications: Communications strategy includes tools such as fashion shows, advertising, PR, direct marketing and celebrity endorsement.

3. Product integrity: Includes product quality, craftsmanship and attention to detail thus also a requirement to be innovative and creative.

4. Brand signature: Refers to the brand's iconic products: the designer's distinctive styles, the designer's handwriting and the brand DNA. More specifically, in the Nueno and Quelch study, they state that the properties of a brand's fabrics, colors, or shapes are also critical elements because these allow the product to be widely recognizable (64).

5. Premium price: High prices create a barrier of entry that which develops the luxury brand status; the high price reflects the aforementioned attributes associated with luxury.

6. Exclusivity: Controls the distribution and accessibility; thus, limited production ensures exclusivity; a luxury brand positioning strategy.

7. Heritage: The history behind the brand and the original creator of the brand allows for luxury brands to adopt this positioning strategy; this is usually where the values of the company are derived from and allows the company to maintain its authenticity.

8. Luxury environment and experience: Flagship, boutiques, wholesale, and licensee; provides an experiential dimension for the consumer and personalised service.

9. Culture: Management of the internal and external relationships of the brand; thus, creating the culture of the brand that refers to the expertise behind it. It is important that a company identifies with the following attributes: morality, teamwork, integrity and honesty.

Source: Fionda, Antoinette M. \& Moore, Christopher M. "The Anatomy of the Luxury Fashion Brand." Brand Management 16. 5-6. (2009): 347-363. ProQuest Business Collection. Web. 11 Nov. 2013. 
Appendix 3: RETAIL PRATT INSTITUTE

\section{Integrating Marketing Campaigns}

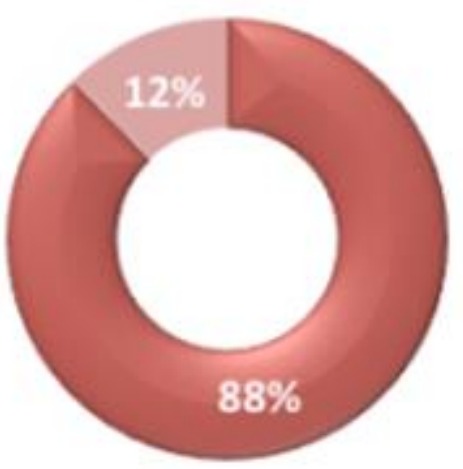

ㅂes

No

Figure 2: Multi-Channel Integration Status

Source: Retail Attitudes and Adoption Trends of Multi-Channel and Omni-Channel Marketing. Platt Retail Institute, LLC, 2013. October 2013. Digital Signage Expo. Web. 11 Nov. 2013. 


\section{Appendix 4: RETAIL PRATT INSTITUTE}

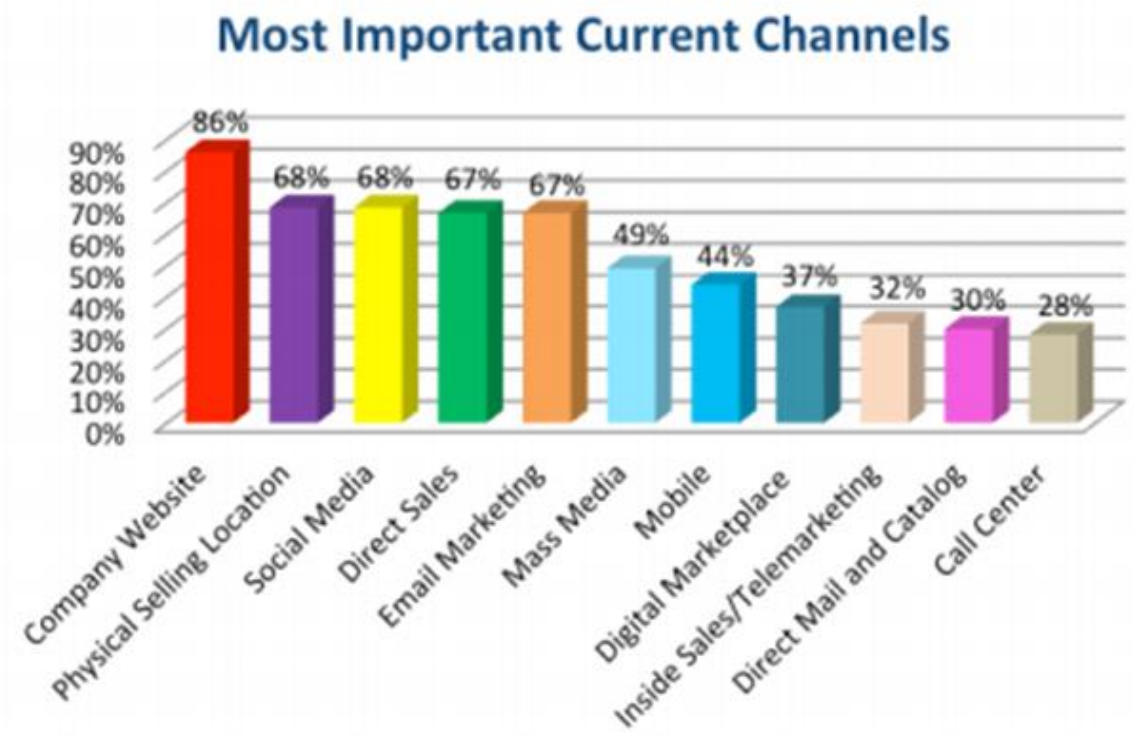

Figure 3: Most Important Current Retail Marketing Channels

Source: Retail Attitudes and Adoption Trends of Multi-Channel and Omni-Channel Marketing. Platt Retail Institute, LLC, 2013. October 2013. Digital Signage Expo. Web. 11 Nov. 2013. 


\section{Appendix 5: RETAIL PRATT INSTITUTE}

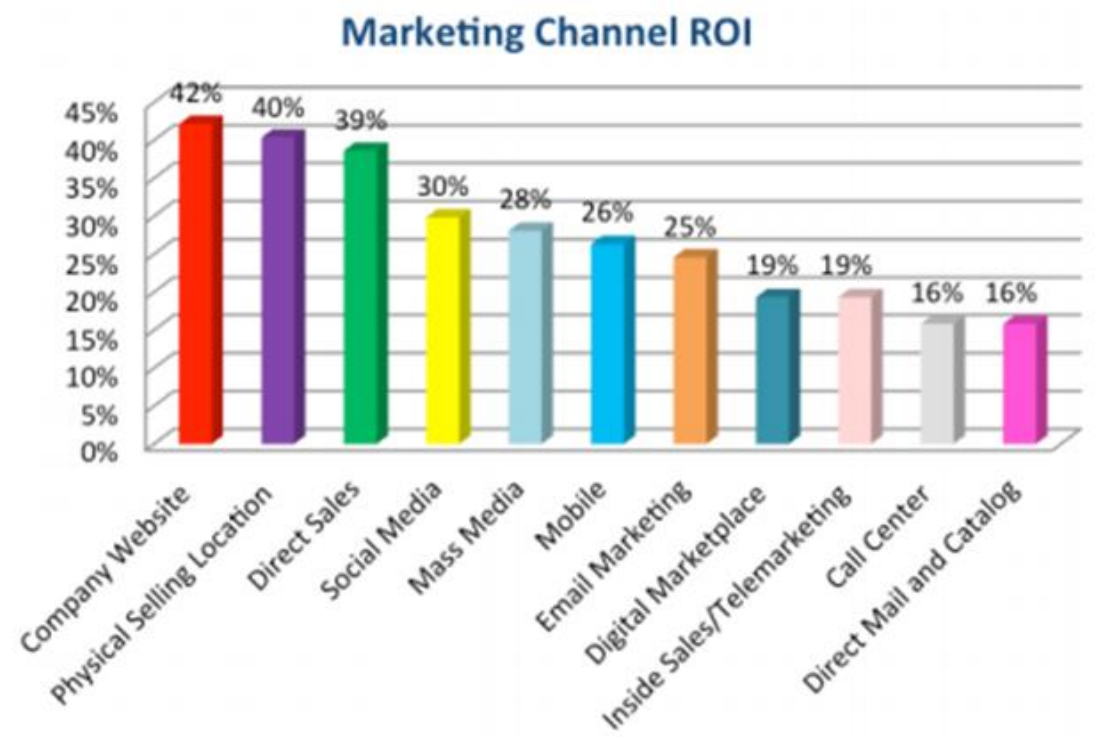

Figure 4: Marketing Channel ROI

Source: Retail Attitudes and Adoption Trends of Multi-Channel and Omni-Channel Marketing. Platt Retail Institute, LLC, 2013. October 2013. Digital Signage Expo. Web. 11 Nov. 2013. 


\section{Appendix 6: RETAIL PRATT INSTITUTE}

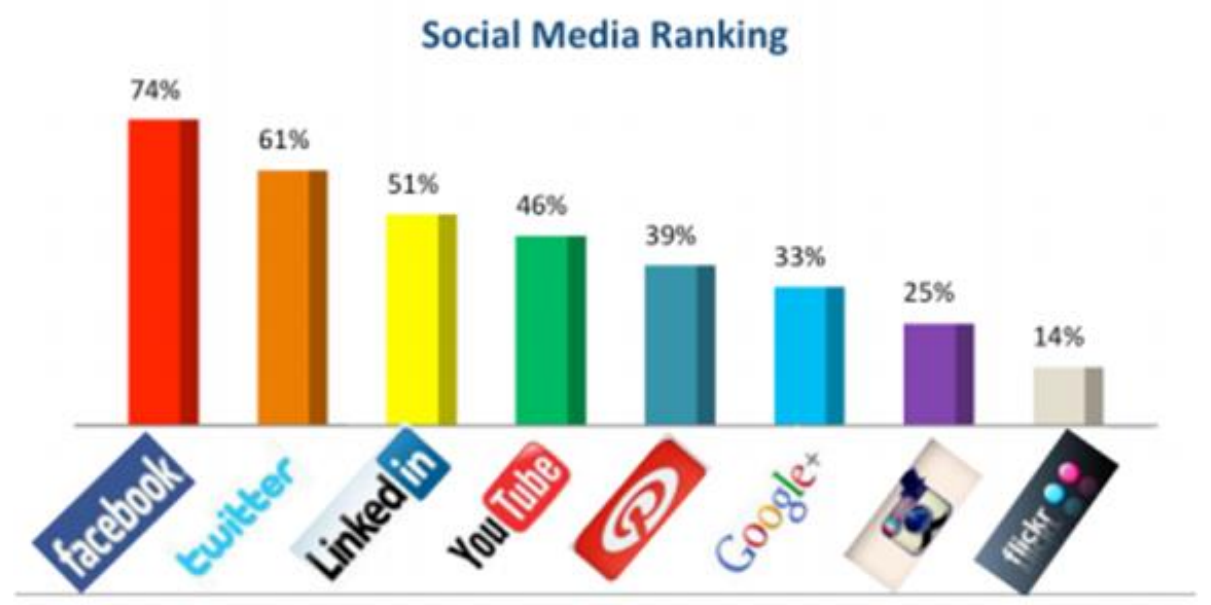

Figure 5: Social Media Ranking

Source: Retail Attitudes and Adoption Trends of Multi-Channel and Omni-Channel Marketing. Platt Retail Institute, LLC, 2013. October 2013. Digital Signage Expo. Web. 11 Nov. 2013. 


\section{Appendix 7: PHASE ONE}

\begin{tabular}{|c|c|c|}
\hline $\begin{array}{l}\text { Type of } \\
\text { product } \\
\text { and/or } \\
\text { service } \\
\text { categories }\end{array}$ & 1980 & 2013 \\
\hline $\begin{array}{l}\text { Skin-care (face \& } \\
\text { body): }\end{array}$ & $\begin{array}{l}\text { Neutrogena; Clinique Laboratories; Almay; } \\
\text { Stendhal; Revenescence; Christine Valmy } \\
\text { (Care Salons); Tova; Georgette Klinger, } \\
\text { Inc.; Doak Pharmacal Co, Inc.; Orlane } \\
\text { Institut De Beauté; C. H. R. Collagen } \\
\text { Protein System; Estée Lauder, Inc.; Jolen } \\
\text { Inc.; Milopa Cosmetics; Samantha Jones } \\
\text { Corporation; Germaine Monteil; Erno } \\
\text { Laszlo Company; Janet Sartin Inc.; Payot, } \\
\text { Inc.; Vidal Sassoon, Inc.; Riker } \\
\text { Laboratories, Inc.; Jean d'Aveze; Princess } \\
\text { Marcella Borghese, Inc.; Pretty Feet, } \\
\text { Inc.;Orlane Institut De Beauté; Stendhal; } \\
\text { Charles Of The Ritz Group Ltd.; Coty Inc.;: } \\
\text { Princess Marcella Borghese; Germaine } \\
\text { Monteil; Frances Denney, Inc;Erno Laszlo } \\
\text { Company; Avon Products; } \\
\text { Supplegen;Millenium; Lancaster; Milopa } \\
\text { of Switzerland; Evian(face spray); Doak } \\
\text { Pharmacal Co, Inc; Lancaster; Coppertone; }\end{array}$ & $\begin{array}{l}\text { Neutrogena; Lancome Inc.; L'Oreal; } \\
\text { Aveeno; Vidal Sasson Inc.; Estée } \\
\text { Lauder, Inc,; Clinique Laboratories Inc.; } \\
\text { Clarins; Philosophy; Elizabeth Arden; } \\
\text { Clarisonic; Sk-II; La Mer; Living Proof; } \\
\text { Urban Decay; Cle de Peau Beaute; } \\
\text { Olay; Philosophy; Secret; Peter } \\
\text { Thomas Roth; Roc; La Prairie; Bond } \\
\text { n.9; Simple; }\end{array}$ \\
\hline $\begin{array}{l}\text { Cosmetics } \\
\text { (make-up \& nail } \\
\text { care): }\end{array}$ & $\begin{array}{l}\text { Merle Norman Cosmetics Inc.; Fabriella; } \\
\text { Christian Dior; Chanel Beauty; Helena } \\
\text { Rubinstein; Revlon Research Group; } \\
\text { Elizabeth Arden Co.;Lancôme, Inc.; Charles } \\
\text { of the Rittz Inc.; L'Oréal; Coty; Fabriella } \\
\text { Cosmetici, Inc.; Rouges Lyriques; The } \\
\text { Denney Face; Maybelline Co.; Living Nail; } \\
\text { Charles Revson; Jōvan Inc.; Countess } \\
\text { Isserlyn; (La Maur Inc.); Cosmétique; } \\
\text { Barielle; Norton Simon Inc; Formula 2; } \\
\text { Germaine Monteil; Helena Rubinstein Inc.; } \\
\text { Buf-Puf; Jean D'avége Paris; Maybelline }\end{array}$ & $\begin{array}{l}\text { Covergirl; Olay; Essie; MAC Cosmetics; } \\
\text { O.P.I Products Inc.; Maybelline Co.; } \\
\text { Revlon; Dolce \& Gabbana; Tom Ford } \\
\text { Beauty; Bobbi Brown Cosmetics; } \\
\text { Laura Mercier; Giorgio Armani; } \\
\text { Rimmel; Jane Iredale; Lancôme; } \\
\text { Clinique Laboratories Inc.); Revlon; } \\
\text { Sephora Inc.; }\end{array}$ \\
\hline
\end{tabular}




\begin{tabular}{|c|c|c|}
\hline & Co; Barielle; & \\
\hline Hair Care: & $\begin{array}{l}\text { Pantene; Regis Hairstylists; Agree; Perma } \\
\text { Tweez; Surgi-Cream; Mg; Well Corp.; } \\
\text { Conair Corporation; Ogilvie Sisters; Breck; } \\
\text { Clairesse By Clairol; Jhirmack Enterprises, } \\
\text { Inc.; Wella shampoo; Style II; Enrich; }\end{array}$ & $\begin{array}{l}\text { Pantene Co.; Fekkai; Aveda; Garnier; } \\
\text { Moroccan Oil; Vidal Sassoon: Olia by } \\
\text { Garnier; Clear Scalp and Hair Beauty } \\
\text { Therapy; Nexxus; }\end{array}$ \\
\hline Fragrance: & $\begin{array}{l}\text { Oscar de la Renta; Red; Dana Perfumes, } \\
\text { Inc.; Yves Saint Laurent Parfums Corps.; } \\
\text { Chimère; Chanel; Chloe; Flora Danica } \\
\text { Perfume; Houbigant Inc.; Cachet; Pavlova; } \\
\text { Nina Ricci; Lanvin Parfums Inc.; Guerlain } \\
\text { Inc.; Van Cleef \& Arpels; Bill Bass Inc.; } \\
\text { Tuxedo; Norelli; Aramis (Cologne); } \\
\text { Royalsecret; Houbigant Inc.; Diane Von } \\
\text { Furstenberg; }\end{array}$ & $\begin{array}{l}\text { BCBG Max Azria; Dolce \&Gabbana; } \\
\text { Marni; Calvin Klein; Chanel; Guess; } \\
\text { Dior; Marc Jacobs; Chloe; Just Cavalli; } \\
\text { Jimmy Choo; Bottega Veneta; } \\
\text { Ne'emah; Calvin Klein Euphoria; Kate } \\
\text { Spade; Yves Saint Laurent; Gucci; } \\
\text { Narciso Rodriguez; Balenciaga; Viktor } \\
\text { \& Rolf; Thierry Mugler; Bond N.9 }\end{array}$ \\
\hline Swimwear: & $\begin{array}{l}\text { Hawaiian Tropic (Jay Cee Swimwear); } \\
\text { Lycra; The Kitty Cat (Sun Up/ Sun Down); } \\
\text { Sirena; : Leonard Paris ; : May Co. ; Criss } \\
\text { Cross bathing suits; }\end{array}$ & \\
\hline $\begin{array}{l}\text { Women's } \\
\text { Intimate } \\
\text { Apparel: }\end{array}$ & $\begin{array}{l}\text { Lady Lynne; Bali; Sirena; Poppy; Victoria } \\
\text { Secret; Roxanne; Bodysilk; Hanes Hosiery, } \\
\text { Inc.; Givenchy Inc.; The Kitty Cat (Sun } \\
\text { Up/Sun Down); Janet Reger; Maiden Form } \\
\text { Brassiere Company ; Olga Co.; Prima } \\
\text { Boutique; Lily of France; Fruit of the } \\
\text { Loom; Vanity Fair Inc.; Merle Norman; } \\
\text { Playtex; Olgalon; Lejaby Paris; Formfit } \\
\text { Rogers; Burlington; }\end{array}$ & \\
\hline
\end{tabular}


Ralph Lauren; Lina Lee; Gianni Versace; Christian Dior; Andre Laug; Essence De Colon; Nat Kaplan, Inc.; Rich's, Inc.; Ann Taylor; I. Magnin \& Co.; Donna Karen; Anne Klein; Jack Mulqueen Ltd. (Silk Fashion Group Ltd.); Roberta Di Camerino (Roberta Di Camerino); Guy Laroche; Dana Côte D'Azur; Rodier; Robinson's;

Castleberry Knits Ltd.); Missoni; Carole Little; Givenchy Inc.; Don Sayres; Geoffrey Beene; Howard Wolf; Richard Assatly; Dominic Rompollo; Morton Myles; Lorch (New Era Trevira); Gallant; Diane Von Furstenberg; Giorgio Armani; Mary McFadden; Judith Leiber; Karl Lagerfeld for the House of Chloe; Calvin Klein Jeans; Ralph Lauren; Krizia; Saint Laurent; Lane Bryant; Jaeger Company Inc.); Adolfo; Meyers; Valentino; Braghenti; Chloé Paris (Chloé); Charles Jourdan; Bill Blass Jeans; Nazareno Gabrielli; Frances Henaghan; Emanuel Ungaro; JH; Norma Walters; Gianfranco Ferre; Jack Fuller, Ltd; Genny Inc.; Complice; Lilian Burty;
Louis Vuitton; Chanel; Dior; Saint Laurent; Marc Jacobs; Cartier; Brahmin; Bottega Veneta; Roberto Cavalli; Michael Kors; Attilio Giusti Leombruni; Calvin Klein; Gucci; Burberry Prorsum (Mens+Children); Dolce \& Gabbana; Prada; Fendi; DKNY; Donna Karan Company; Miu Miu; Celine; Givenchy; Valentino; Mulberry; Alberta Ferretti; Moschino; Longchamp Paris; Tommy Hilfiger; Chloe; Balmain; Jil Sander; Isabel Marant; Miss Me; J BRAND Jeans; Belk; Paige USA; Balenciaga; Versace; Donna Karan; Gap; Ralph Lauren; Jimmy Choo; Belstaff; Gap Kids; Oscar de la Renda; Erdem; Hugo Boss Inc.; Emilio Pucci; Marni; Akris; Nina Ricci; Erdem; Carolina Herrera; Alexander McQueen; Vera Wang; Giambattista Vali; Stella McCartney; Oscar de la Renta; Etro; Haider Ackermann; Lanvin; Donna Karen New York; Diesel; Rag \& Bone; Escada; Lanvin; H\&M; 7 for All Mankind; Leon Max Studio; Express; Ann Taylor; True Religion Brand Jeans; Loft; Lacoste; Kenzo; Banana Republic; WHBM; NYDJ; Topshop; J.Crew; Lucky Brand Jeans; Sperry Topsider; Tom Ford; Proenza Schouler;Cesare-Paciotti; 


\begin{tabular}{|c|c|c|}
\hline $\begin{array}{l}\text { Women's } \\
\text { apparel } \\
\text { Continuation: }\end{array}$ & $\begin{array}{l}\text { Thierry Mugler; Jordache Enterprises, } \\
\text { Inc.;Gloria Vanderbilt Corporation; } \\
\text { Jacques Cohen Ltd.; Helga; St. Gillian (St. } \\
\text { Gillian); Bessi; Jack Fuller Ltd.; Halston; } \\
\text { Jamison; Donald Johns; Moygashel; } \\
\text { Talbots; Martha; Bal Harbour Shops; } \\
\text { Boston; Marshall Field \& Co. ; Nat } \\
\text { Kaplan;Bonwit Teller; Rich's; Lillie Rubin; } \\
\text { Frederick \& Nelson; Sakowitz; Martha; } \\
\text { Sonia Rykiel; Montaldo's;Roberta Di } \\
\text { Camerino;be Schrader Corporation ;Abe } \\
\text { Schrader Corporation; Ferragamo; } \\
\text { Kaufmann's; Balliet's; Gordon; Best of } \\
\text { Blassport; Liberty House of Hawaii; : } \\
\text { Marton Myles; Jamison;Bonwit Teller \& } \\
\text { Co.;Charles Revson; John Yang; John } \\
\text { Wanamaker; Tanner;Jaeger Company } \\
\text { Inc;Courrèges ;Gloria Vanderbilt } \\
\text { Corporation); Higbee Co.;Jacques Cohen } \\
\text { Ltd; les Copains; Honeybee; Emanuel; } \\
\text { Tennis Lady; Jh Collectibles;Du Pont } \\
\text { Company, Inc;Mary McFadden ; (Chas. A. } \\
\text { Stevens \& Co.;St. John; Alpha Cubic }\end{array}$ & $\begin{array}{l}\text { Giuseppe Zanotti Design; Carlos Miele; } \\
\text { Tibi; Hermes; Icb; Juicy Couture; } \\
\text { United Colors Of Benetton (Benetton } \\
\text { Group, Inc.; Maje; Nic + Zoe; J.Mendel; } \\
\text { Reed Krakoff; The Row; Azzedine } \\
\text { Alaia; Nina Ricci; 3.1. Phillip Lim; I.N.C } \\
\text { International Concepts (I-N-C); Eileen } \\
\text { Fisher; Michael Stars; Ugg Australia; } \\
\text { Ash; Joe's; Bottega Veneta; Diesel; } \\
\text { Chico's; Kenneth Cole; Stella } \\
\text { McCartney; AG+Liberty Art Fabrics; } \\
\text { Kate Spade;Comptoir Des Cotonniers; } \\
\text { Massimo Dutti; AG Jeans; Edun; Rock } \\
\text { Revival; }\end{array}$ \\
\hline $\begin{array}{l}\text { Department } \\
\text { Stores: }\end{array}$ & $\begin{array}{l}\text { Saks Fifth Avenue (...) Lillie Rubin } \\
\text { (Halston); Bonwit Teller \& Co.; Neiman- } \\
\text { Marcus Company; Bergdorf Goodman \& } \\
\text { Co.; Lord \& Taylor Co.; Marshall Field \& } \\
\text { Co.; Bloomingdale's; Frederick \& Nelson; } \\
\text { Sakowitz Bros.; Martha; Basile (Basile } \\
\text { U.S.A. Inc.); Montaldo's, Razook's Inc.; } \\
\text { Mutual Buying Syndicate, Inc.; Saint- } \\
\text { Tropez West; Kramer Co.; Du Pont } \\
\text { Company, Inc.; Meier \& Frank Co.; } \\
\text { Marshall Field \& Co. (Rich's, Inc.); Jerry } \\
\text { Bernstein Inc.; Kenar Enterprises Ltd.); } \\
\text { Bullock's; Macy's; Chez Catherine; David } \\
\text { Hayes; Nan Duskin; Eaton's; Coureges } \\
\text { Boutiques; The 24 Collection; Lester } \\
\text { Melnick; Jack Mulqueen; Barney's; Higbee } \\
\text { Co.; Gloria Vanderbilt Corporation; Tennis } \\
\text { Lady; Simpson's; Holt Renfrew \& Co. Ltd. ; }\end{array}$ & $\begin{array}{l}\text { Nordstrom; Belk; Target; Saks Fifth } \\
\text { Avenue; Dillard's; Macy's; Barney's; } \\
\text { Bloomingdale's; Kmart;Neiman- } \\
\text { Marcus Company }\end{array}$ \\
\hline
\end{tabular}


Lord \& Taylor (Ralph Lauren-Bonwit Teller); Macy's (Adolfo Sport); Saks (Anne Klein); Macy's (Red perfume); Bergdorf \& Goodman (Halston's); Lord \& Taylor (Calvin Klein); Marshall Fields \& Co. (Basile); Bloomingdale's (Missoni); Saks Fifth Avenue (André Laug); NeimanMarcus (Anne Klein); Harzfelds (André Laug); Bergdorf Goodman (Van Cleef \& Arpels); Jacobson's (Jesper Nyeboe); Neiman-Marcus (Stendhal); Kaufmann's (Calvin Klein); Balliets (Bill Blass); Lord \& Taylor (Dalani II); Holt Renfrew (Milaschöndue); Meier \& Frank (Anne Klein); Berdorf Goodman (Krizia) ; Lord \& Taylor (Bill Blass); Bloomingdale's (Giorgio Armani); Macy's (Calvin Klein); Marshall Field's (Mary McFadden); Bonwit Teller (Missoni); Neiman Marcus (Lillie Rubin); Saks Fifth Avenue (Chloé); Barney's (Giorgio Armani); Neiman-Marcus (Bruno Magli); Bloomingdale's (Diane von Furstenberg); Macy's (Adolfo); I.Magnin (Valentino Boutique); Holt Renfrew (Valentino);
Nordstrom (BCGB Max Azria-Bon Chic Perfume); Belk (Michael KorsHandbags/Apparel); Nordstrom (Attilio Giusti Leombruni); Target (Prabal Gurung); Nordstrom (AGL, Lanvin, Dior, Givenchy, Saint-Laurent, Charlotte Olympia; Chanel; Erdem); Saks Fifth Avenue (Emilio Pucci, Marni, Dior, Akris, Burberry Prorsum; Nina Ricci, Chanel, Erdem, Carolina Herrera; Alexander McQueen, Vera Wang, Giambattista Vali, Stella McCartney, Roberto Cavalli, Oscar de la Renta, Valentino, Calvin Klein Collection, Etro, Haider Ackermann; Saint Laurent, Ralph Lauren Collection; Lanvi, Dolce and Gabbana, Donna Karen New York); Dillard's (Vince Camuto); Nordstrom (Franco Sarto); Nordstrom (NYDJ); Nordstrom (Living Proof); Nordstrom (Dot Marc Jacobs); Saks Fifth Avenue (Stephanie Kantis); Neiman-Marcus Company (Alexander McQueen, Christian Louboutin; Lanvin; Chanel; Saint Laurent, Manolo Blahnik, Jil Sander, The Row, Valentino, Stella McCartney, Oscar de la Renta, Haider Ackermann, Gucci, Tom Ford, Dolce \& Gabbanna, Neiman-Marcus Company; Akris; Burberry Prorsum, Jimmy Choo, Dior, Proenza Schouler); Barney's New York (Saint Laurent, Belstaff, Fendi, Azzedine Alaia); Kmart (Kate Younge); 


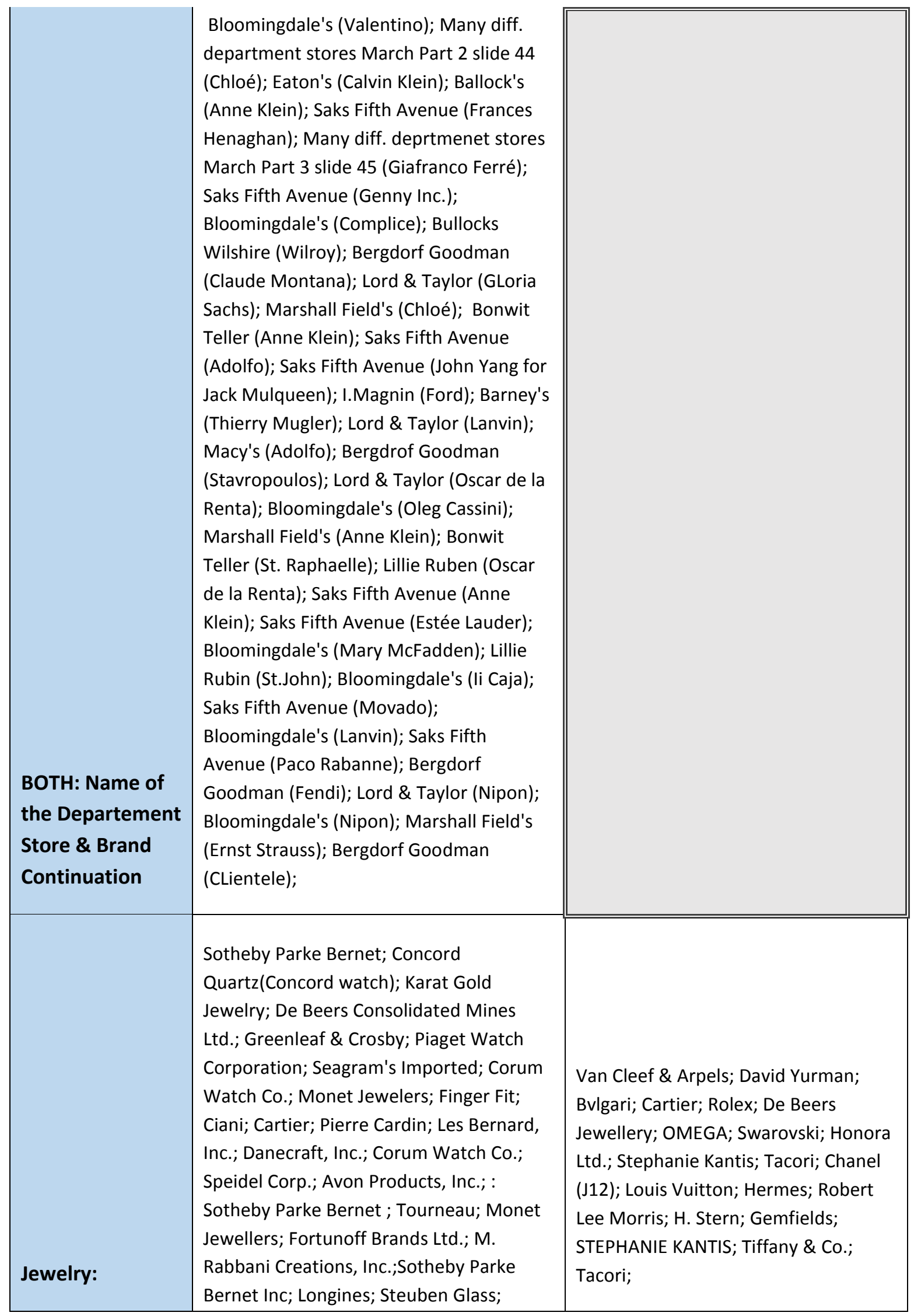




\begin{tabular}{|c|c|c|}
\hline & $\begin{array}{l}\text { Bulgari; Bailey, Banks \& Biddle Co; M. } \\
\text { Rabbani; Harry Winston, Inc.; Pampillonia; } \\
\text { D'aven; Timex Quartz; }\end{array}$ & \\
\hline Footwear: & $\begin{array}{l}\text { Bally Inc.; Macro Martini; Maud Frizon; } \\
\text { Halston; Joan \& David; Garolini; Pancaldi } \\
\text { \& B;Bottega Veneta; Andrew Geller; } \\
\text { Chandler's; Famolare Inc.; Magnin \& Co.; } \\
\text { Monique; Joe Famolare ; }\end{array}$ & $\begin{array}{l}\text { Chanel; Saint Laurent; Dior; Charlotte } \\
\text { Olympia; Vince Camuto; Sam Edelman; } \\
\text { Brian Atwood; Brown Crown } \\
\text { Footwear; Stuart Weitzman; Nine } \\
\text { West; Kenneth Cole; Via Spiga; Franco } \\
\text { Sarto; Tod's; J Crew; Sketchers; Sperry } \\
\text { Topsider; Tom Ford; Christian } \\
\text { Louboutin; Manolo Blahnik; Ugg } \\
\text { Australia; Cesare-Paciotti; Guiseppe } \\
\text { Zanotti Designs; Hermes; Clark's; } \\
\text { Manolo Blahnik; Birkenstock }\end{array}$ \\
\hline Handbags: & $\begin{array}{l}\text { Bally inc.; Meyers Brothers Inc.; Nazareno } \\
\text { Gabrielli; Bottega Veneta; Phillippe; Rolfs } \\
\text { Inc.; Reva; Diane Von Furstenberg, Inc.; }\end{array}$ & $\begin{array}{l}\text { Michael Kors; Ralph Lauren; Givenchy; } \\
\text { Mulberry; Longchamps Paris; Brahim; } \\
\text { Jimmy Choo; Chloe; Fendi; Chanel; } \\
\text { Dior; Prada; Celine; DKNY; Belstaff; } \\
\text { Oscar de la Renta; Saint Laurent; } \\
\text { Givenchy; Chanel; BelkHugo Boss Inc.; } \\
\text { Vince Camuto; Furla; Lanvin; Tod's; } \\
\text { BVLGARI; Valentino; J Mendel; Piero } \\
\text { Guidi; Ralph Lauren; Emilio Pucci; } \\
\text { Piero Guidi; ASH; Loewe; Porsche } \\
\text { Design; }\end{array}$ \\
\hline $\begin{array}{l}\text { Eyewear } \\
\text { (sunglasses): }\end{array}$ & $\begin{array}{l}\text { Au Courant; : Givenchy Eyewear Universal } \\
\text { Optical Company Inc. (Universal Optical } \\
\text { Co.); Ray-Bans; }\end{array}$ & $\begin{array}{l}\text { Dior; Jimmy Choo; : Clear Scalp and } \\
\text { Hair Beauty Therapy ; }\end{array}$ \\
\hline $\begin{array}{l}\text { Cigarette } \\
\text { (brands): }\end{array}$ & $\begin{array}{l}\text { Benson \& Hedges (lights); Salem; Virginia } \\
\text { Slims Lights; Vantage; Now; Max; } \\
\text { Malboro; More; Newport; Rich Lights; } \\
\text { Golden Lights; Merit; Rich Lights; New }\end{array}$ & Camel May 2013 Part 2; \\
\hline
\end{tabular}




\begin{tabular}{|c|c|c|}
\hline & Kent III; Cambridge; More; & \\
\hline $\begin{array}{l}\text { Feminine } \\
\text { Hygiene: }\end{array}$ & $\begin{array}{l}\text { Kotex Co. (Kotex Company); O.B. Tampons } \\
\text { (Johnson \& Johnson Consumer } \\
\text { Companies, Inc); New Freedom (Kimberly- } \\
\text { Clark Corporation); Playtex; Crest; Break; li } \\
\text { Caja (soap); Felicity (soap); Depilatron } \\
\text { Sales, Inc.; Lightdays; }\end{array}$ & Crest; Dove (Secret Clinical Strenght); \\
\hline $\begin{array}{l}\text { Contraceptives/ } \\
\text { Pregnancy } \\
\text { Testing: }\end{array}$ & $\begin{array}{l}\text { Semicid; E.P.T; Predictor; Conceptrol } \\
\text { Disposable; Daisy 2; }\end{array}$ & Nuva Ring; Nexplanon (Merck) \\
\hline Homegoods: & $\begin{array}{l}\text { Burlington, Fieldcrest, Bed Sack, Martex; } \\
\text { Bed And Both (T \& J Vestor); Mombasa } \\
\text { Magic (net for the bed); Ultra Bedsack; } \\
\text { Martex (towels); }\end{array}$ & Vera Wang; \\
\hline $\begin{array}{l}\text { Cleaning } \\
\text { products: }\end{array}$ & Detergent like Woolite & Downy; \\
\hline 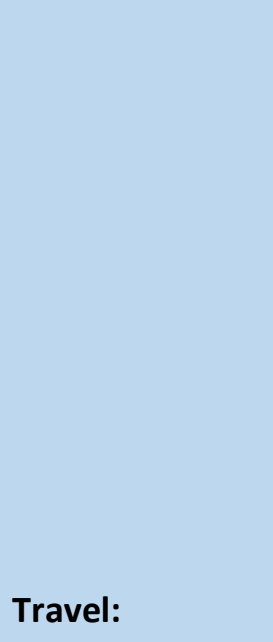 & $\begin{array}{l}\text { Bal Harbour; United States Virgin Islands; } \\
\text { North Carolina; Boston; Five Stars Caravel } \\
\text { Hotel; Hotel Grande Bretagne; } \\
\text { Maupintour; National Bank Of Greece S. } \\
\text { A.; Traveline; Travelforce Inc.; Greece; } \\
\text { Zolotas; Sun Line Cruises; VL; NJV (The N J } \\
\text { Vandinoyannis Group of Companies); } \\
\text { Olympic Airways; Turnberry Isle Yacht And } \\
\text { Racquet Club; North Carolina Travel } \\
\text { Package; Delta Line Cruises; Irish Tourist } \\
\text { Board; Pan Am (Aviation); Mexico; La } \\
\text { Costa Hotel \& Spa ;United Airlines; Queen } \\
\text { Elizabeth 2; }\end{array}$ & \\
\hline
\end{tabular}




\begin{tabular}{|c|c|c|}
\hline Other (lifestyle): & $\begin{array}{l}\text { Oriental Silk Co.; American School; Per } \\
\text { Spook; Multifoods; Maxine Fabrics; } \\
\text { Dayton's; Roche Bois (Furniture); Elizabeth } \\
\text { Arden Salon (Elizabeth Arden Co.); } \\
\text { Butterflies Of The World; Family Library Of } \\
\text { The World's Great Books; V-Bar; Tasis; } \\
\text { Nickolaus Exercise; Armstrong; } \\
\text { International Gallery of Flower Plates; } \\
\text { Barbi International; Royal Copenhagen } \\
\text { Porcelain Manufactory Ltd.;Kraft General } \\
\text { Foods, Inc.; Soft Tip Pen (Cross); Baker } \\
\text { Furniture, Inc.; Marianne 'The Minuet'; } \\
\text { Sea Pines Behavioral Institute; White } \\
\text { Flower Farm (flowers);Vogue Poster Book; } \\
\text { Diet Parkay(margarine); Cartier } \\
\text { (lighters);Empress Josephine's Rose } \\
\text { Garden (porcelain boxes); Parker (pens); } \\
\text { Alba'77 (milkshakes); Polaroid Corp.; } \\
\text { American Express; Hartman (lugage); } \\
\text { United Way;Trimline phones; }\end{array}$ & $\begin{array}{l}\text { Fage USA; Vera Wang; Academy of Art } \\
\text { University; Geico; Nostalgia in Vogue } \\
\text { (Book); The Vogue List ; Architectural } \\
\text { Digest Home Design Show; Highland } \\
\text { Park Village (April Part } 2 \text { 2013); GNC } \\
\text { April } 2013 \text { part 2; Movie Peru: Empire } \\
\text { of Hidden Treasures; Woolmark May } \\
2013 \text { Part1; Courage (Breast Cancer } \\
\text { Awareness); Guy Laroche; }\end{array}$ \\
\hline $\begin{array}{l}\text { Alcohol/Non- } \\
\text { Alcoholic: }\end{array}$ & $\begin{array}{l}\text { Smirnoff; Meier \& Frank Co.; Wine } \\
\text { Remembers; Wolfschmidt Genuine Vodka; } \\
\text { Metaxa; Grand Marnier Liqueur; } \\
\text { Seagram's Crown Royal; Kahlua; Ernest \& } \\
\text { Julio Gallo; Arrow; Drambuie; Le Papillon } \\
\text { Corset Co.; Coffee Liqueur (Tia Maria);Vo; } \\
\text { Chenin Blanc wine; Perrier-Jouët; Arrow; } \\
\text { Lamborghini alcohol; }\end{array}$ & Crystal Light; \\
\hline $\begin{array}{l}\text { Software/ } \\
\text { Technology } \\
\text { and/or } \\
\text { Services/Teleco- } \\
\text { mmunications: }\end{array}$ & & $\begin{array}{l}\text { Windows 8; Windows } 8 \text { (featuring } \\
\text { Conde Nast); Microshoft (Surface); HP } \\
\text { Windows Notebook; Geico; AT\&T; }\end{array}$ \\
\hline Automobile: & Ford Motor Company; Buick; & $\begin{array}{l}\text { Lincoln Motor Company; Lexus; } \\
\text { Mercedes-Benz; Ford Motor Company; } \\
\text { Cadillac ATS; }\end{array}$ \\
\hline Men's Apparel: & Jaymar-Ruby, Inc.; & $\begin{array}{l}\text { Burberry Prorsum; Belstaff; Banana } \\
\text { Republic; Lucky Brand Jeans; }\end{array}$ \\
\hline
\end{tabular}




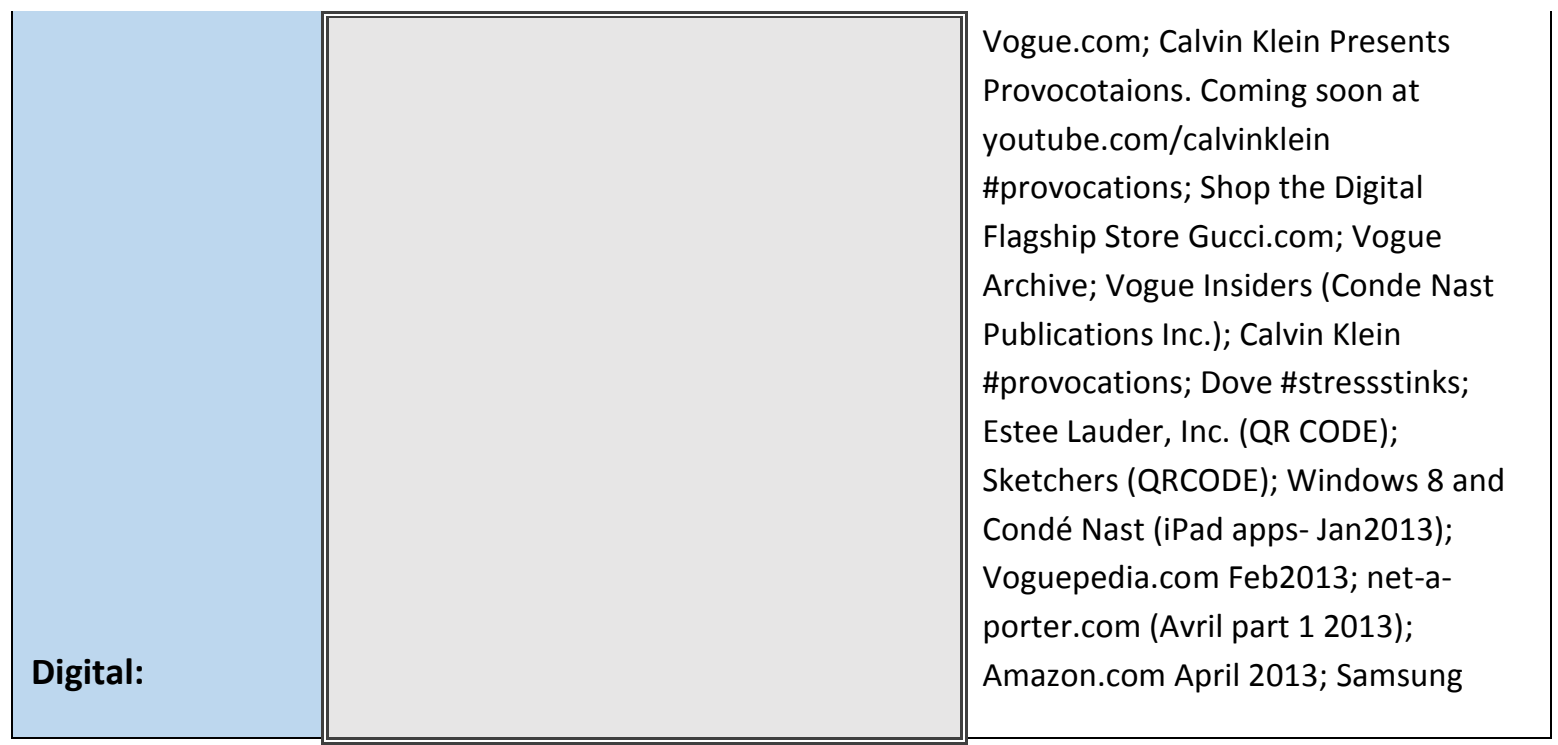




\section{Appendix 8: PHASE TWO: CODEBOOK}

1. Brand Identity

a. Brand Values

2. Marketing Communications

a. Fashion Shows

b. Advertising Channels

i. Print

1. Vogue US print advertising images from 2013 February issue ii. Digital

2. Official Website

3. Facebook

4. Instagram

c. Celebrity Endorsement

3. Product Integrity

a. Product quality

b. Craftsmanship (attention to detail)

4. Brand Signature

a. Iconic products

i. Designer styles

ii. Designer handwriting

iii. Brand DNA

b. Properties of a brand

i. Fabrics

ii. Colors

iii. Shapes

5. Premium Price

6. Exclusivity

a. Distribution

i. Country of origin

ii. Accessibility

1. Boutiques

2. Department Stores

7. Heritage

8. Luxury environment and experience

9. Culture 


\section{Appendix 9: FIRST CATEGORY: TYPES OF PRODUCT OR SERVICE:} TRAVEL ADVERTISEMENTS 1980

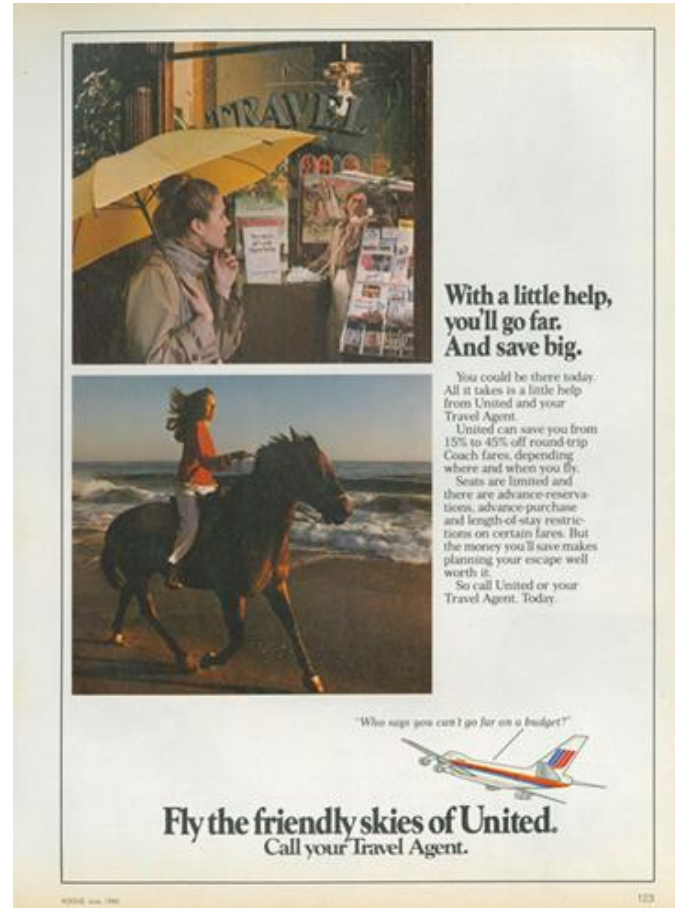

Figure 6: Travel Advertisement Vogue 170.6 (Jun 1, 1980): 123.

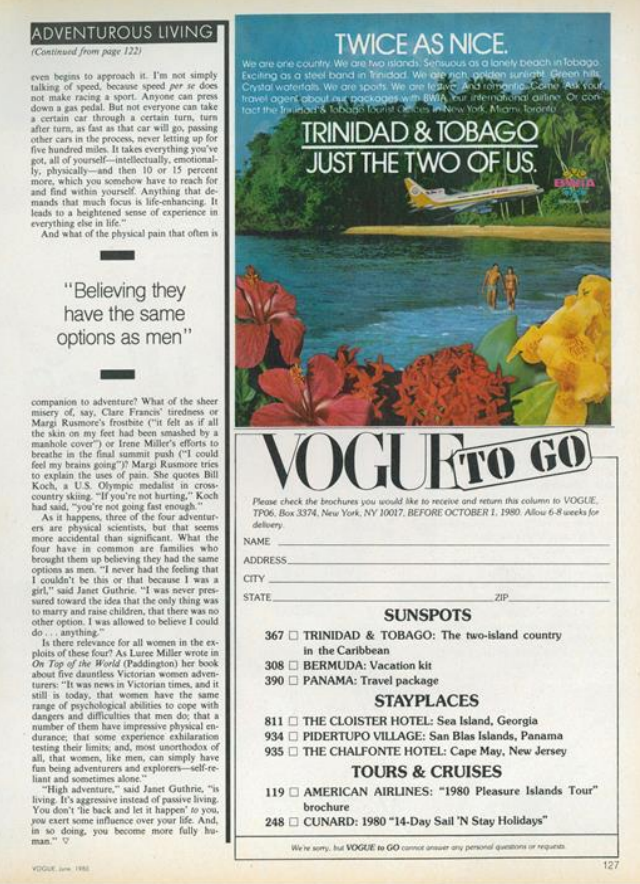

Figure 8: Travel Advertisement Vogue 170.6 (Jun 1, 1980): 127.

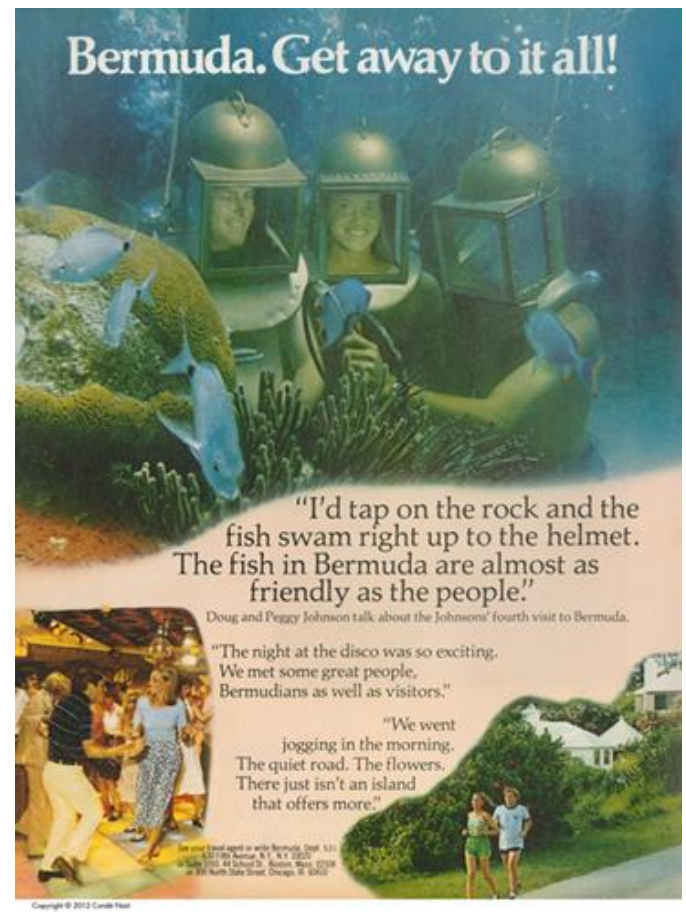

Figure 7: Travel Advertisement

Vogue 170.6 (Jun 1, 1980): 124

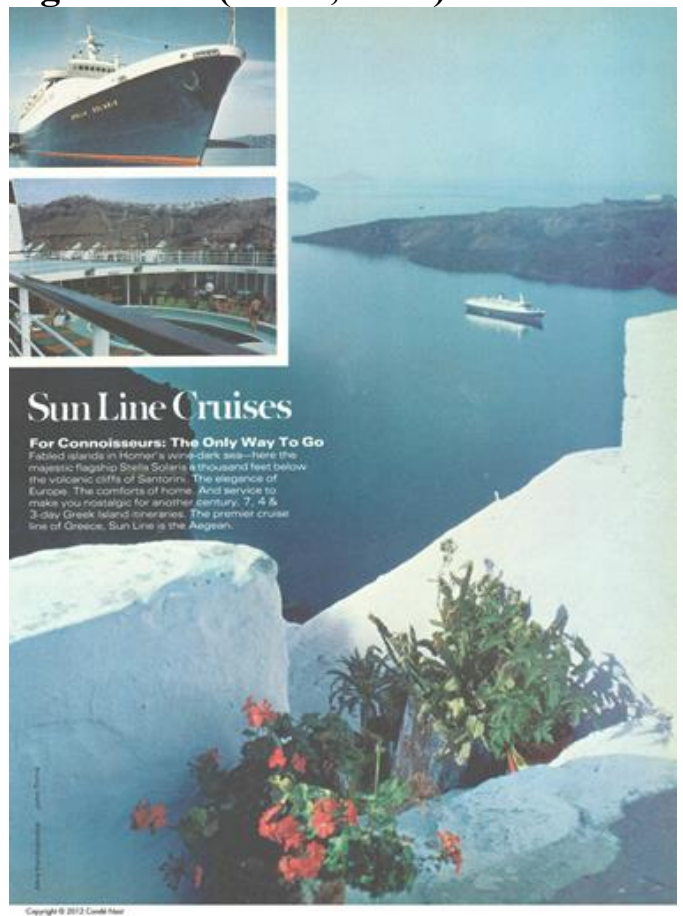

Figure 9: Travel Advertisement Of Sun Line Cruises (Sun Line Cruises) 
Vogue 170.2 (Feb 1, 1980): 179.

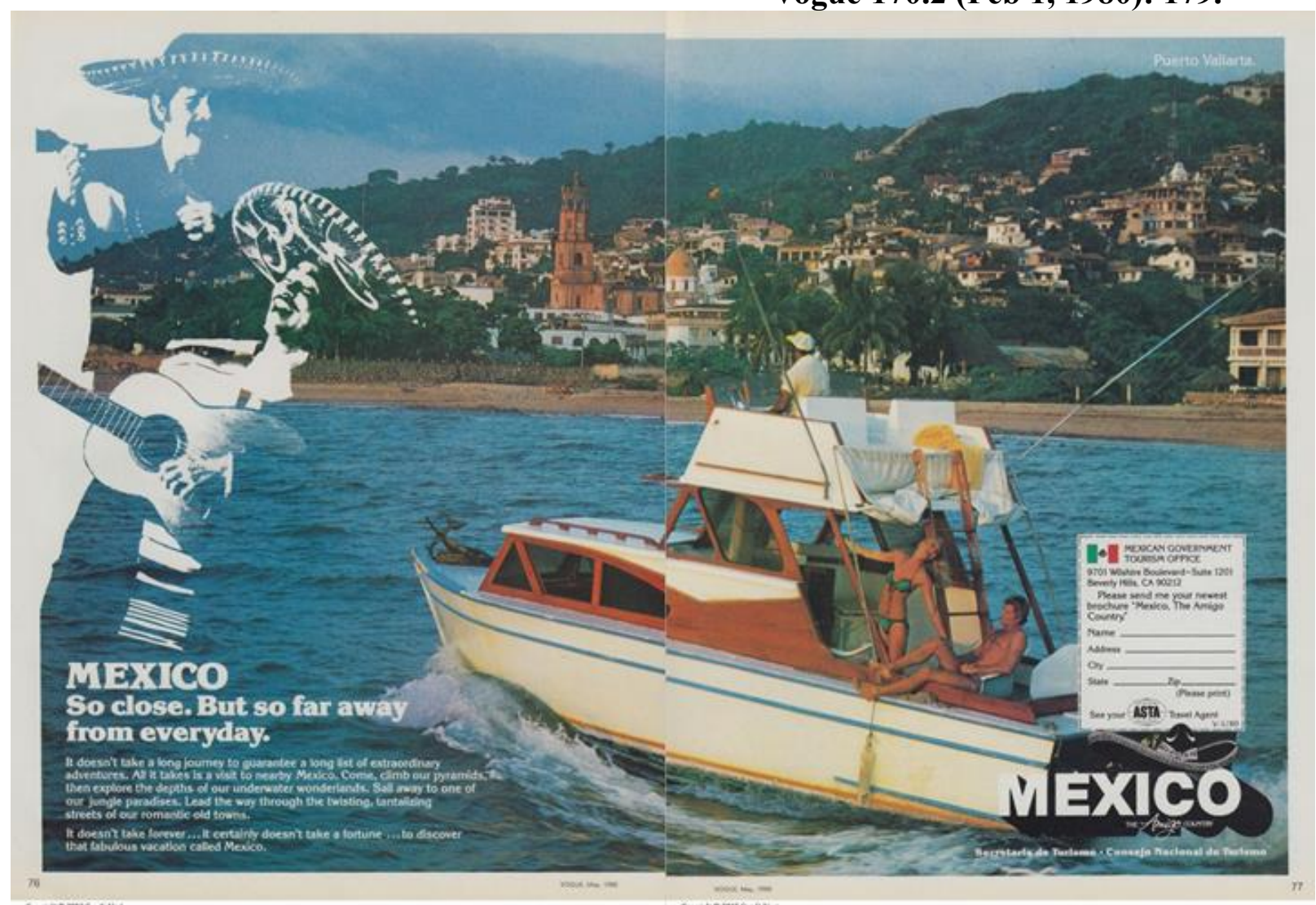

Figure 10: Travel Advertisement Vogue 170.5 (May 1, 1980): 76, 77. 


\section{Appendix 10: FIRST CATEGORY: TYPES OF PRODUCT OR SERVICE: EXAMPLES OF PRINT ADVERTISEMENTS WITH COUPONS OR 'PREFERRED SUBSCRIPTION RESERVATION' 1980}

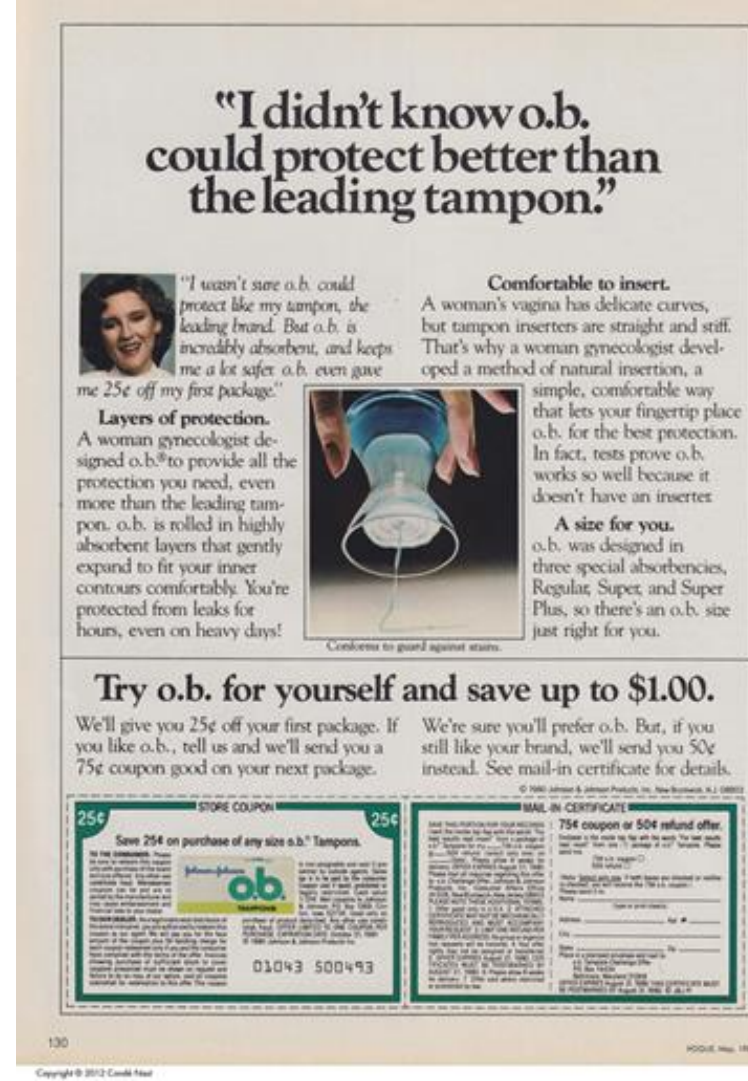

Figure 11: Johnson Johnson O.B. Advertisement with Coupon from Vogue 170.5 (May 1, 1980): 130.

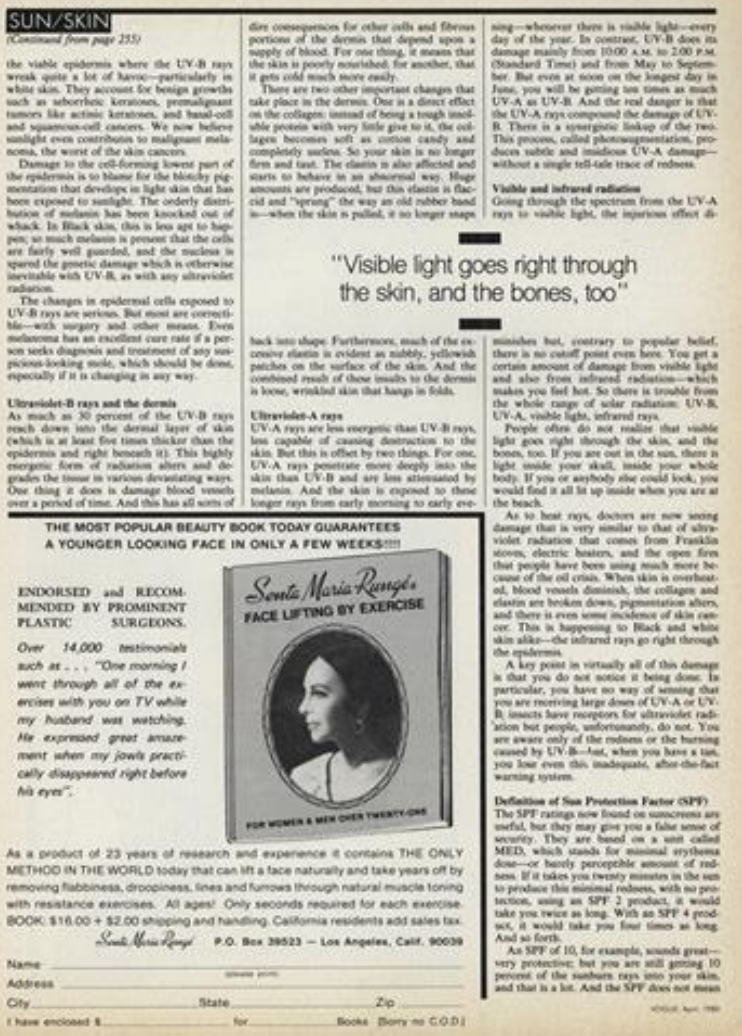

Figure 12: Senta-Maria Rungé (Senta Maria Rungé) from Vogue 170.4 (Apr 1, 1980): 308. 
Appendix 11: FIRST CATEGORY: TYPES OF PRODUCT OR SERVICE: HIGH-FASHION PRINT ADVERTISEMENTS AND FAST-FASHION PRINT ADVERTISEMENTS 2013

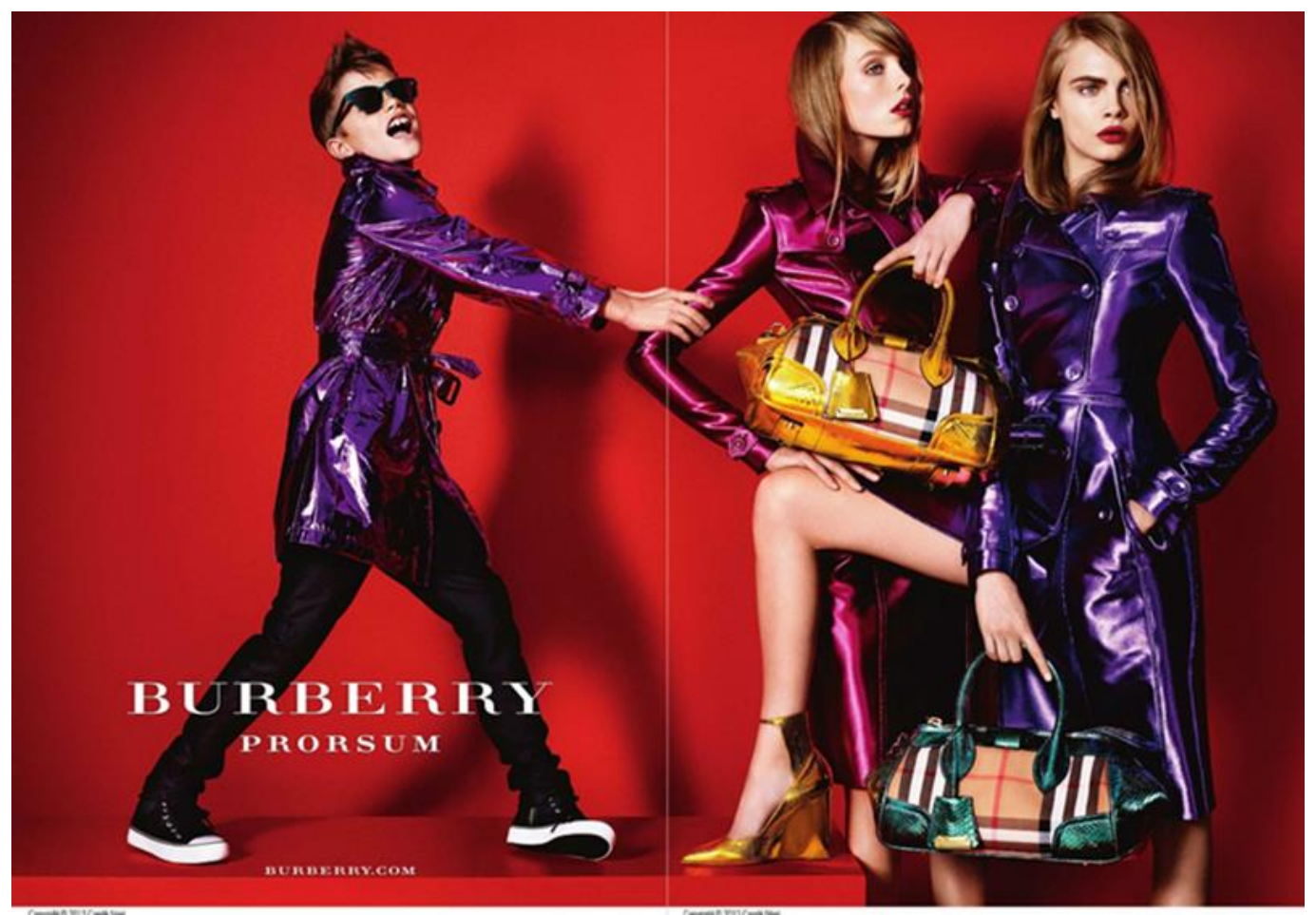

Figure 13: Burberry Prorsum Print Advertisement from Vogue 203.4 (Apr 1, 2013): 16, 17.

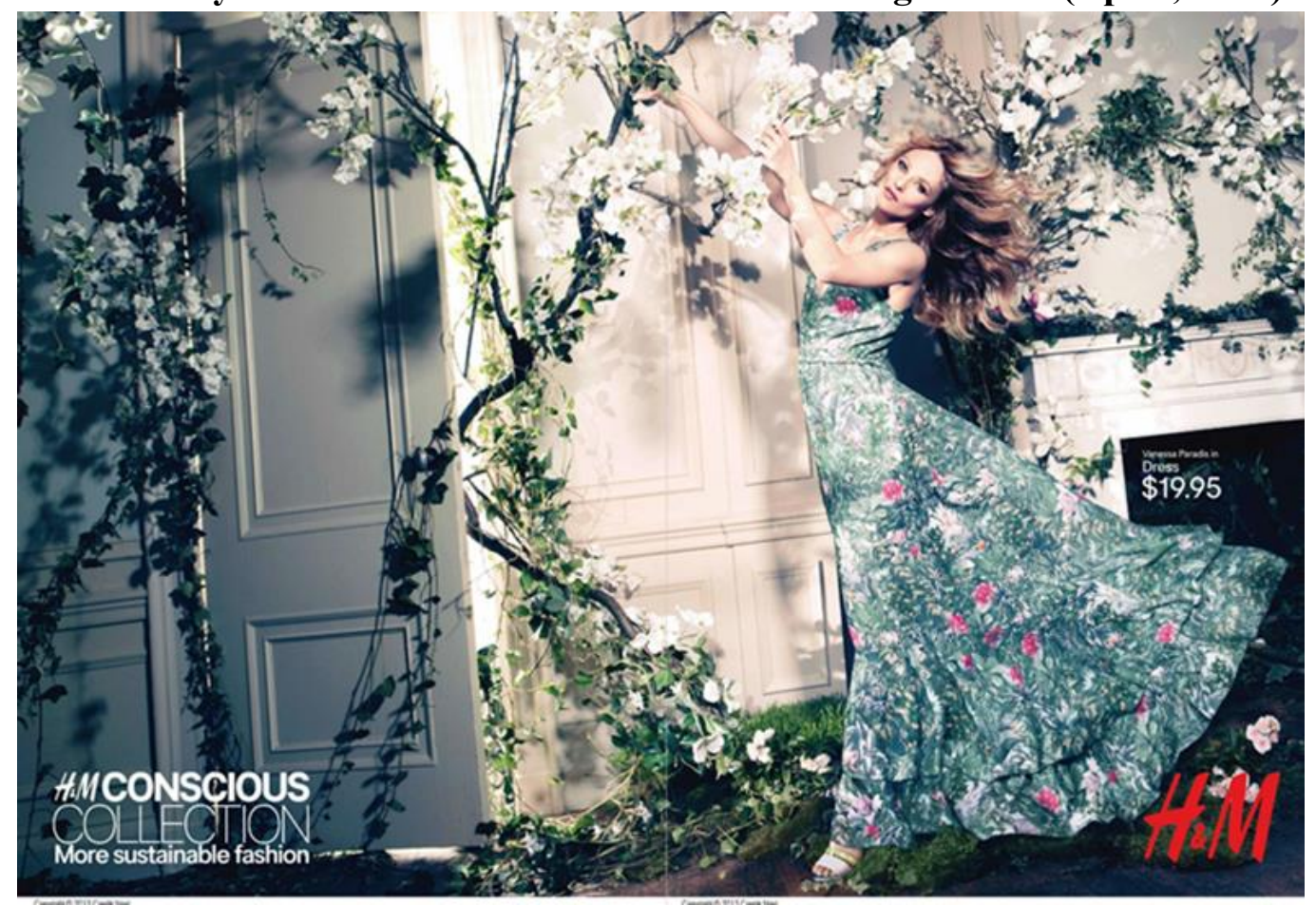


Figure 14: H. \& M. Conscious Collection Print Advertisement from Vogue203.4 (Apr 1, 2013): 76, 77. 


\section{Appendix 12: FIRST CATEGORY: TYPES OF PRODUCT OR SERVICE: RETAILER OR DEPARTEMENT STORE PRINT ADVERTISEMENT SPREADS 1980}

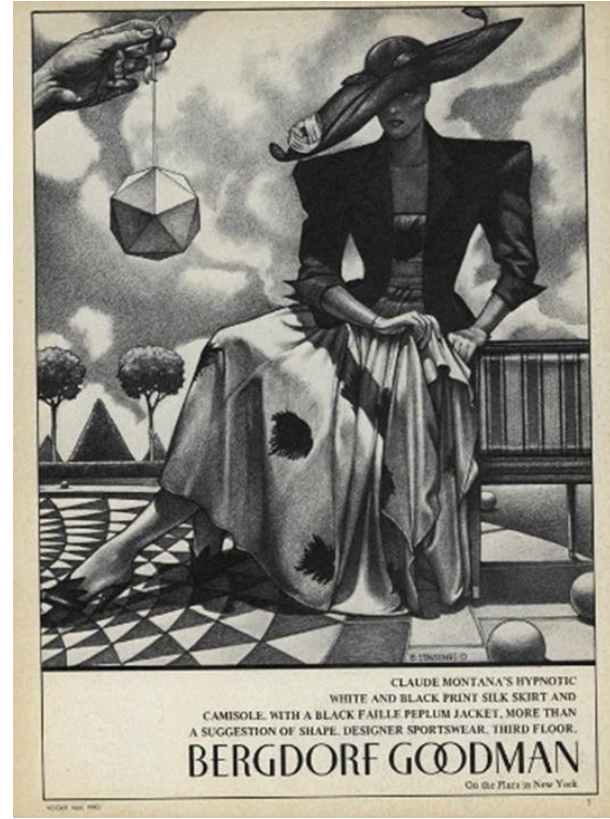

Figure 15: Peplum Jacket (Bergdorf Goodman \& Co.) Sportswear Co., Inc. (Bergdorf Goodman \& Co.) from Vogue 170.4 (Apr 1, 1980): 1.

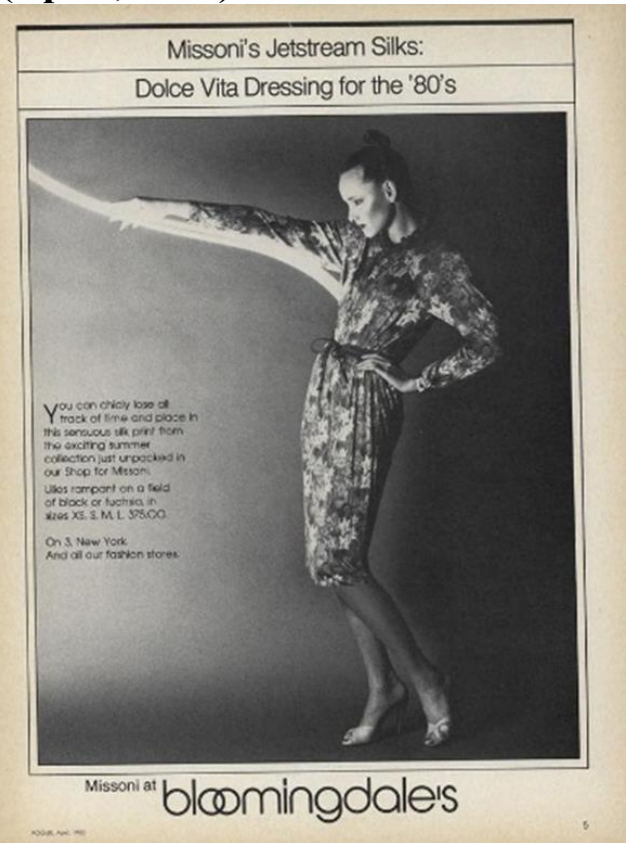

Figure 17: Silks (Bloomingdale's) from Vogue 170.4 (Apr 1, 1980): 5.

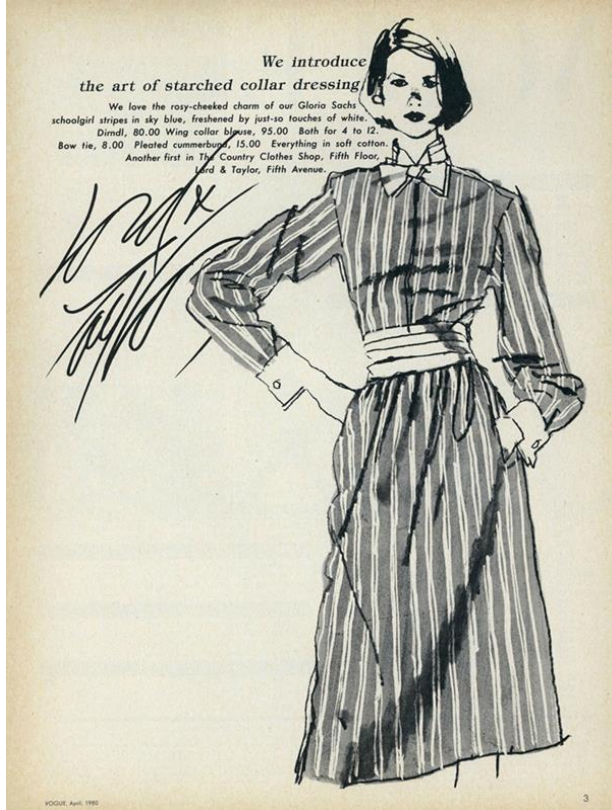

Figure 16: Collar Blouse (Lord \& Taylor Co.) from Vogue 170.4 1, 1980): 3.

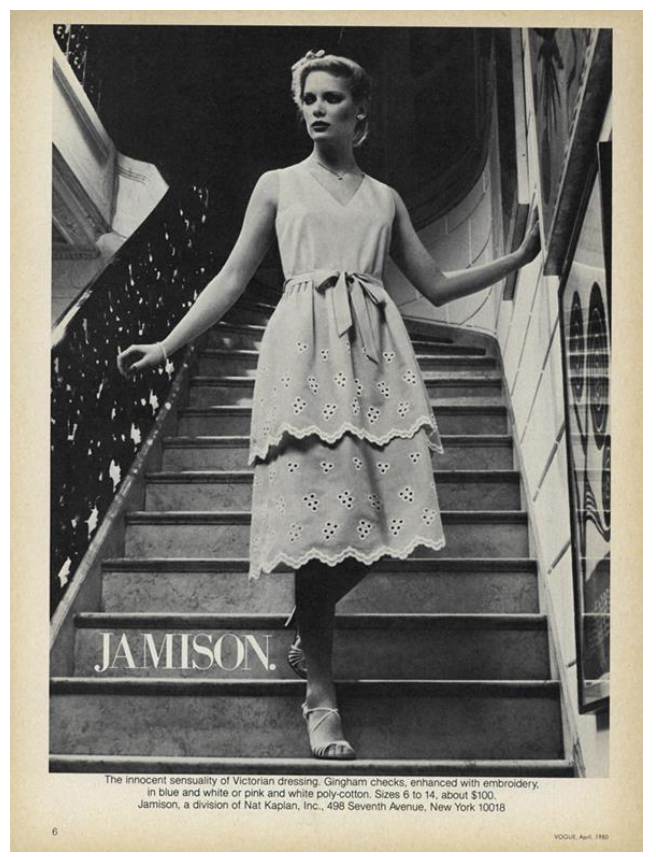

Figure 18: White Poly-Cotton (Jamison) from Vogue 170.4 (Apr 1, 1980): 6 . 


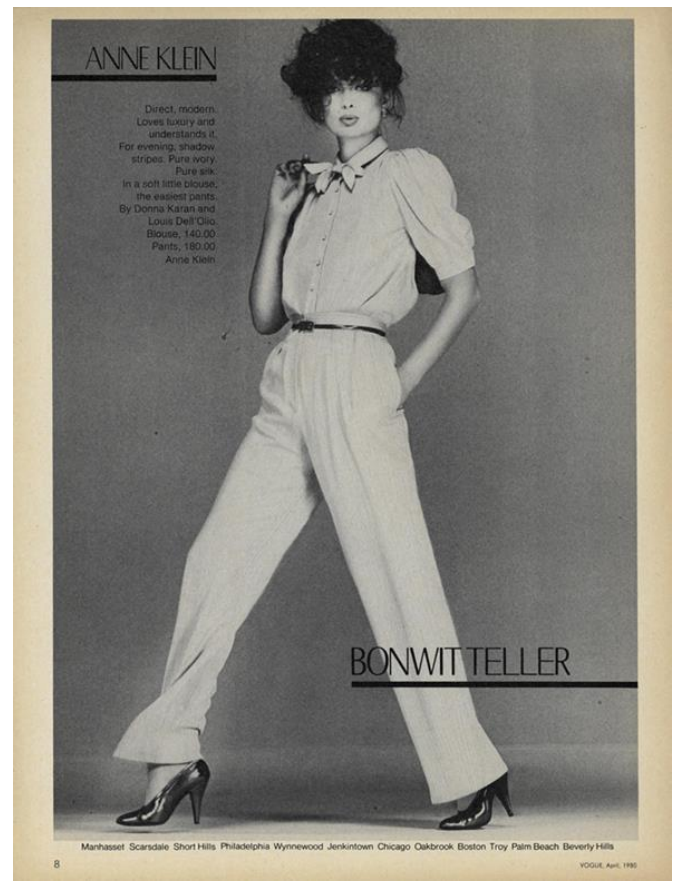

Figure 19: Easiest Pants (Bonwit Teller \& Co.) from Vogue 170.4 (Apr 1, 1980): 8.

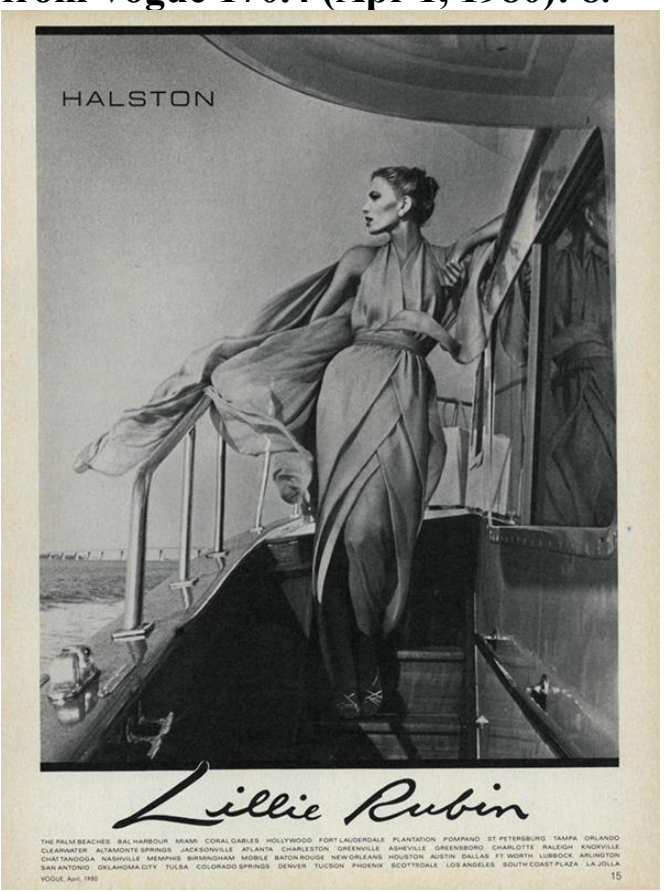

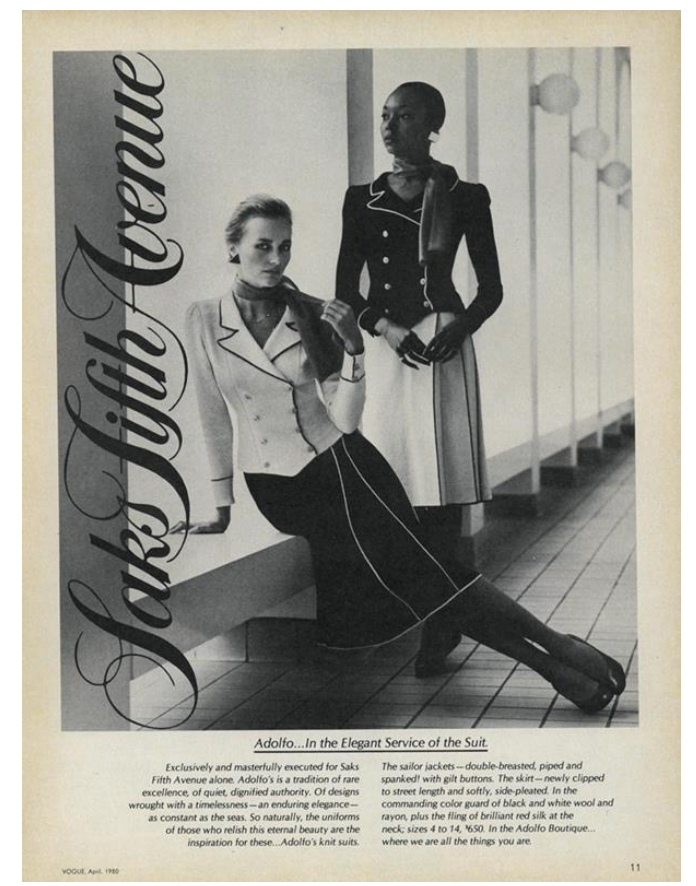

Figure 20: Suit (Saks \& Company) from Vogue 170.4 (Apr 1, 1980): 11.

Figure 21: Lillie Rubin (Lillie Rubin) Print Advertisement from Vogue 170.4 (Apr 1, 1980): 15. 
Appendix 13: FIRST CATEGORY: TYPES OF PRODUCT OR SERVICE: EXAMPLE OF A 10 TO 15 AGE ADVERTISEMENT SPREAD OF A DEPARTEMENT STORE 2013
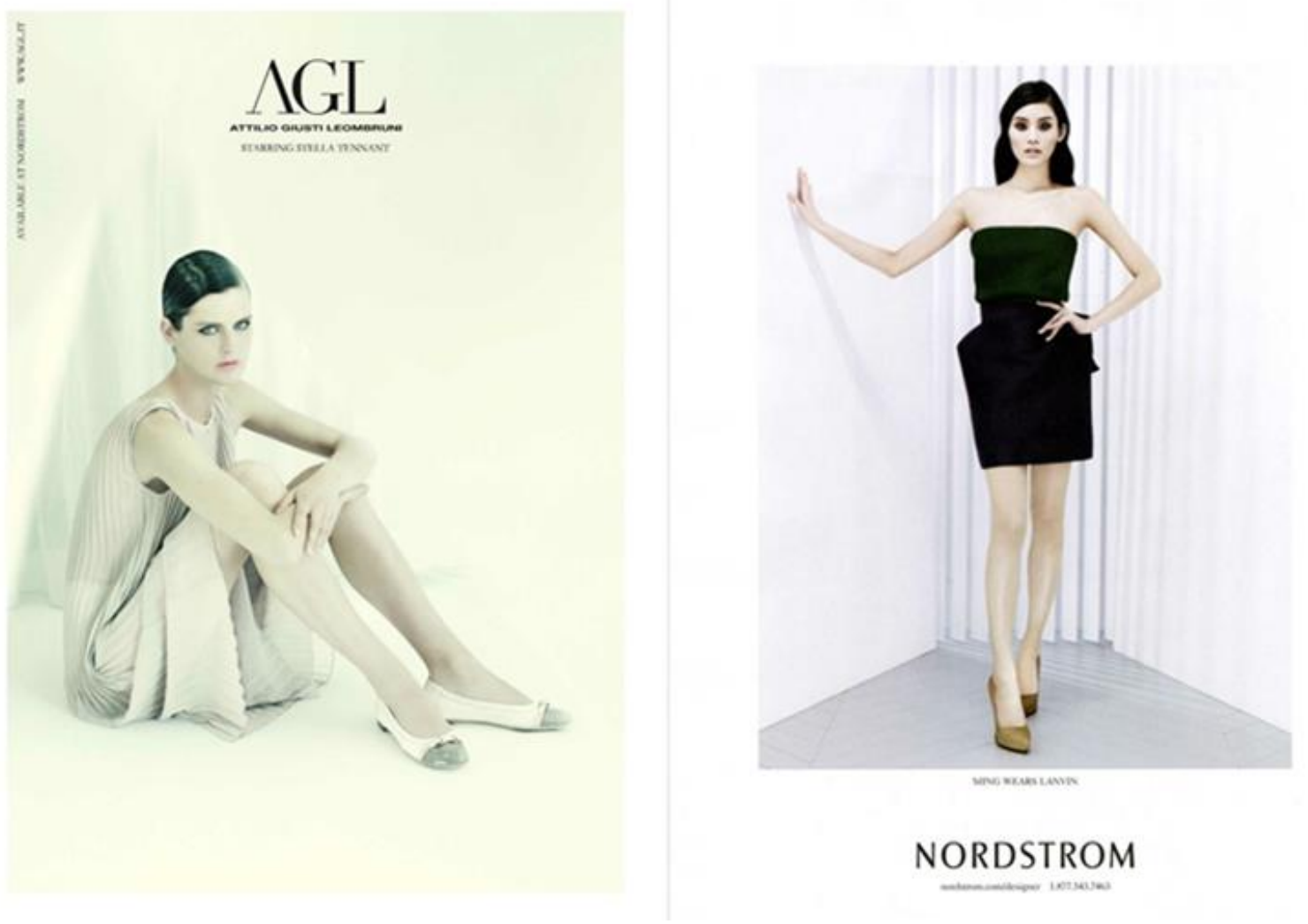

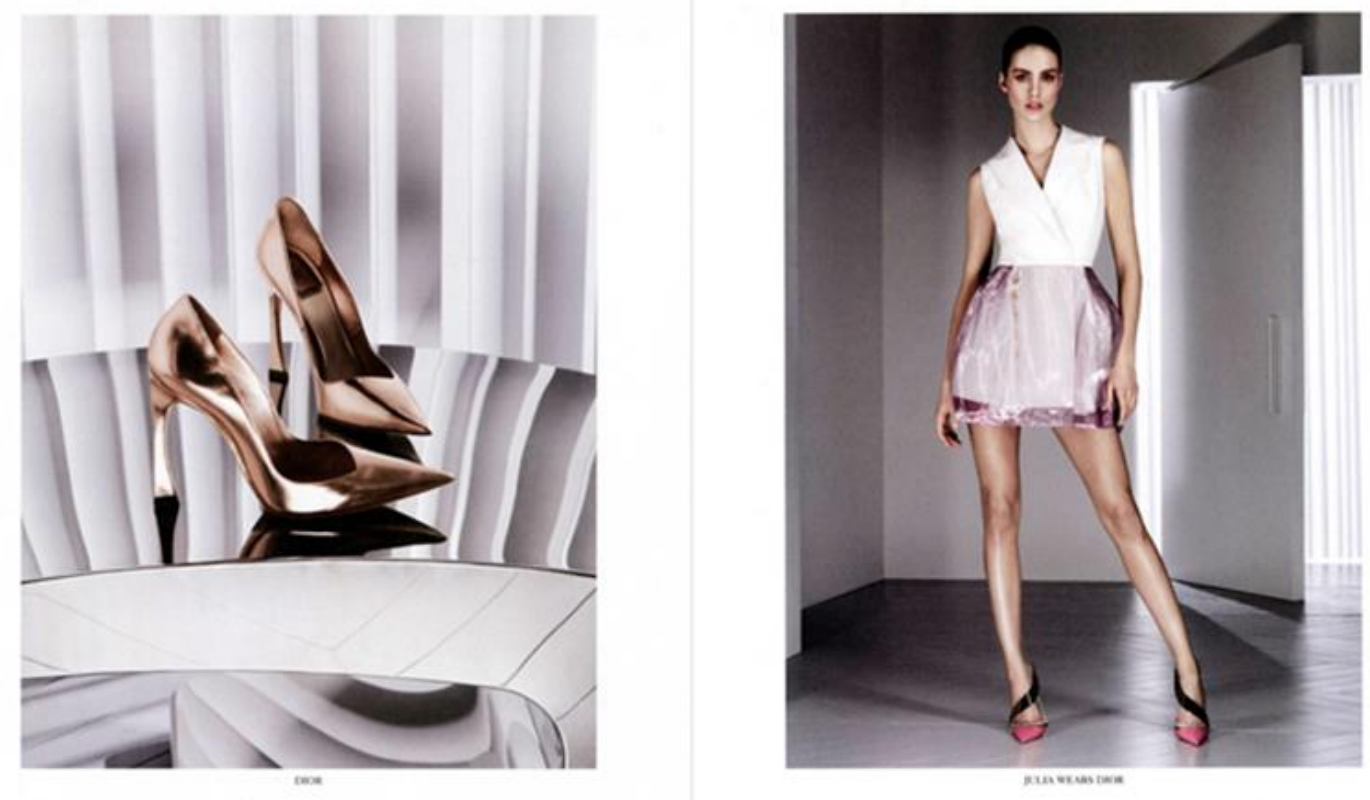

NORDSTROM
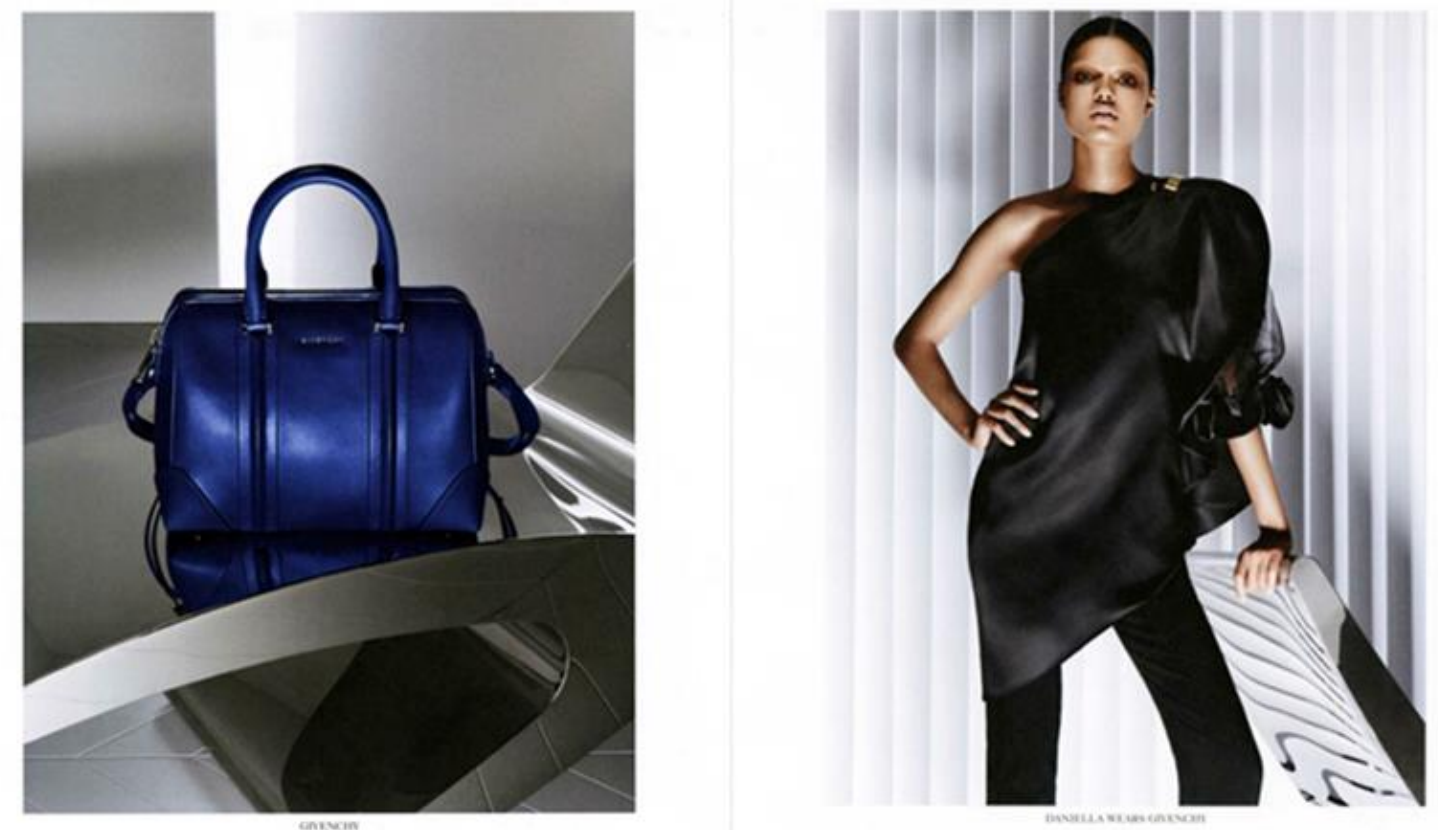

NORDSTROM 

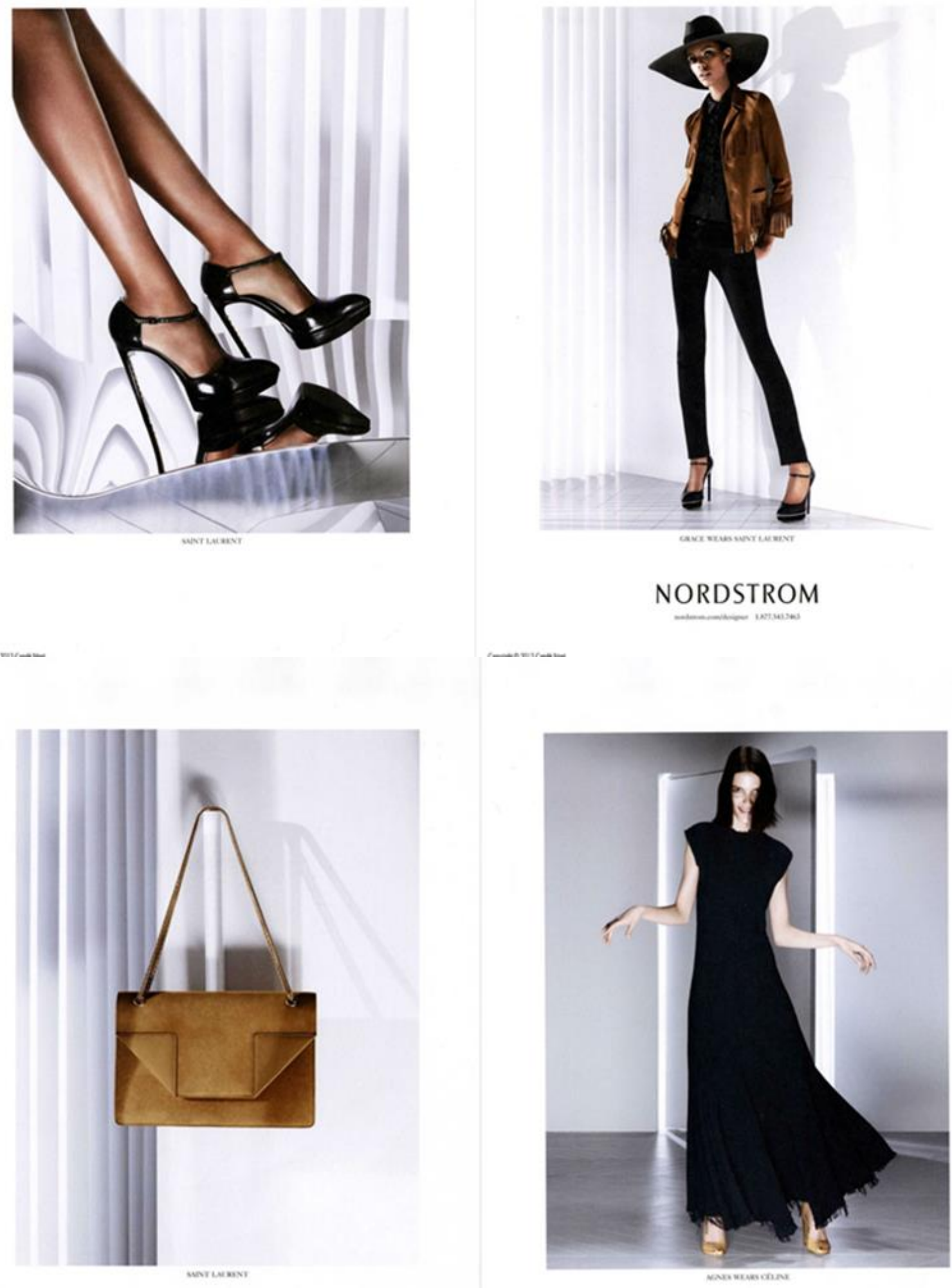

NORDSTROM 

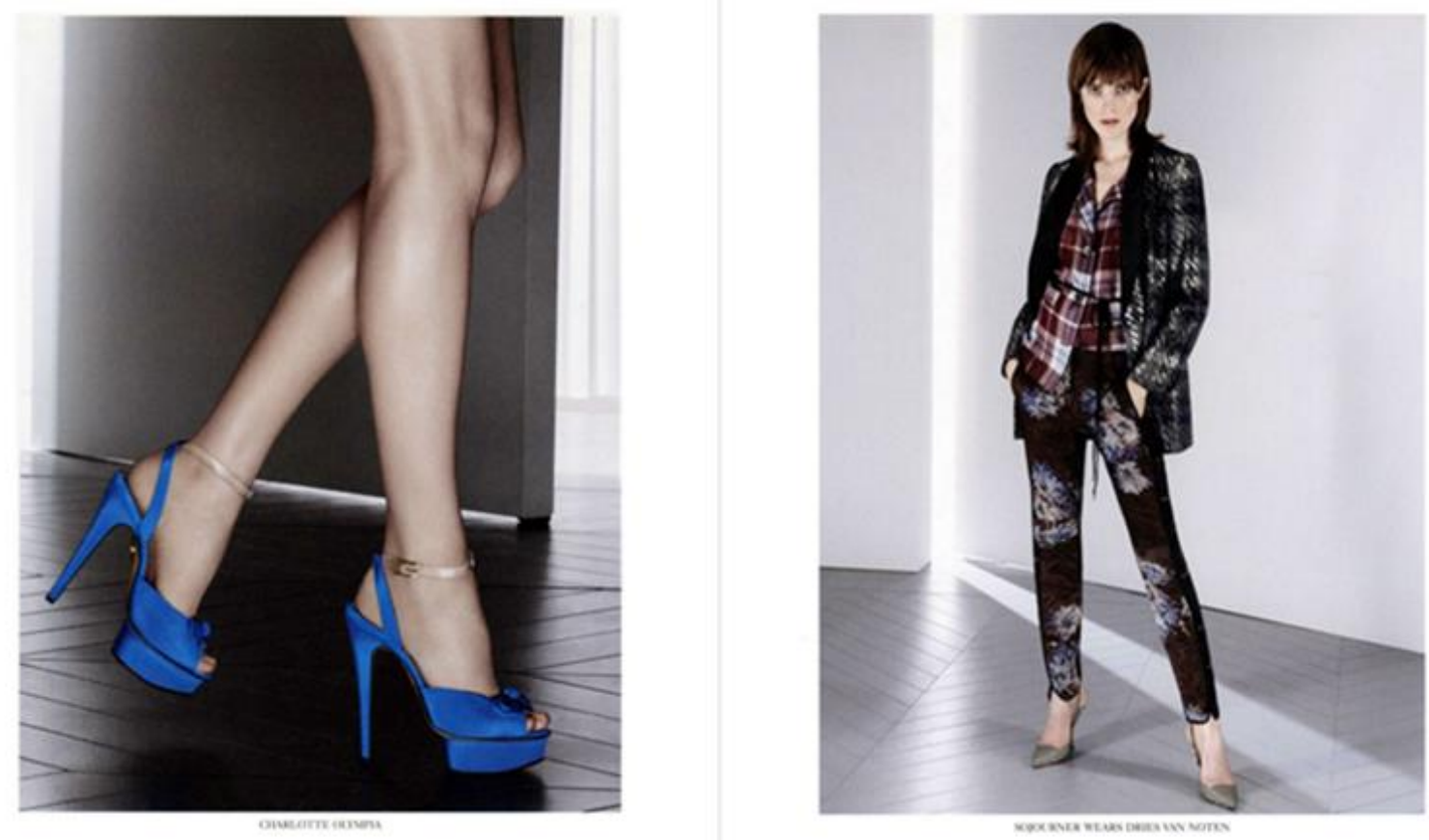

NORDSTROM
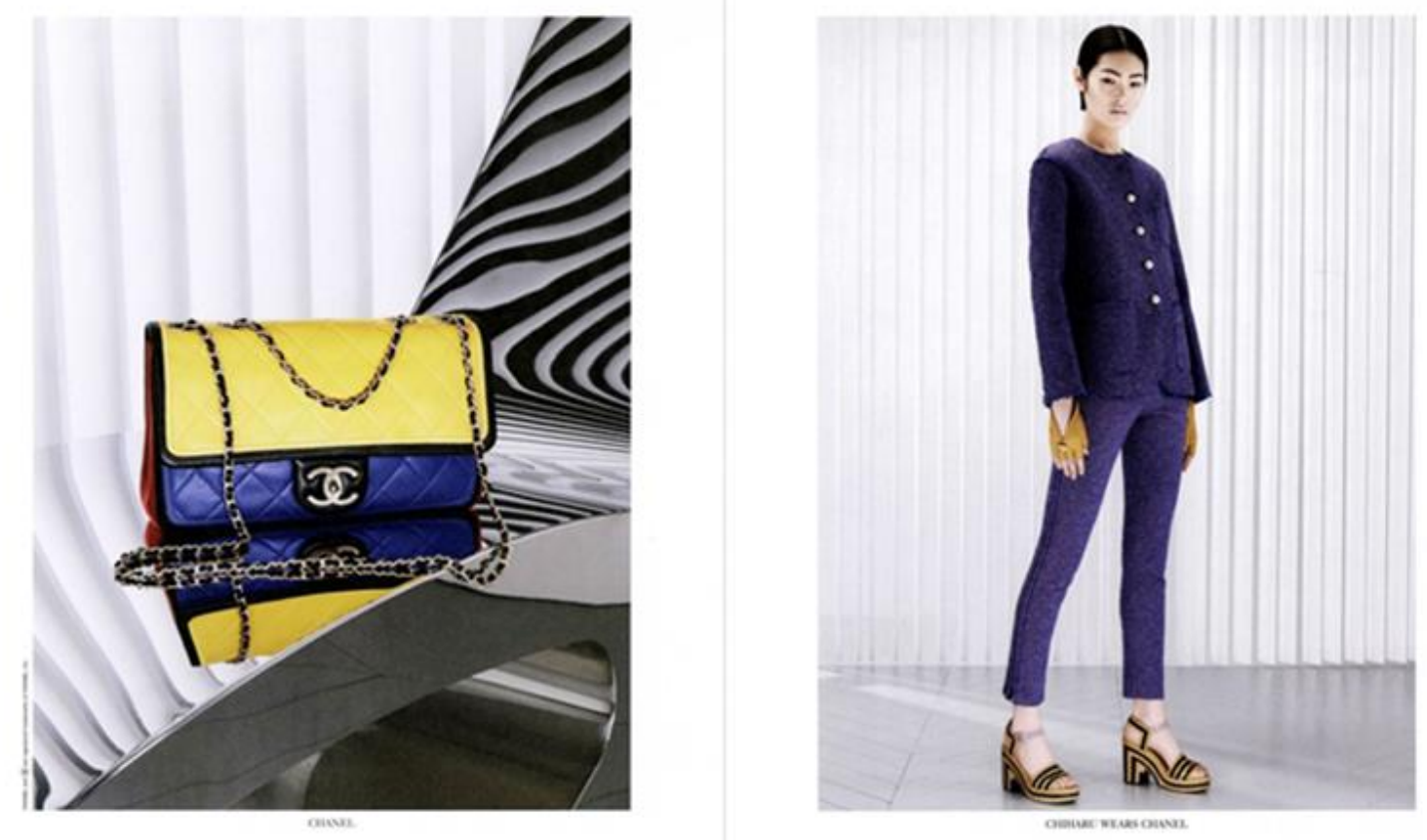

NORDSTROM 


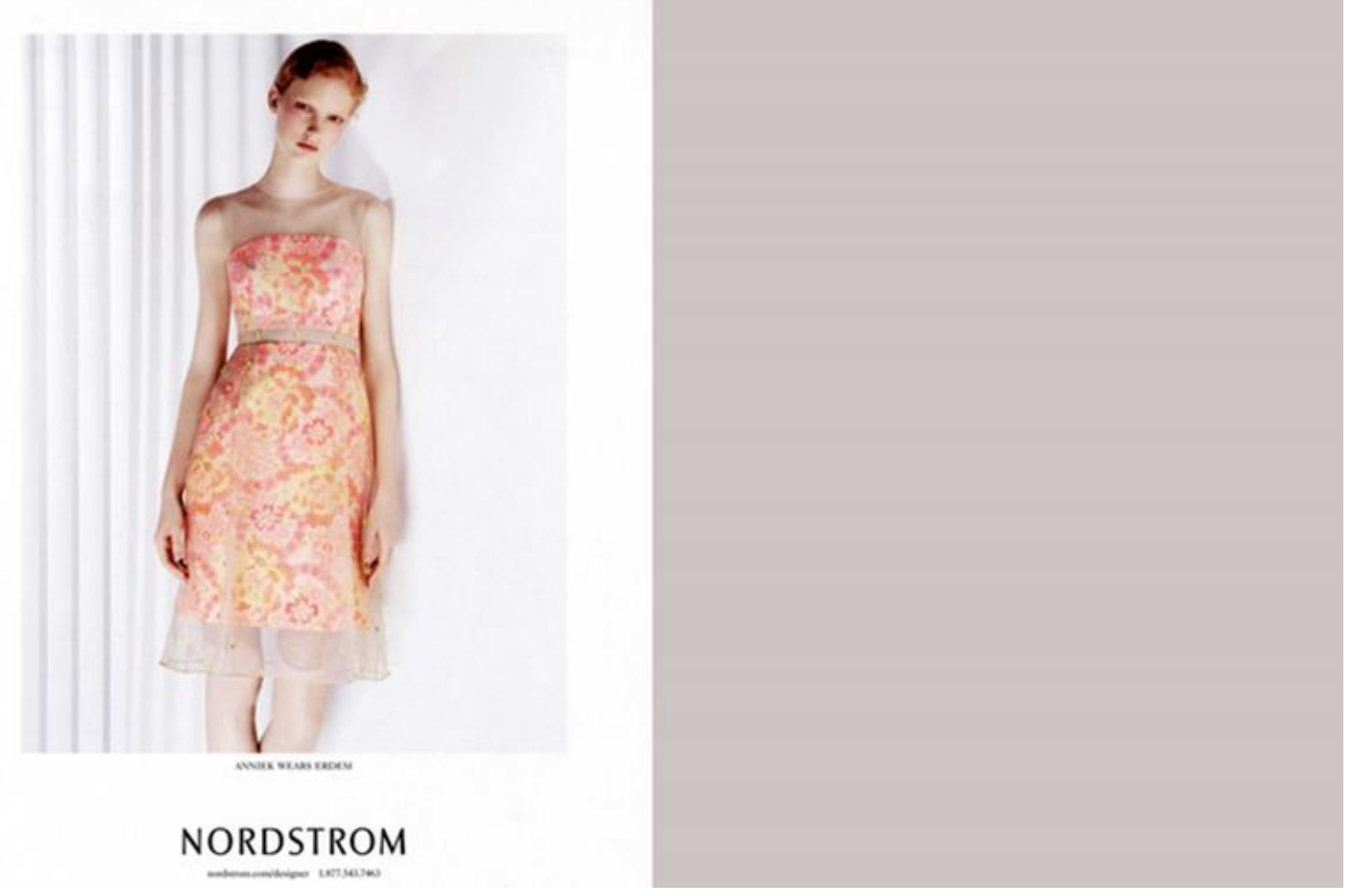

Figure 22: Nordstrom (Nordstrom) Print Advertisement from Vogue 203.3 (Mar 1, 2013): 90, 91, 92, 93, 94, 95, 96, 97, 98, 99, 100, 101, 102, 103, 104, 105, 106. 


\section{Appendix 14: FIRST CATEGORY: TYPES OF PRODUCT OR SERVICE: EXAMPLE OF A TWO-PAGE ADVERTISEMENT SPREAD OF A BRAND LISTING DEPARTEMENT STORE LOCATIONS}

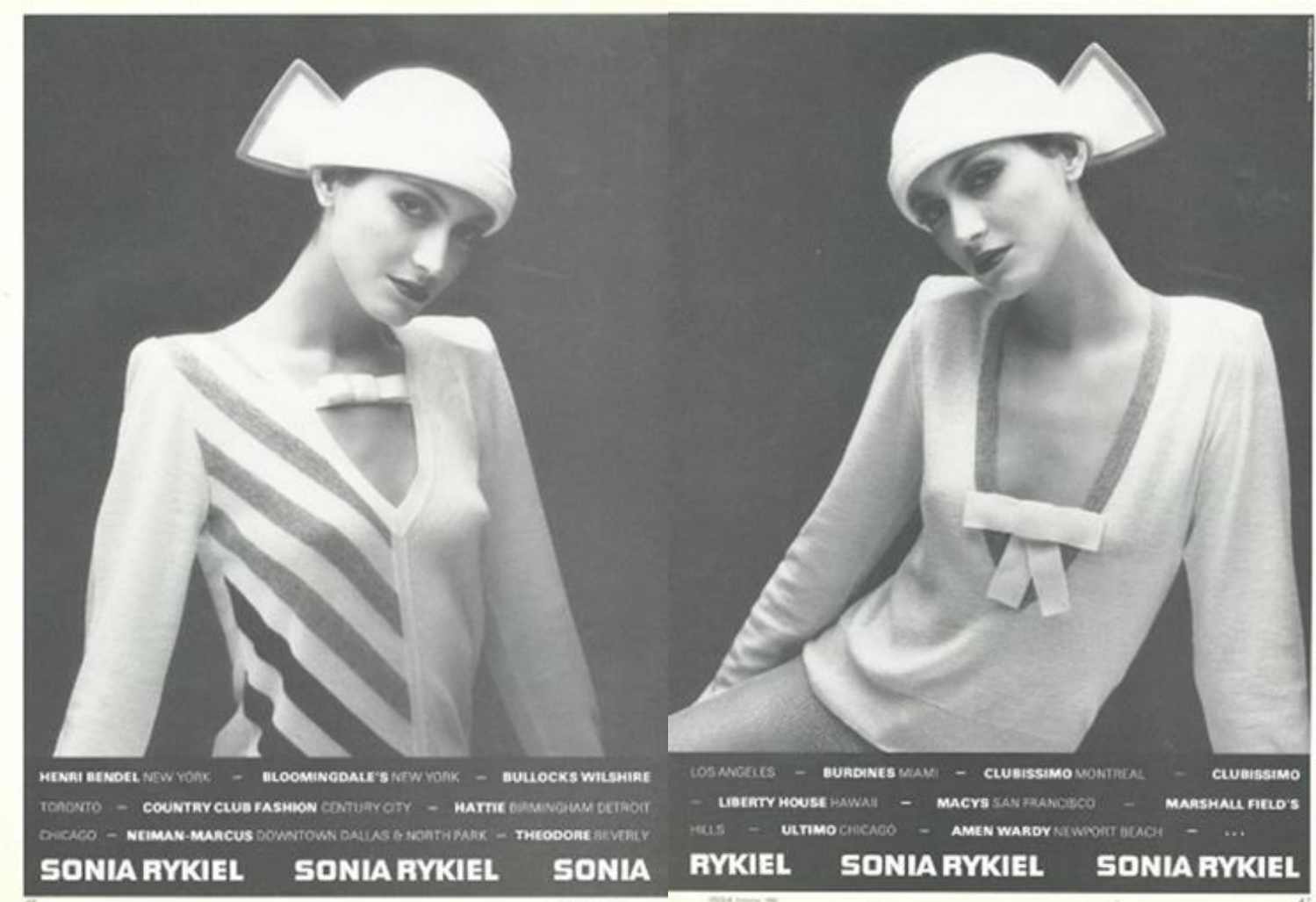

Figure 23: : Sonia Rykiel (Sonia Rykiel) Print Advertisement from Vogue 170.2 (Feb 1, 1980): $46,47$. 
Appendix 15: FIRST CATEGORY: TYPES OF PRODUCT OR SERVICE: EXAMPLE OF ADVERTISED BRANDS 2013 (WITHOUT DEPARTEMENT STORES)
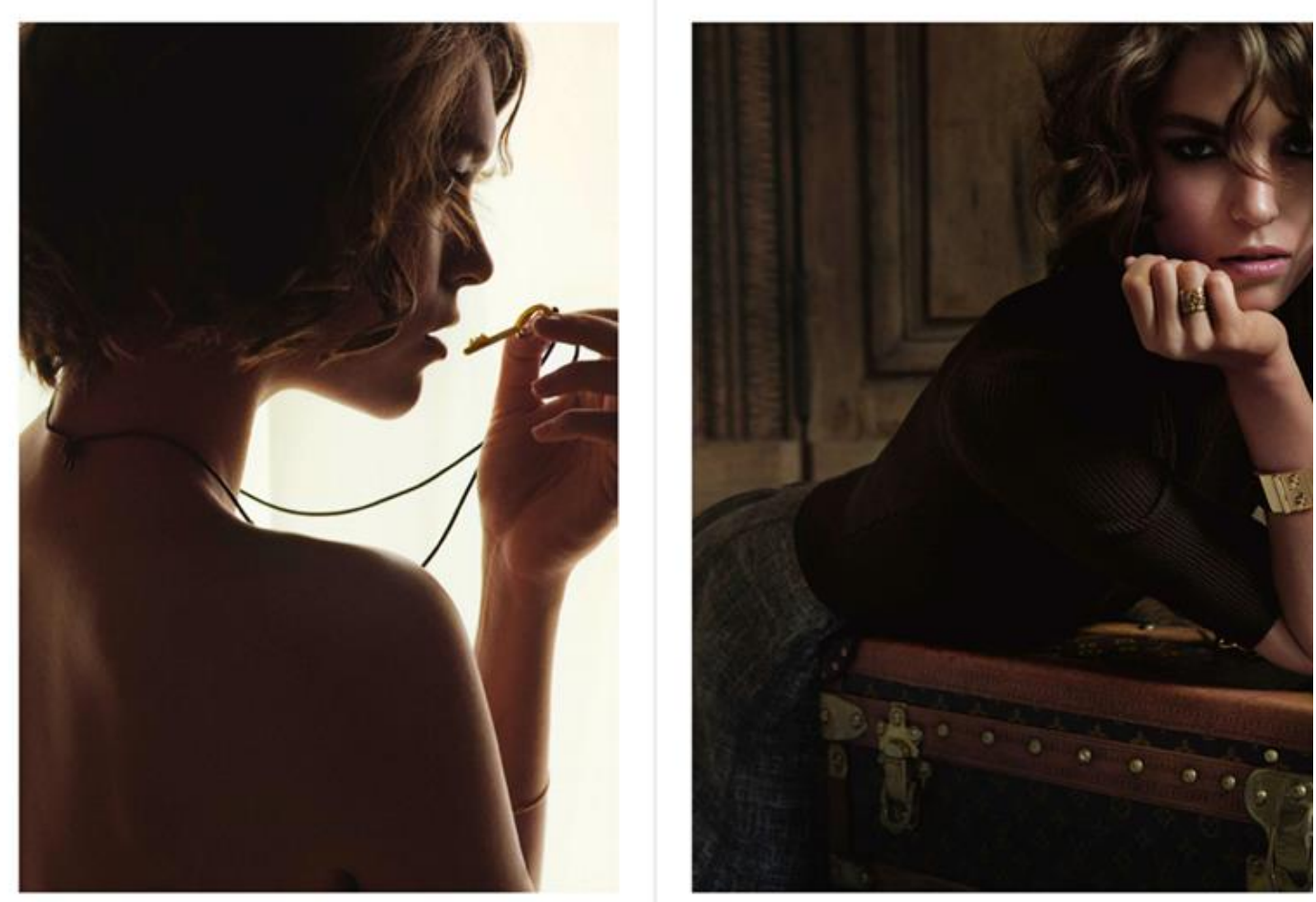

LOUIS VUITTON
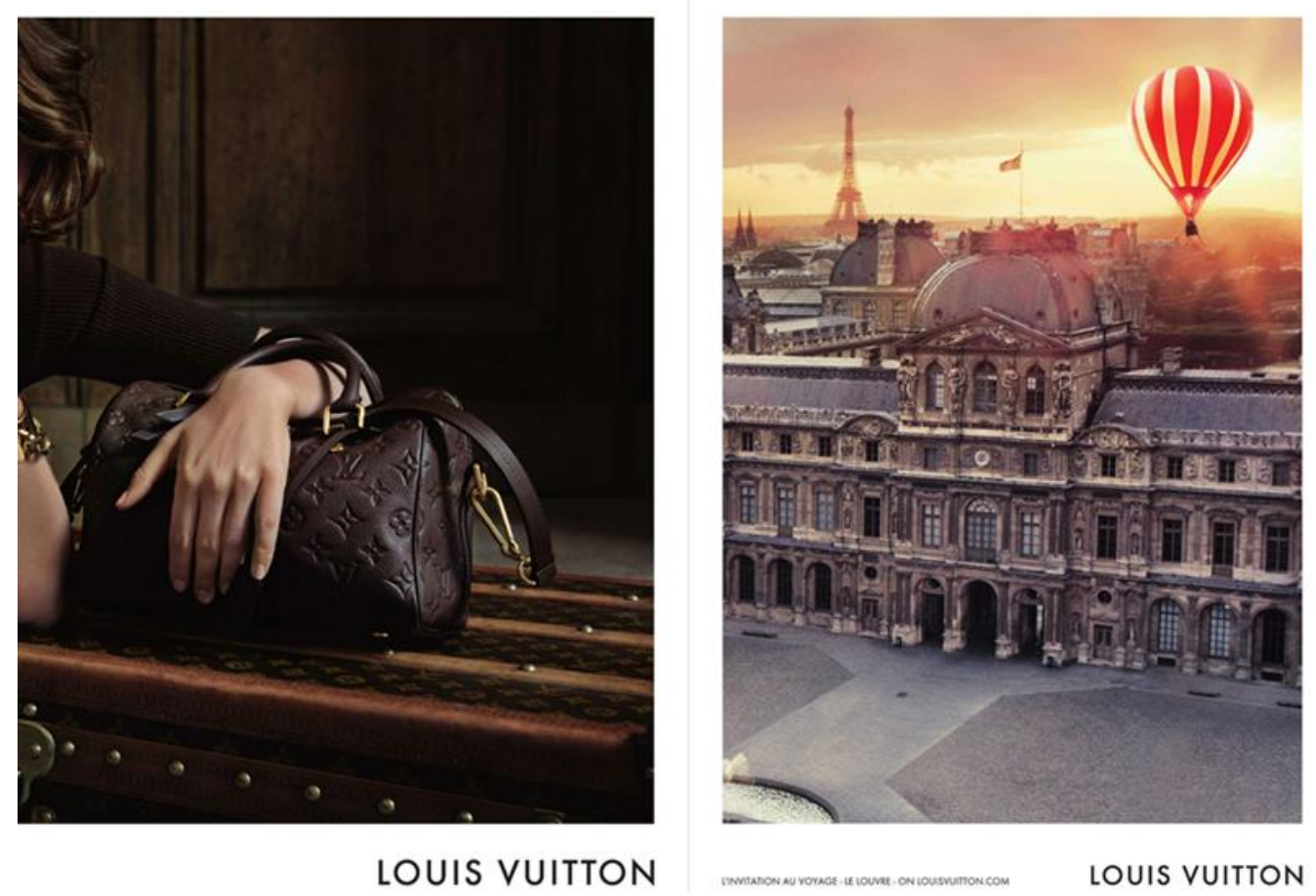

LOUIS VUITTON

LOUIS VUITTON 
Figure 24: Louis Vuitton: (Louis Vuitton) Print Advertisement from Vogue203.1 (Jan 1, 2013): C2,C3,C4,1.

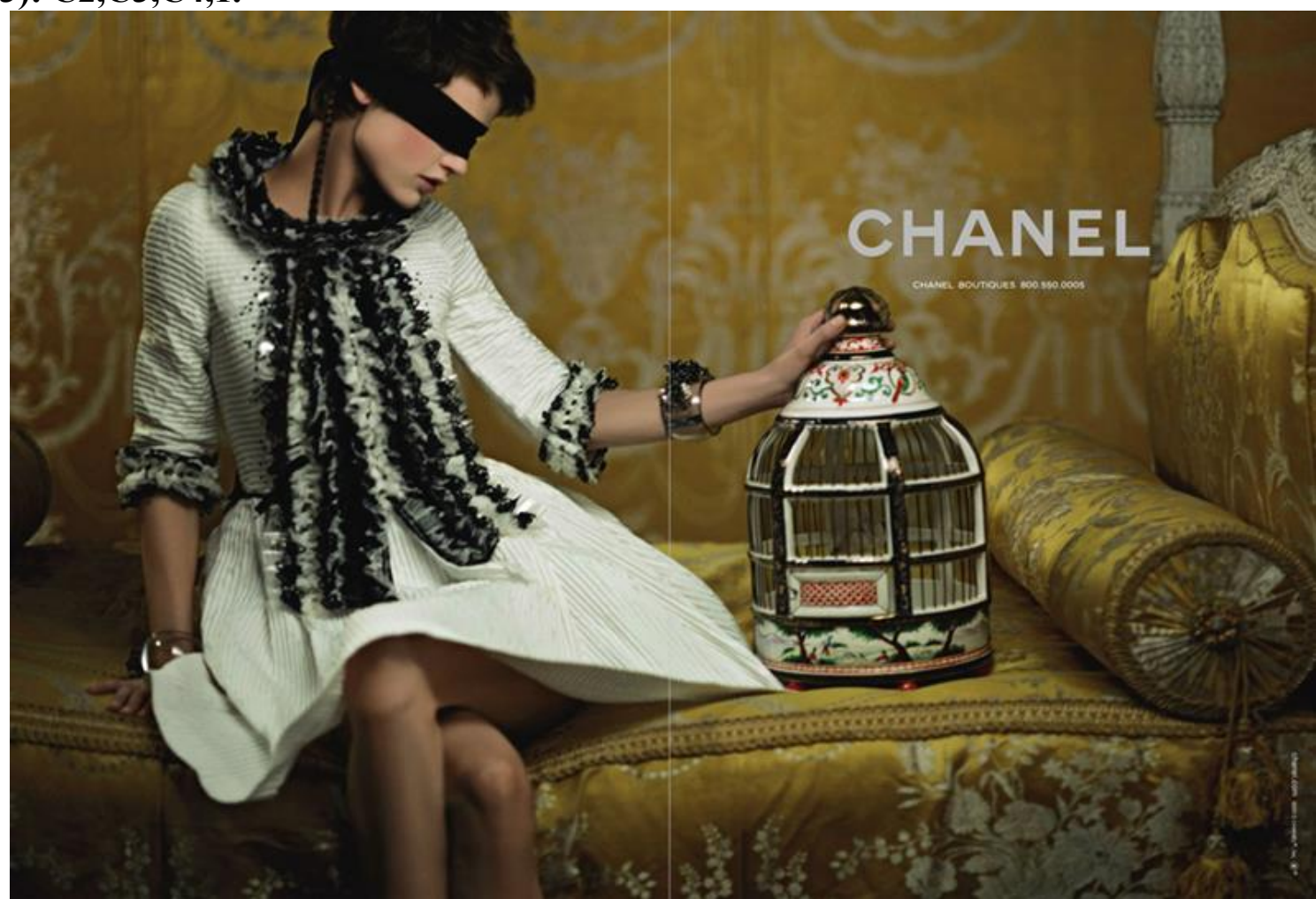

Figure 25: Chanel: (Chanel) Print Advertisement from Vogue203.1 (Jan 1, 2013): 2,3.

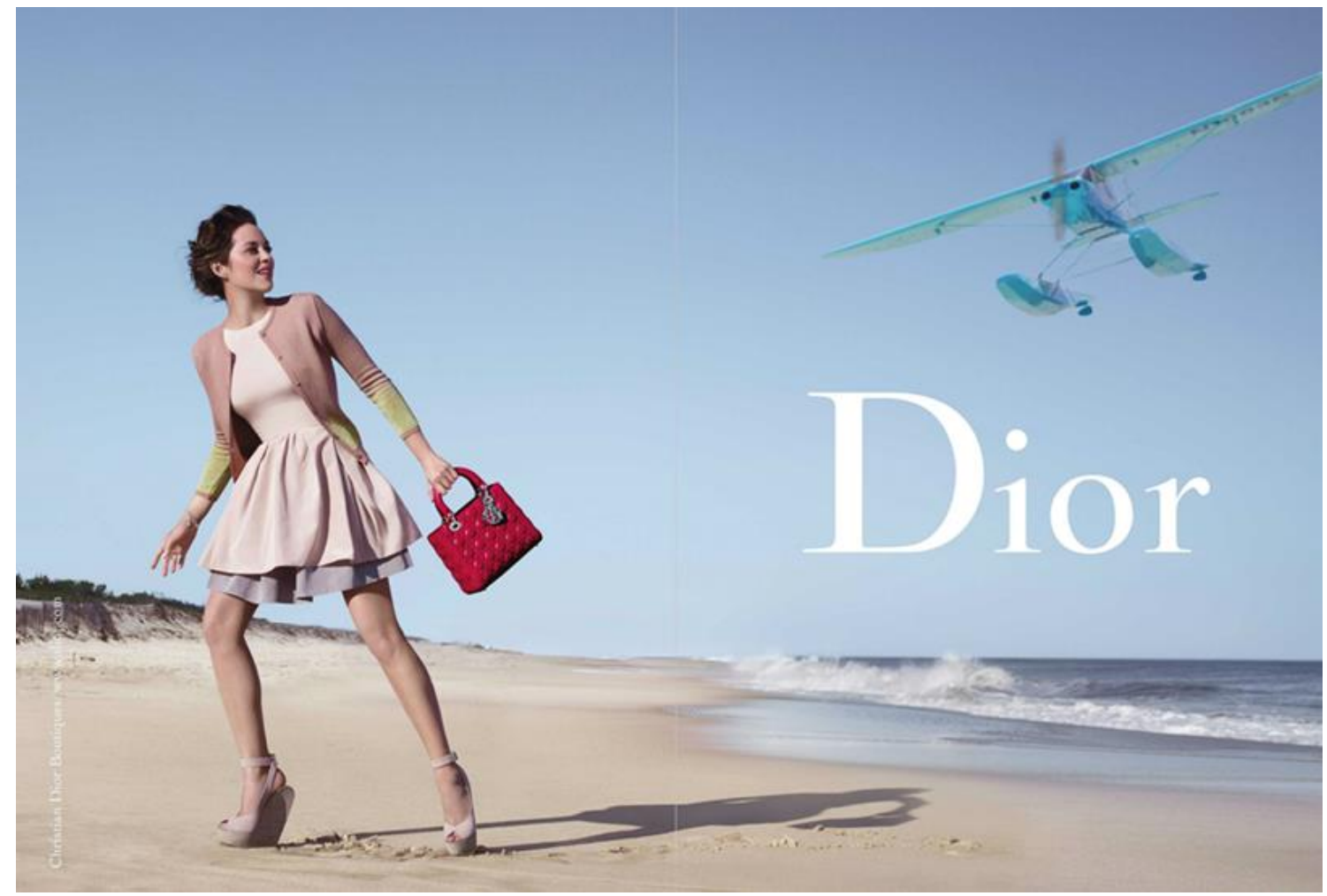

Figure 26: Dior: (Christian Dior) Print Advertisement from Vogue203.1 (Jan 1, 2013): 4, 5. 


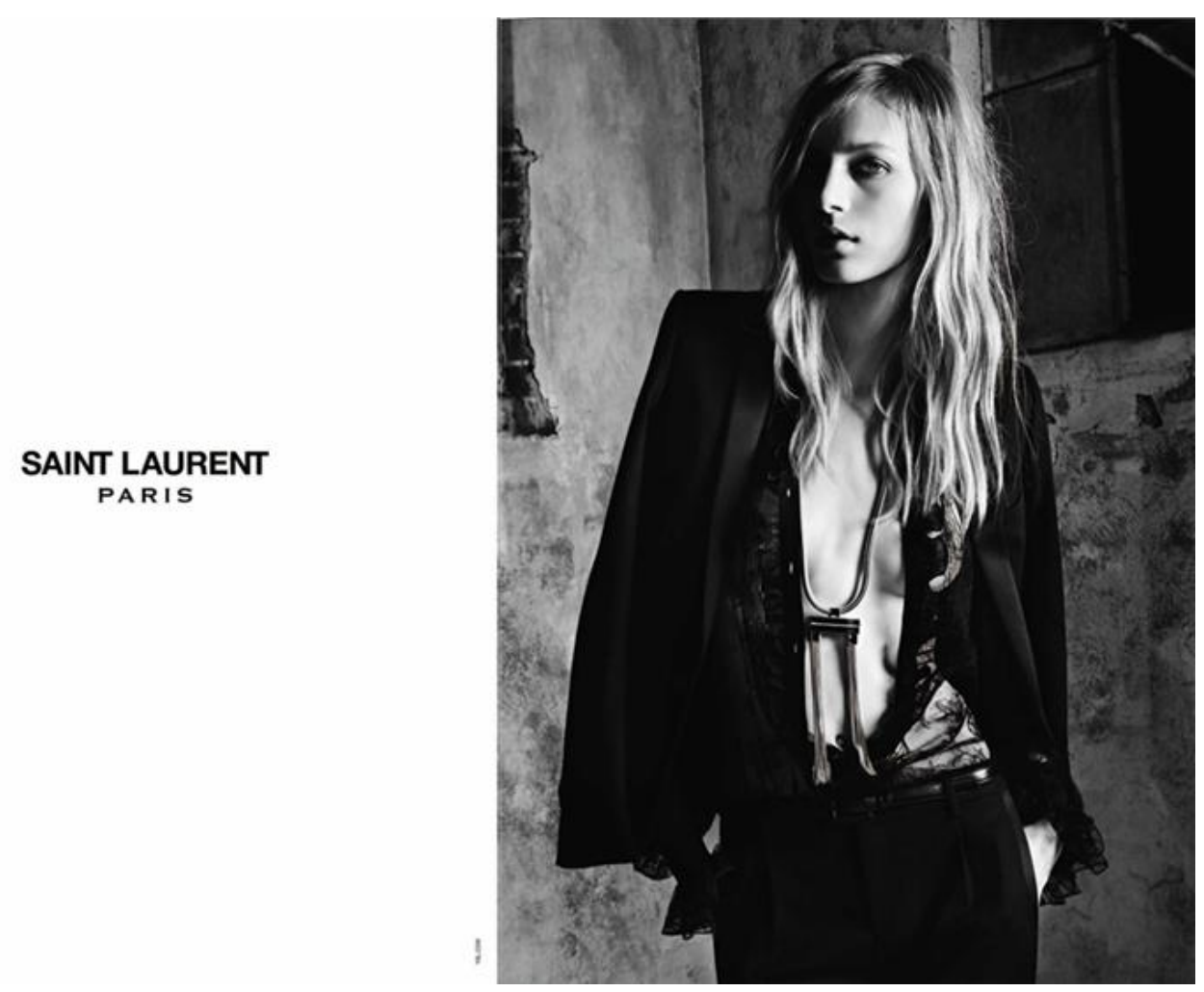

Figure 27: Saint Laurent: (Yves Saint Laurent) Print Advertisement from Vogue203.1 (Jan 1, 2013): 6, 7. 


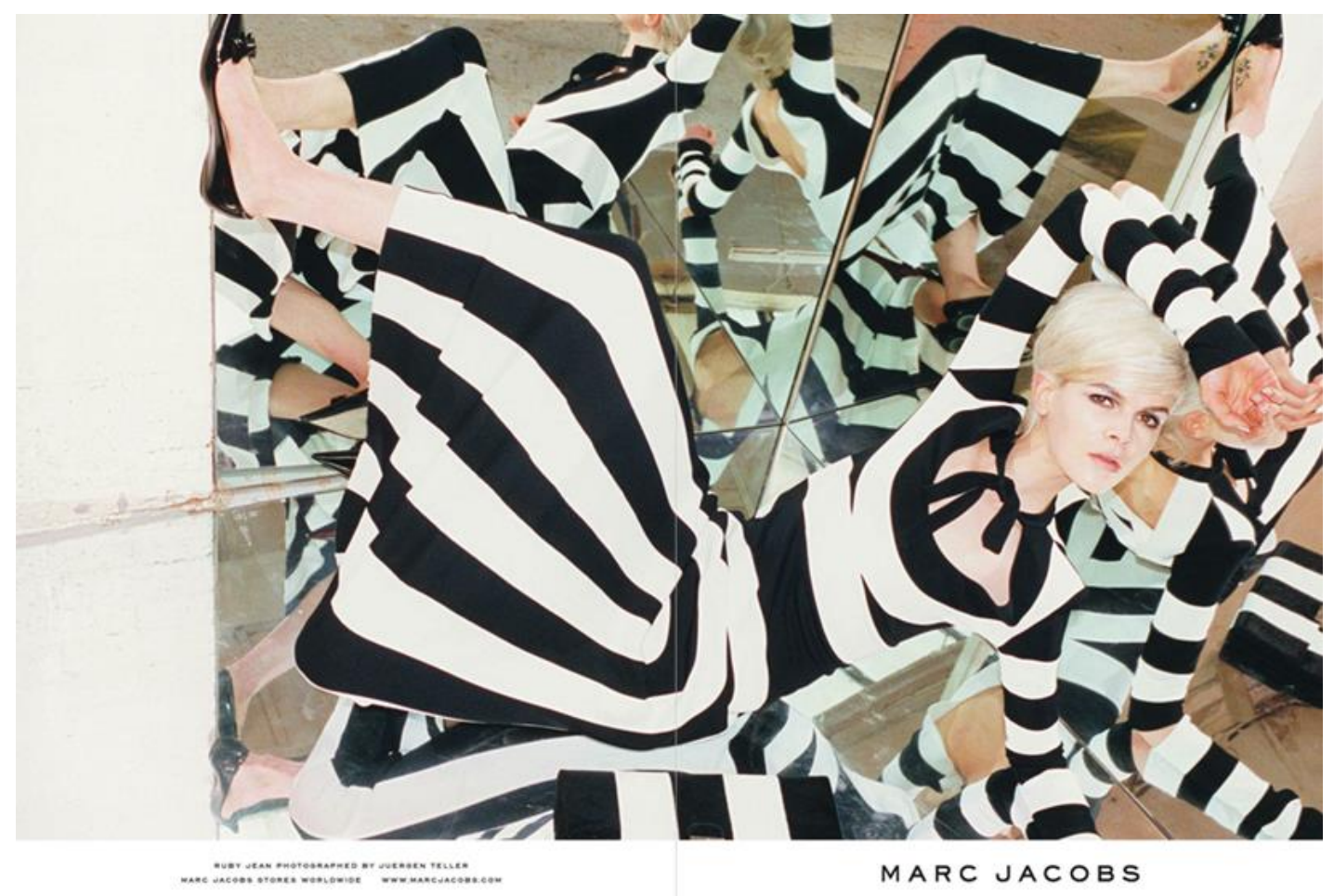

Figure 28: Marc Jacobs: (Marc Jacobs) Print Advertisement from Vogue203.1 (Jan 1, 2013): 8,9. 


\section{Appendix 16 SECOND CATEGORY: THE OVERALL PRESENTATION: EXAMPLES OF HALF OR QUARTER PAGE ADVERTISING SPREADS \\ 1980}

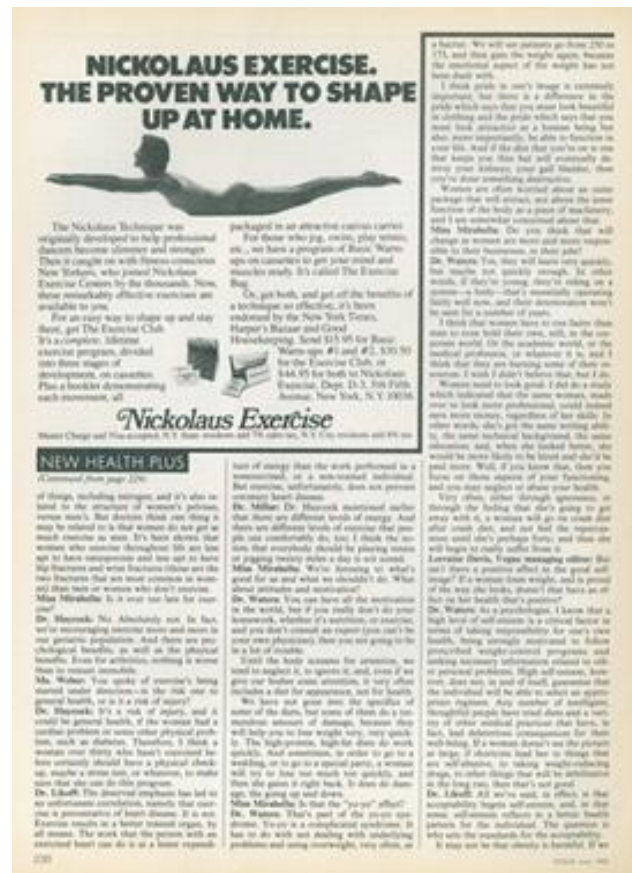

Figure 29: Nickolaus Exercise Print Ad. from Vogue 170.6 (Jun 1, 1980): 230.

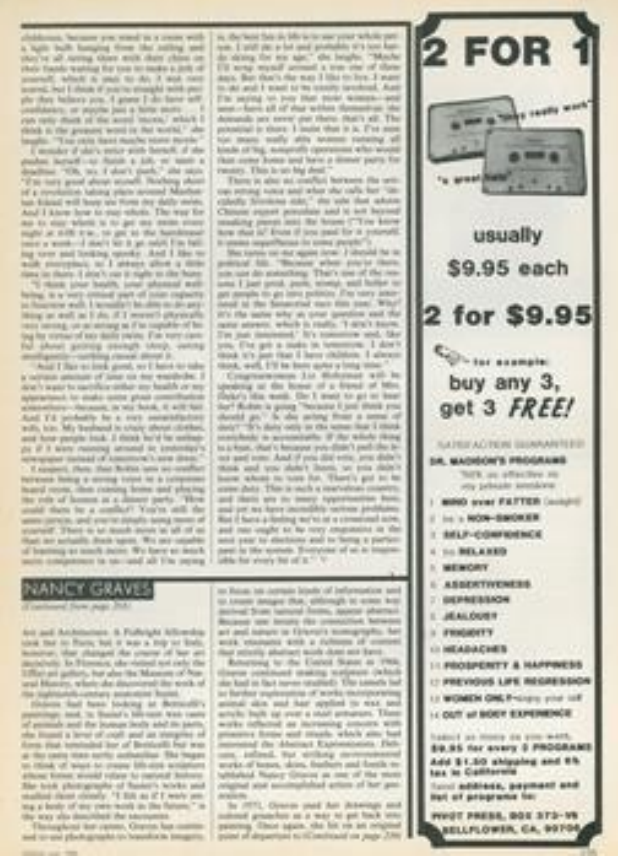

Figure 31: Print Advertisement from Vogue 170.6 (Jun 1, 1980): 235.

(Jun 1, 1980): 239.

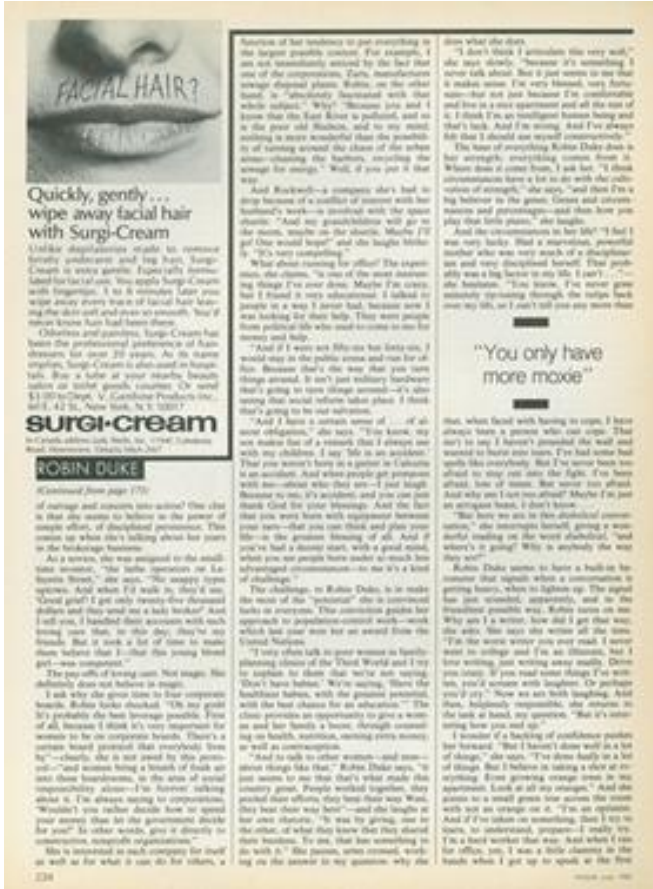

Figure 30: Cream (Surgi-Cream) Print Advertisement from Vogue 170.6 (Jun 1, 1980): 234.

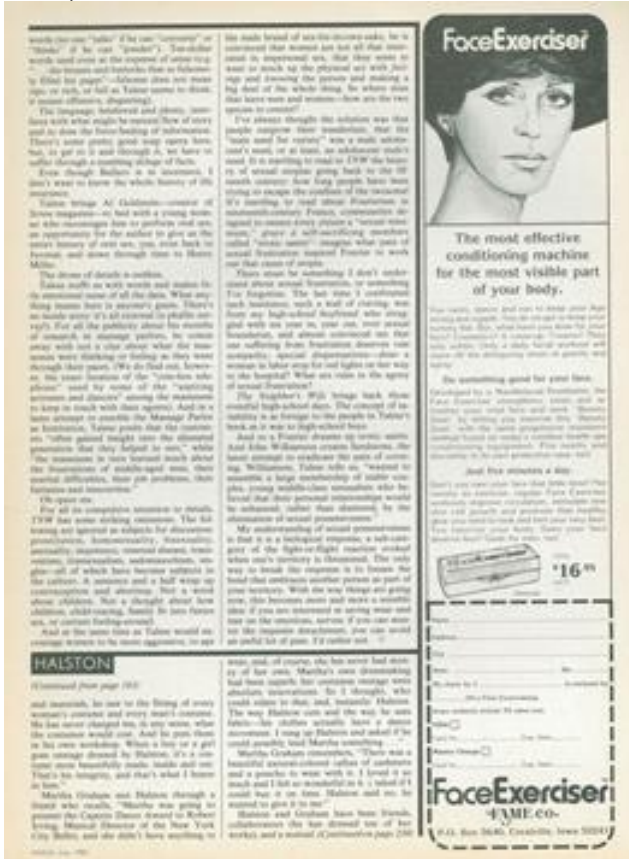

Figure 32: General Medical Co. Print Advertisement from Vogue 170.6 
Appendix 17: SECOND CATEGORY: THE OVERALL PRESENTATION: EXAMPLES OF 4 TO 6 PAGE ADVERTISING SPREADS 2013
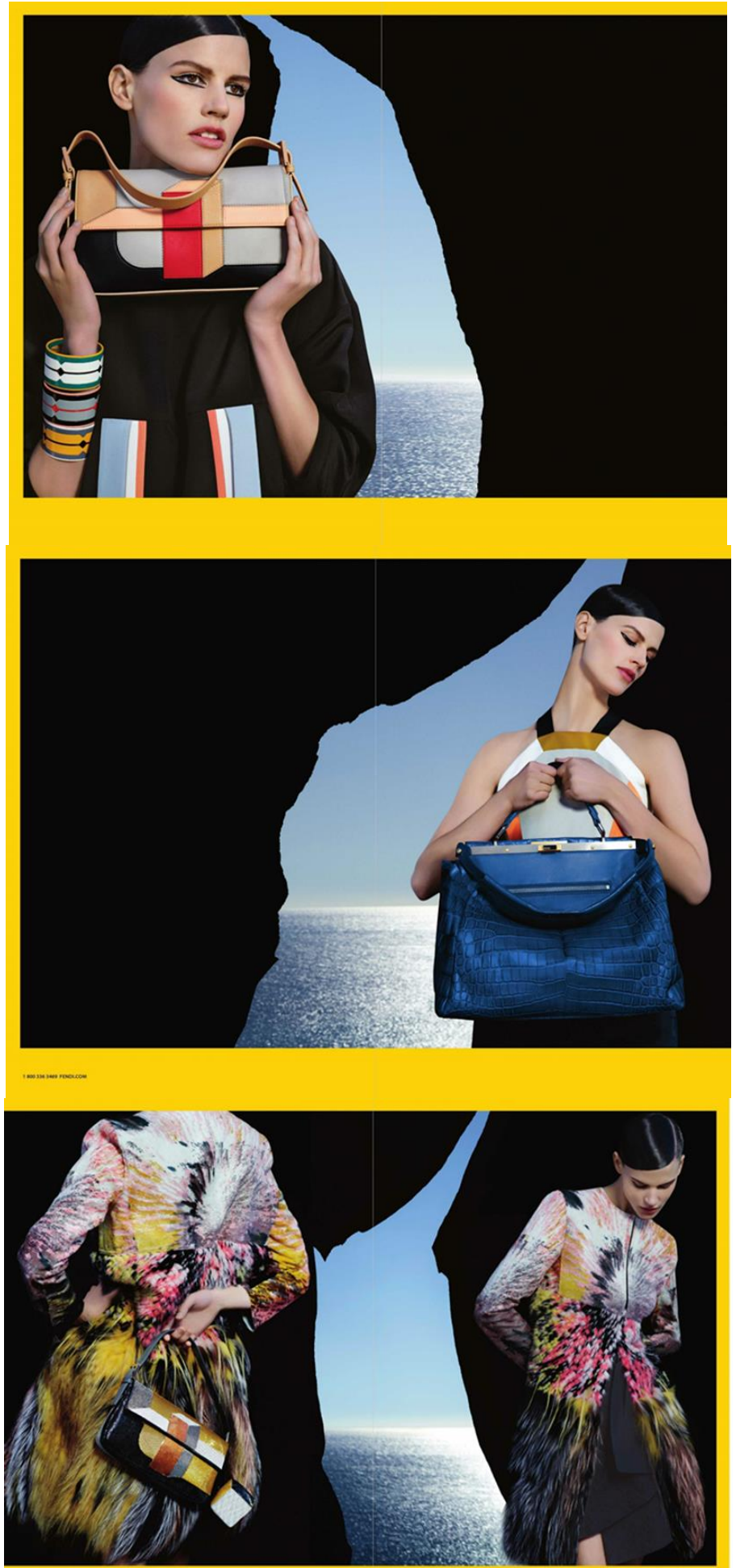
Figure 33: Fendi Print Advertisement From Vogue203.3 (Mar 1, 2013): C2, C3, C4, C5, C6, 1.
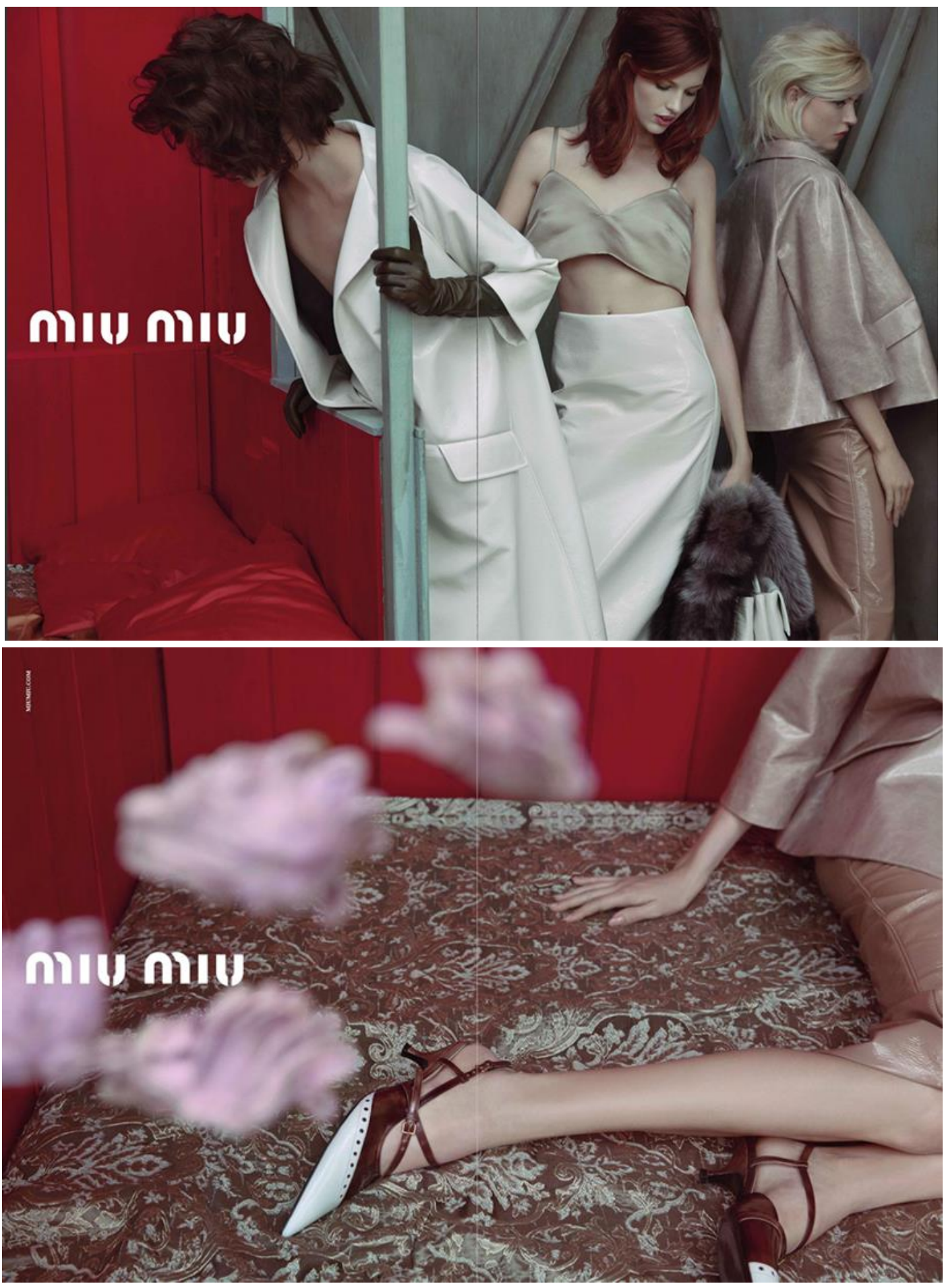

Figure 34: Miu Miu Print Advertisement From Vogue 203.2 (Feb 1, 2013): 34, 35, 36, 37. 
Appendix 18: SECOND CATEGORY: THE OVERALL PRESENTATION: VOGUE FRONT PAGE COVERS (JANUARY TO JUNE 1980)

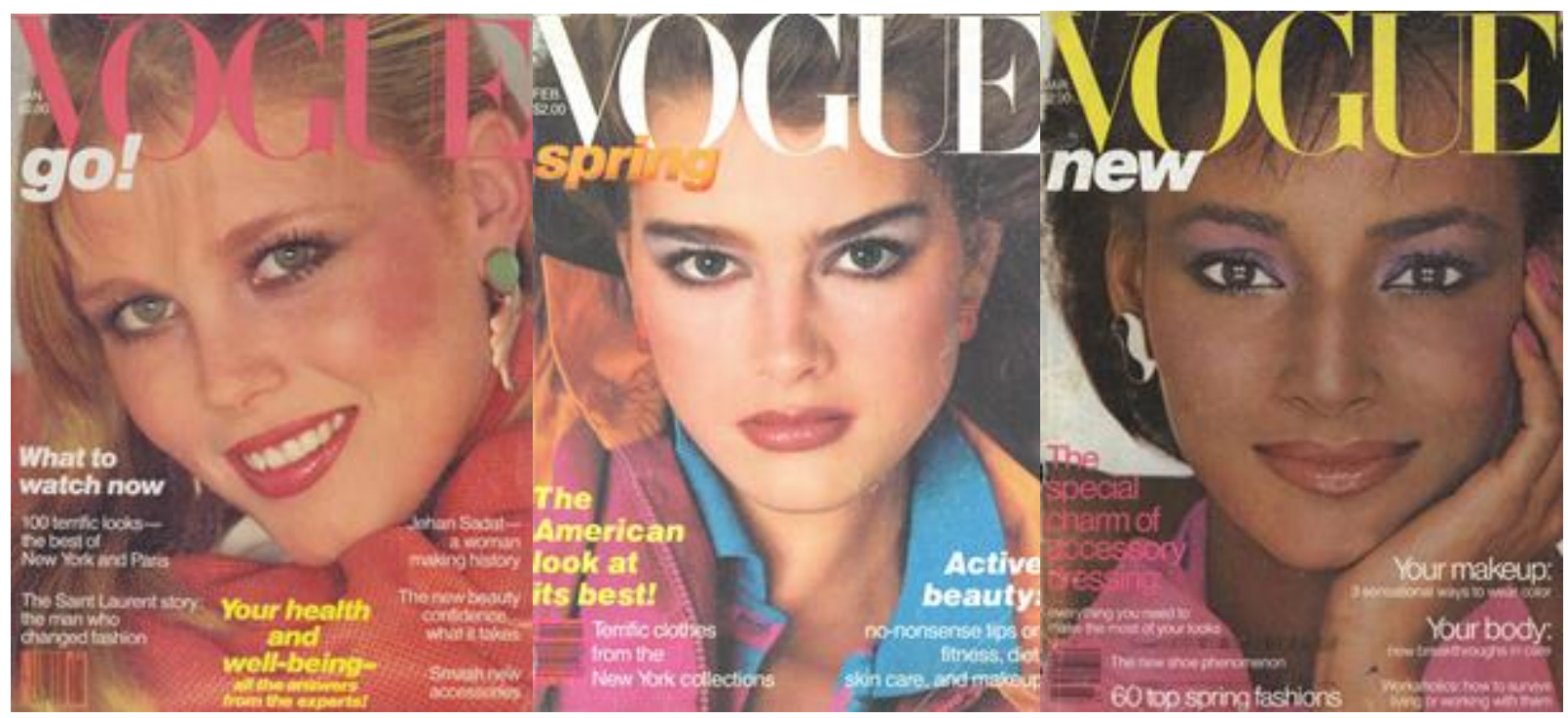

Figure 35: Vogue Cover from

Figure 36: Vogue Cover from

Figure 37: Vogue Cover from

Vogue 170.1 (Jan 1, 1980): C1.

Vogue 170.2 (Feb 1, 1980): C1.

Vogue170.3 (March 1, 1980): C1.

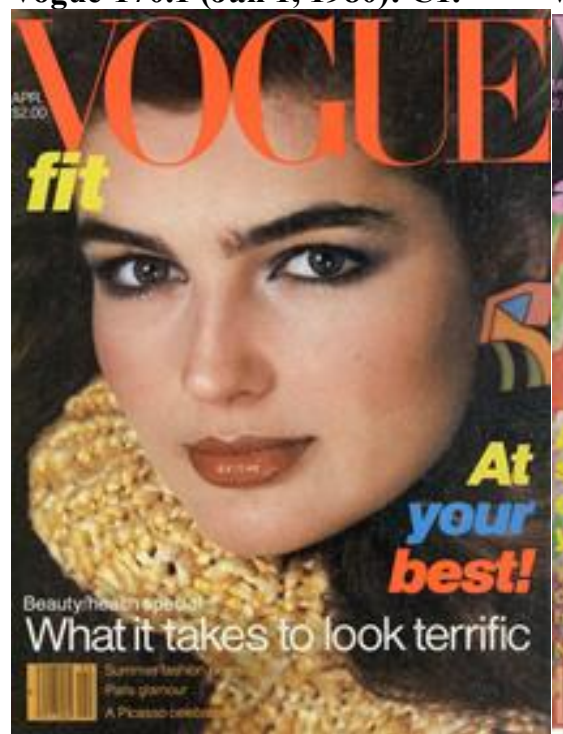

Figure 38: Vogue Cover from Vogue 170.4 (Apr 1, 1980): C1
Figure 39: Vogue Cover from

Vogue 170.5 (May 1, 1980): C1.
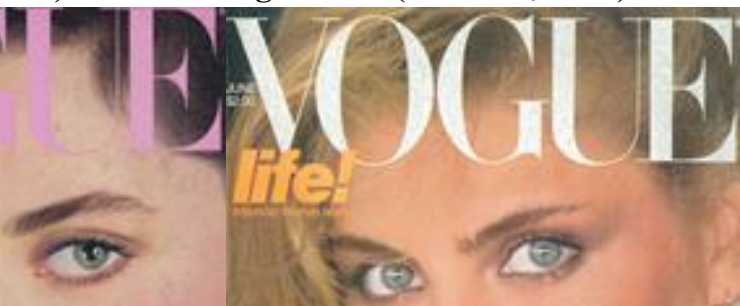

Thenew

cham of

American

sbye

Tis-minte find:

150 encer hotwanther boks

Ifrifo har nows ?

\section{Self care:}

Figure 40: Vogue Cover from Vogue 170.6 (Jun 1, 1980): C1. 
Appendix 19: SECOND CATEGORY: THE OVERALL PRESENTATION: VOGUE FRONT PAGE COVERS (JANUARY TO JUNE 2013)

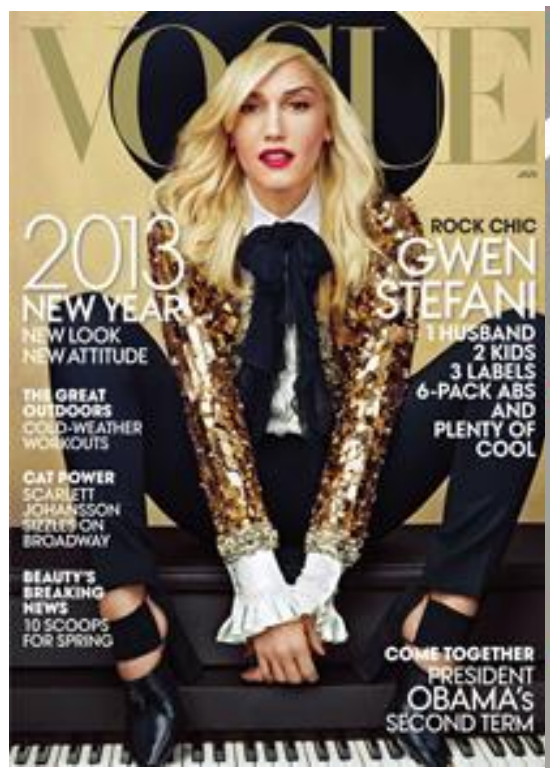

Figure 41: Vogue Cover from

Vogue 203.1 (Jan 1, 2013): C1.

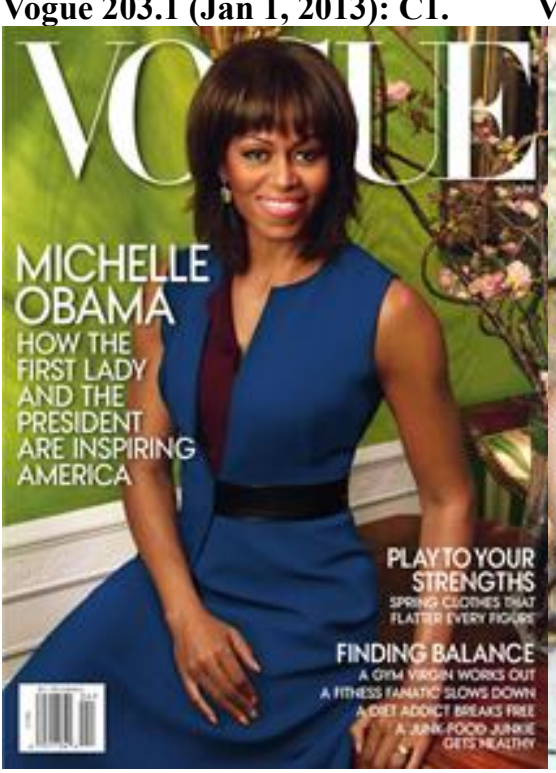

Figure 44: Vogue Cover from

Vogue 203.4 (Apr 1, 2013): C1.

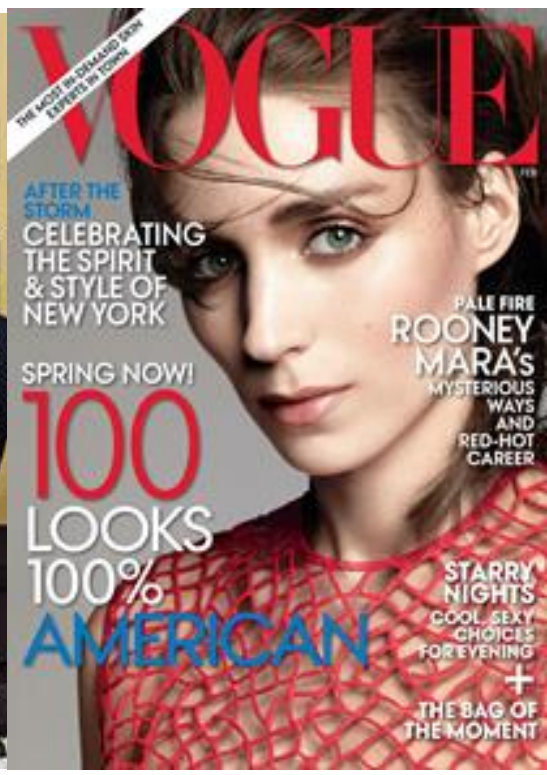

Figure 42: Vogue Cover from Vogue 203.2 (Feb 1, 2013): C1.

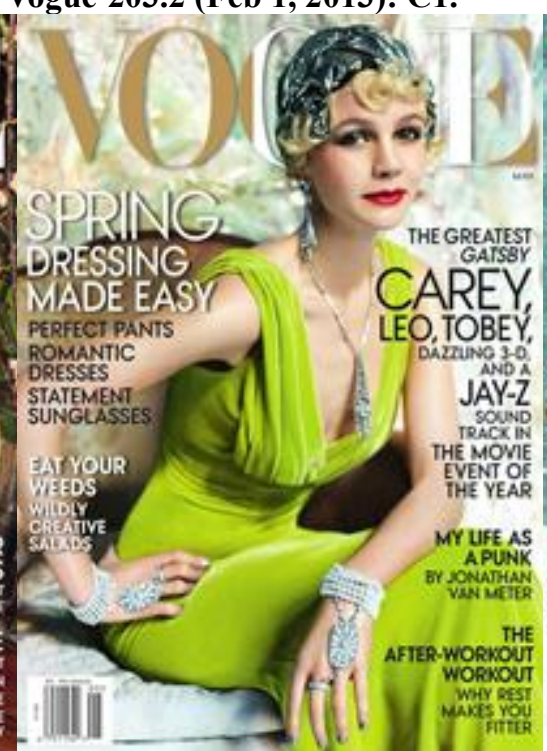

Figure 45: Vogue Cover from Vogue 203.5 (May 1, 2013): C1

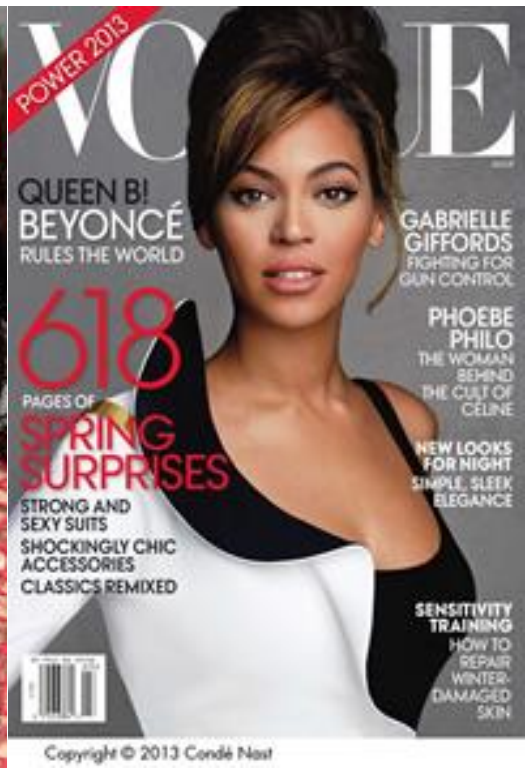

Figure 43: Vogue Cover from Vogue 203.3 (Mar 1, 2013): C1.

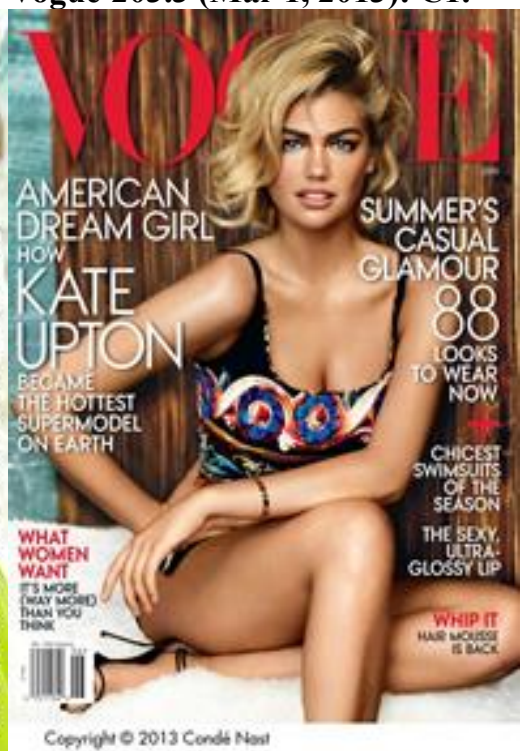

Figure 46: Vogue Cover from Vogue203.6 (Jun 1, 2013):C1. 
Appendix 20: SECOND CATEGORY: THE OVERALL PRESENTATION: THE OVERALL PRESENTATION: EXAMPLES OF PRINT

\section{ADVERTISING CONTENT 1980}

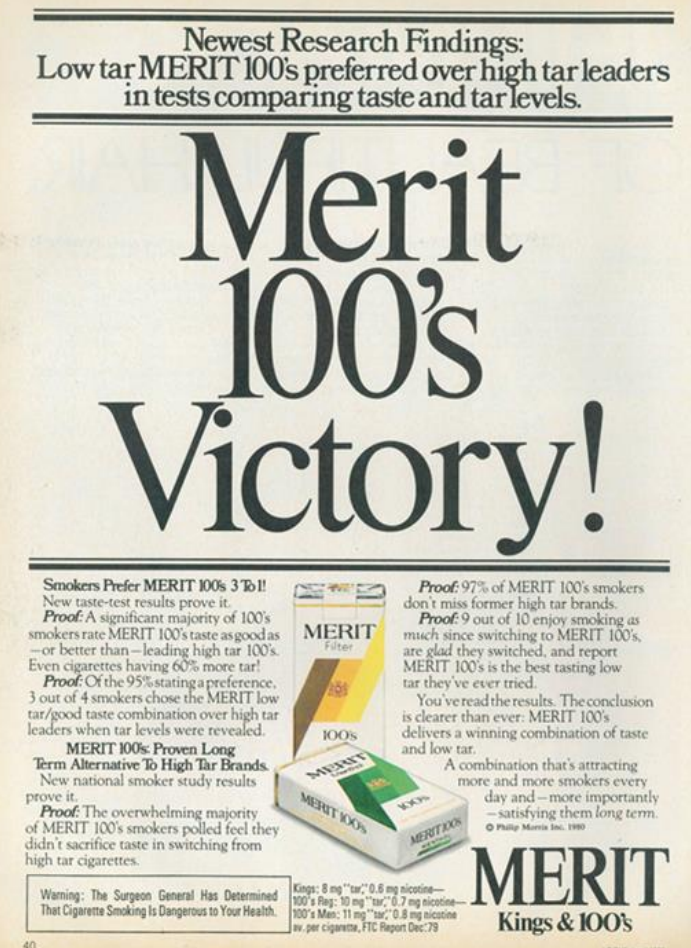

Figure 47: Merit Advertisement from Vogue 170.6 (Jun 1, 1980): 40.

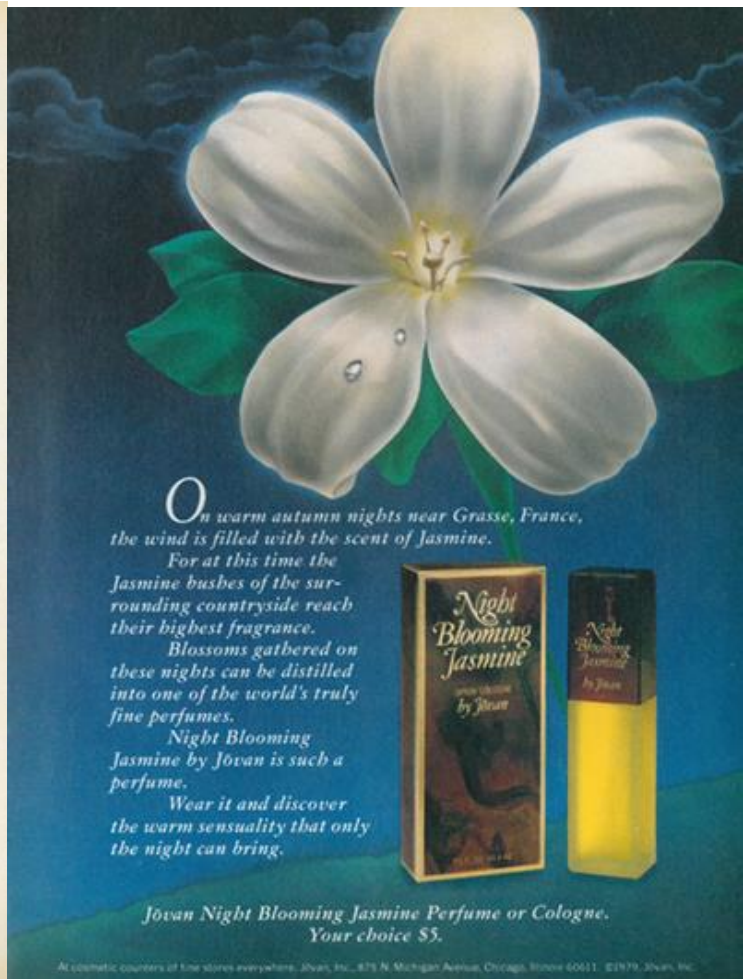

Figure 48: Cologne/Perfume (Night Blooming Jasmine) Advertisement from Vogue 170.6 (Jun 1, 1980): 31.

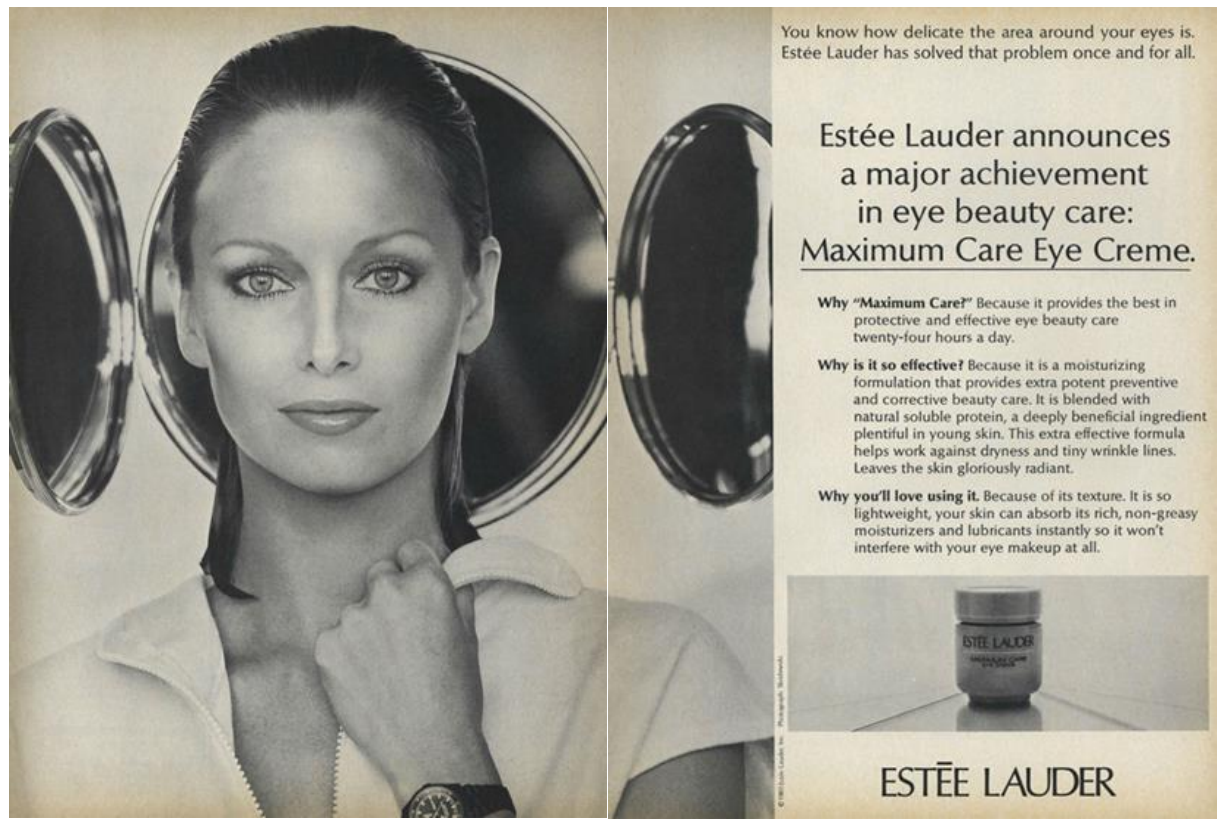

Figure 49: Estée Lauder Advertisement from Vogue 170.3 (Mar 1, 1980): 22, 23. 


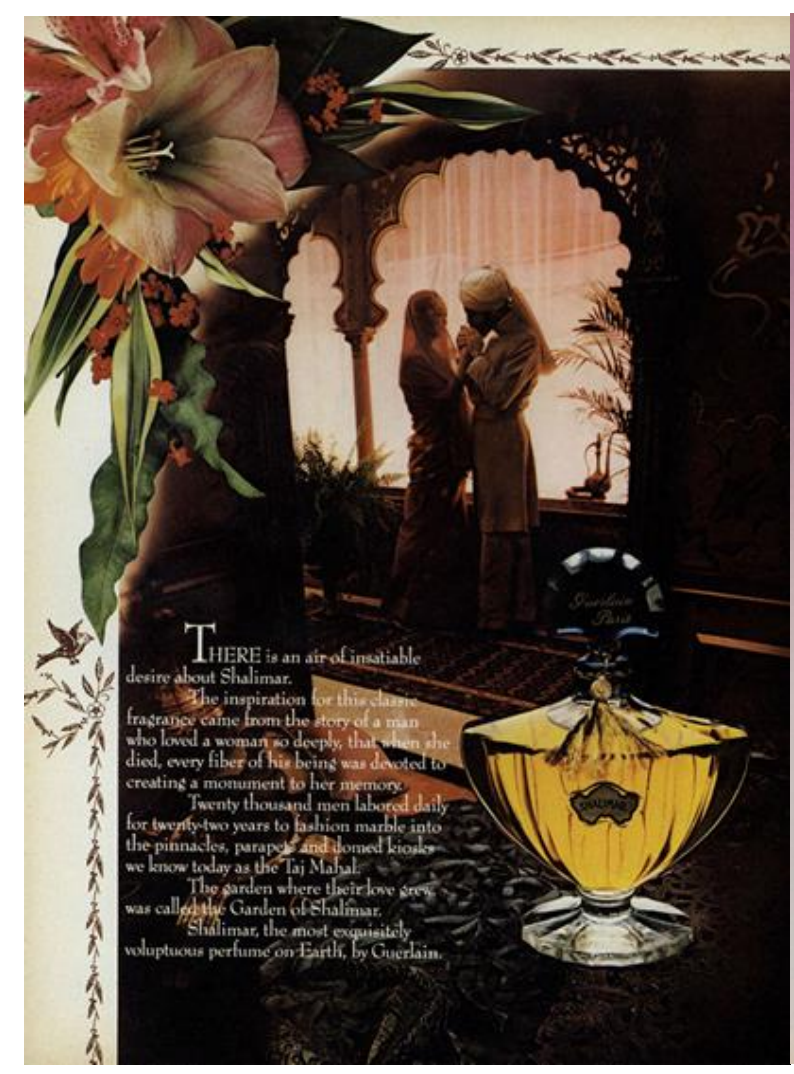

Figure 50: Fragrance (Guerlain, Inc.) Advertisement from Vogue170.4

\section{${ }^{66} \mathrm{My}$ \\ uncompromising sunglasses."}

Introducing Ray-Ban Naturals.
All the fashion you want... all the protection you need.

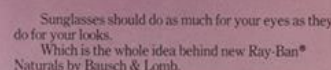

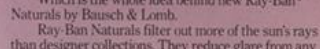

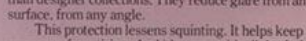

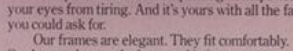
Mur lens styles are the last wurd in len

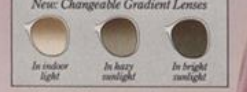

Especially our new, dangeable
gradients. As the drawing show:

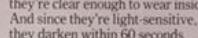

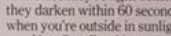
hovew Ray-Ban Natural Ments thoreses

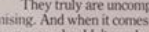
P Ban Ray. Ban
Figure 51: Sunglasses (Ray-Ban) Ad. from Vogue 170.5 (May 1, 1980): 45.

(Apr 1, 1980): 100.

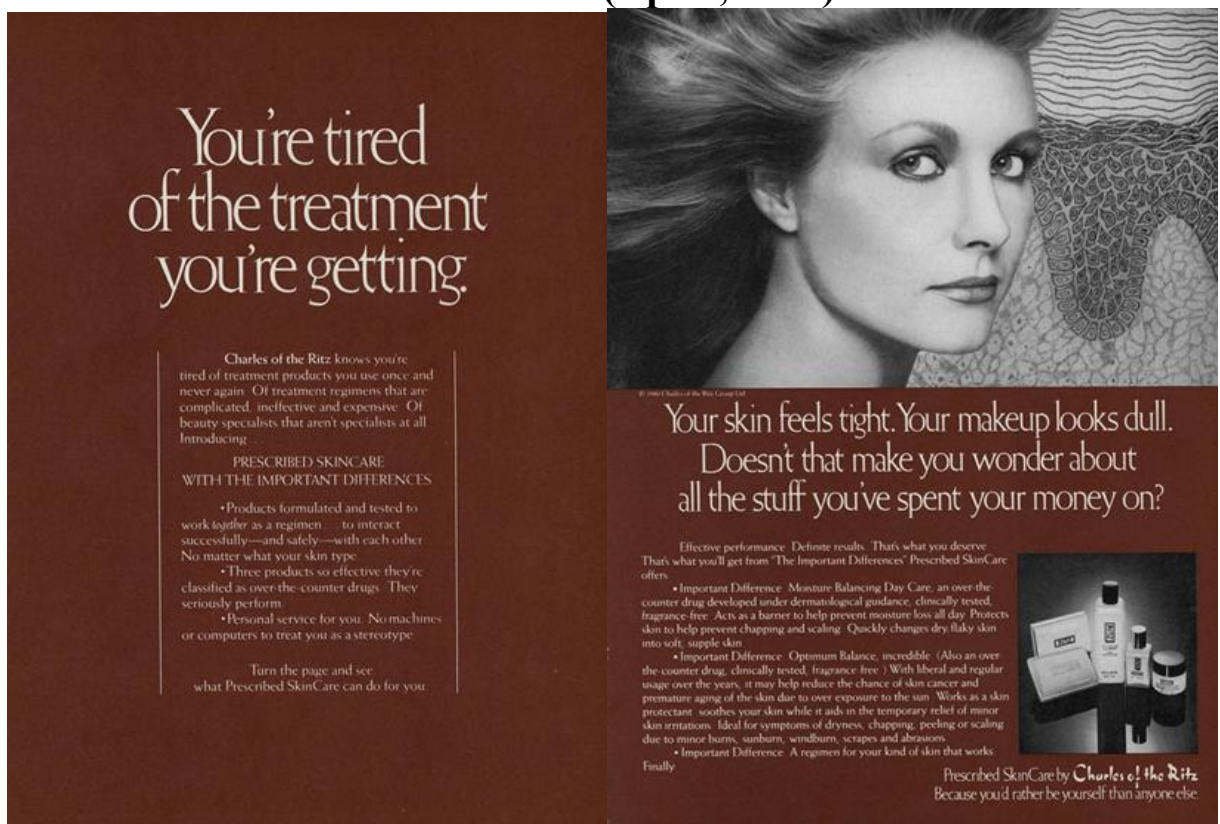

Figure 52: Beauty Products (Charles Of The Ritz) Advertisement from Vogue 170.4 (Apr 1, 1980): 43. 
Appendix 21: SECOND CATEGORY: THE OVERALL PRESENTATION: EXAMPLES OF PRINT ADVERTISING CONTENT 2013

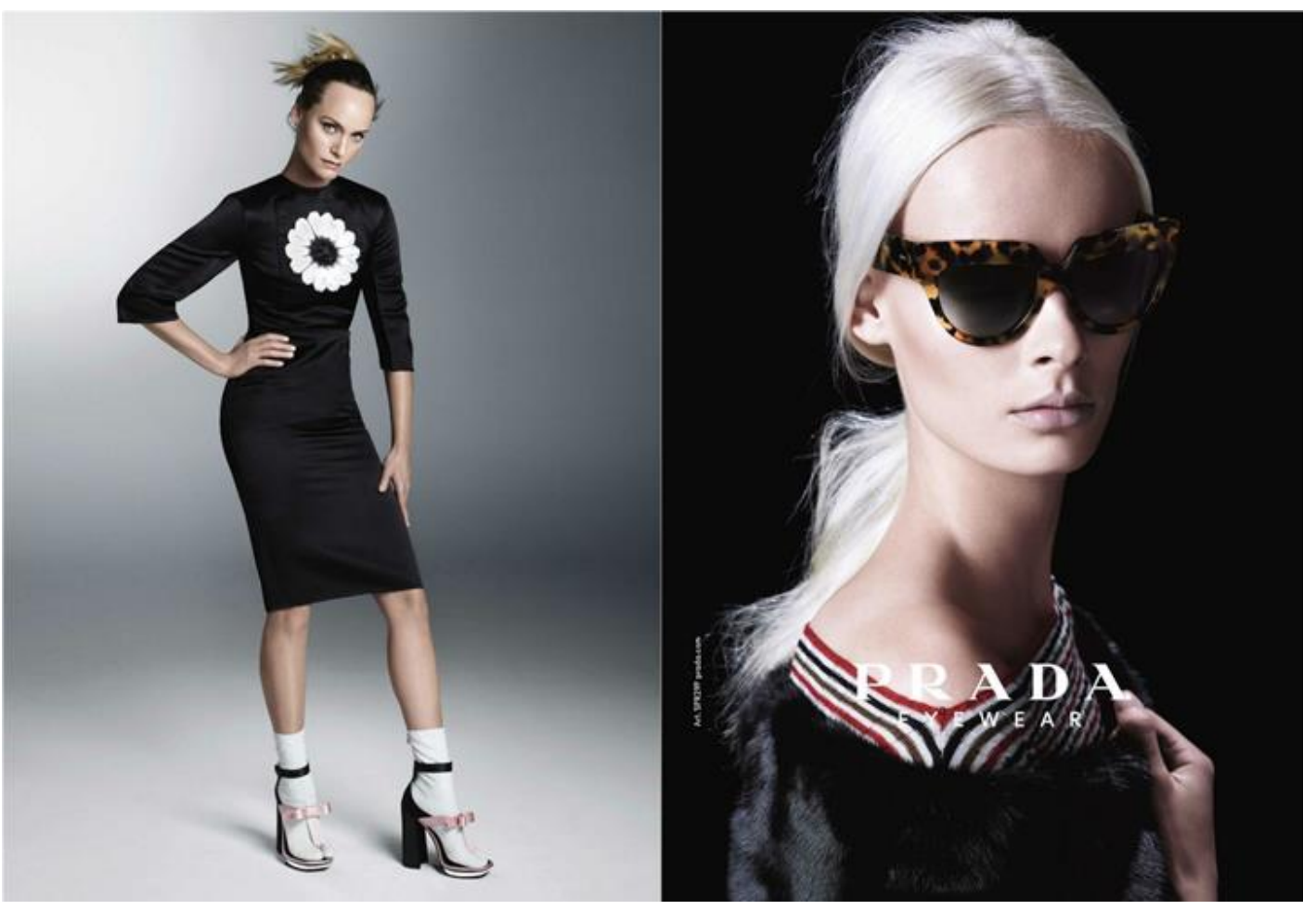

Figure 53: Prada Advertisement from Vogue 203.4 (Apr 1, 2013): 14, 15.

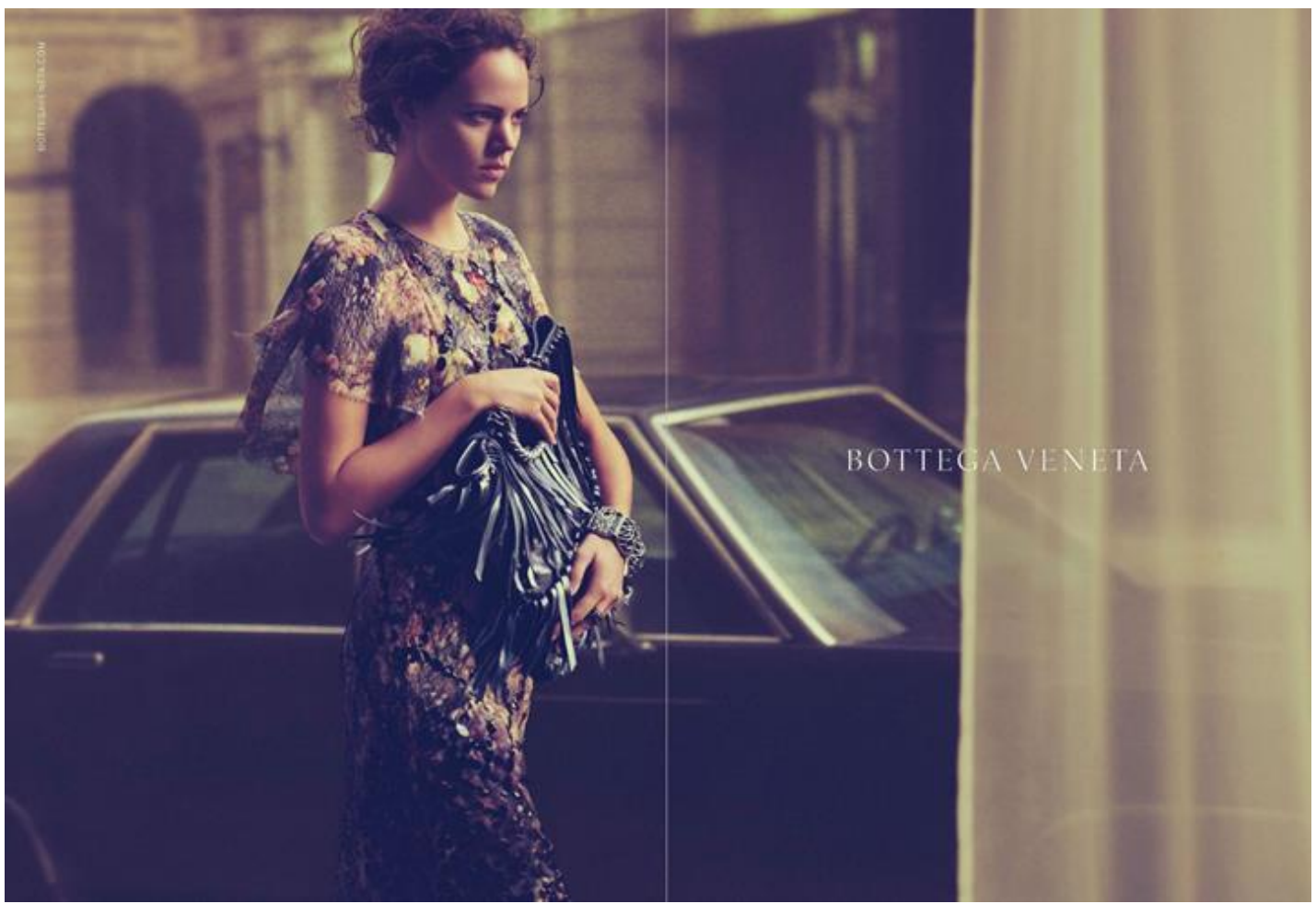


Figure 54: Bottega Veneta Advertisement from Vogue 203.4 (Apr 1, 2013): 22, 23.

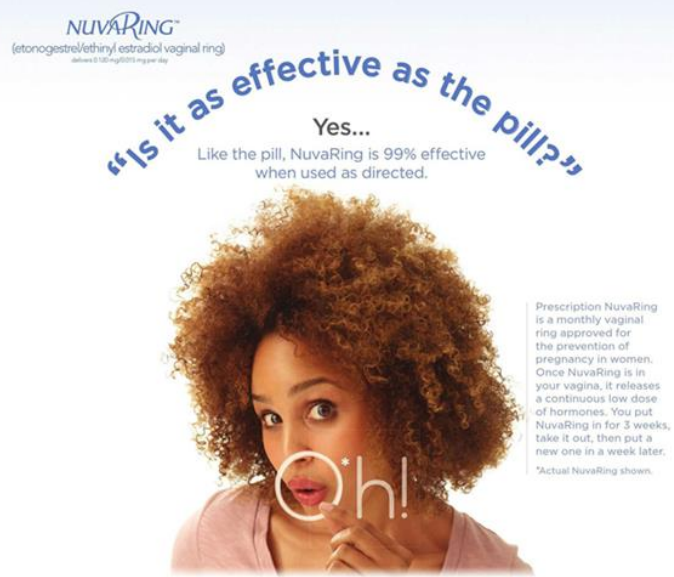

Important Safety Information

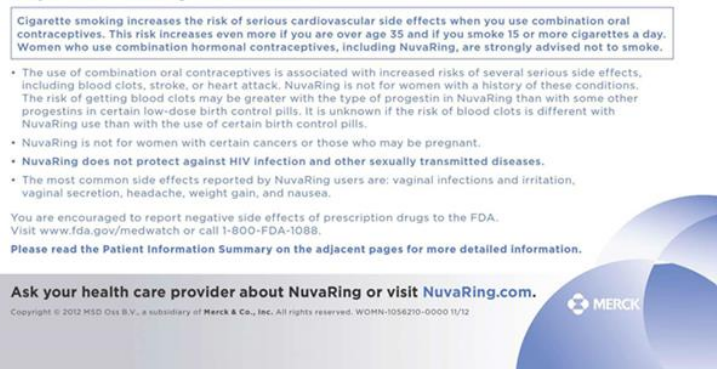

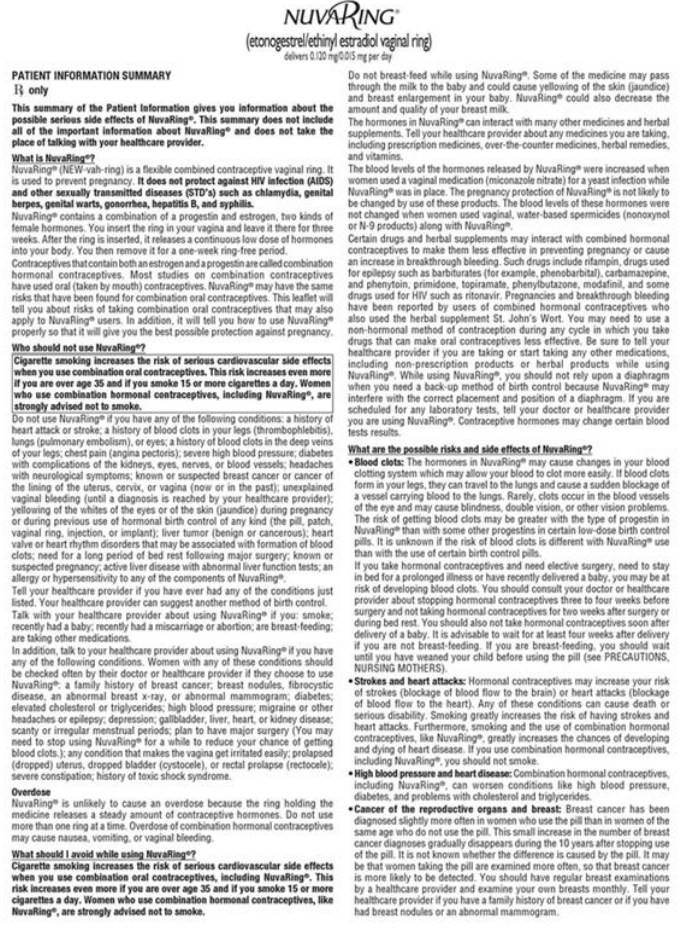

\section{NUVARING \\ (etonogestrelletetinyl stradodol vaginal ring)}

Women who currently have or have had breast cancer should not use hormonal contraceptives, including NuvaRing", because breast cancer is

Some studies have tound an increase in the incidence of cancer of the cenvis in women who use oral contraceptives. However, this finding may be related evidence to nula out the possibility that pills may cause such canoers - Gallablader disease: Combination bormonal contractetive users may have a - Galshadder disease: Combination hormonal cor

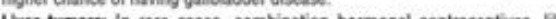
Uwer tumors: in tare cases, combination hormonal contraceptives, live These benion thar tumors can break and cause fotel internal bleeding In addition, it is possible that women who use combination hermon contraceptives, lke NuraRing" have a higher chance of getting ther cancer. However, liver cancess are extremely ares.

- Lipid metabolism and inflammastion of the pancreas: In women with inherited defects of lipid metabolism, there have been repots of significant elenations of plasma triglycerides during estrogen therapy. This has led to pancreatiss in some cases.

The common side effects reparted by Nwralinge users are vaginat infections and irritation, vaginal secretion; headrche; weight gain nuses

In addition to the risks and side effects listed above, users of combination hormonal contraceptives hrve teparted the following side effects: vomition: change in appetite: abdominal cramps and bloating, breast tenderness of enlargement; irregular vaginal bleeding of spotting: changes in menstrual cycle: temporary infertily after treatment fluid tetention (edema); spotty darkening of the skin, particularly on the face; rash; weight changes: depression; intolerance to contact lenses; nervousness; dicziness; loss of scalp hair.
Call your healthcare provider right away if you get any of the symptoms listed below. They may be signs of a serious problemr sharp chest pain, coughing bood, or sudden shorthess of breath (possible ciot in the lung). pain in the cal

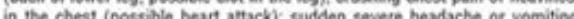
diriness of tointing problems aith vision of specth, weokness, or numbers n an arm or leg (cossible stroke) : sudden partial or complete loss of vision

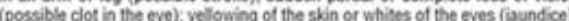
especinlly with fever, iredness, loss of appetite, dark colored urine, of light colored bowel movements (possible fiver problems); severe pain, suetling. of tenderness in the abdomen (gallbladder of liver problems): sudden teve? usually $102^{*}$ for more). vomiting, dianthes, dizziness, fainting. or a sunburn. whe rash on the face or body (very rarely, toxic shock sjndrome) ; breast lumps (possible breast cancer or bengon breast disease), irregular vaginal bleeding or spotting that happens in more than one mentsirual cyele or lasts for more man a low days, urgent, frequent, borming andror paintuif uninusion, and cannot

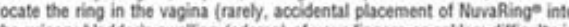
the urinary bladder). sweling (edema) of your fingers or ankles; difficulty in sleeping, weakness, lack of energy, fatigue, or a change in mood (possible To report SUSPECTED ADVERSE REACTIONS, contact Merck \& Co., inc. at 1-800-526-4099 or FDA at 1-800-FOA-1058 of mmw. fda.gow/medwatch. 1.877-NUVARING

Manufactured for: Merck Sharp \& Dohme Corp a subsidiary of Merck \& Co., Inc, Whitehouse Station, NJ 08889, USA

Manufactured by: N.V. Organcon, Oss, The Nethertands, a subsidiary of Merck \& Co., Inc, Whitehouse Station, Nu 08889, USA WOMN-1056210-0000 11/12

Figure 55: Nuva Ring Advertisement from Vogue203.4 (Apr 1, 2013): 227, 228, 229. 
Appendix 22: SECOND CATEGORY: THE OVERALL PRESENTATION: EXAMPLES OF PRINT ADVERTISING CONTENT WITH STORE LOCATIONS 2013

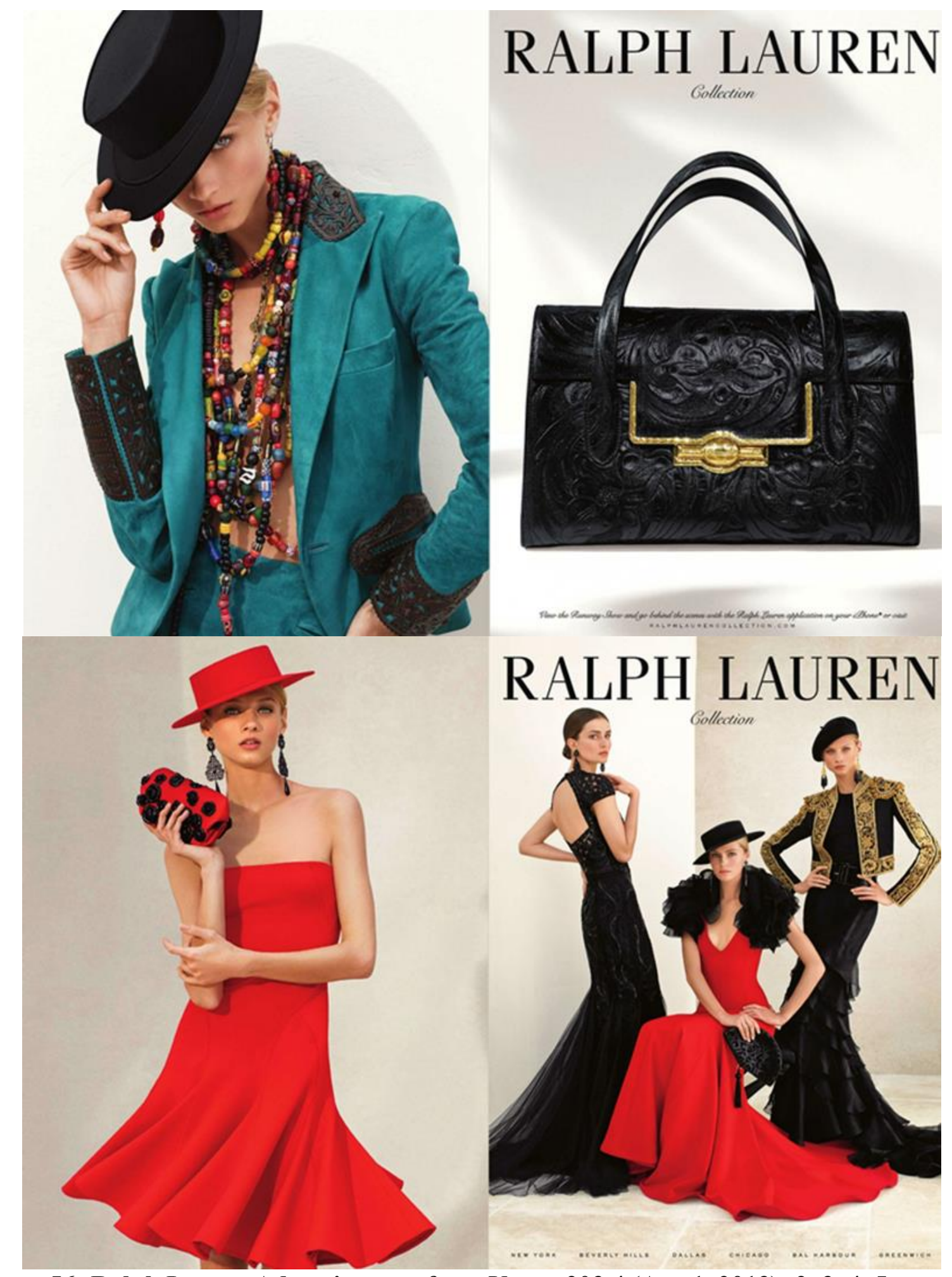

Figure 56: Ralph Lauren Advertisement from Vogue 203.4 (Apr 1, 2013): 2, 3, 4, 5. 


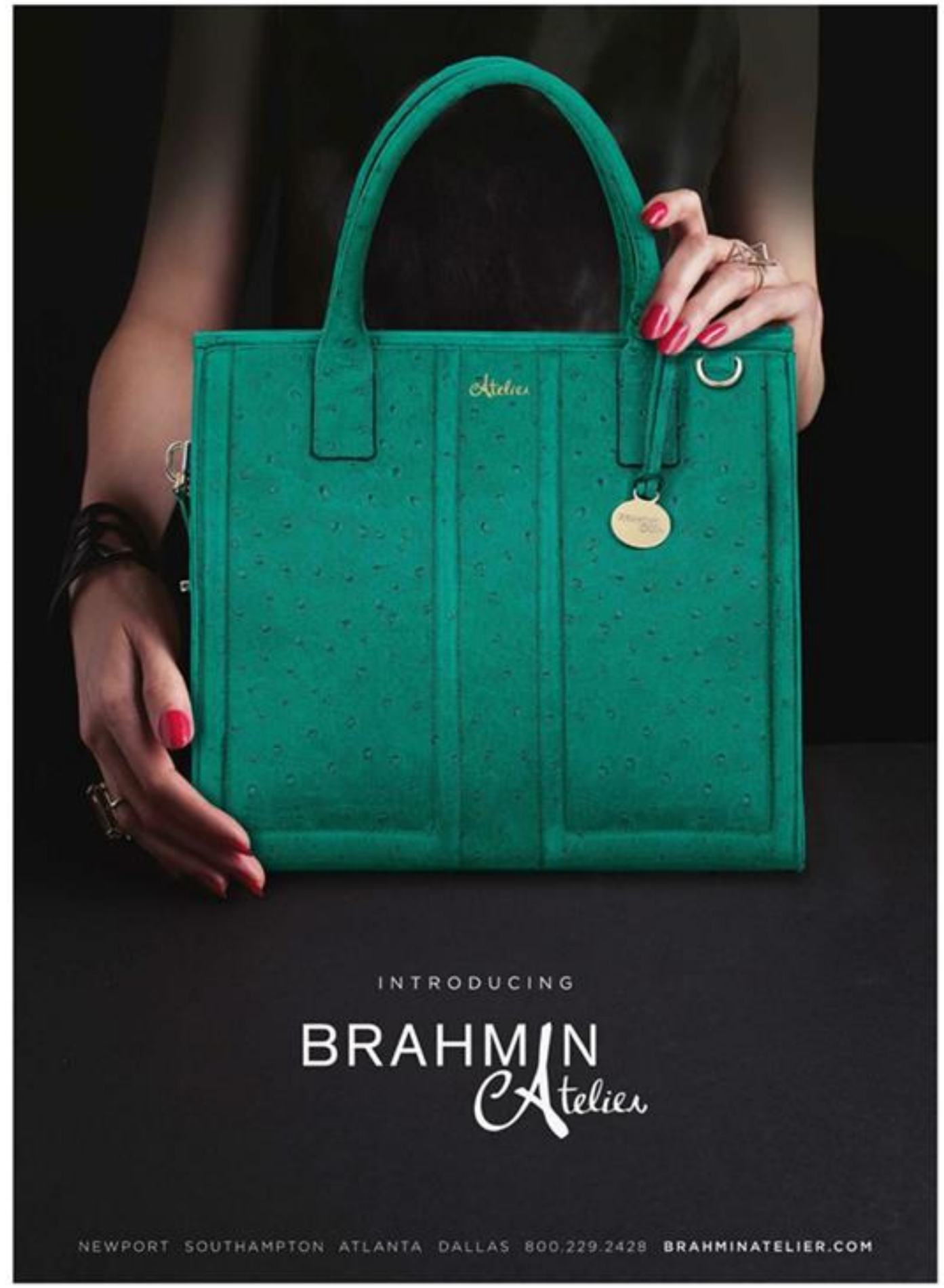

Figure 57: Brahmin Advertisement from Vogue 203.5 (May 1, 2013): 61, 62. 
Appendix 23: SECOND CATEGORY: THE OVERALL PRESENTATION: EXAMPLES OF PRINT ADVERTISING LAYOUT OF MODEL-PRODUCT OR AD-PRODUCT PLACEMENT 1980

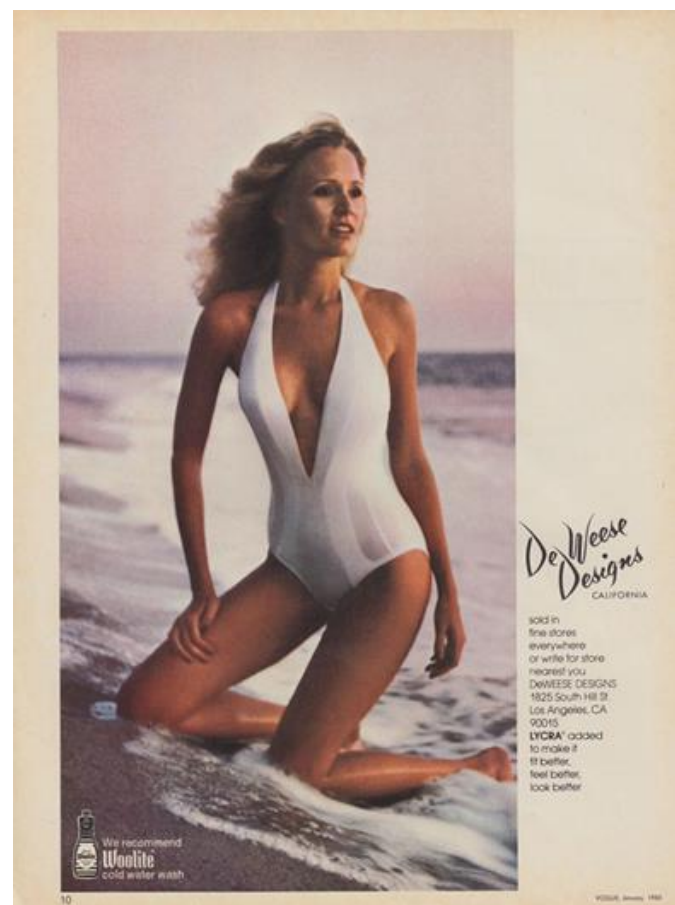

Figure 58: Cold Water Wash (Woolite) Advertisement from Vogue 170.1 (Jan 1, 1980): 10.

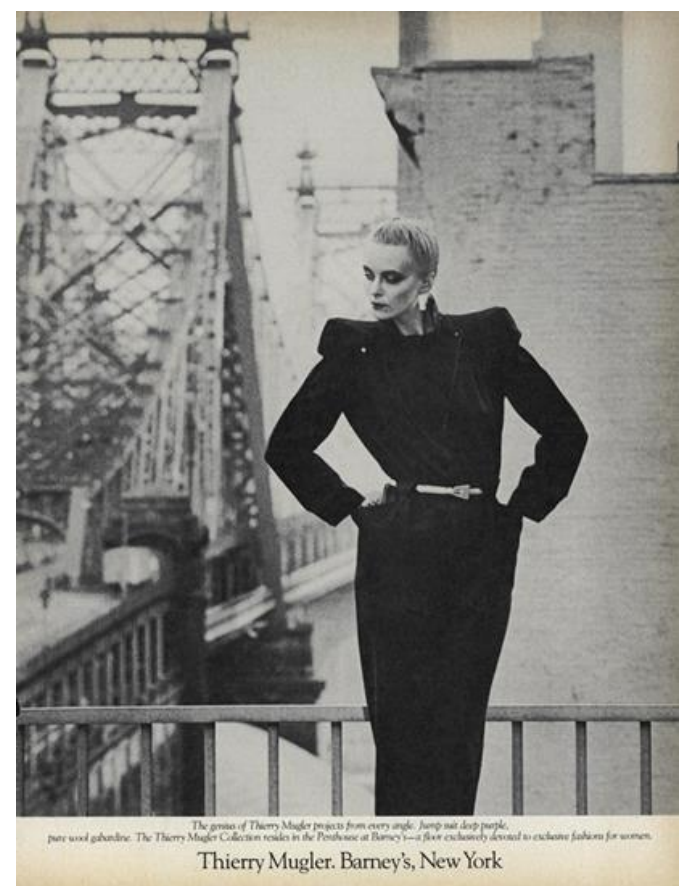

Figure 60: Jump Suit (Thierry Mugler) Ad. from Vogue 170.4 (Apr 1, 1980): 47.

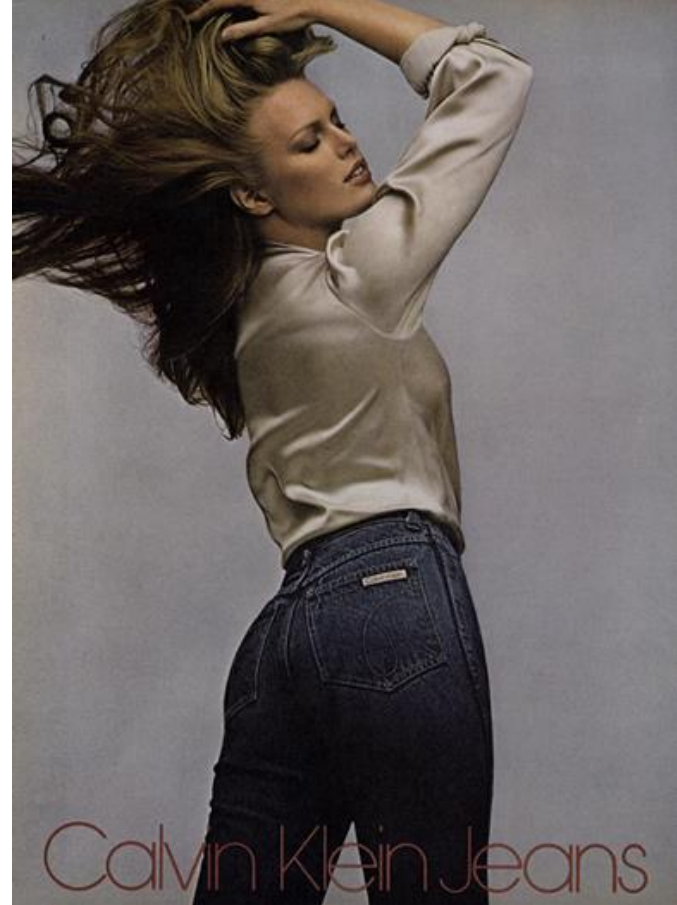

Figure 59: Calvin Klein Jeans Advertisement from Vogue 170.4 (Apr 1, 1980): 40.

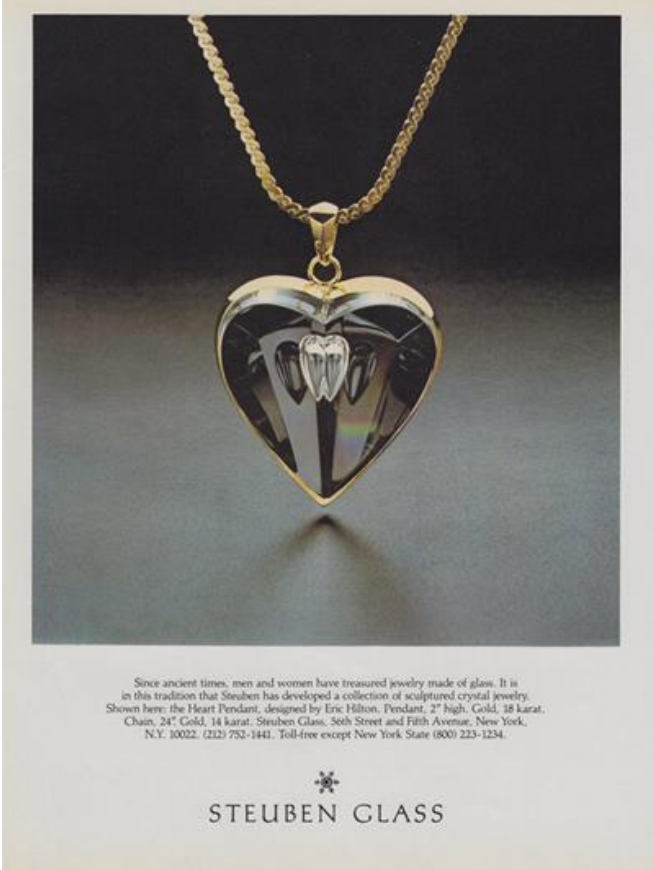

Figure 61: Gold (Steuben Glass) Ad. from Vogue 170.5 (May 1, 1980):80 


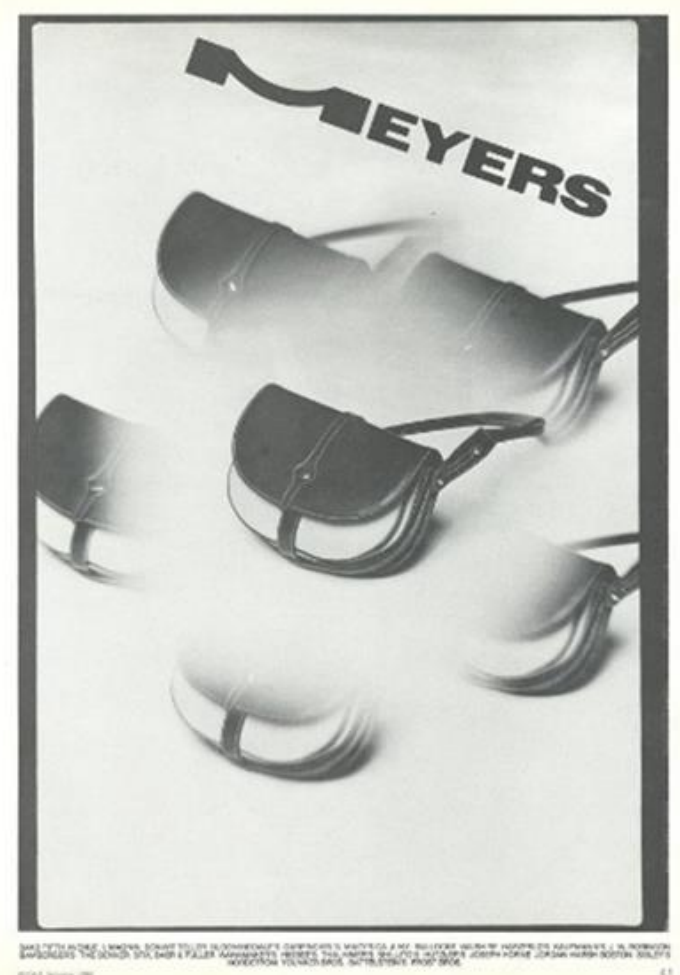

Figure 62: Meyers Brothers Inc. Advertisement From Vogue 170.2 (Feb 1, 1980): 41.

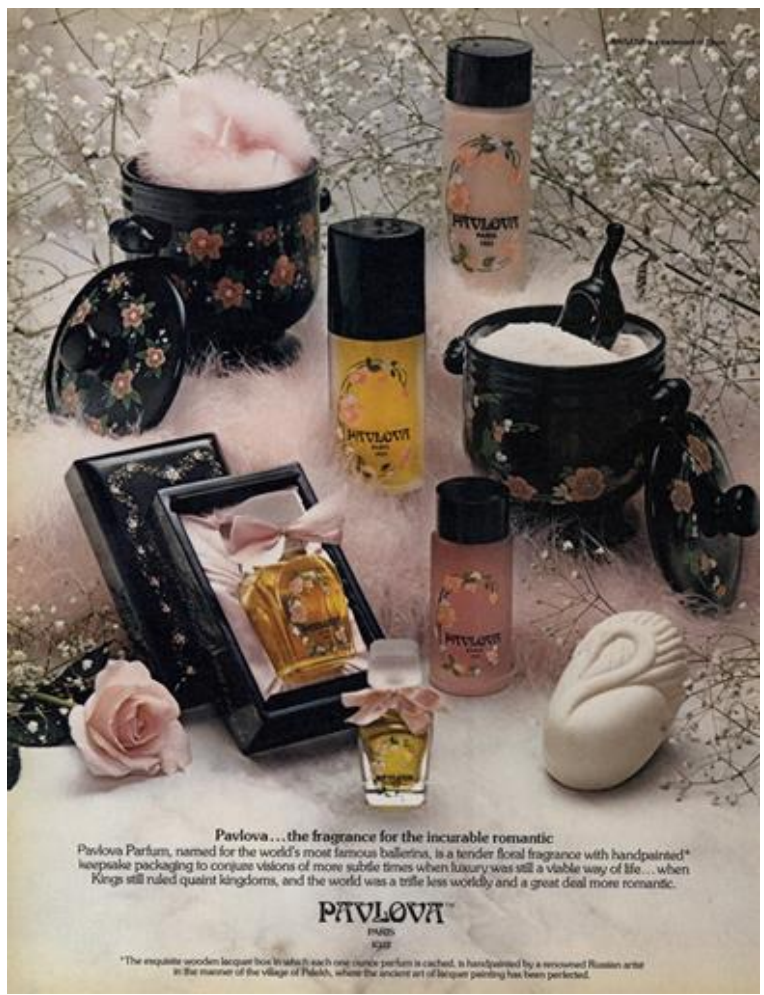

Figure 63: Pavlova Advertisement From Vogue 170.4 (Apr 1, 1980): 54. 


\section{Appendix 24: SECOND CATEGORY: THE OVERALL PRESENTATION: EXAMPLES OF CELEBRITY ENDORSEMENT PRINT ADVERTISEMENTS 2013}

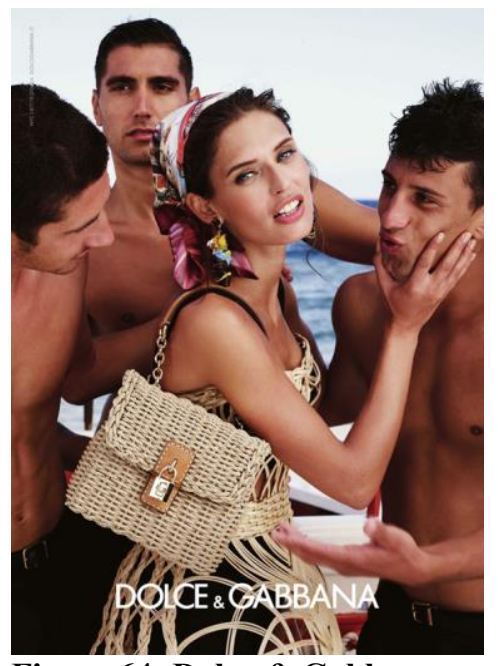

Figure 64: Dolce \& Gabbana Advertisement from Vogue 203. (Apr 1, 2013): 73.

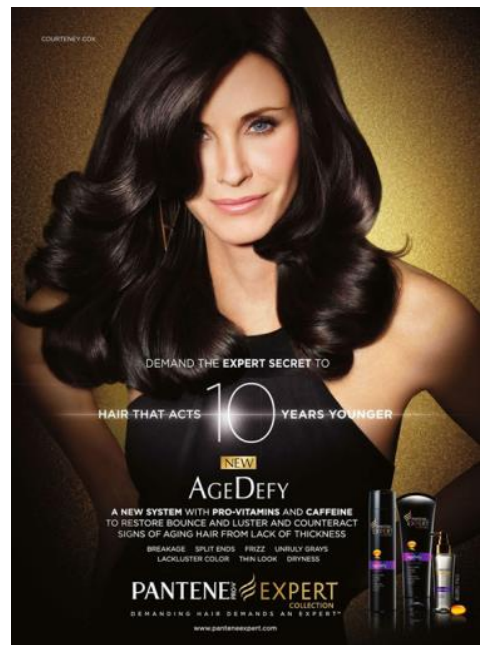

Figure 67: Pantene Pro-V Collection Advertisement from Vogue 203.3 (Mar 1, 2013): 451.

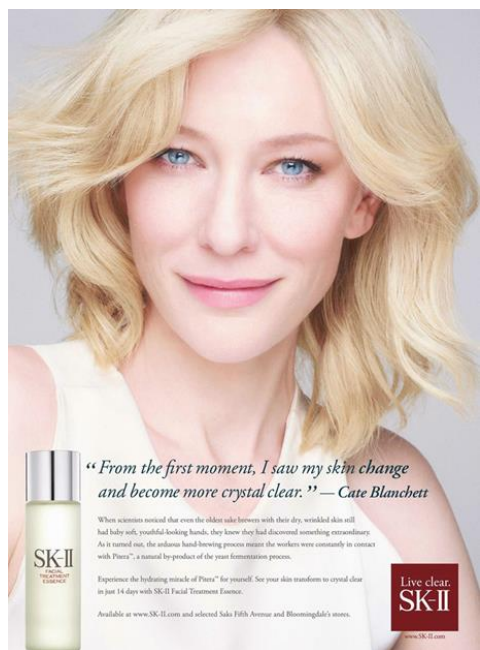

Figure 65: Sk-II Advertisement from Vogue 203.3

(Mar 1, 2013): 259.

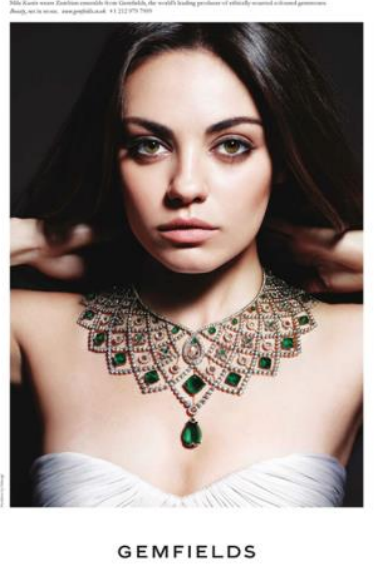

Figure 68: Gemfields Advertisement from Vogue 203.4 (Apr 1, 2013): 169.

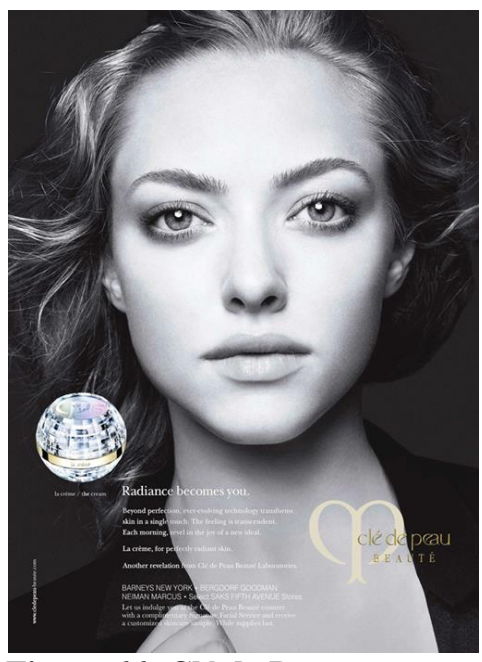

Figure 66: Clé de Peau from Vogue 203.2

(Mar 1, 2013): 443.

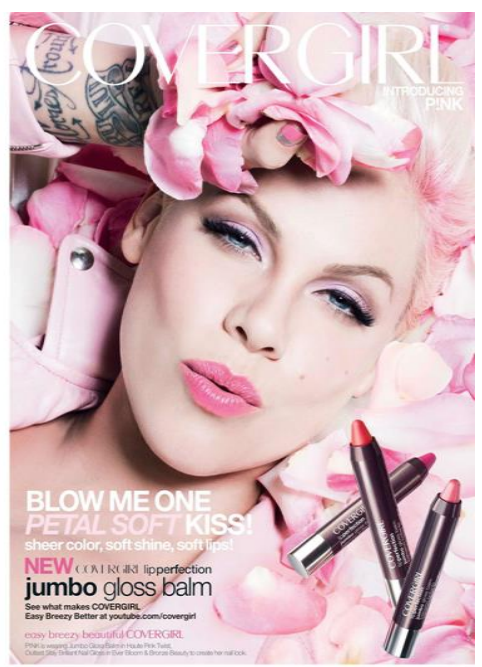

Figure 69: Covergirl

Advertisement from

Vogue 203.2 (Feb 1, 2013): 83. 
Appendix 25: THIRD CATEGORY: THE OVERALL APPEARANCE OF THE DIGITAL CONTENT: EXAMPLES OF WEBSITES PRESENT ON PRINT ADVERTISEMENTS 2013

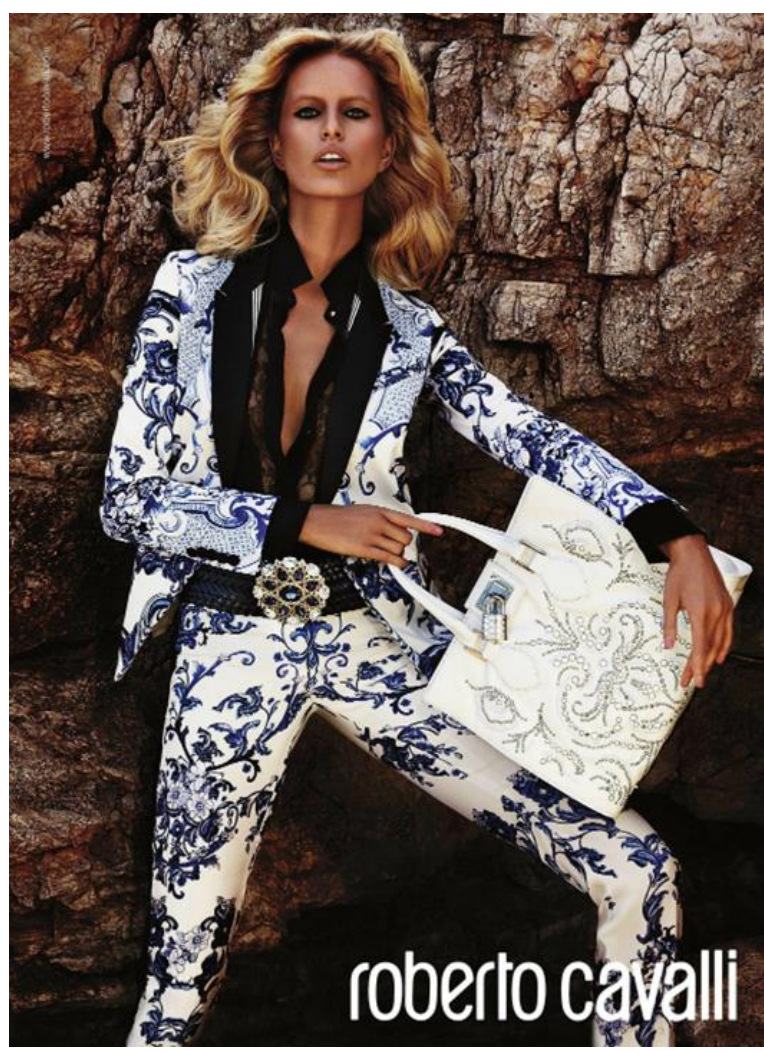

Figure 70: Roberto cavalli Advertisement from Vogue 203.1 (Jan 1, 2013): 29.

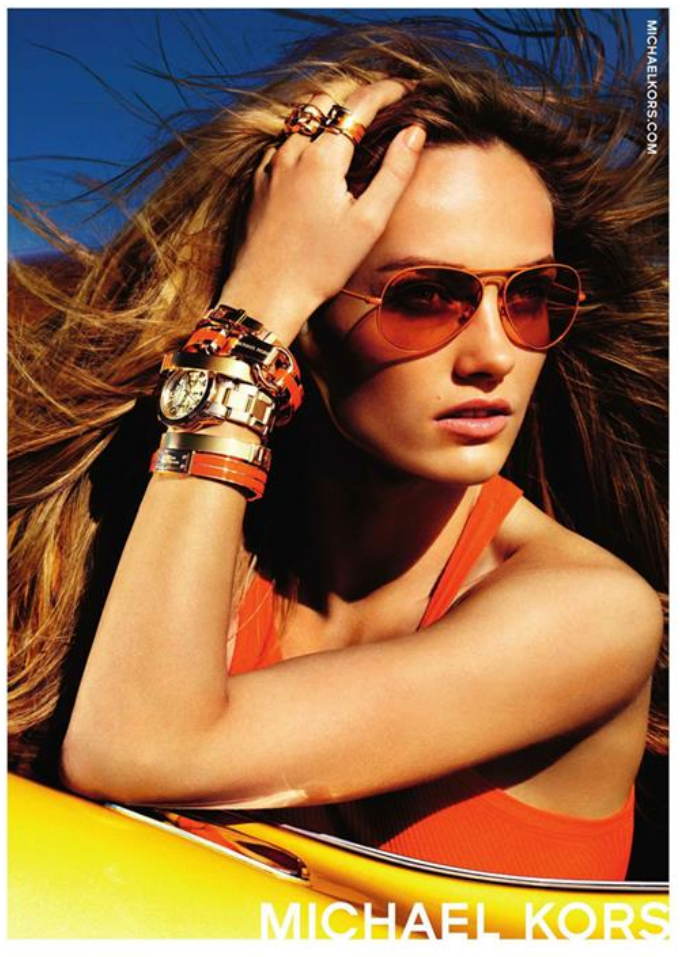

Figure 71: Michael Kors Advertisement from Vogue 203.5 (May 1, 2013): 137. 


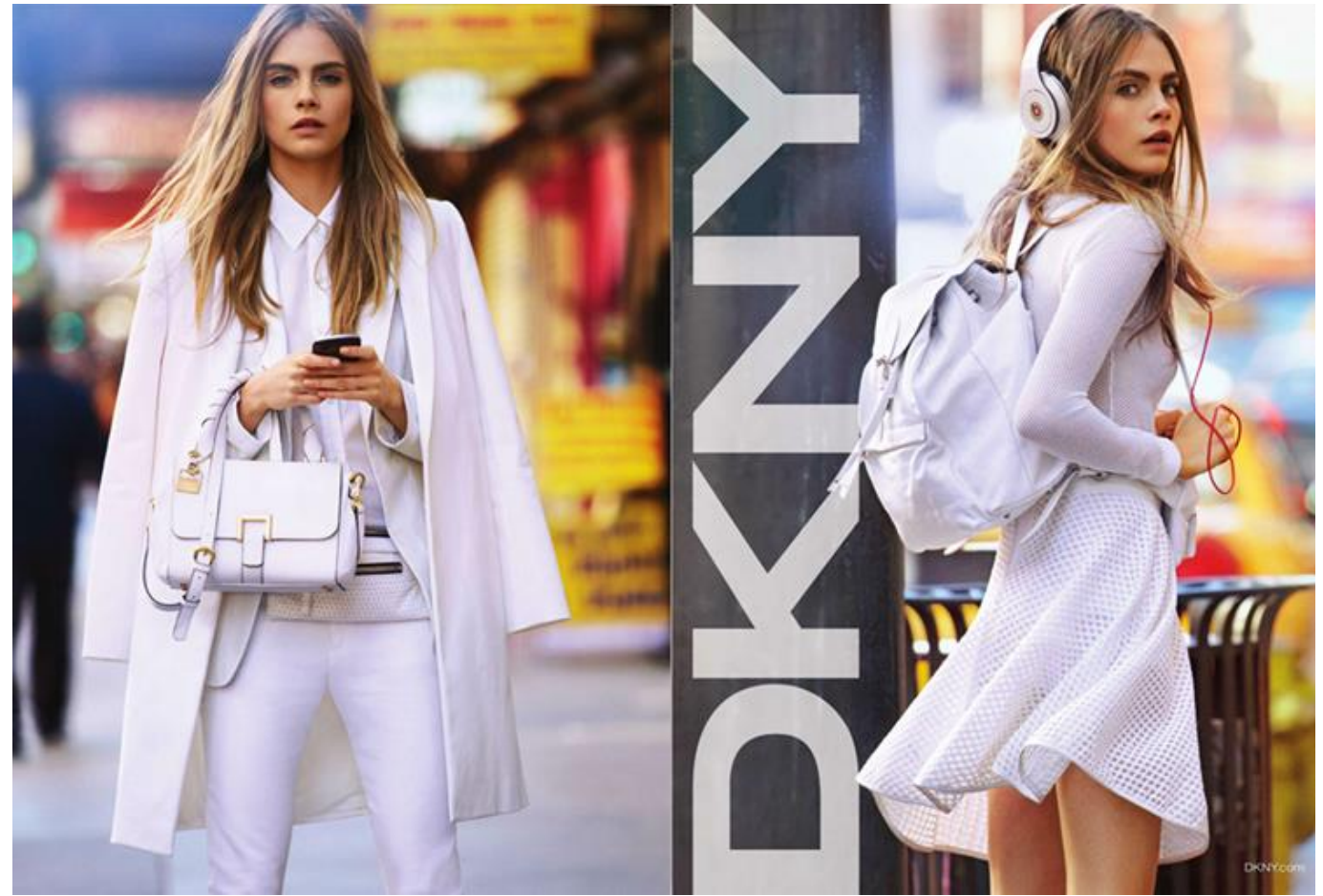

Figure 72: DKNY Advertisement from Vogue 203.2 (Feb 1, 2013): 30, 31.

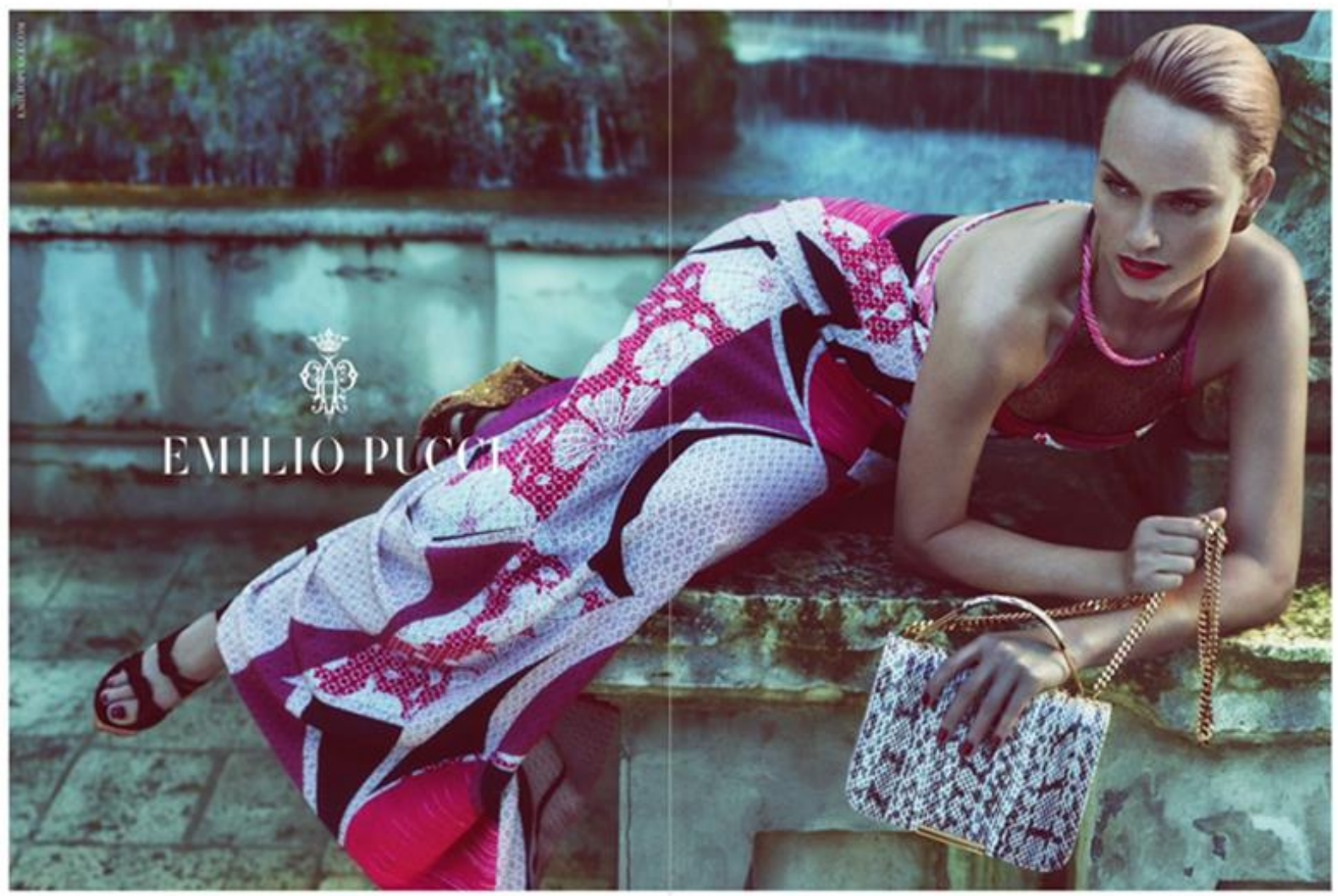

Figure 73: Emilio Pucci Advertisement from Vogue 203.3 (Mar 1, 2013): 272, 273. 


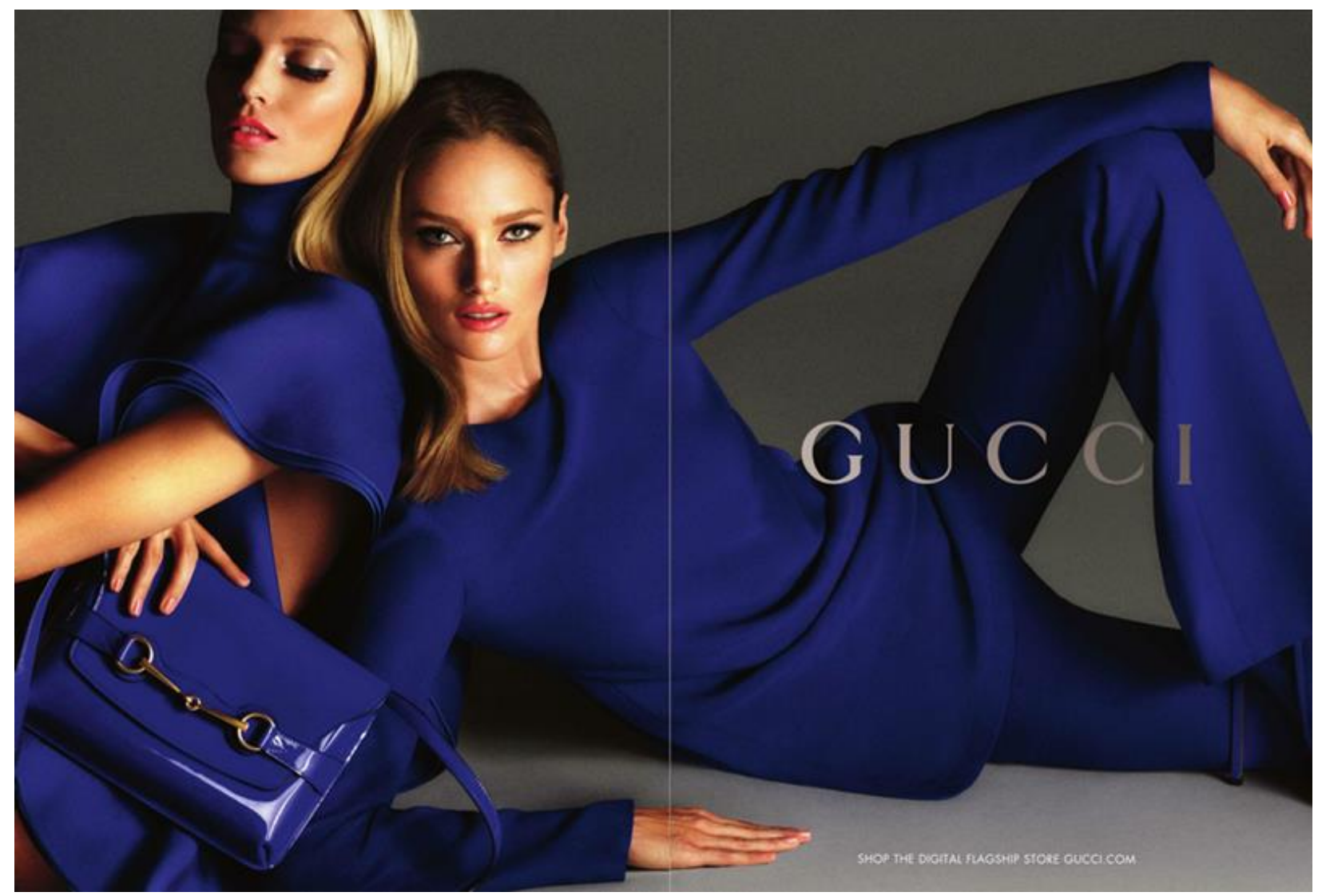

Figure 74: Gucci Advertisement from Vogue 203.2 (Feb 1, 2013): 8, 9. 
Appendix 26: THIRD CATEGORY: THE OVERALL APPEARANCE OF THE DIGITAL CONTENT: EXAMPLES OF DIGITAL CONTENT ON PRINT ADVERTISEMENTS 2013

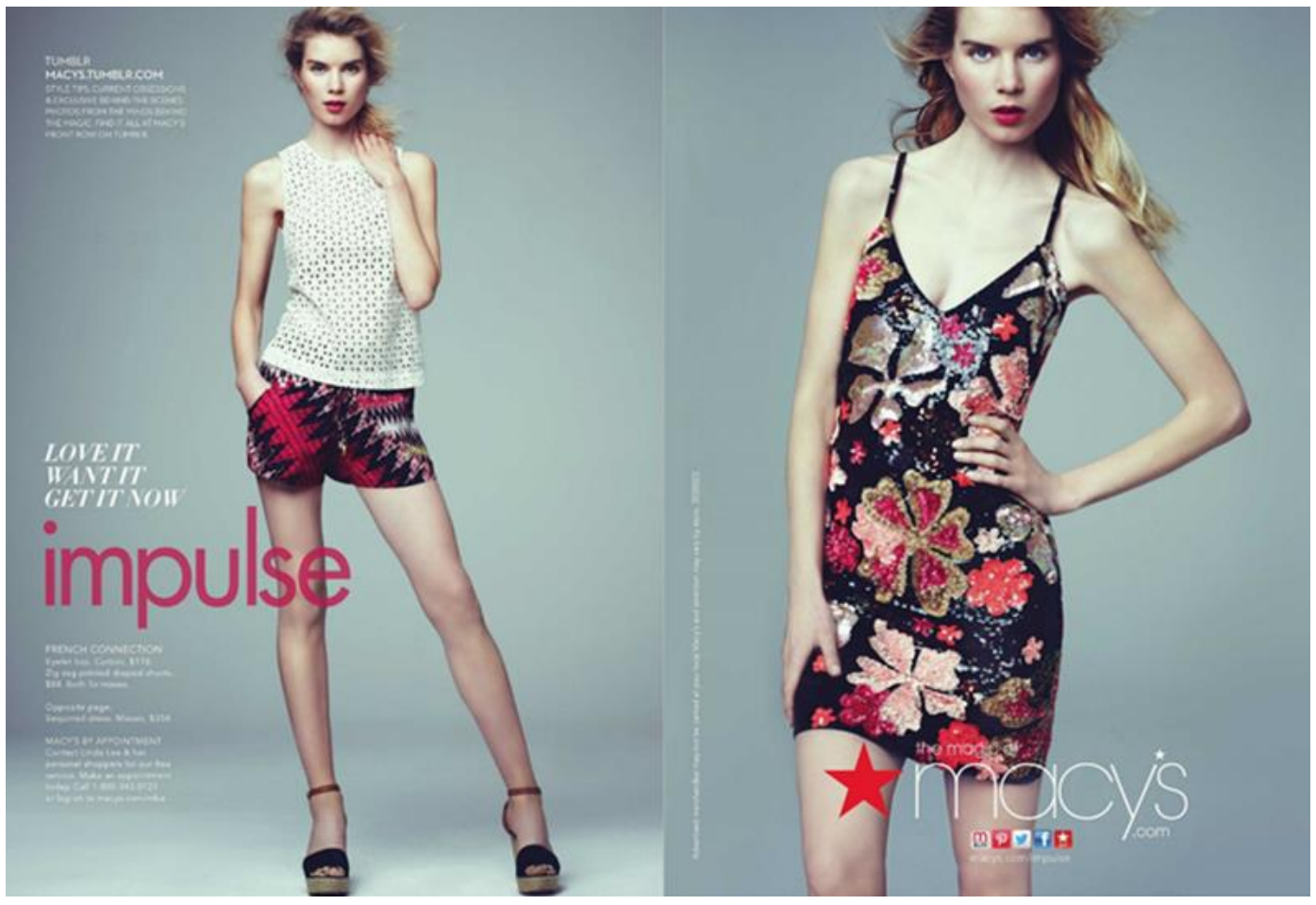

Figure 75: Macy's Advertisement from Vogue 203.5 (May 1, 2013): 50, 51.
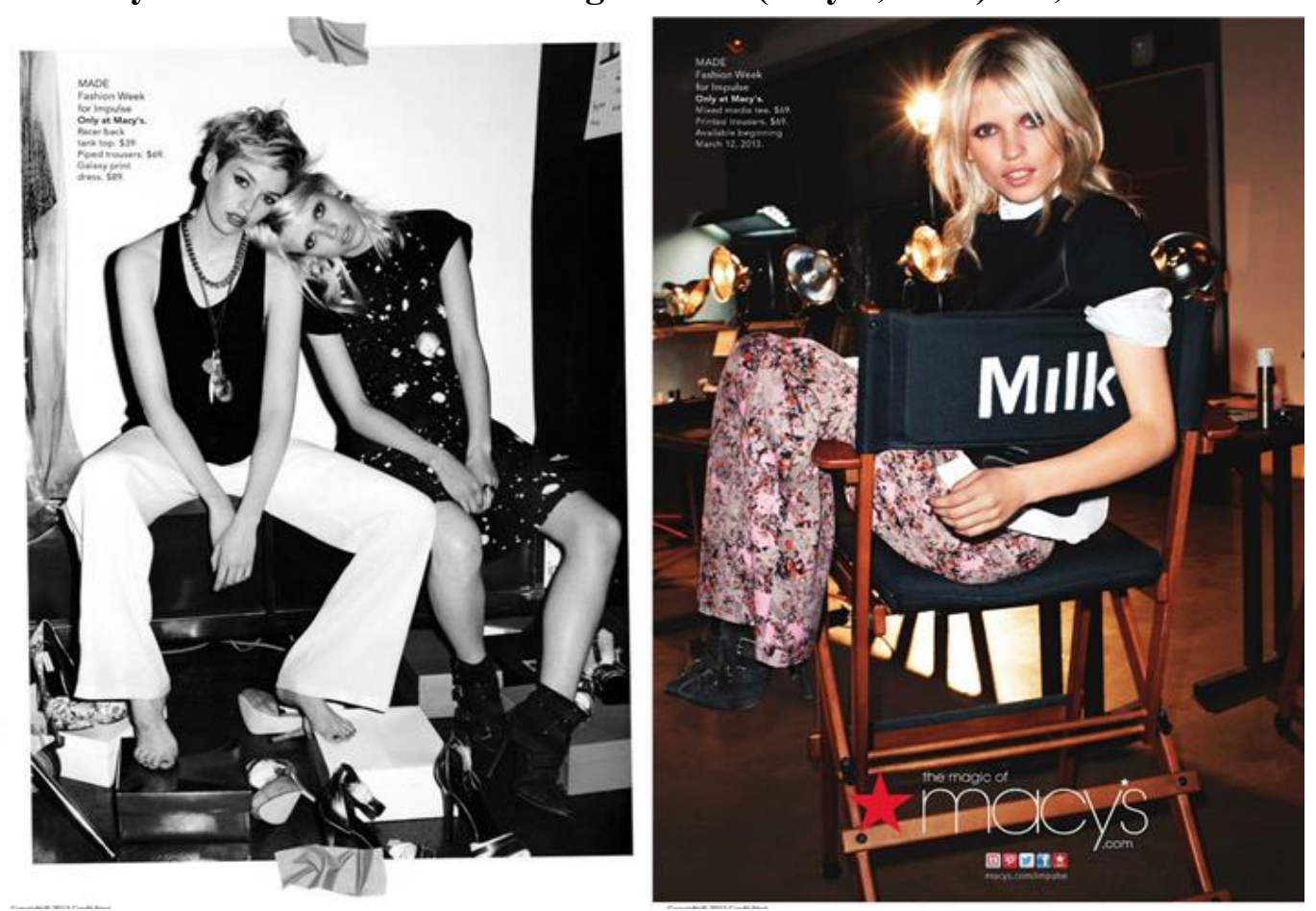

Figure 76: Macy's Advertisement from Vogue 203.3 (Mar 1, 2013): 154, 155. 


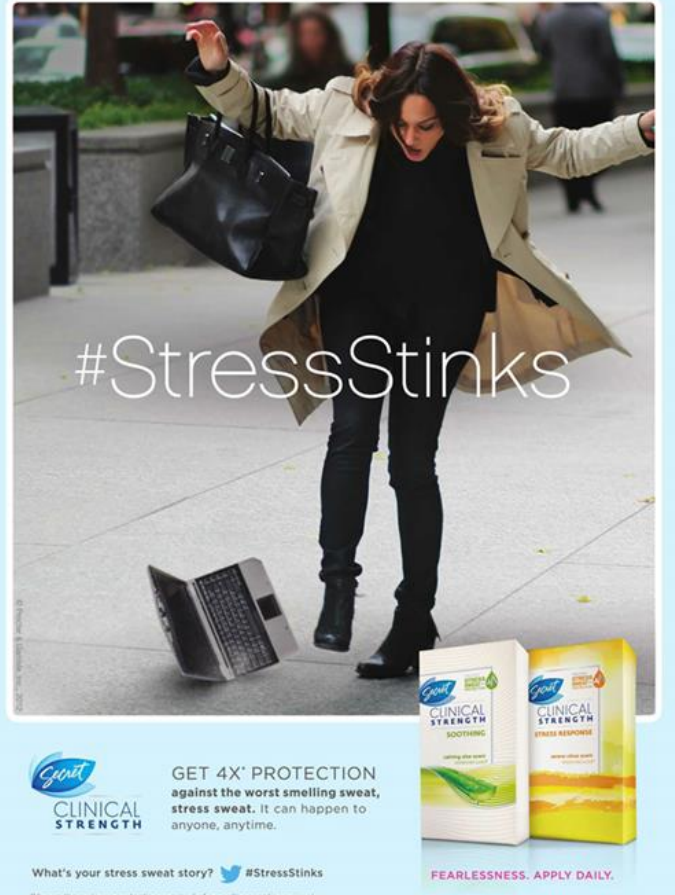

Figure 77: Secret Clinical Strength (Dove) Advertisement from Vogue 203.3 (Mar 1, 2013): 491.

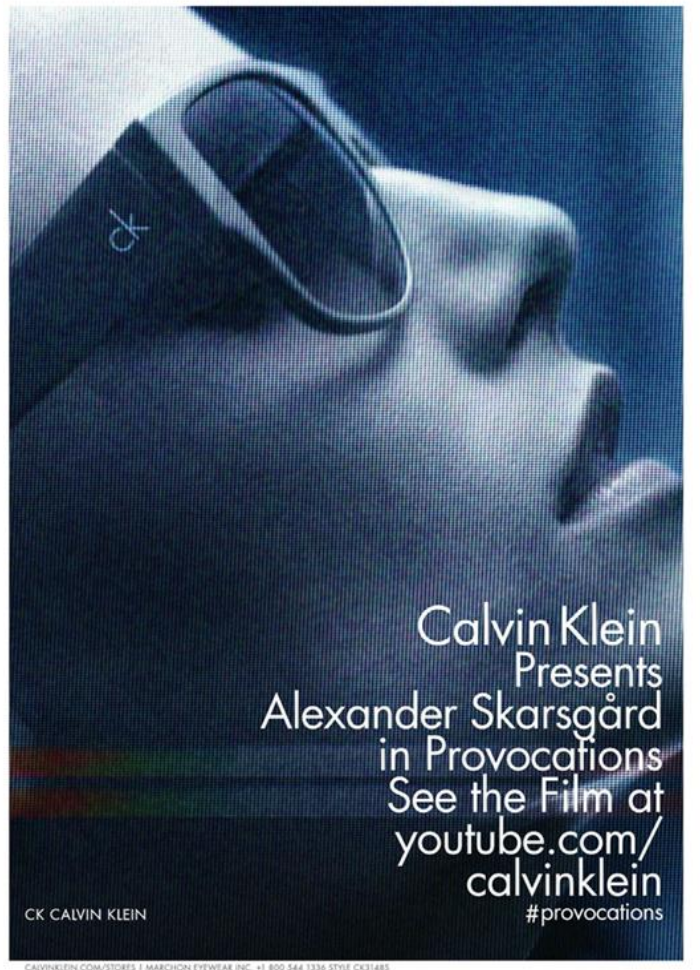

Figure 78: Calvin Klein Advertisement from Vogue 203.5 (May 1, 2013): 53.

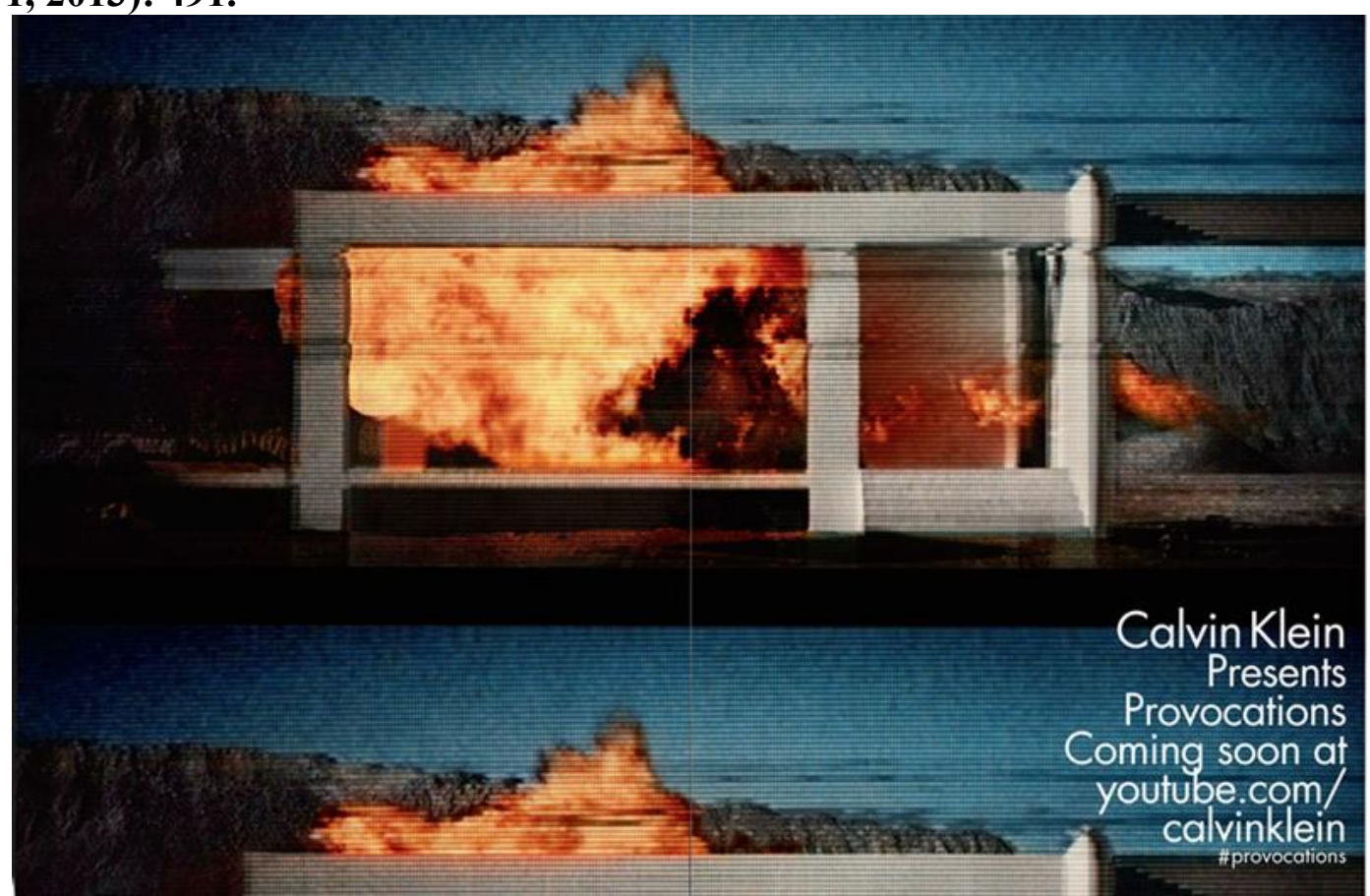

Figure 79: Calvin Klein Advertisement from Vogue 203.2 (Feb 1, 2013): 6, 7. 


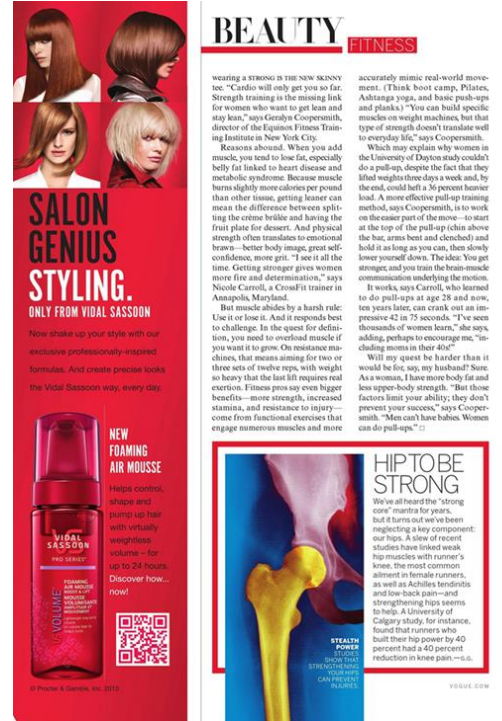

Figure 80: Vidal Sassoon, Inc. Ad from Vogue 203.3 (Mar 1, 2013): 48

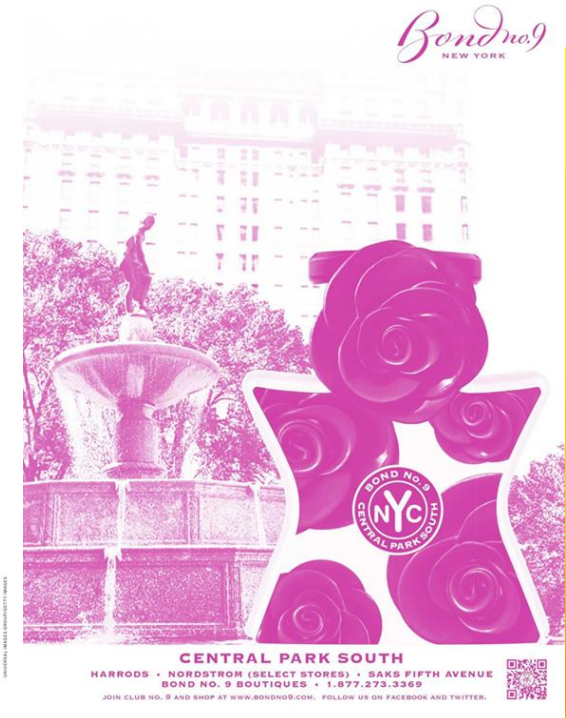

Figure 81: Bond No.9 Ad from Figure 82: Skechers Ad from Vogue . Vogue 203.4 (Apr 1, 2013): 231. 203.4 (Apr 1, 2013): 233.

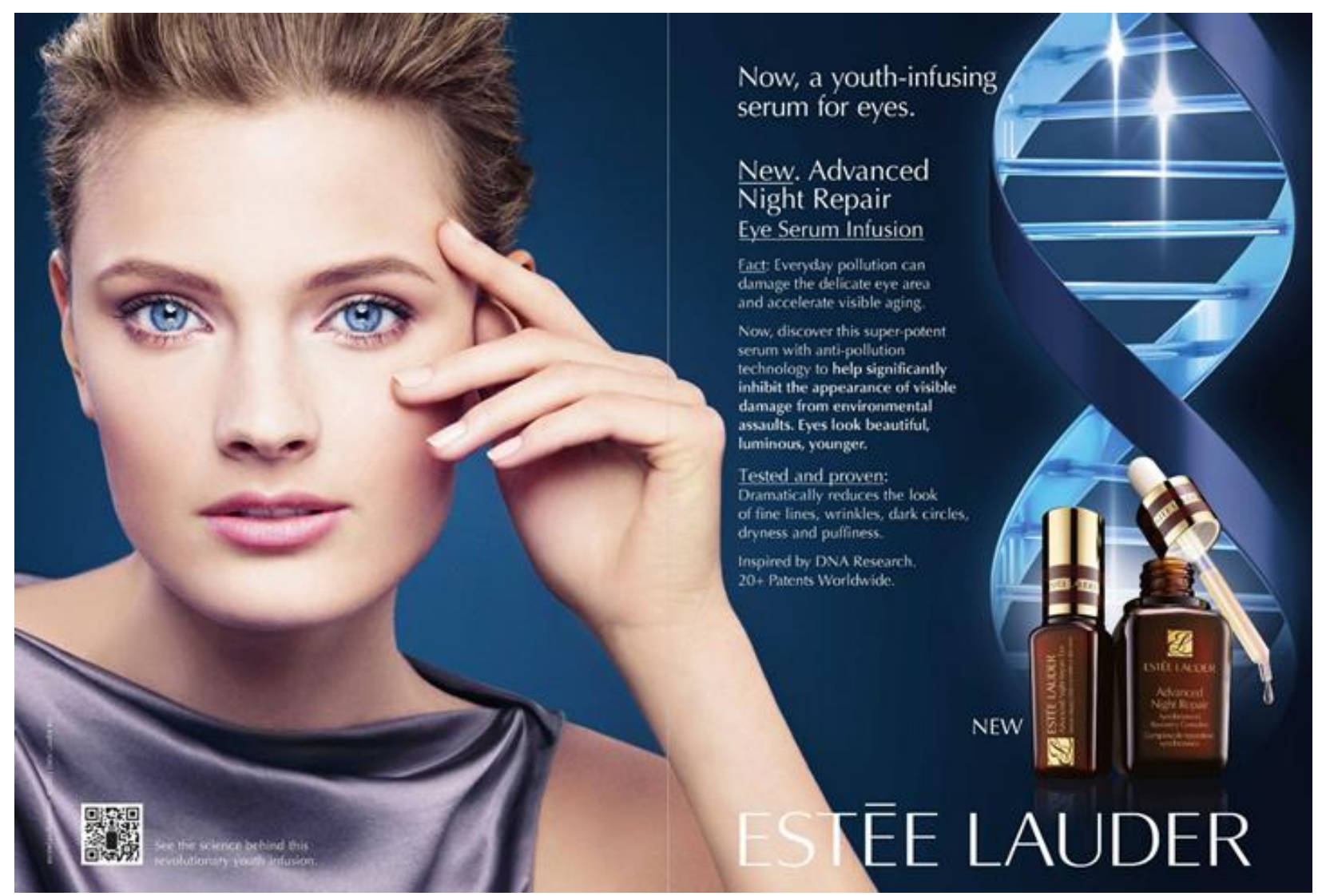

Figure 83: Estée Lauder, Inc. Advertisement from Vogue203.3 (Mar 1, 2013): 10, 11. 


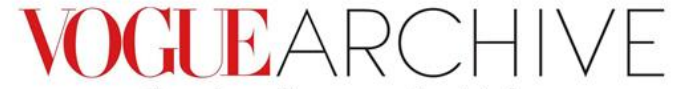

Every issue. Every page. $189^{2}$ to today.

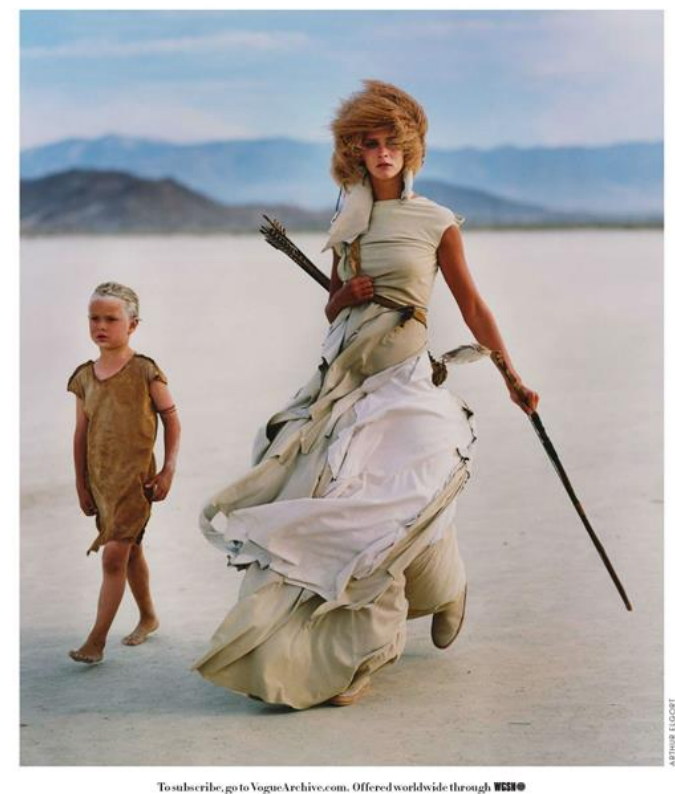

Figure 84: Vogue Archive (Condé Nast Publications Inc.) Advertisement from Vogue 203.2 (Feb 1, 2013): 63.

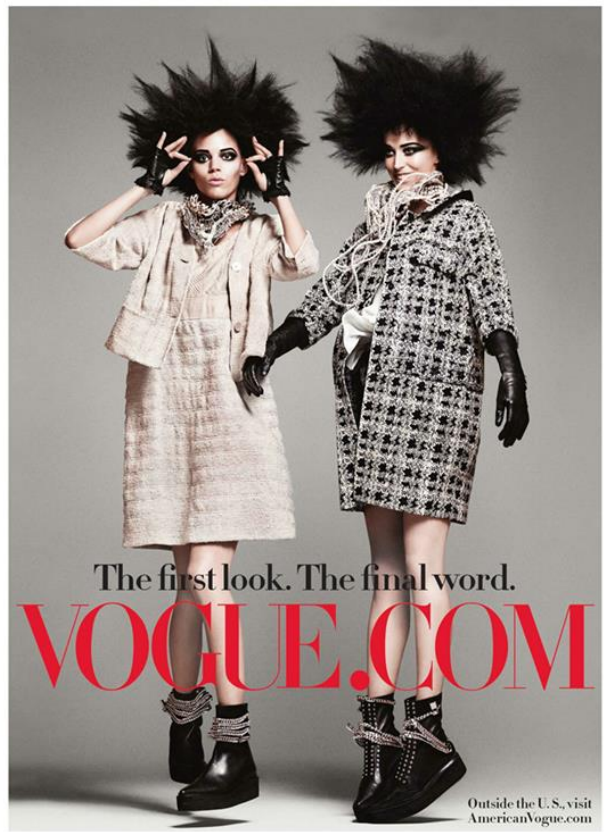

Figure 86: Vogue.com (Vogue) Ad from Vogue 203.5 (May 1, 2013):143

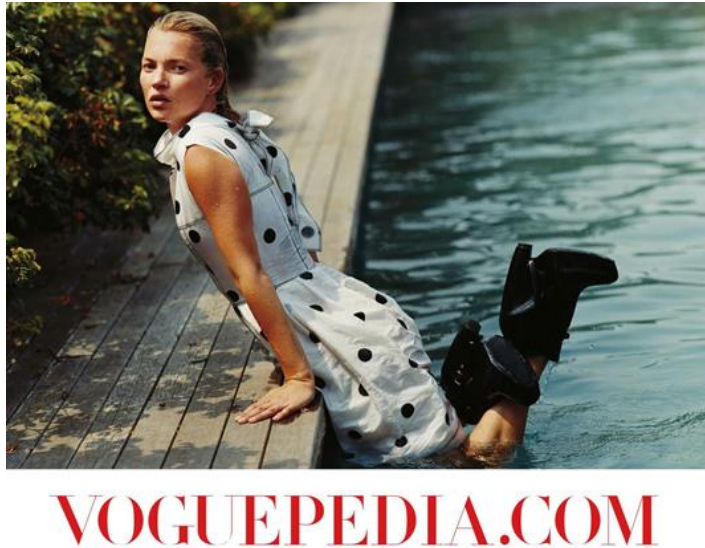

The World of Fashion in Vogue

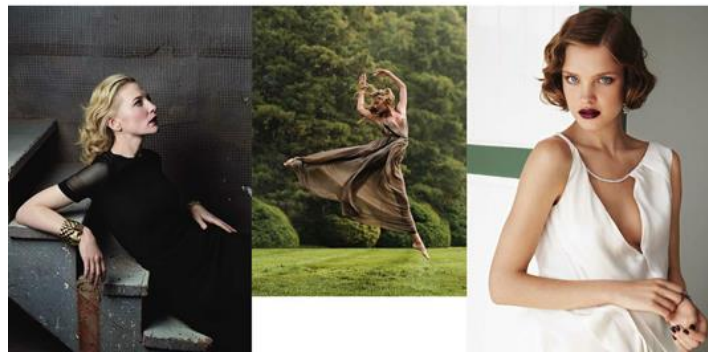

Figure 85: Voguepedia.Com (Vogue) Ad from Vogue 203.2 (Feb 1, 2013): 105.

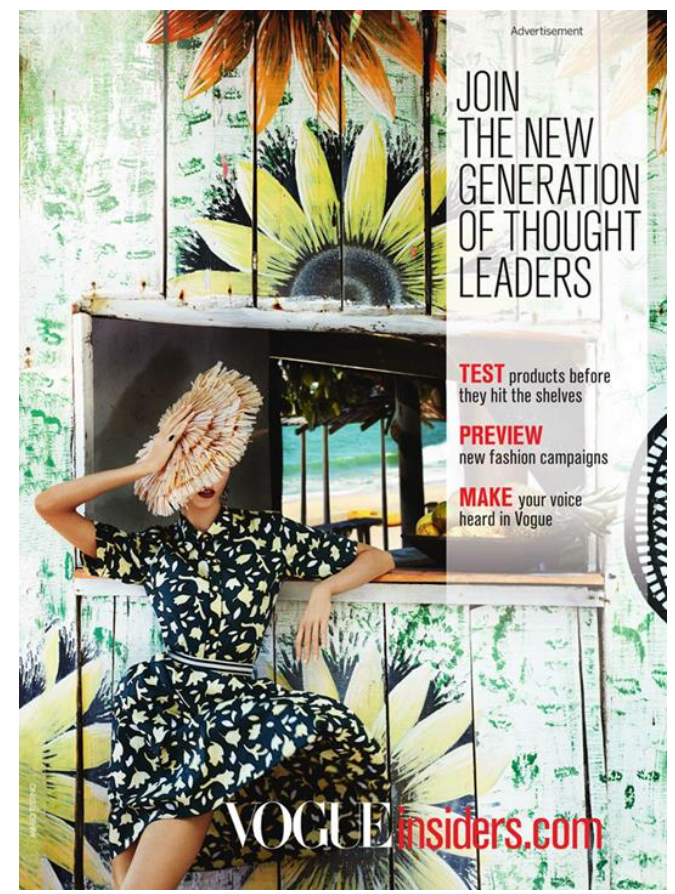

Figure 87: Vogueinsiders.com (Vogue) Ad from Vogue 203.3 (Mar 1, 2013): 249. 


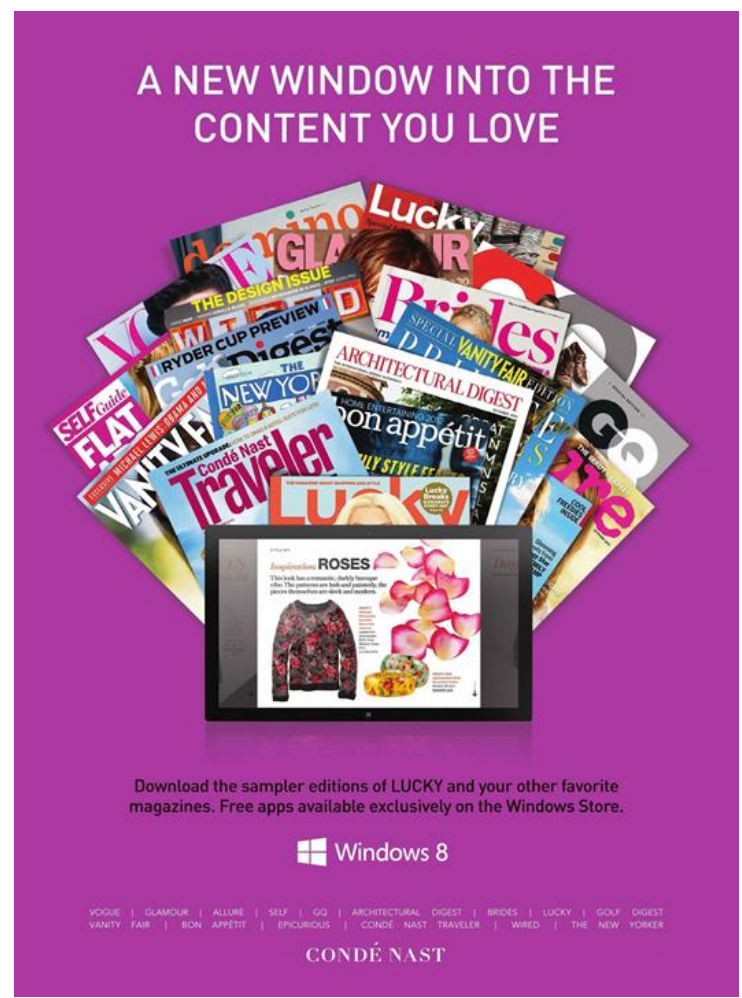

Figure 88: Windows Store Apps (Condé Nast Publications inc.) Ad from Vogue 203.1 (Jan 1, 2013): 49.

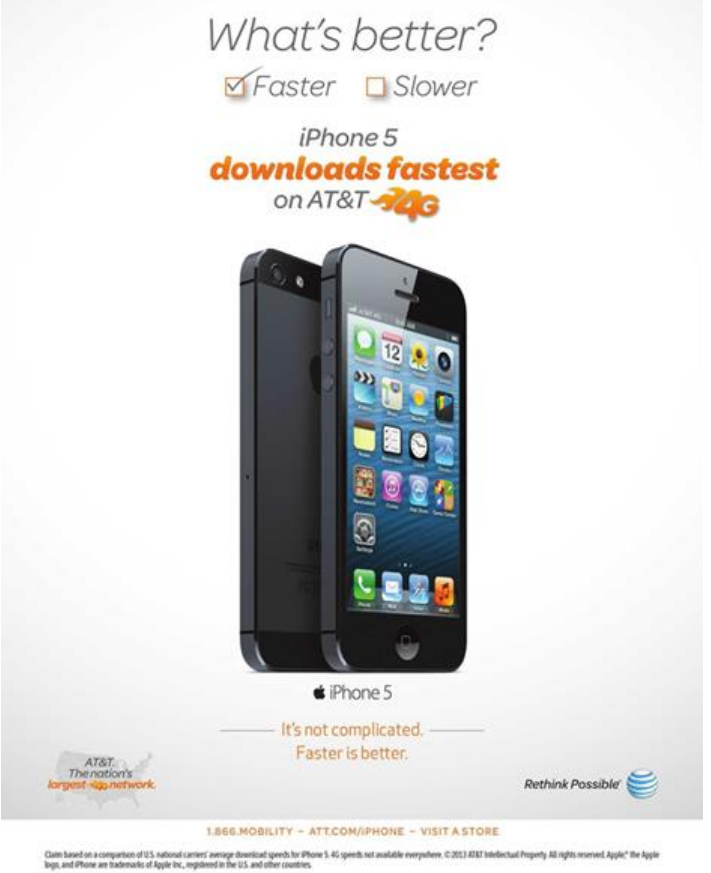

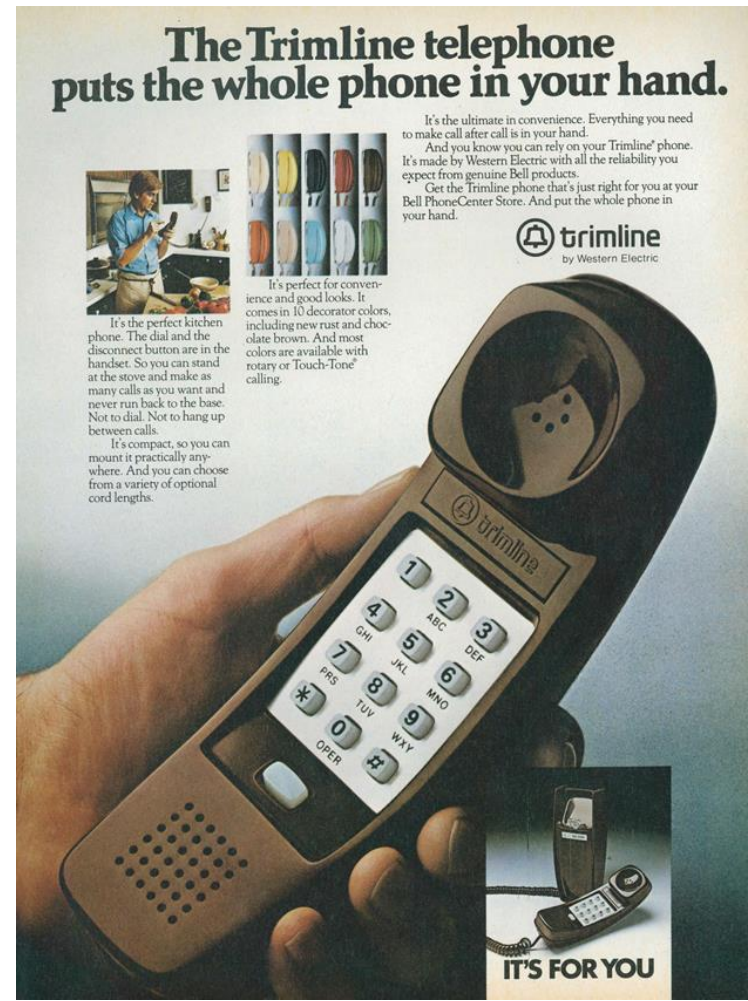

Figure 89: Telephone (Trimeline) Ad. from Vogue 170.6 (Jun 1, 1980): 139.

Figure 90: iPhone 5 Advertisement from Vogue 203.4 (Apr 1, 2013): 245. 


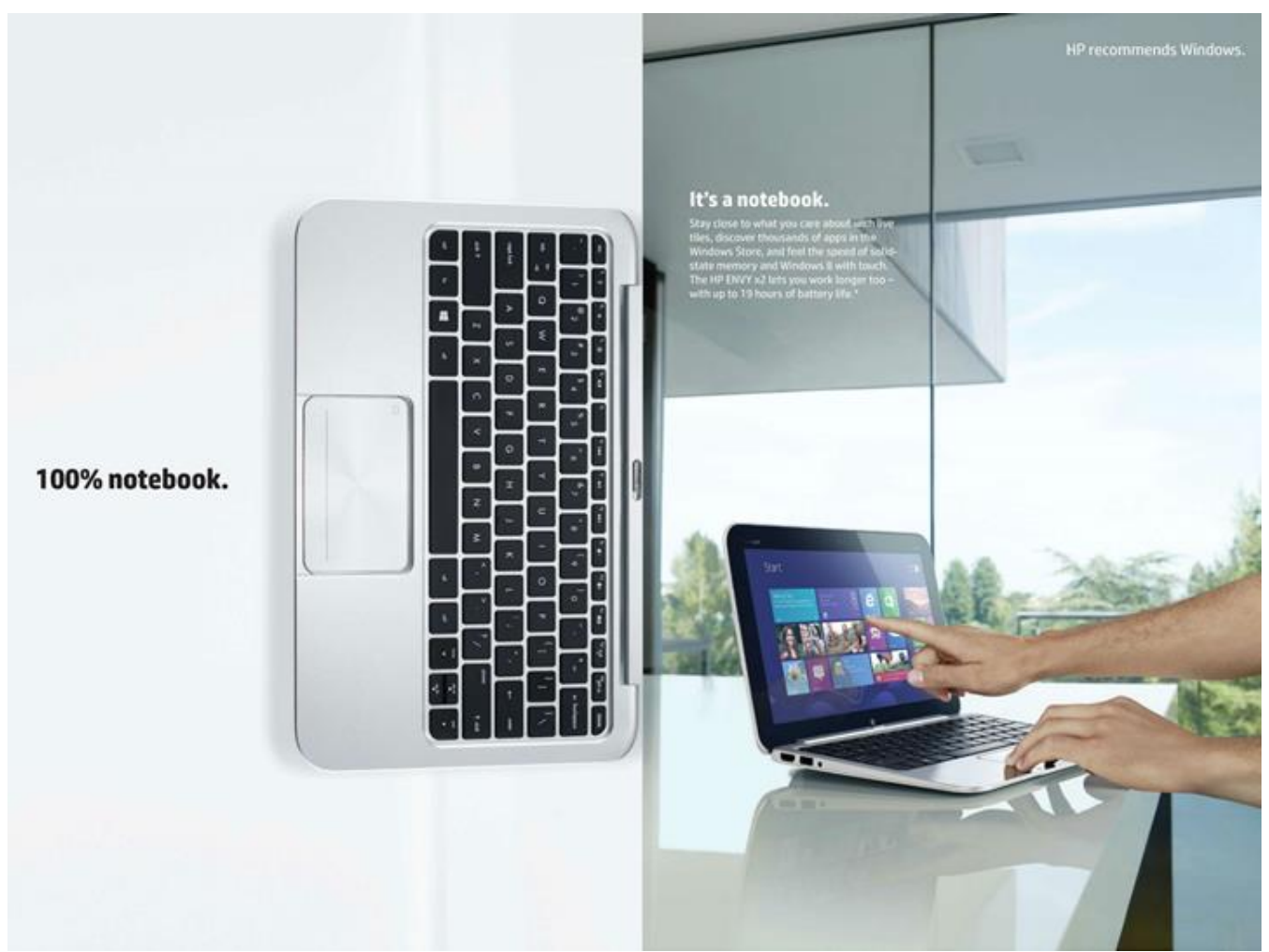

Figure 91: HP Envy x 2 (HP) Advertisements from Vogue 203.2 (Feb 1, 2013): 174, 175.

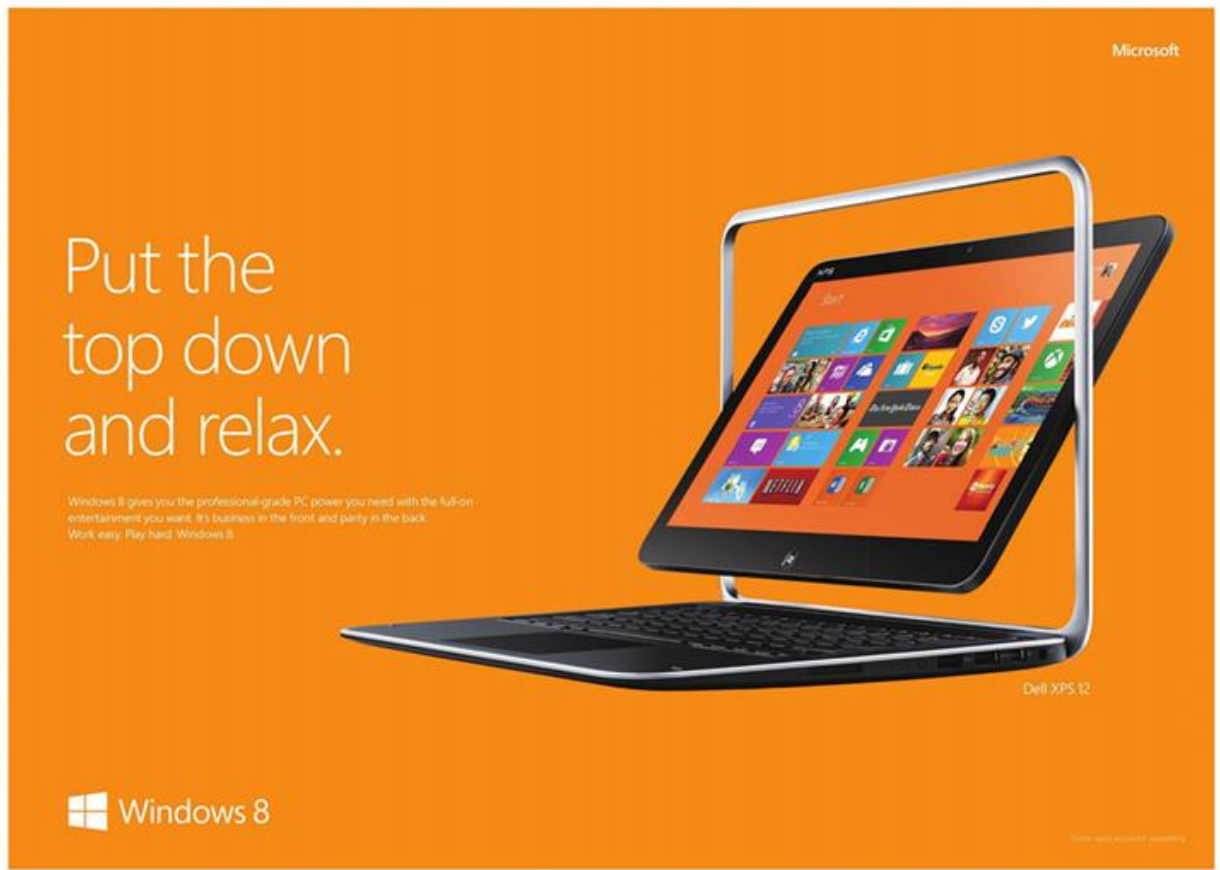

Figure 92: Windows 8 Advertisement from Vogue 203.6 (Jun 1, 2013): 221. 


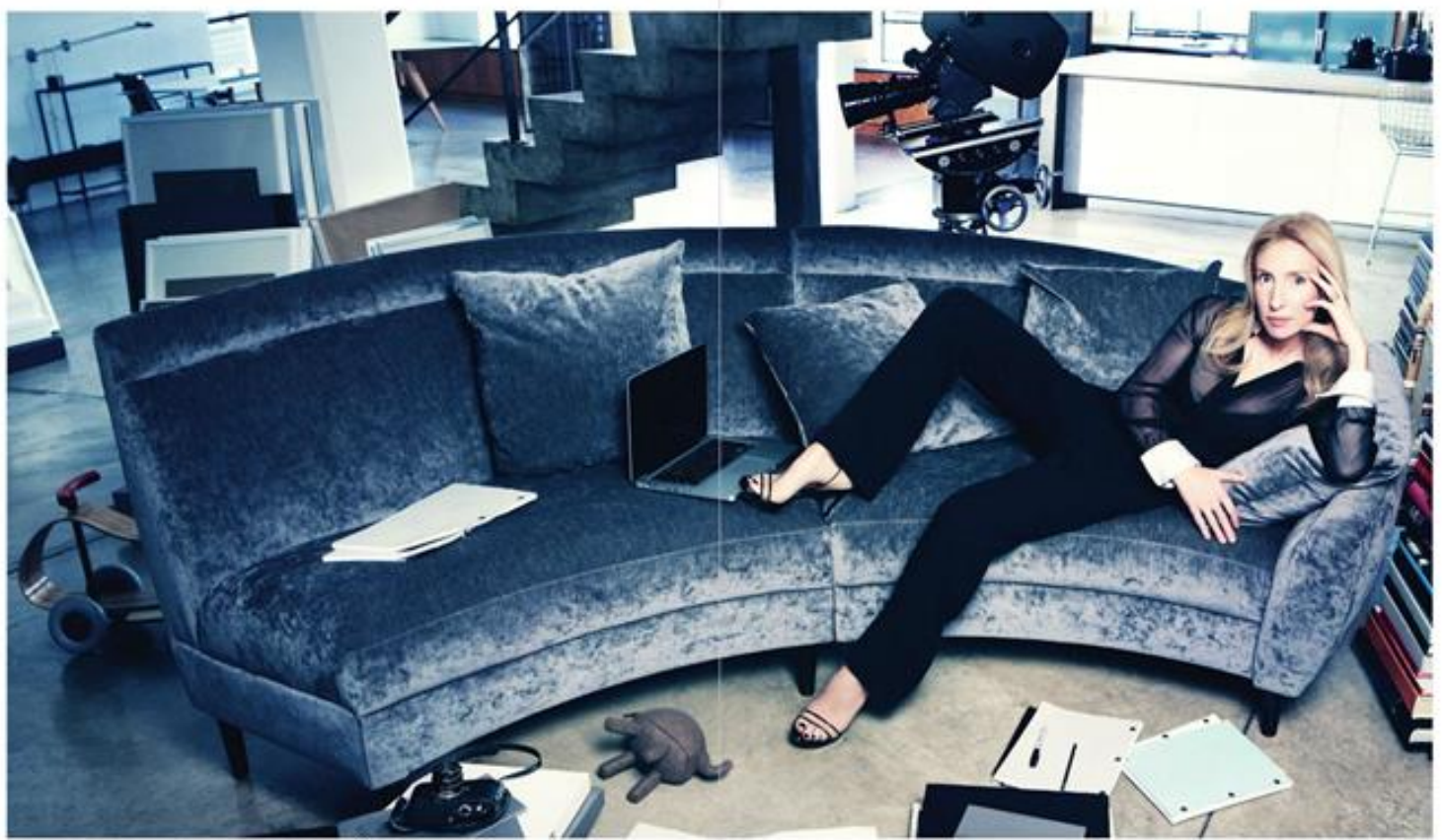

Sue TAYLOR-SOLXNoXX, artit \& flim maber

NET-A - PORTER.COM

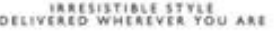

Figure 93: Net-A-Porter.Com Advertisement from Vogue 203.4 (Apr 1, 2013): 60, 61.

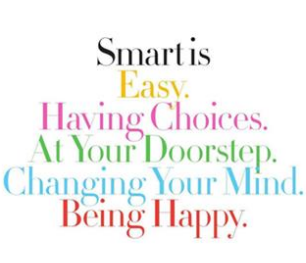

Amazon.com/Fashion

Smart is Beautiful.
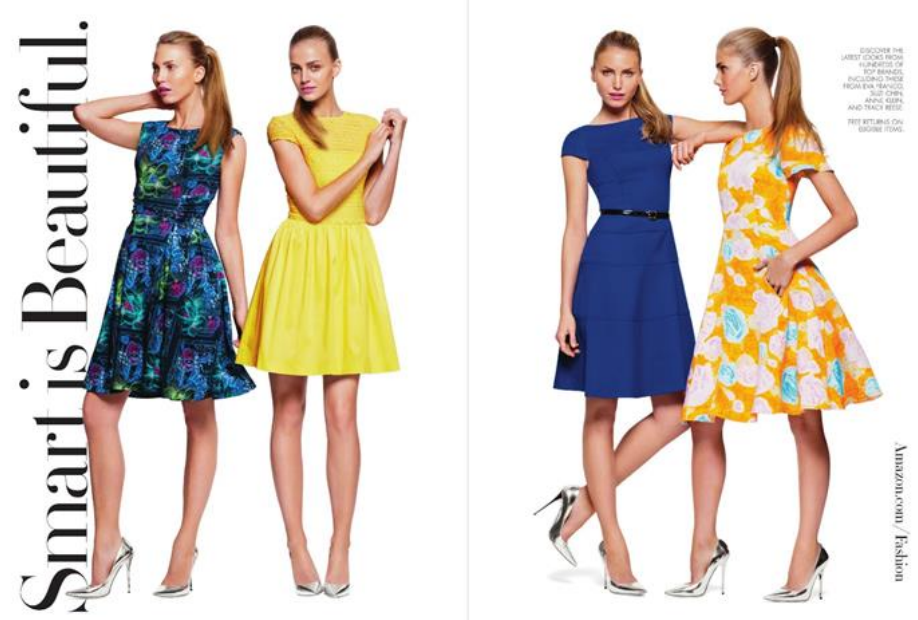

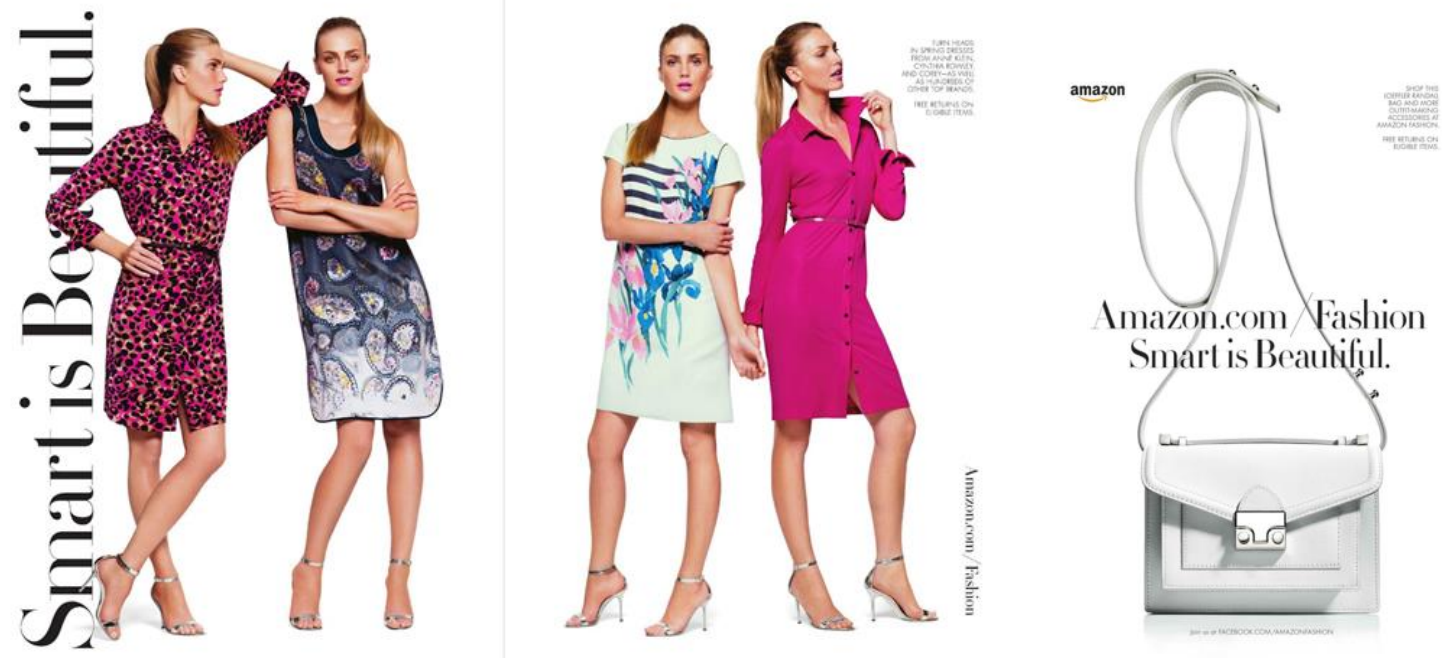

Smart is Beautiful.

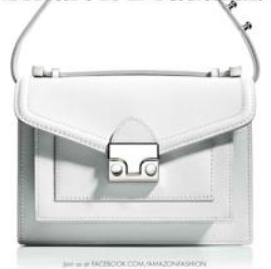

Figure 94: Amazon Advertisement from Vogue 203.4 (Apr 1, 2013): 119, 120, 121, 122, 123, 124.

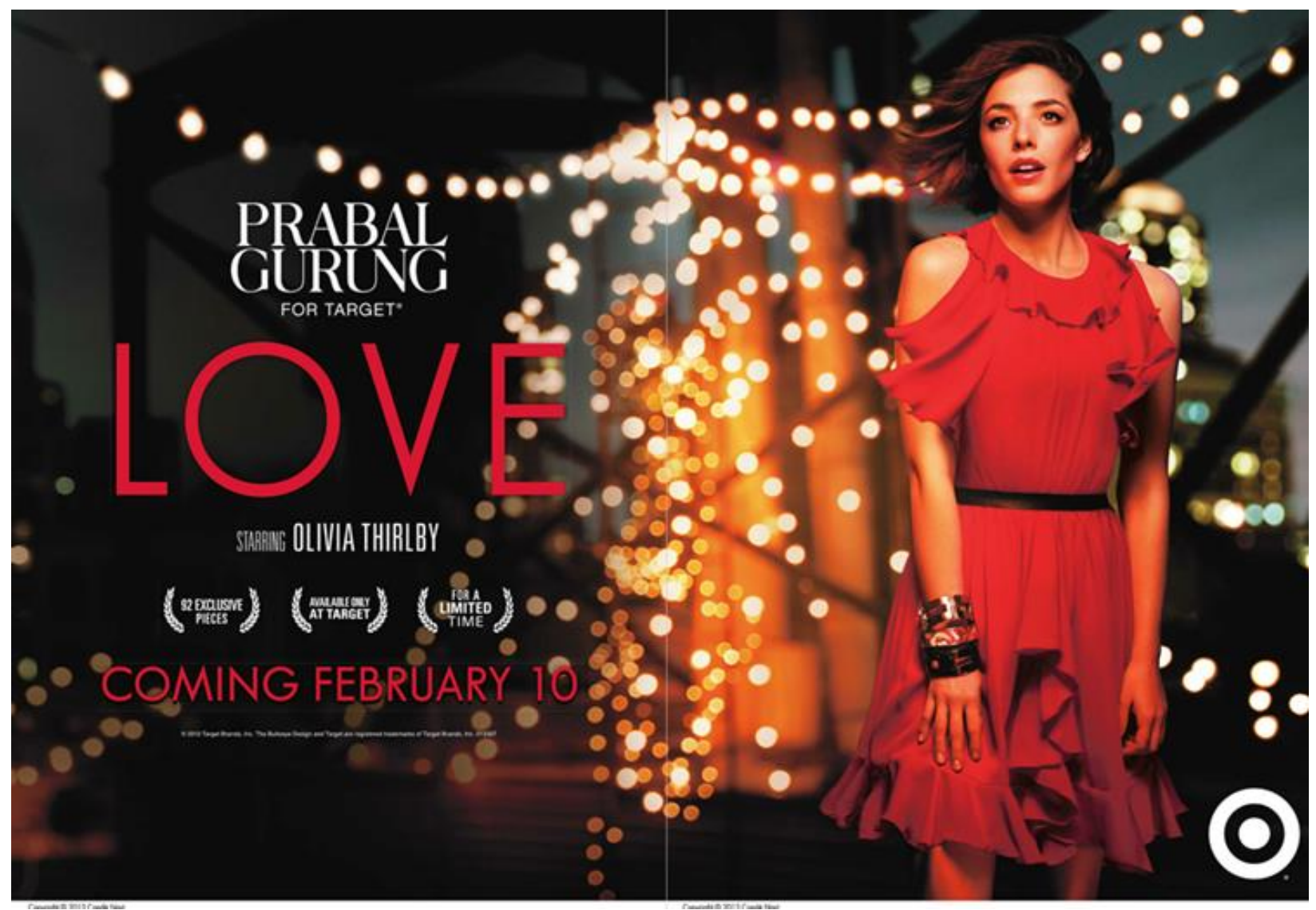

Figure 95: Prabal Gurung (Target Corporation) Advertisement from Vogue 203.2 (Feb 1, 2013): 46, 47. 


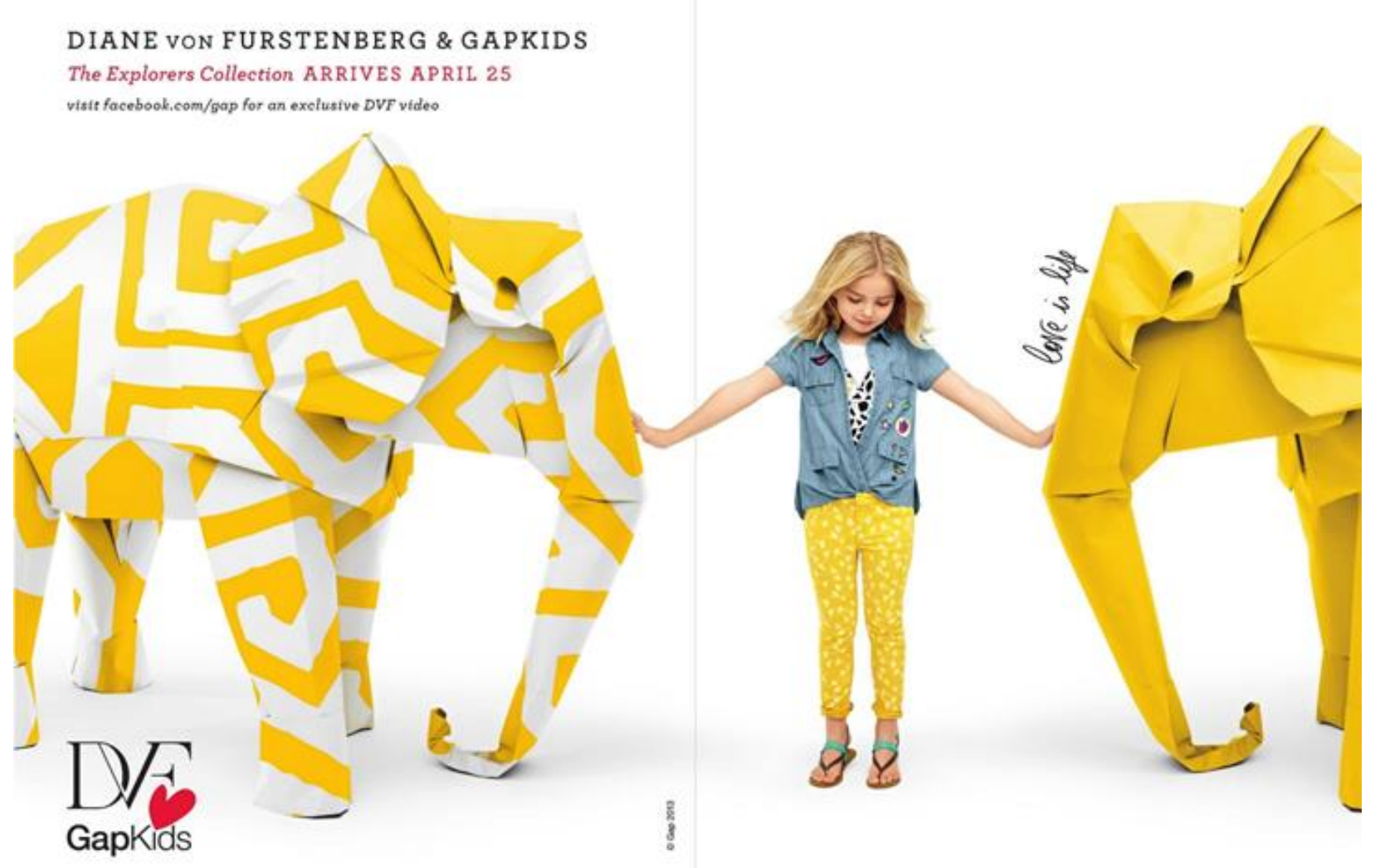

Figure 96: Gap Kids Advertisement from Vogue 203.5 (May 1, 2013): 18, 19. 


\section{Appendix 27: PHASE TWO: FIRST DIMENSION: BRAND IDENTITY}

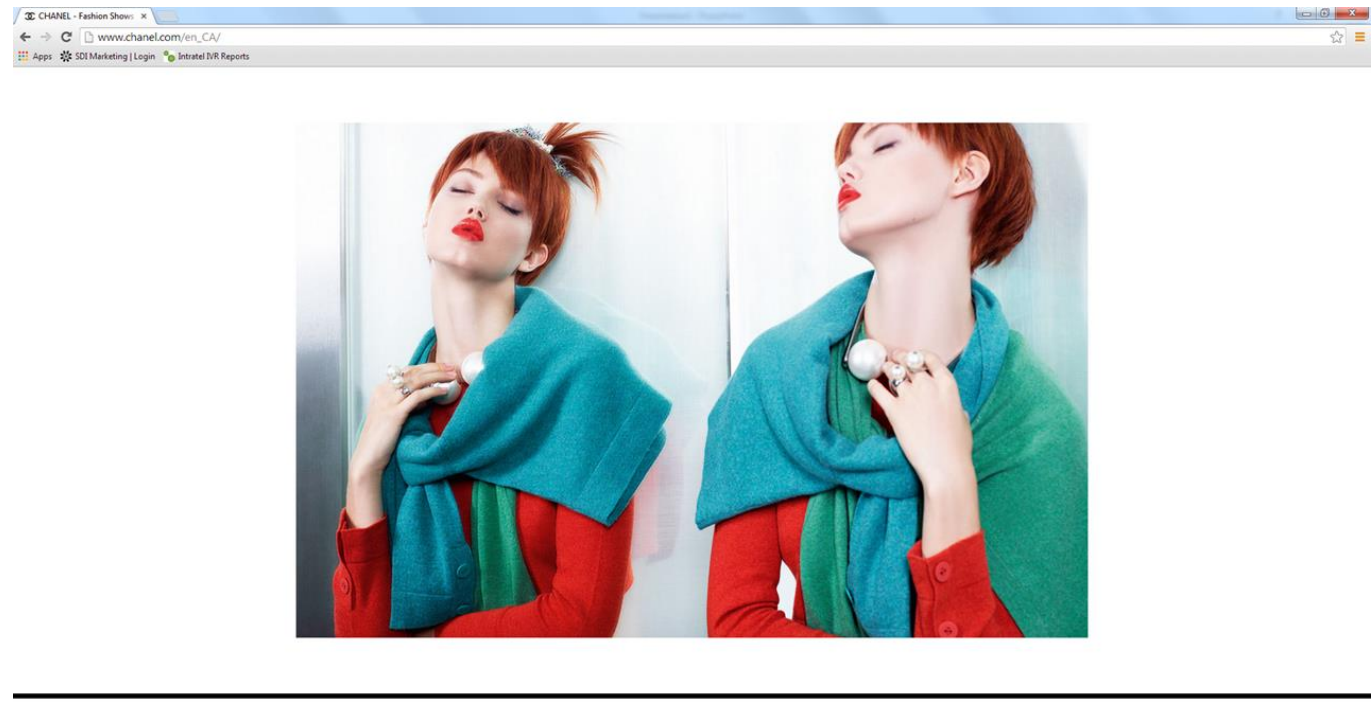

Figure 97 A: Chanel Official Website Home Page

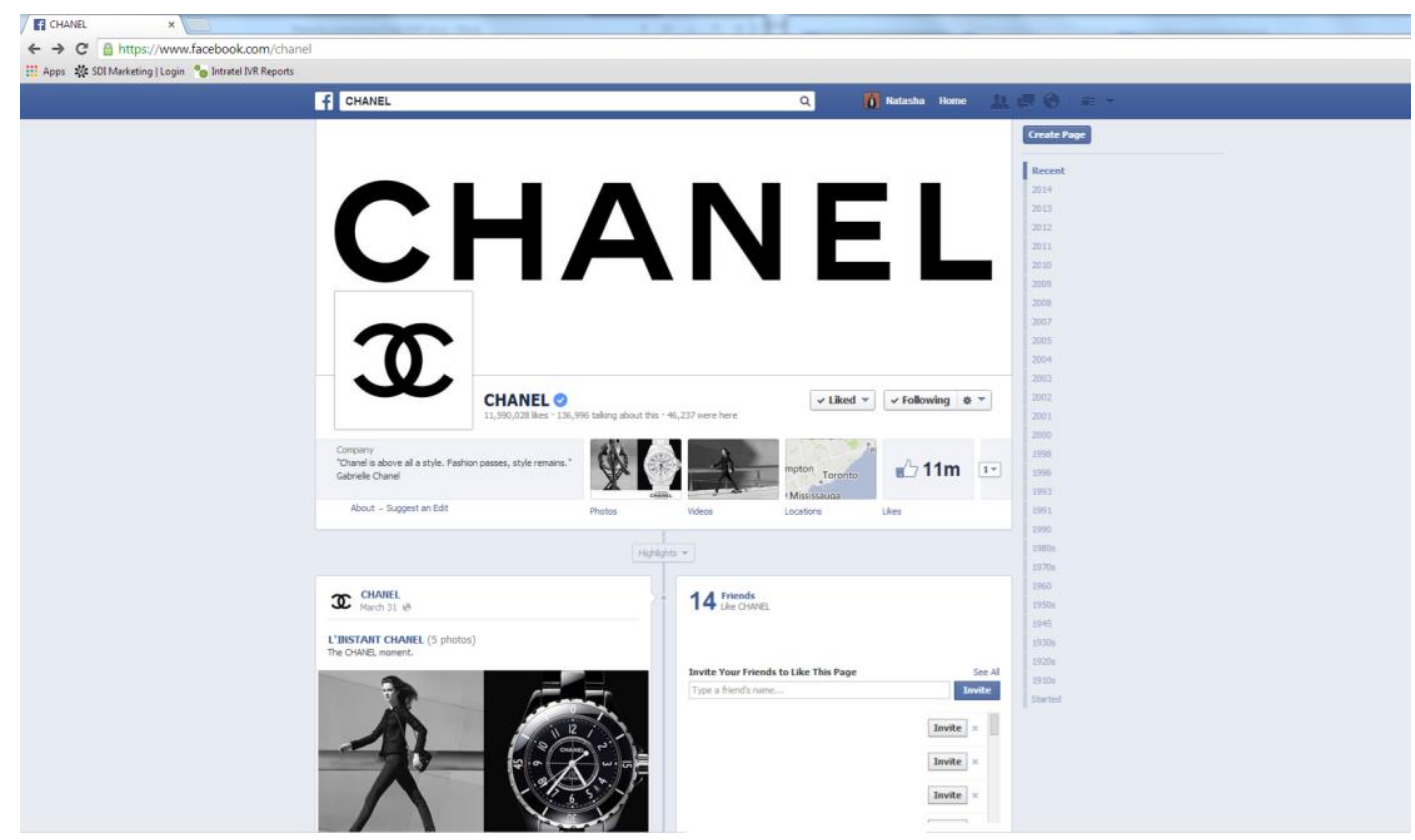

Figure 97 B: Chanel Official Facebook Page 


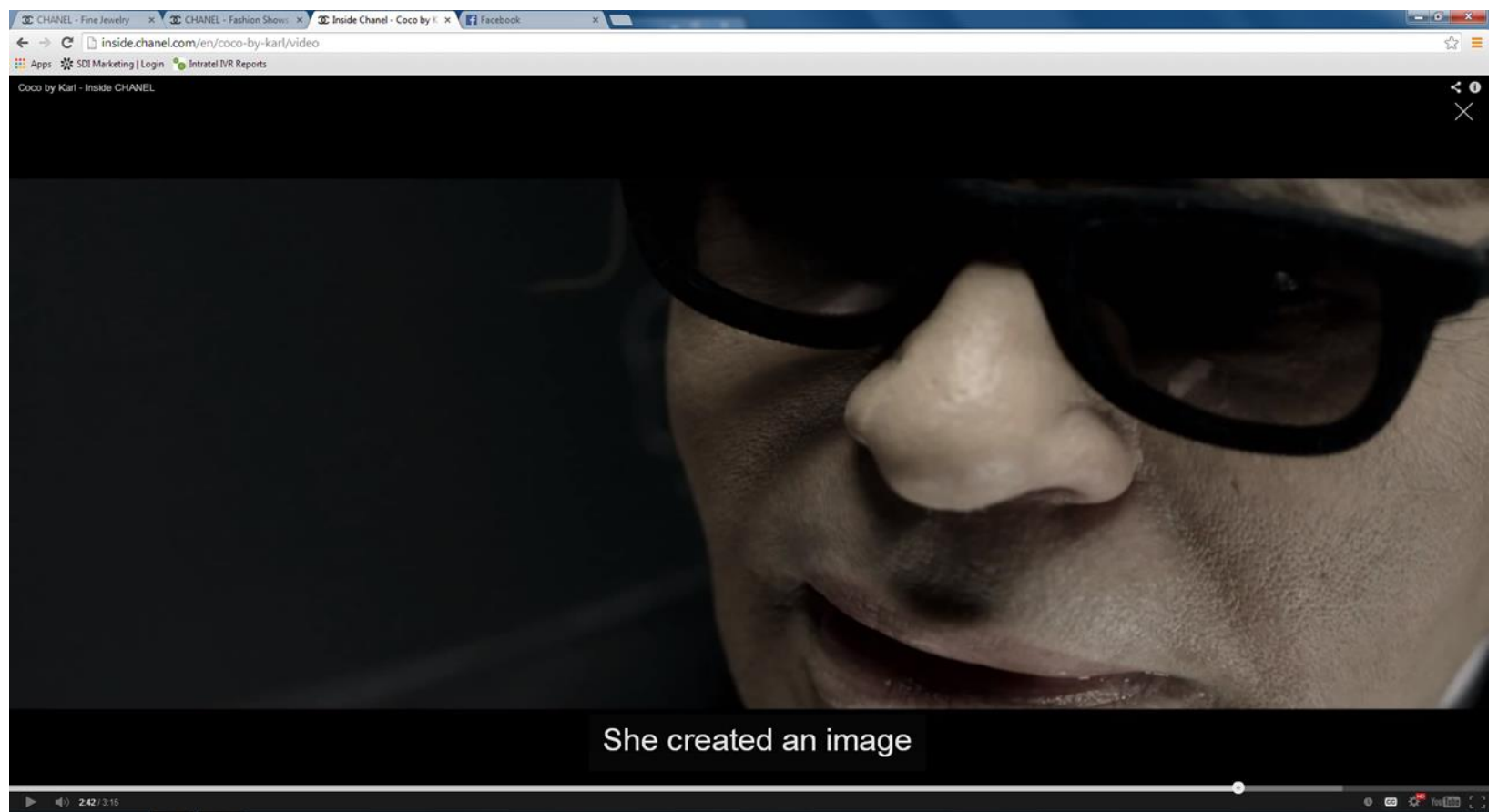

Figure 97 C: Inside Chanel Official Website- Karl Lagerfeld

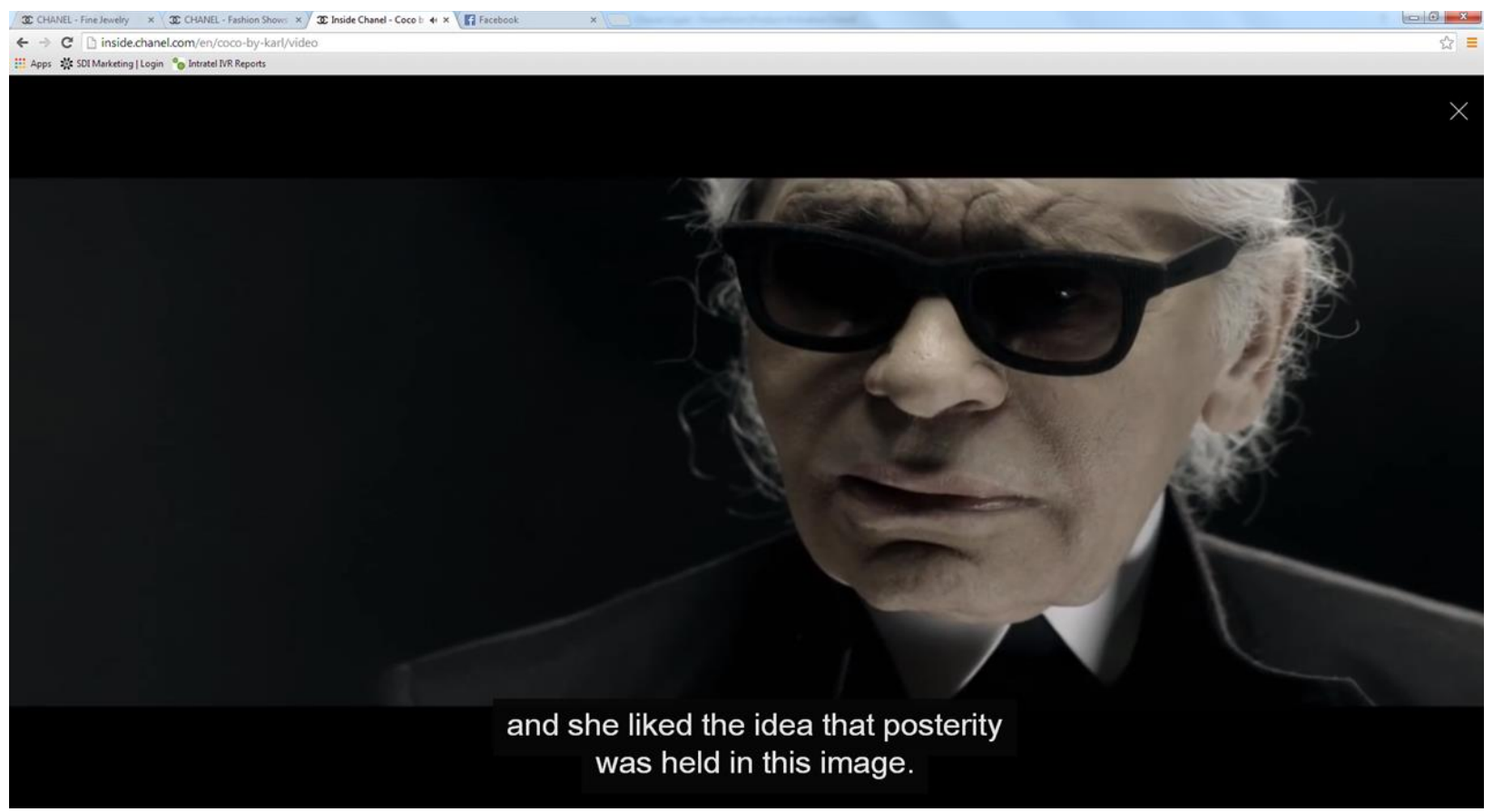

Figure 97 D: Inside Chanel Official Website- Karl Lagerfeld 


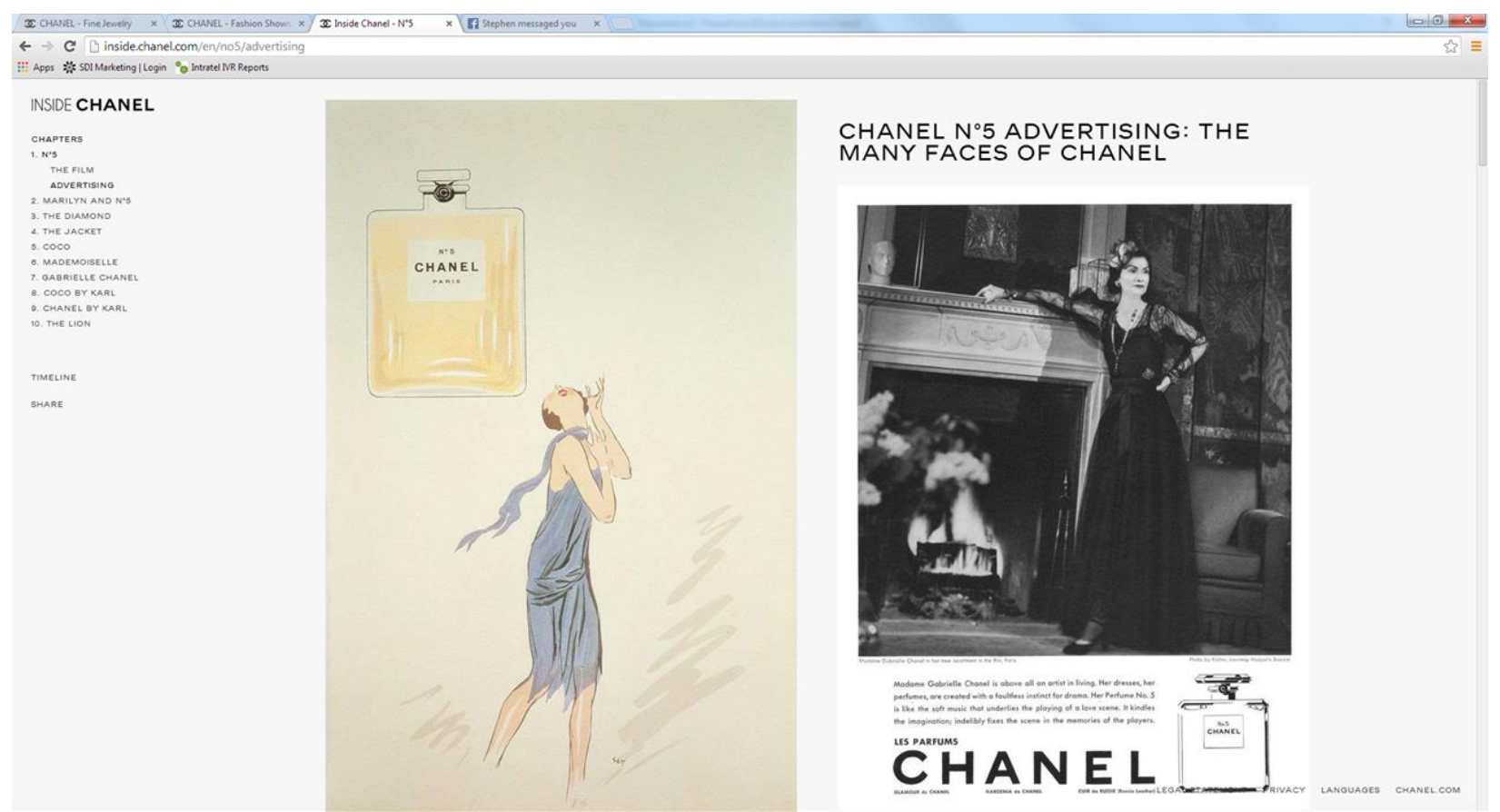

Figure 98 A: Inside Chanel Official Website

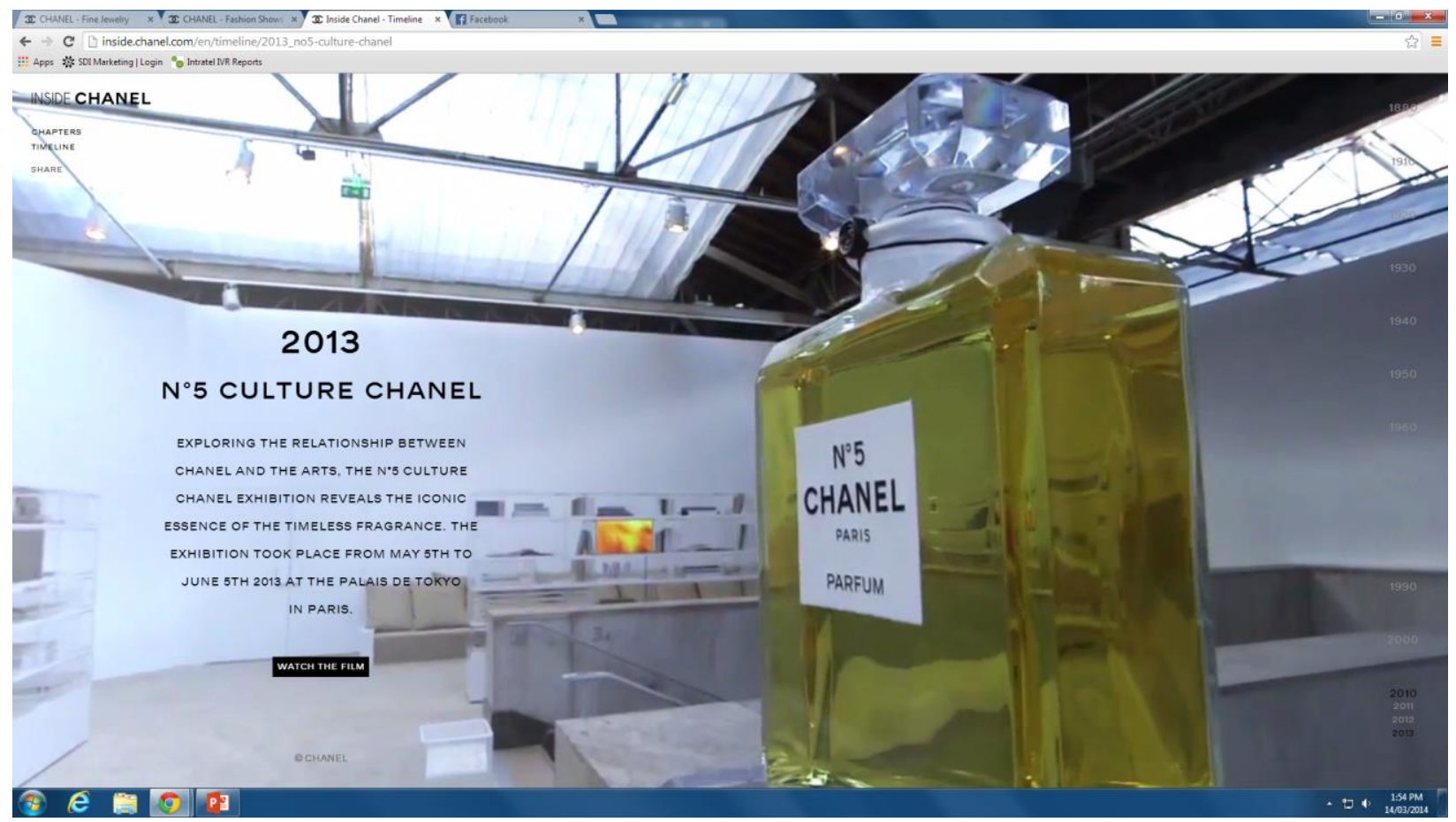

Figure 98 B: Inside Chanel Official Website 


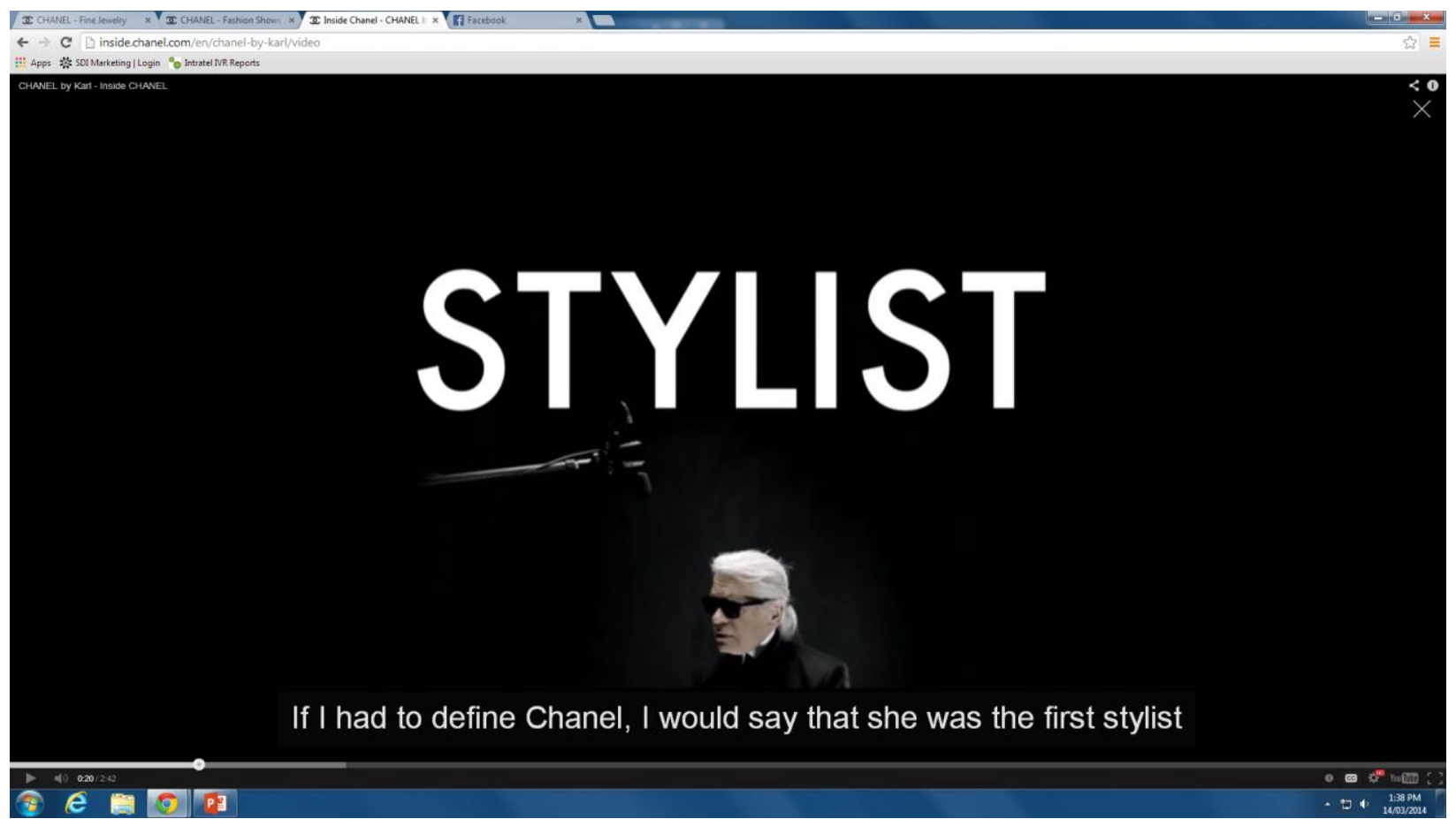

Figure 99 A: Inside Chanel Official Website

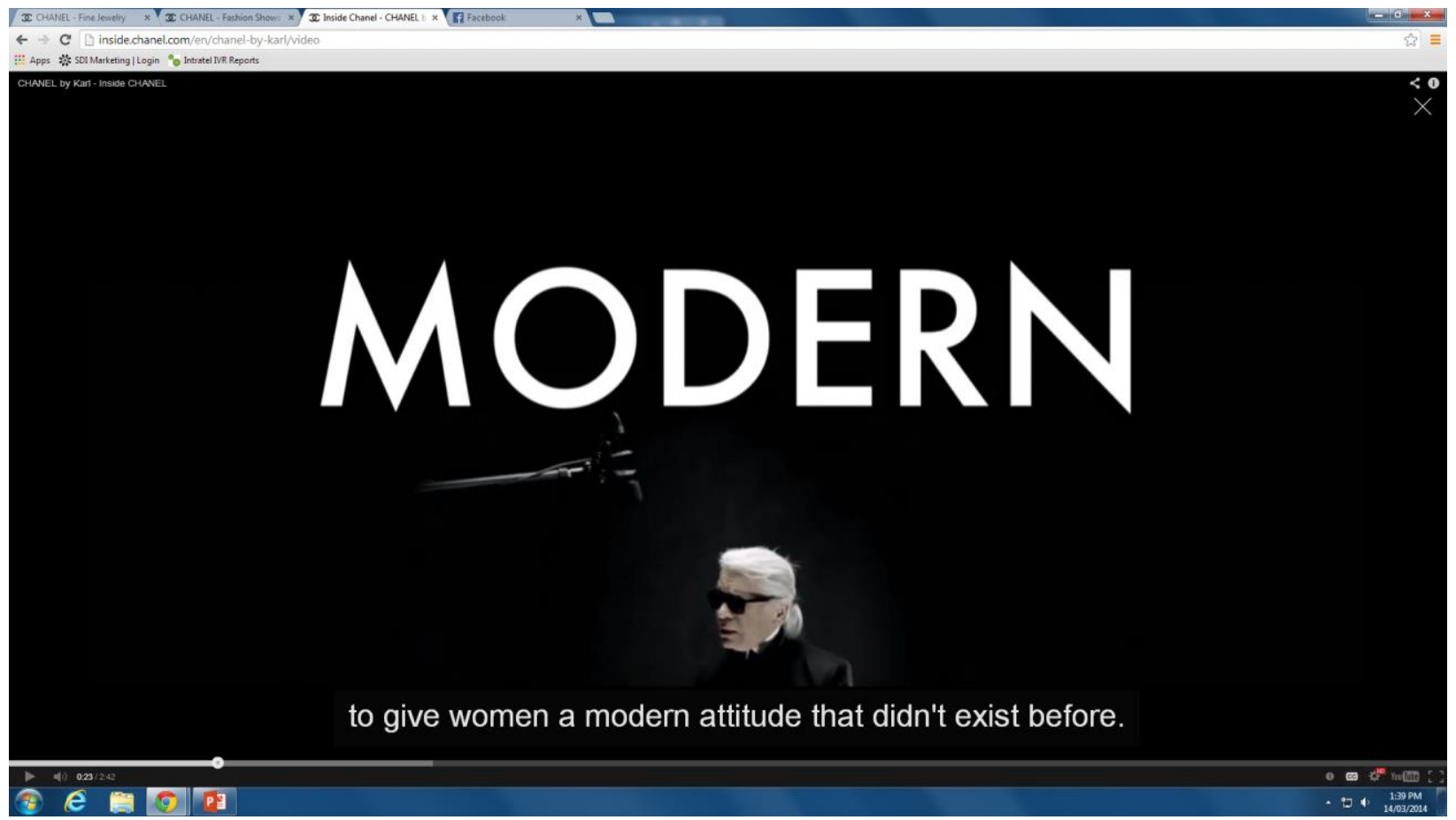

Figure 99 B: Inside Chanel Official Website 


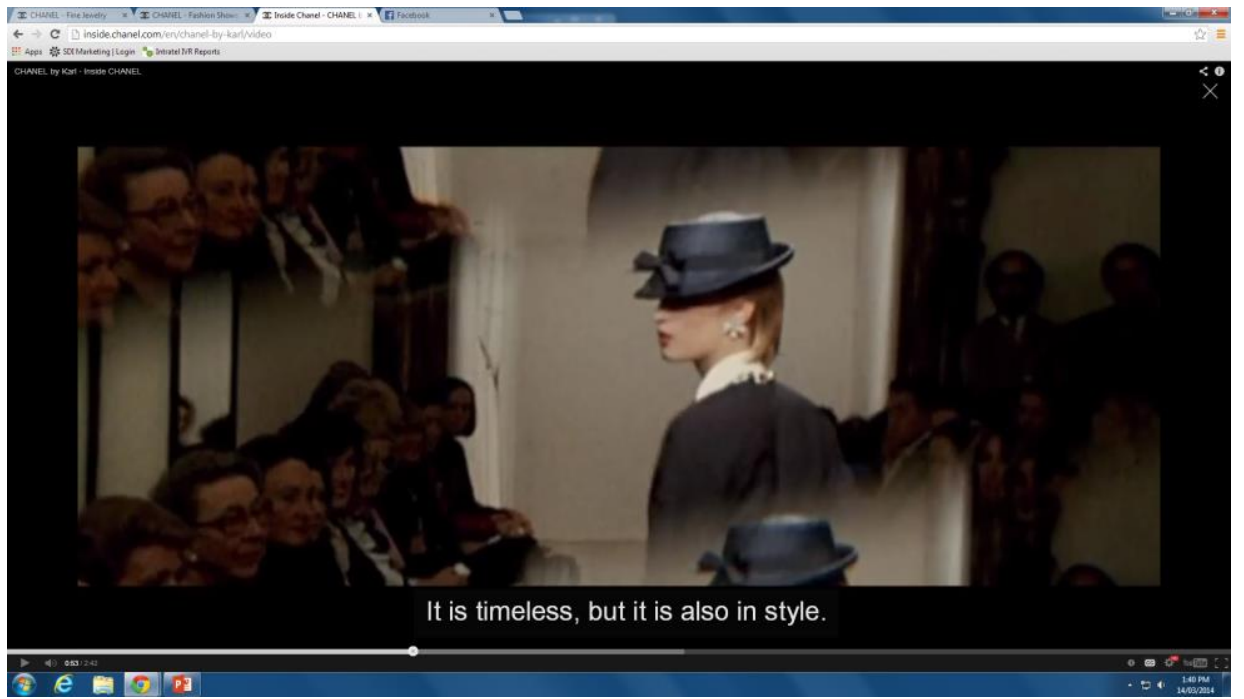

Figure 99 C: Inside Chanel Official Website

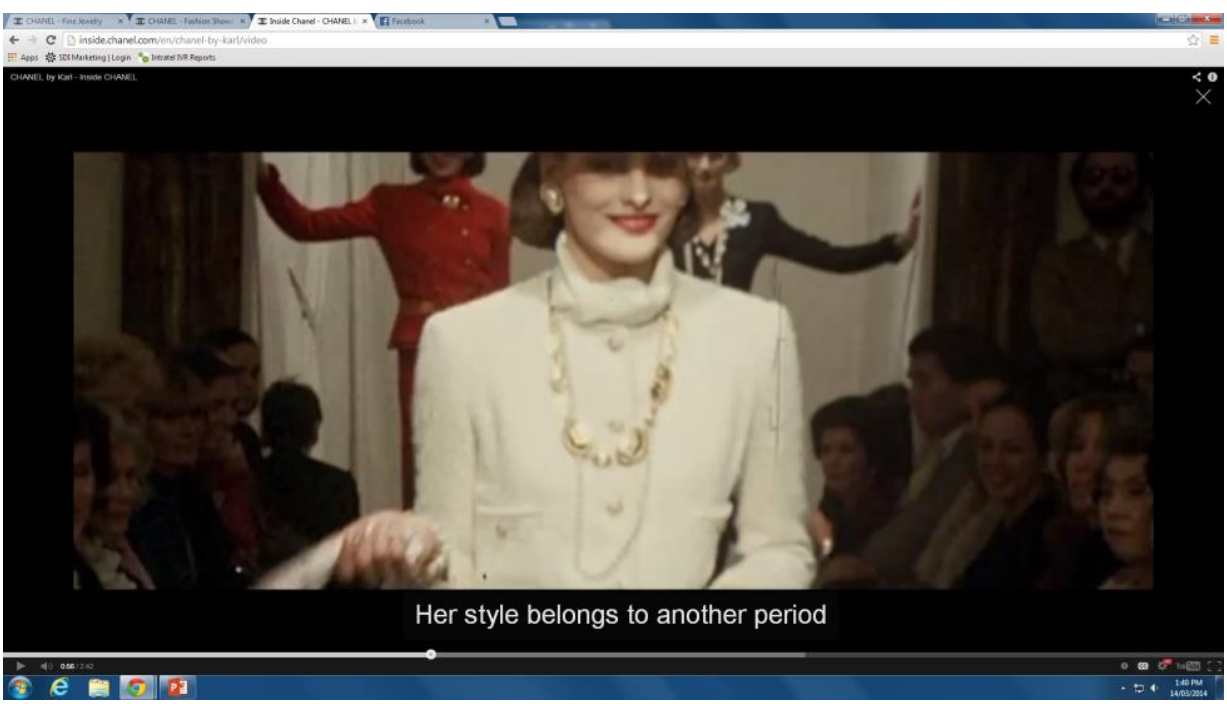

Figure 99 D: Inside Chanel Official Website

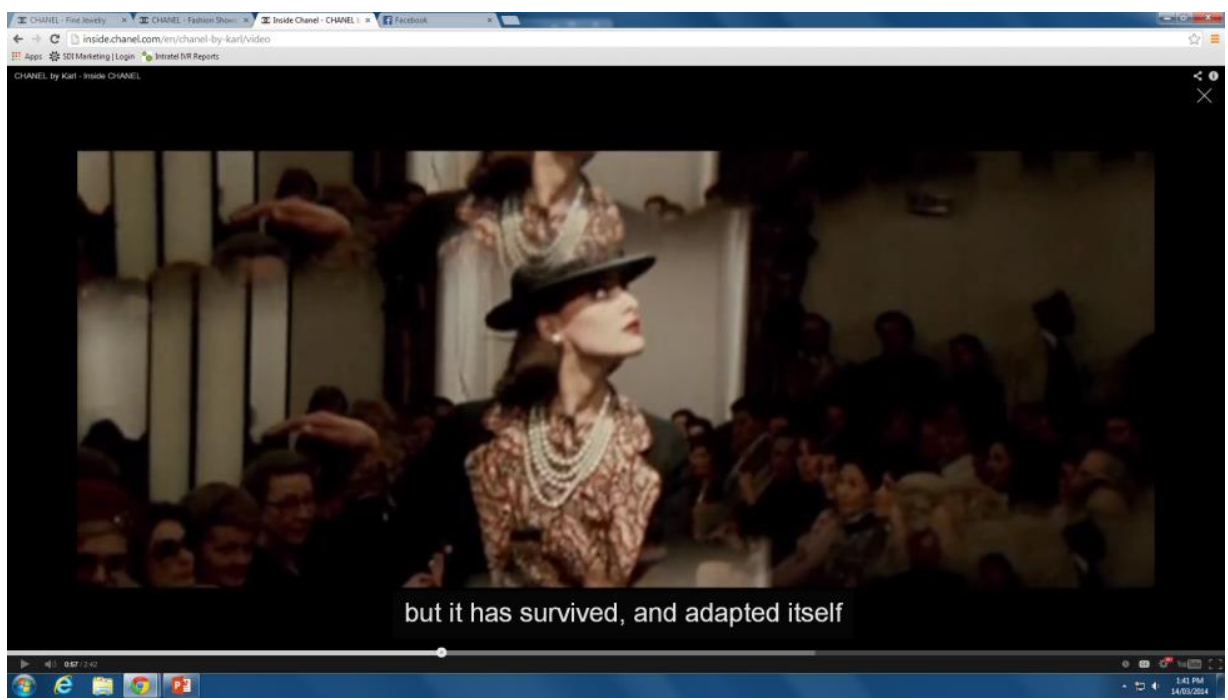


Figure 99 E: Inside Chanel Official Website

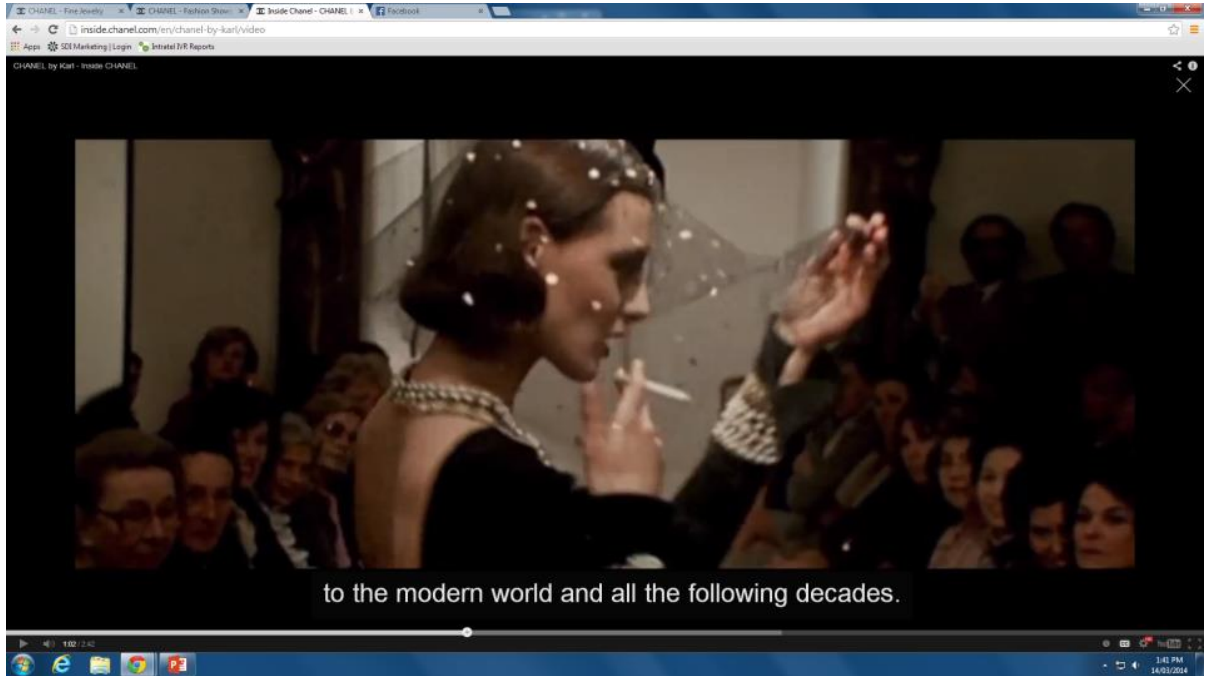

Figure 99 F: Inside Chanel Official Website

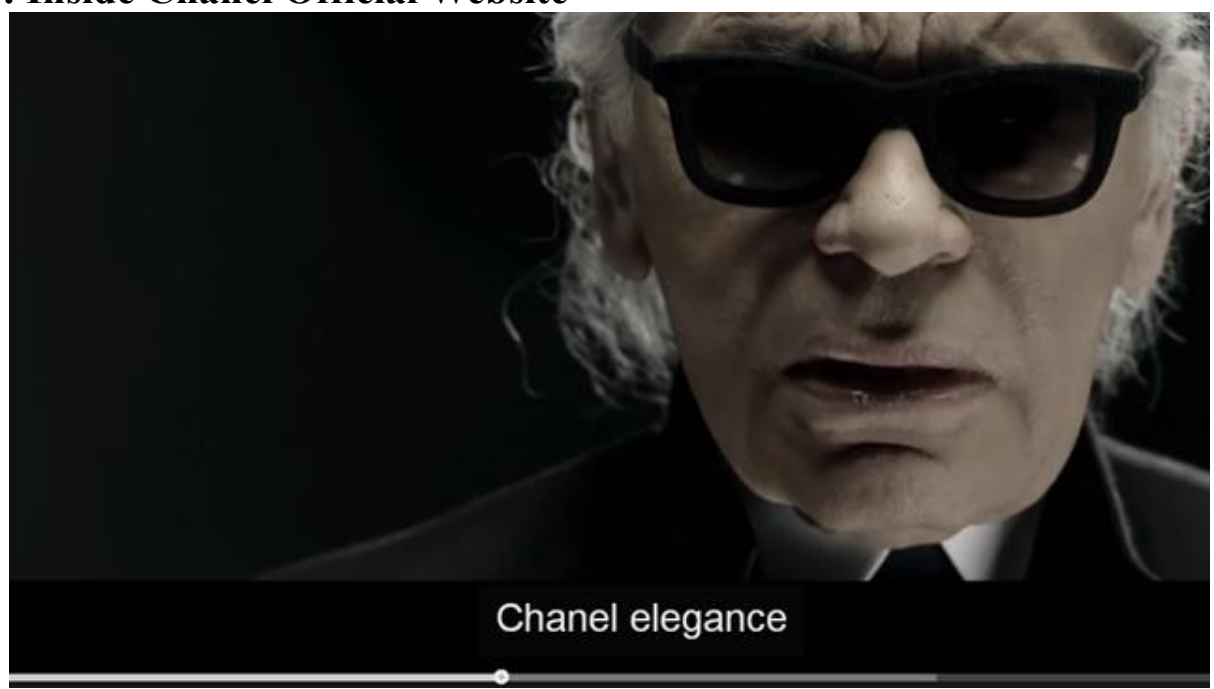

Figure 99 G: Inside Chanel Official Website 


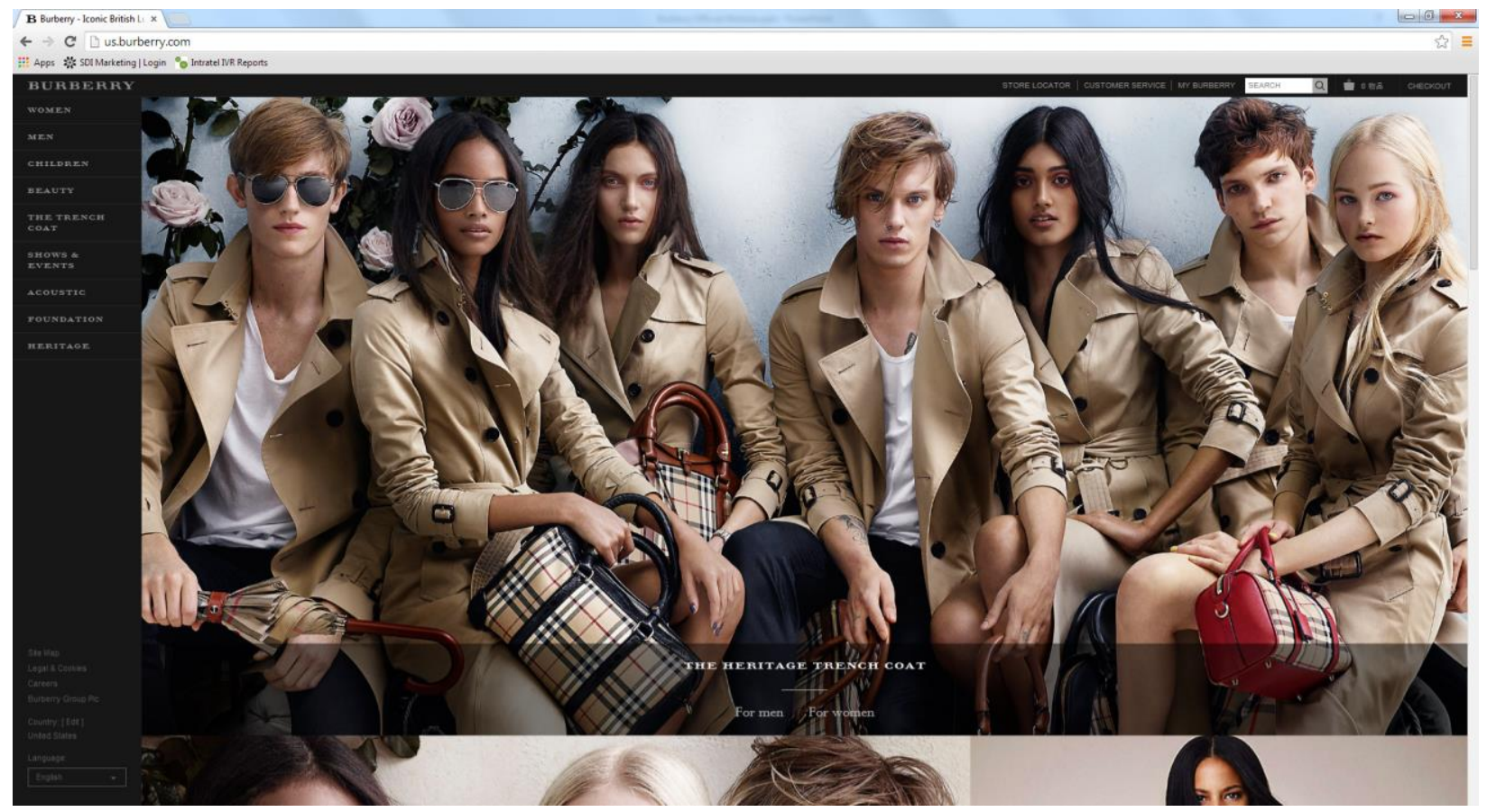

Figure 100 A: Burberry Home Page Official Website

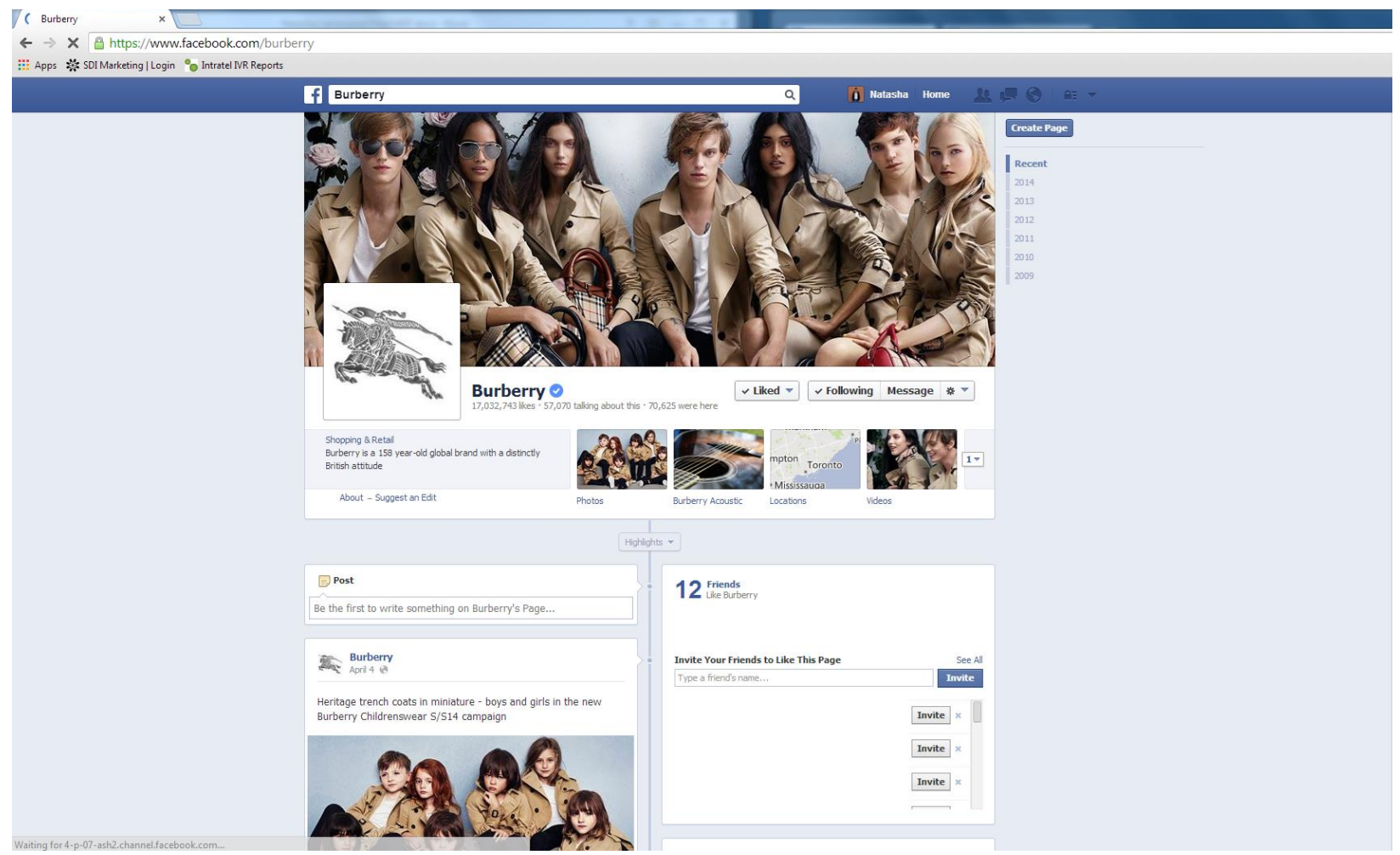

Figure 100 B: Burberry Home Page Official Facebook Page 


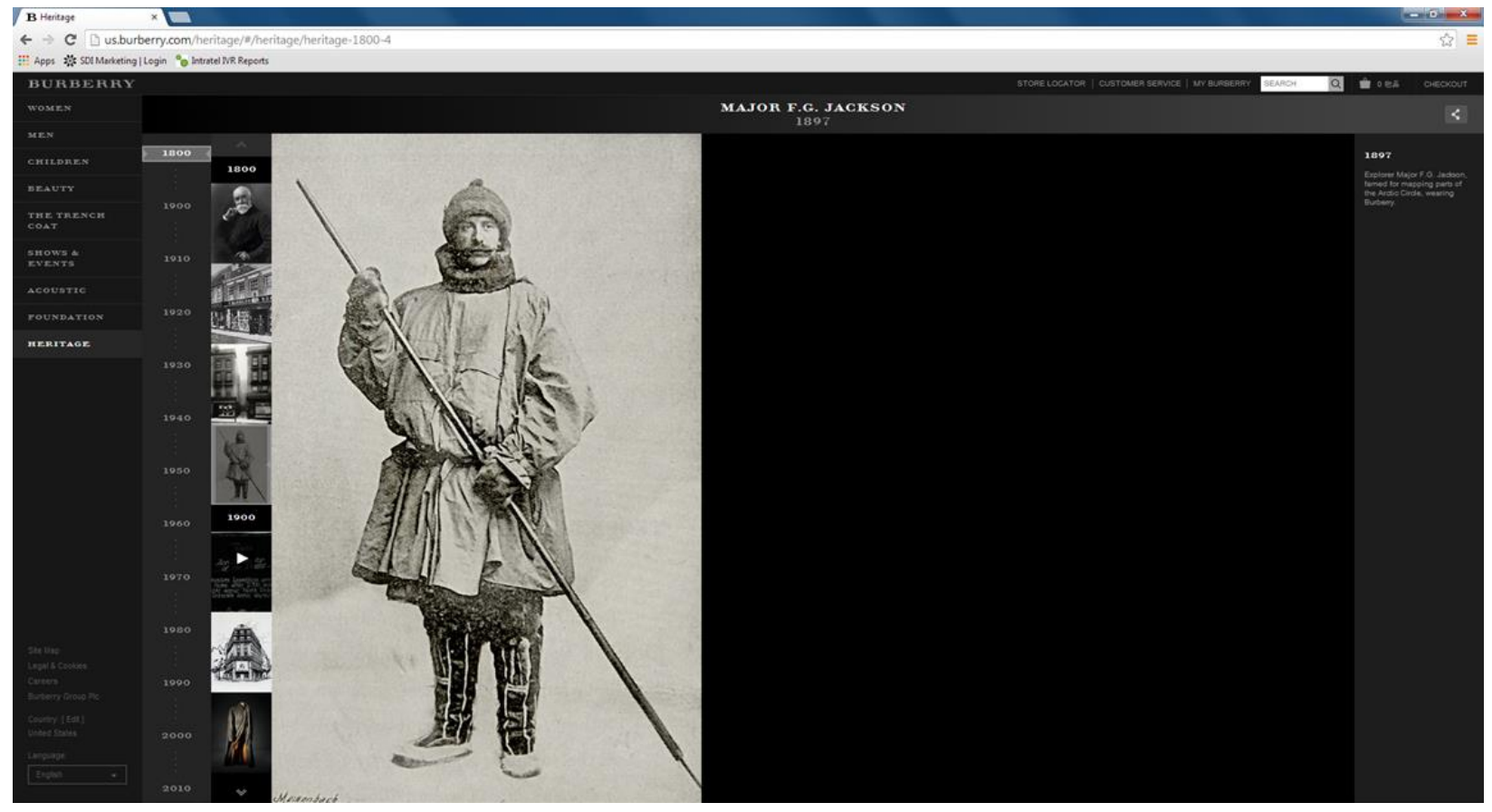

Figure 101: Burberry Heritage Official Website 
Appendix 28: PHASE TWO: SECOND DIMENSION: MARKETING COMMUNICATIONS

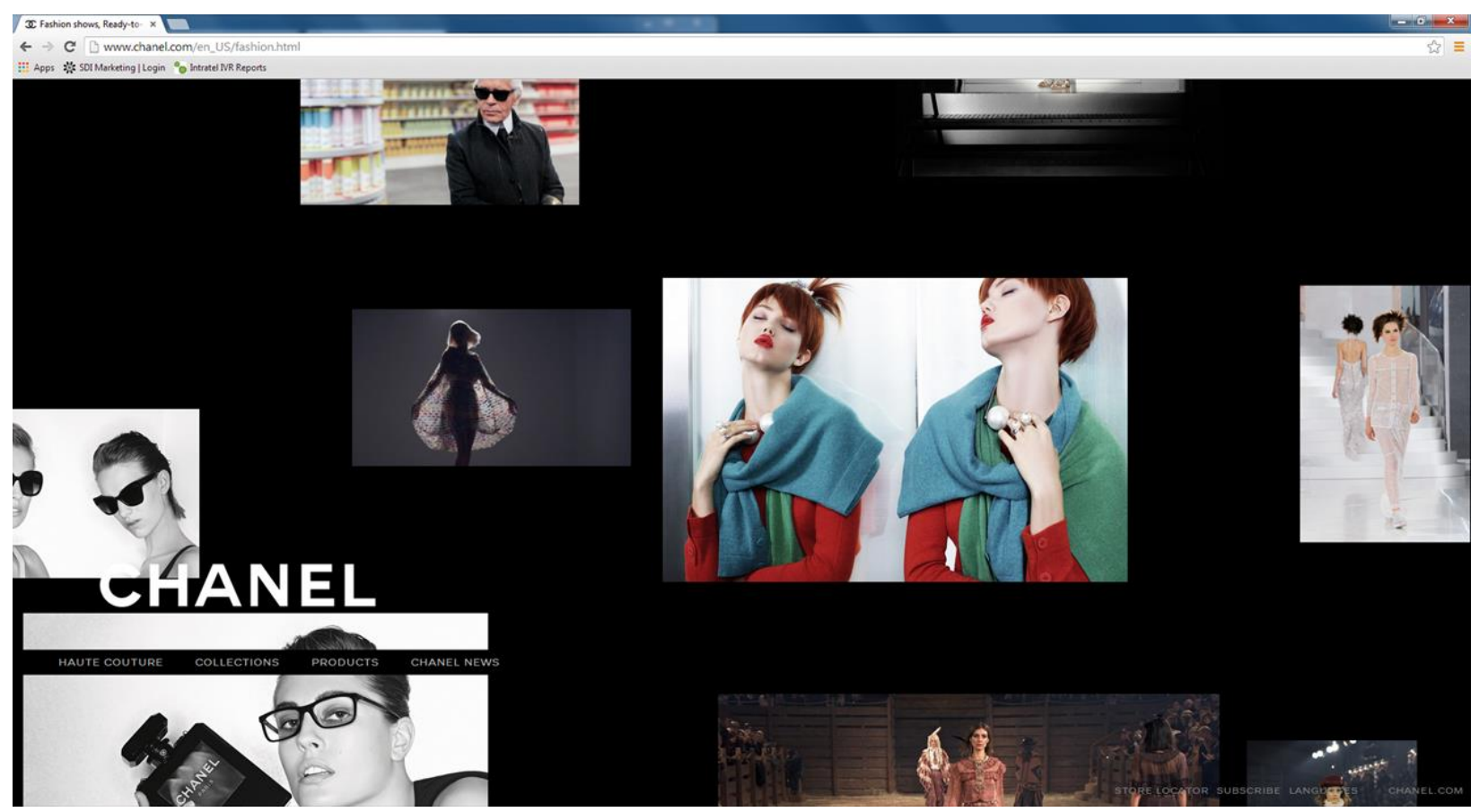

Figure 102: Chanel "Fashion" Official Website

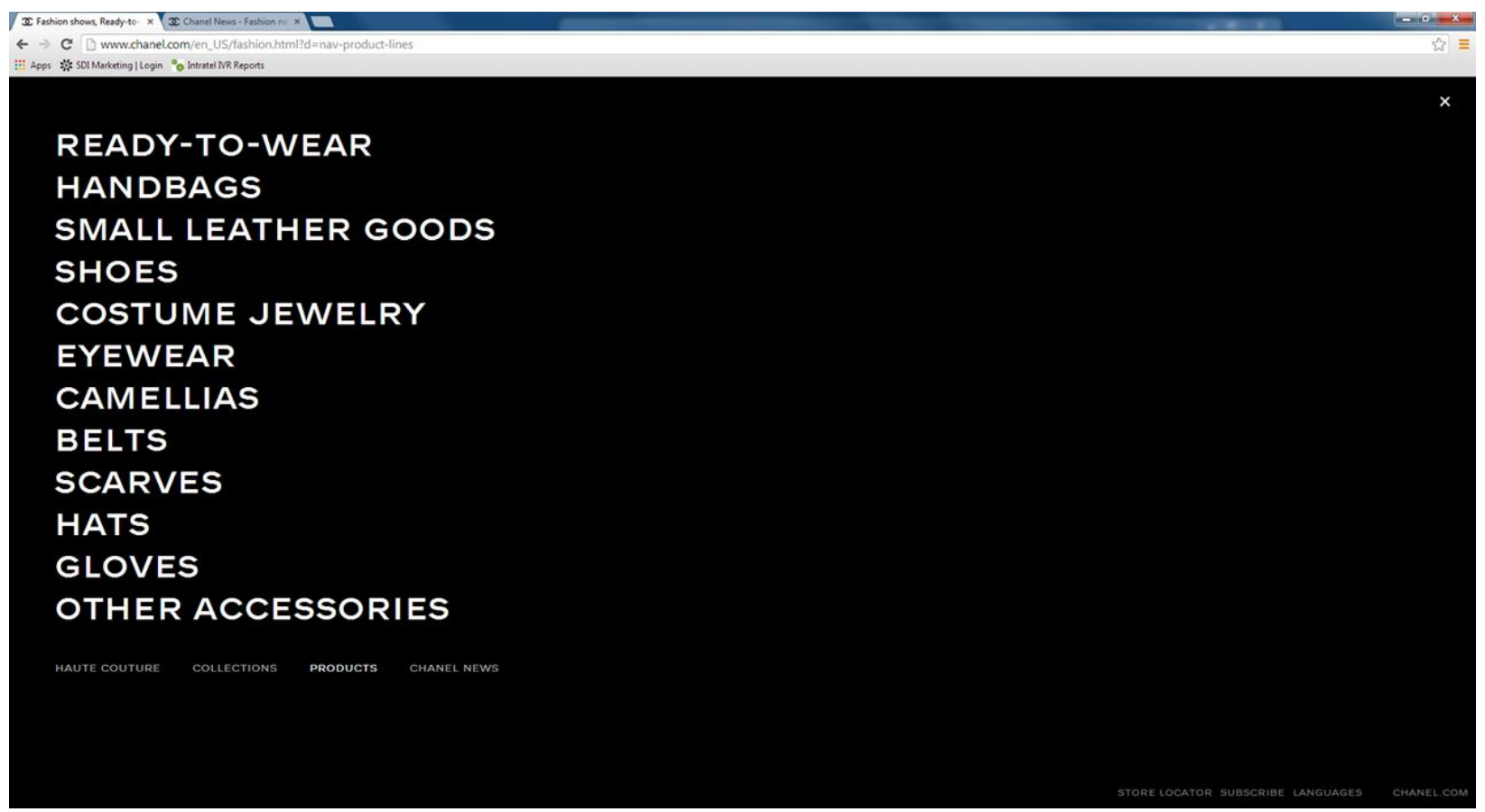

Figure 103: Chanel "Fashion" Official Website 


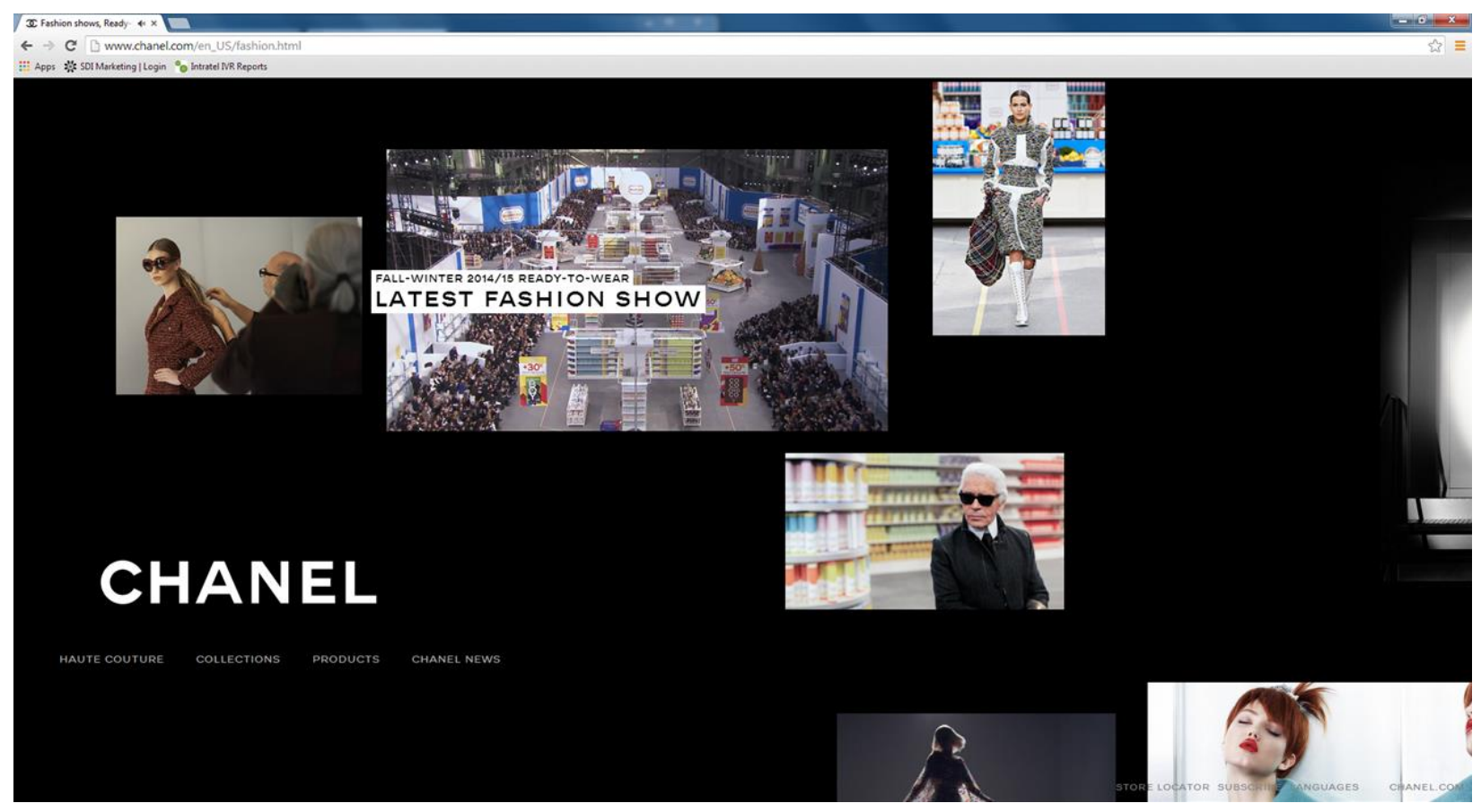

Figure 104: Chanel "Fashion" Official Website

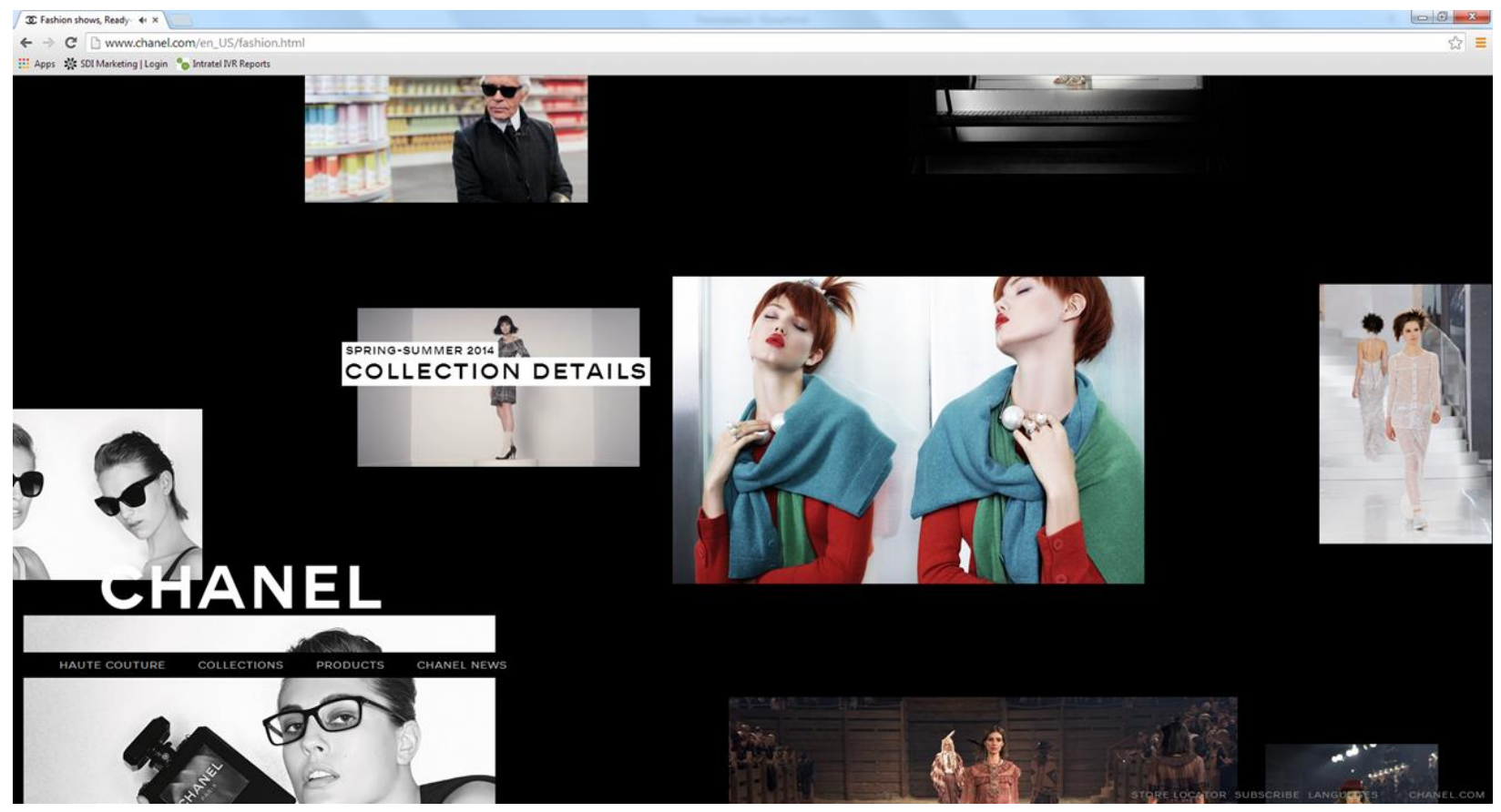

Figure 105: Chanel "Fashion" Official Website 


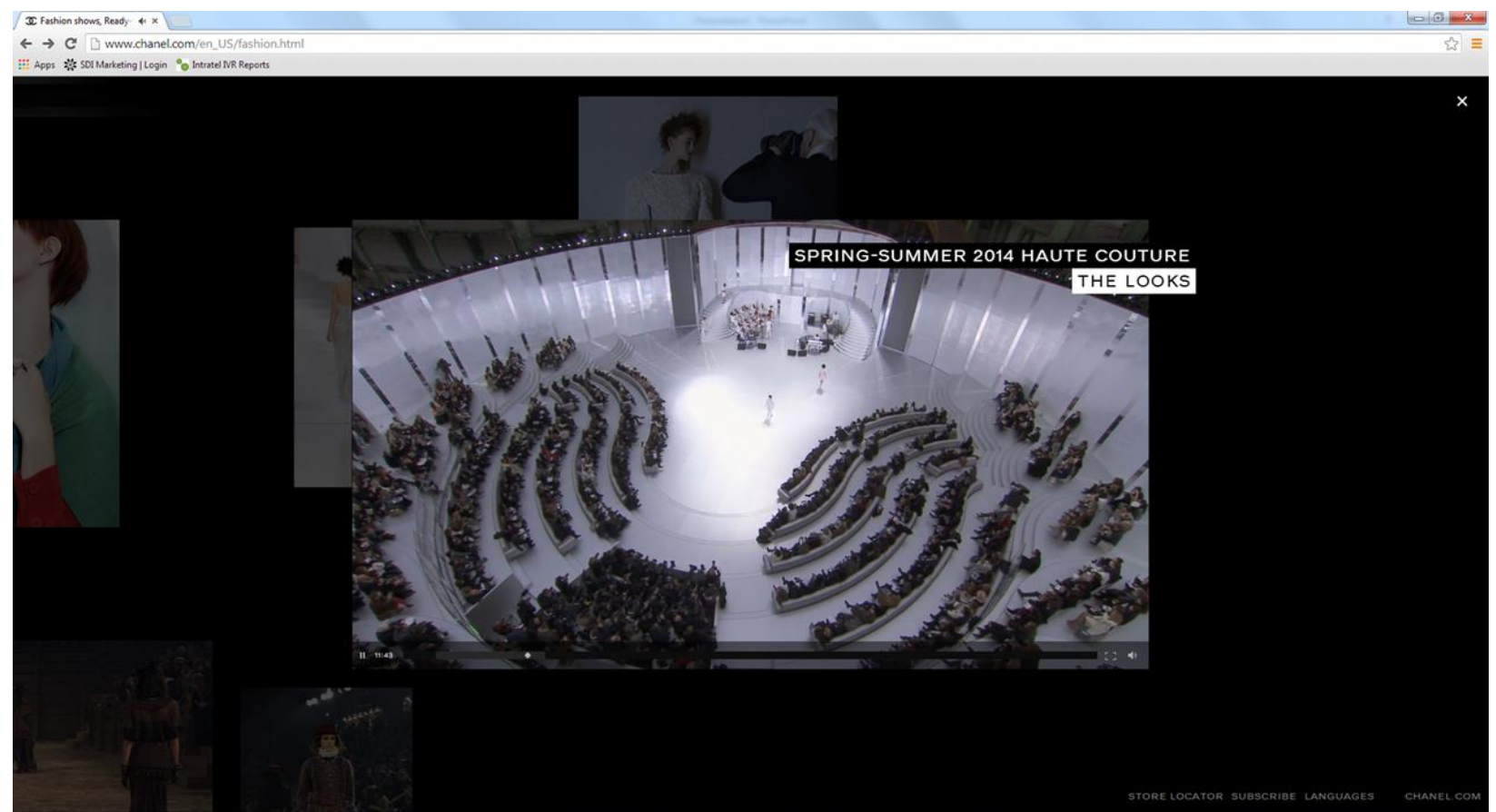

Figure 106: Chanel "Fashion" Official Website

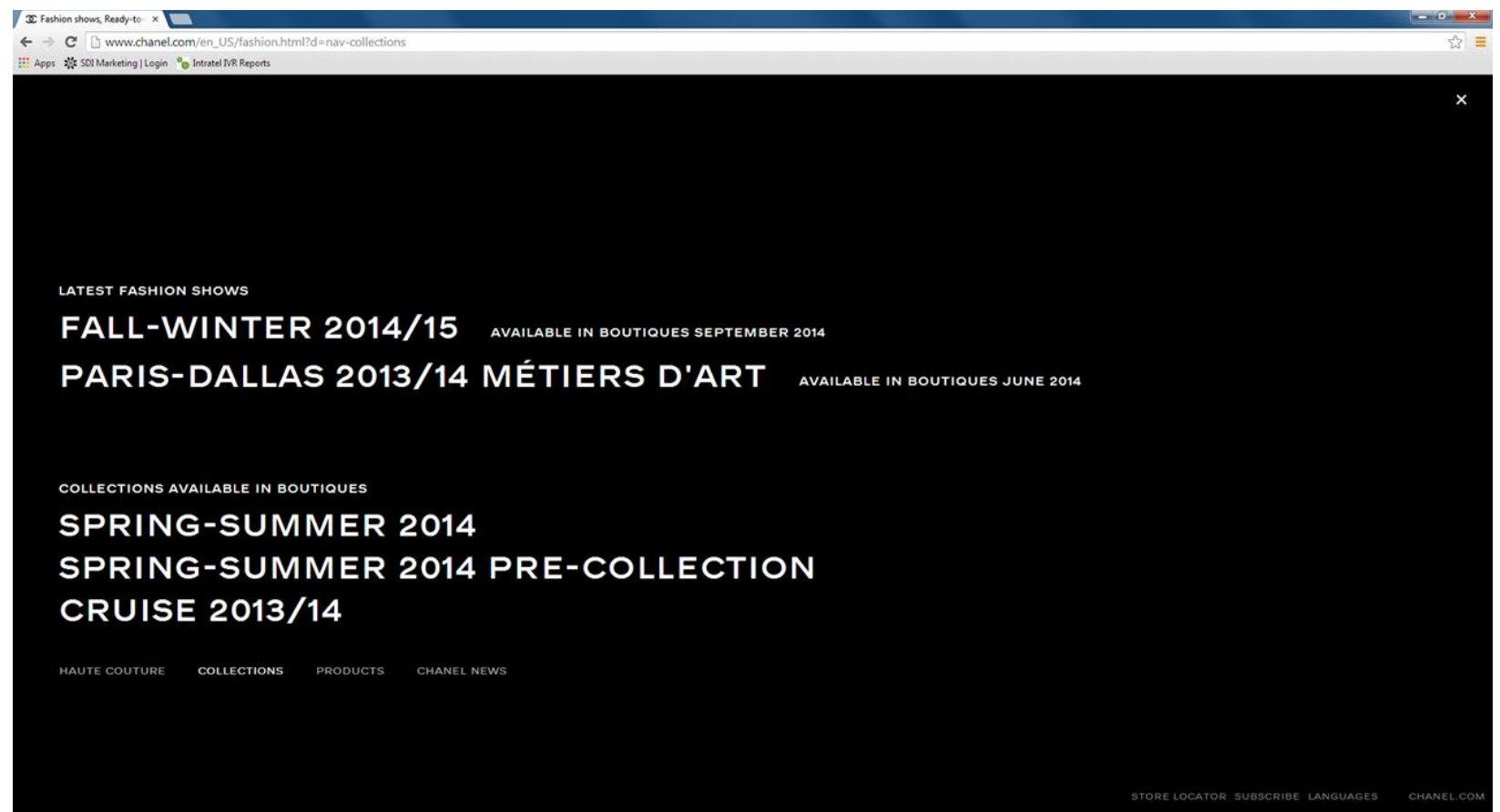

Figure 107: Chanel "Fashion" Official Website 


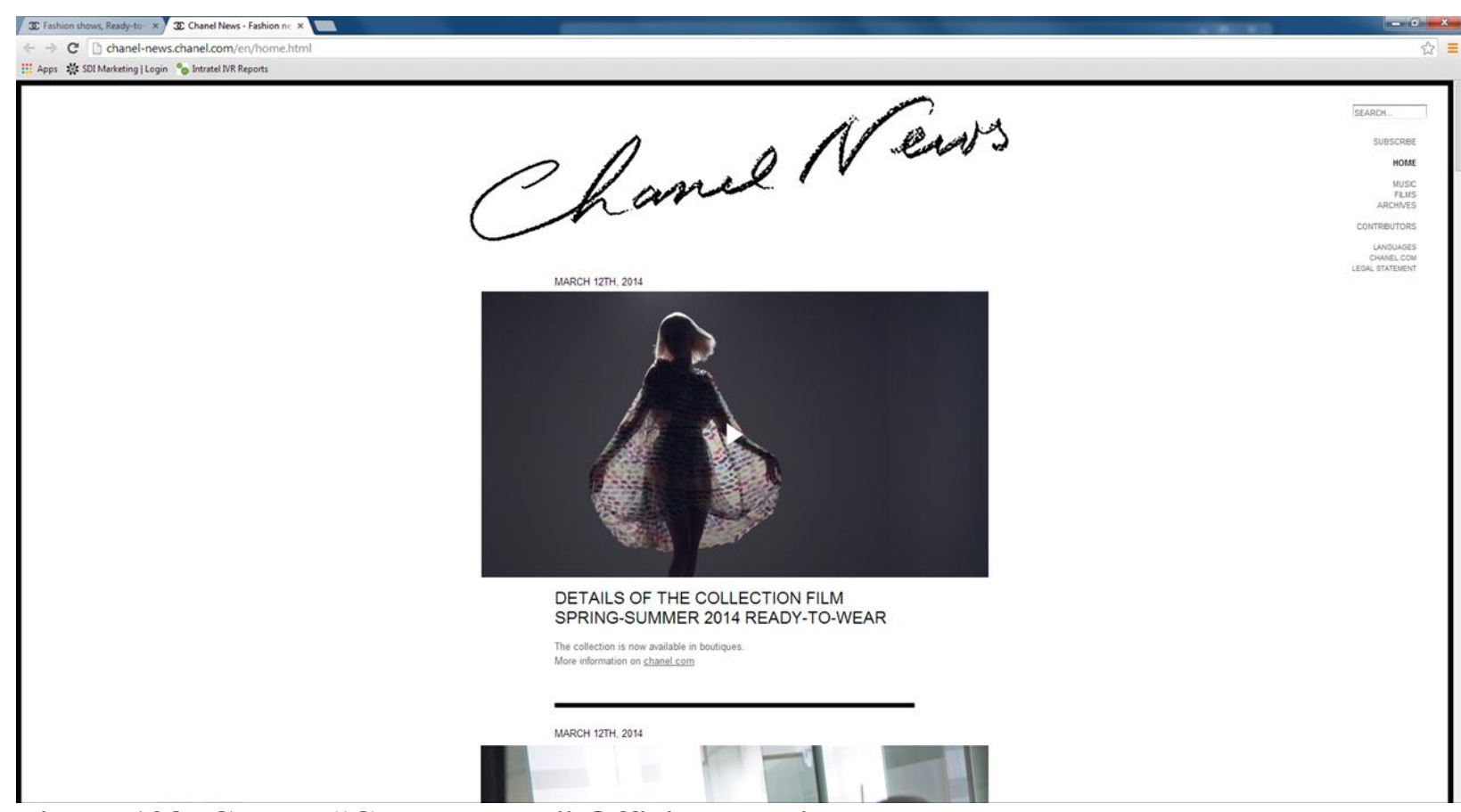

Figure 108: Chanel "Chanel News" Official Website

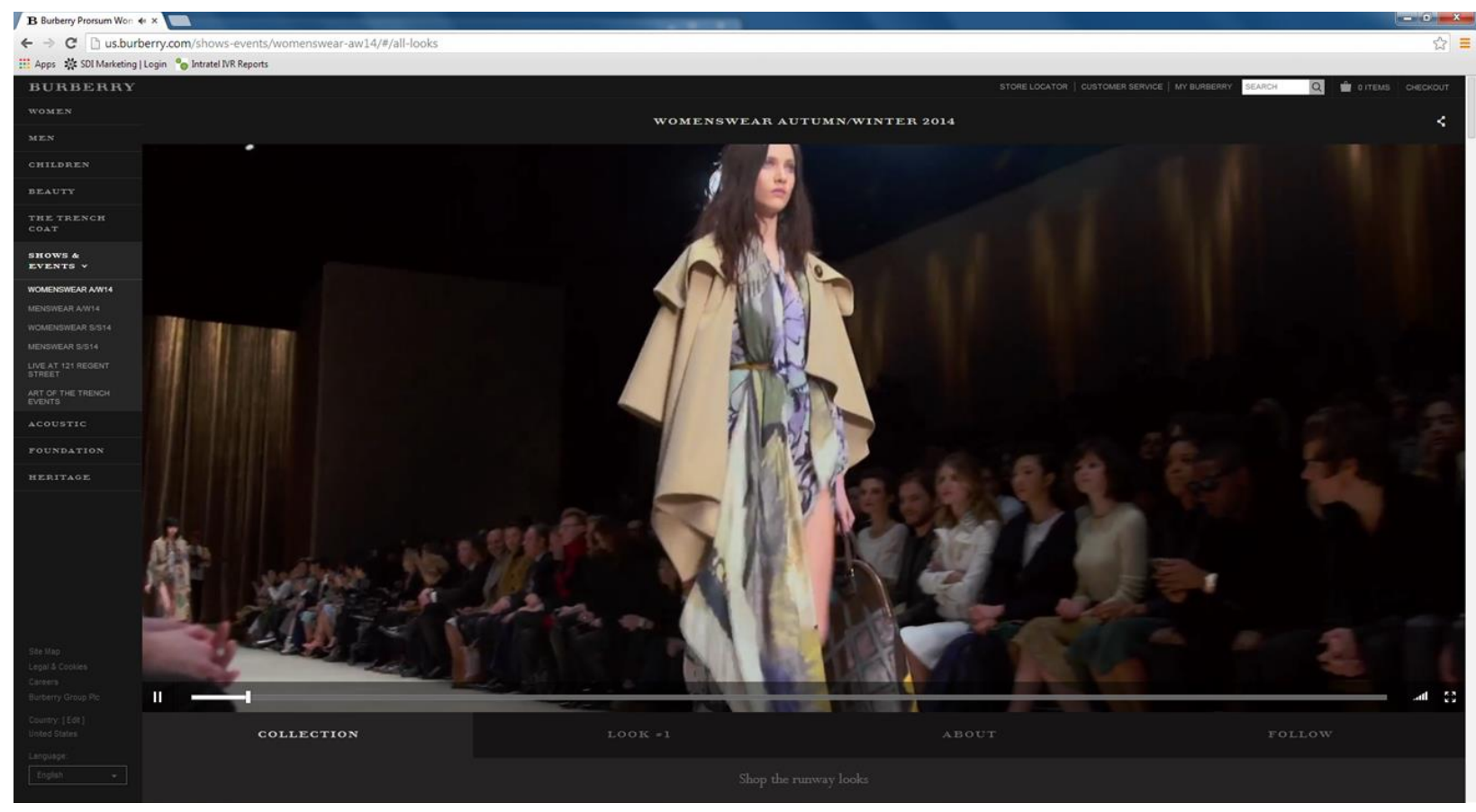

Figure 109: Burberry "Shows and Events" Official Website- WOMENSWEAR A/W14 


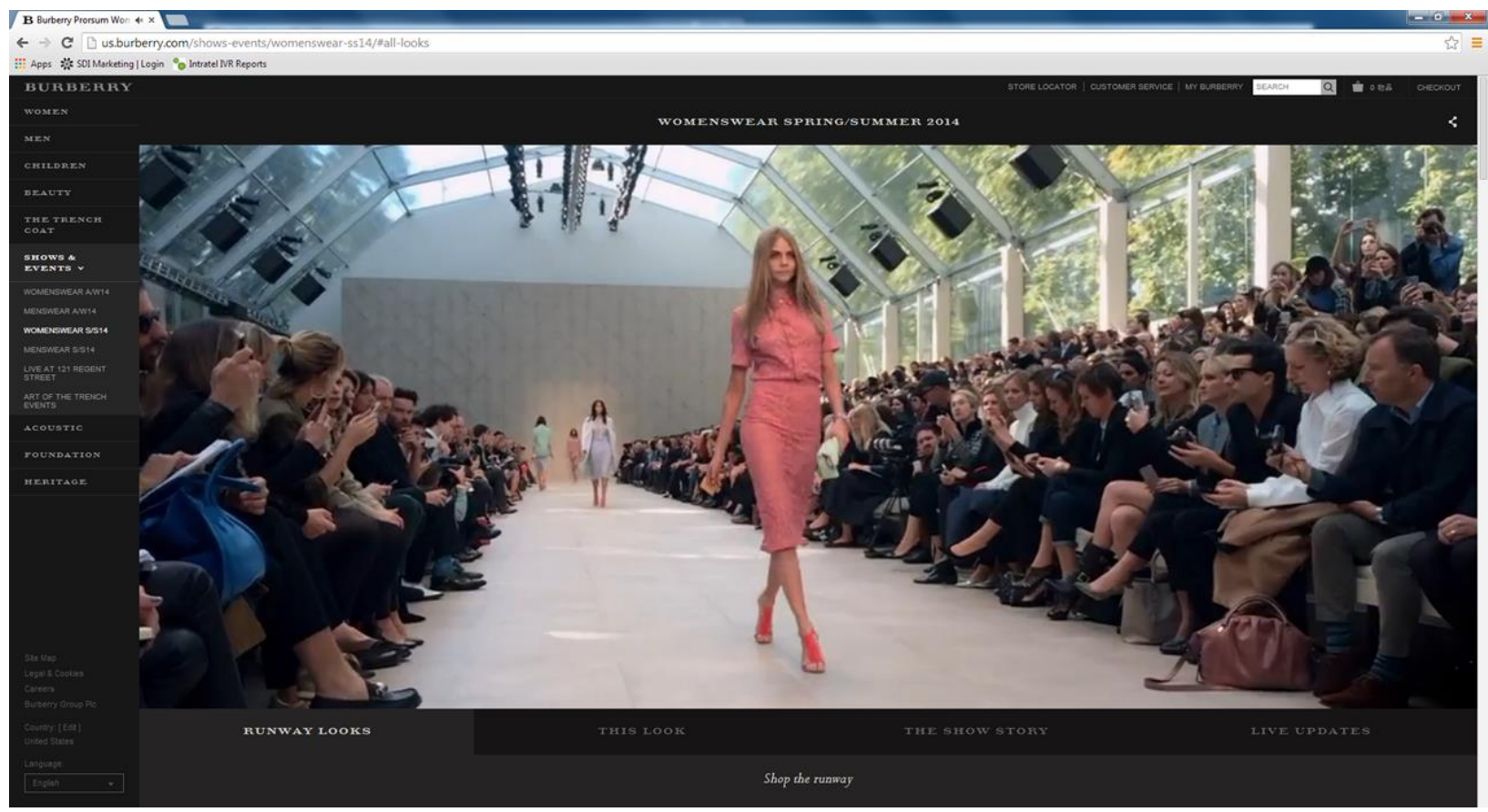

Figure 110 A: Burberry "Shows and Events" Official Website- WOMENSWEAR S/S14

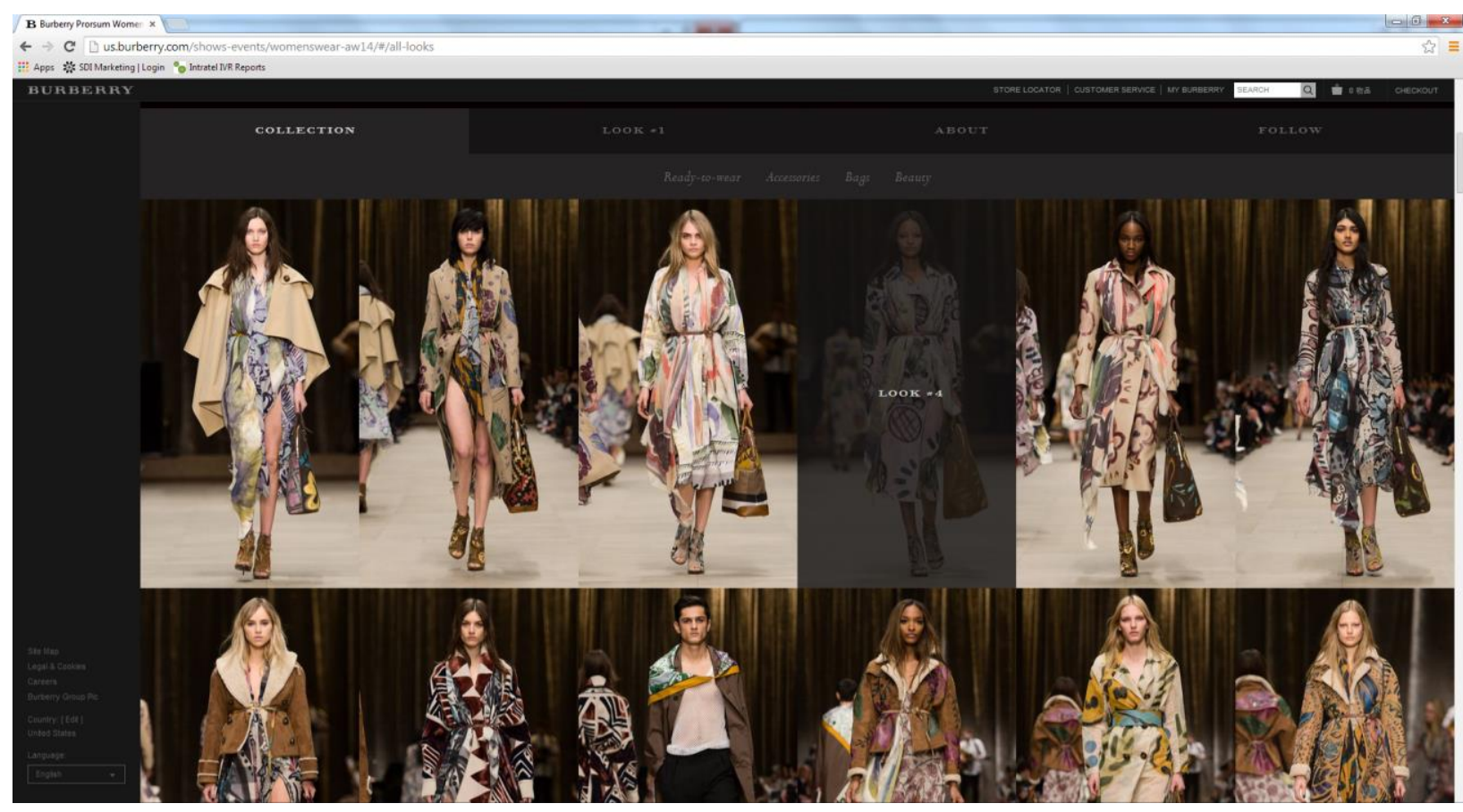

Figure 110 B: Burberry "Shows and Events" Official Website- WOMENSWEAR A/W14 


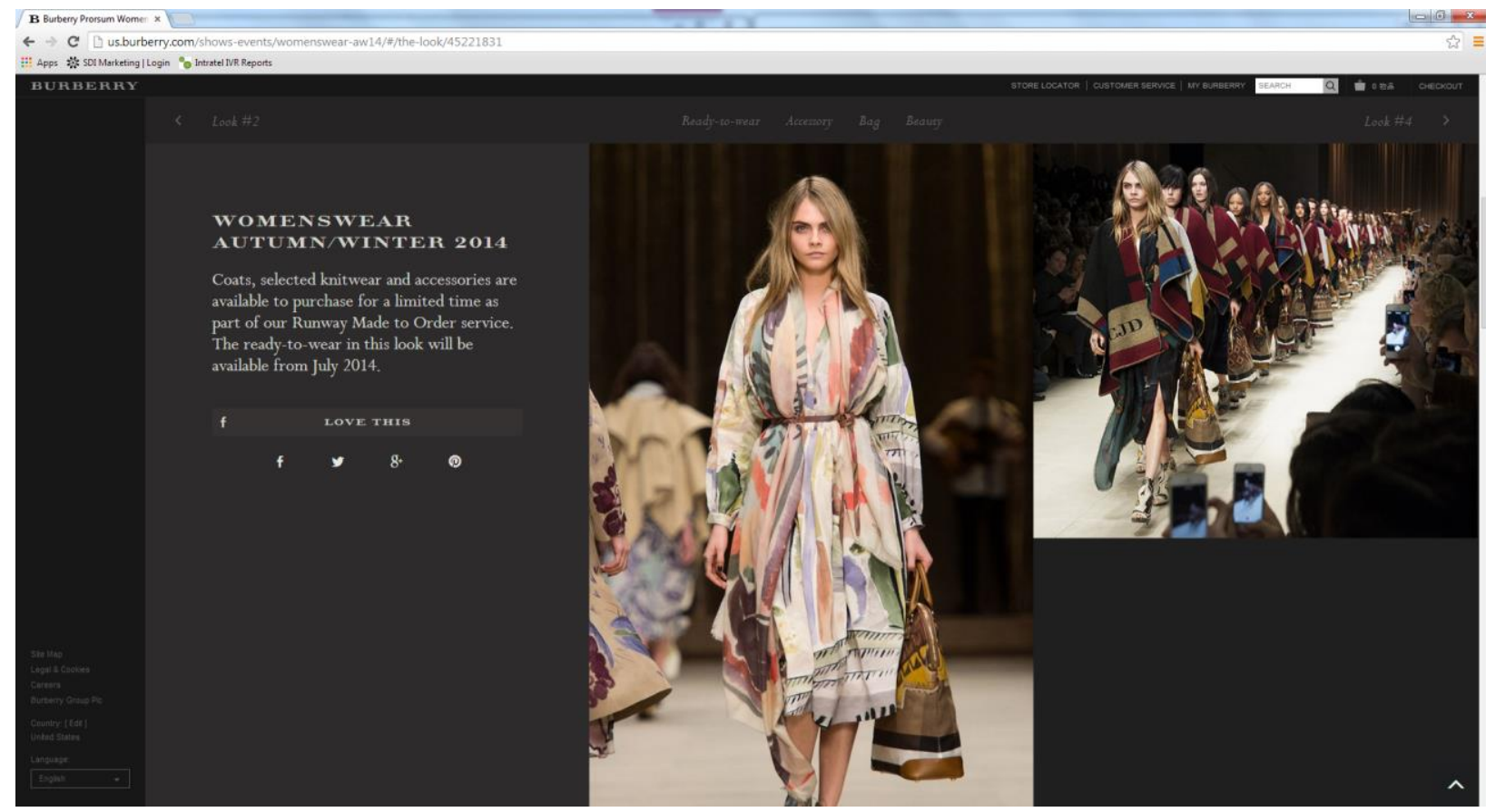

Figure 110 C: Burberry "Shows and Events" Official Website- WOMENSWEAR A/W14

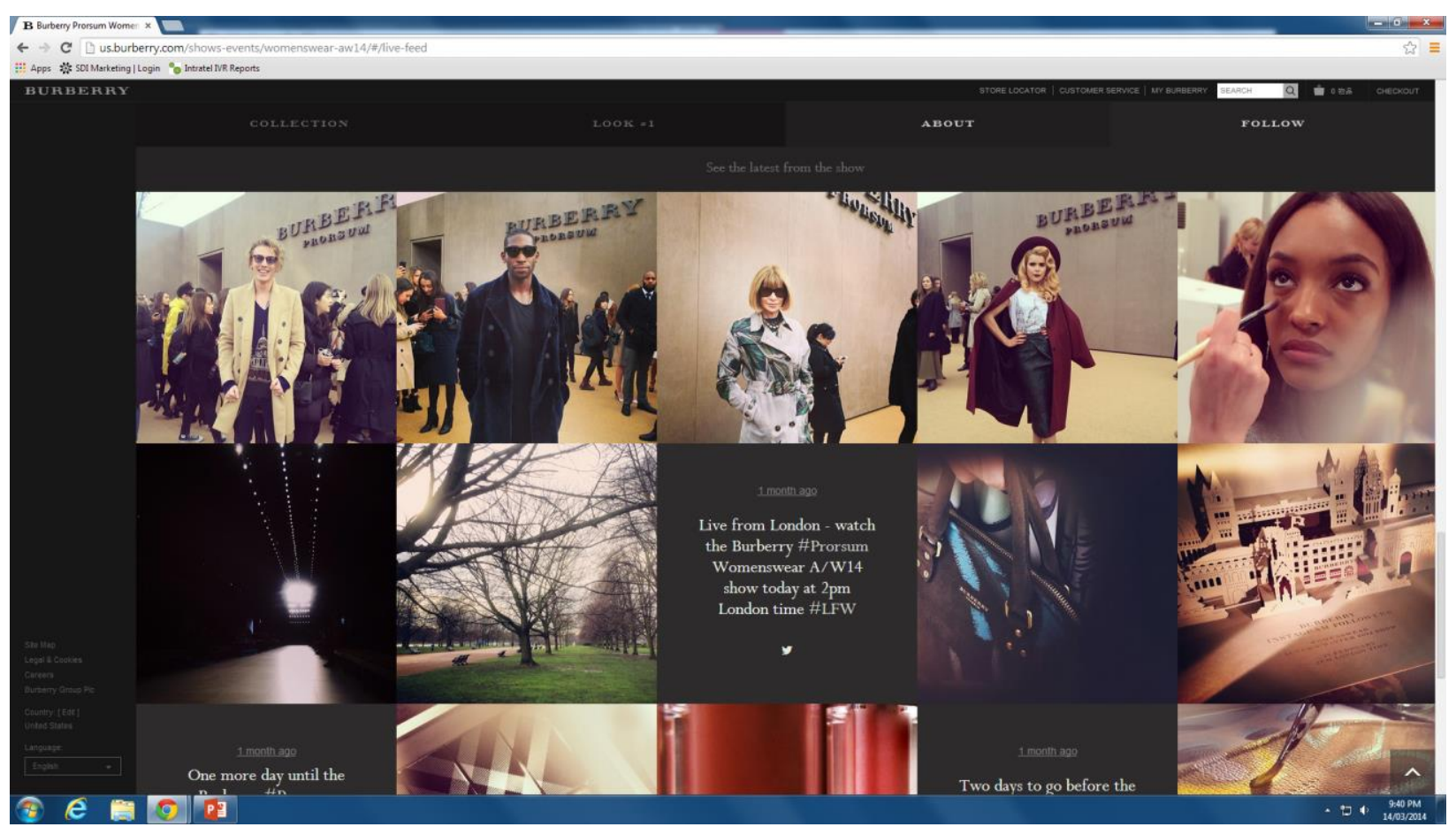

Figure 110 D: Burberry "Shows and Events" Official Website- WOMENSWEAR A/W14 


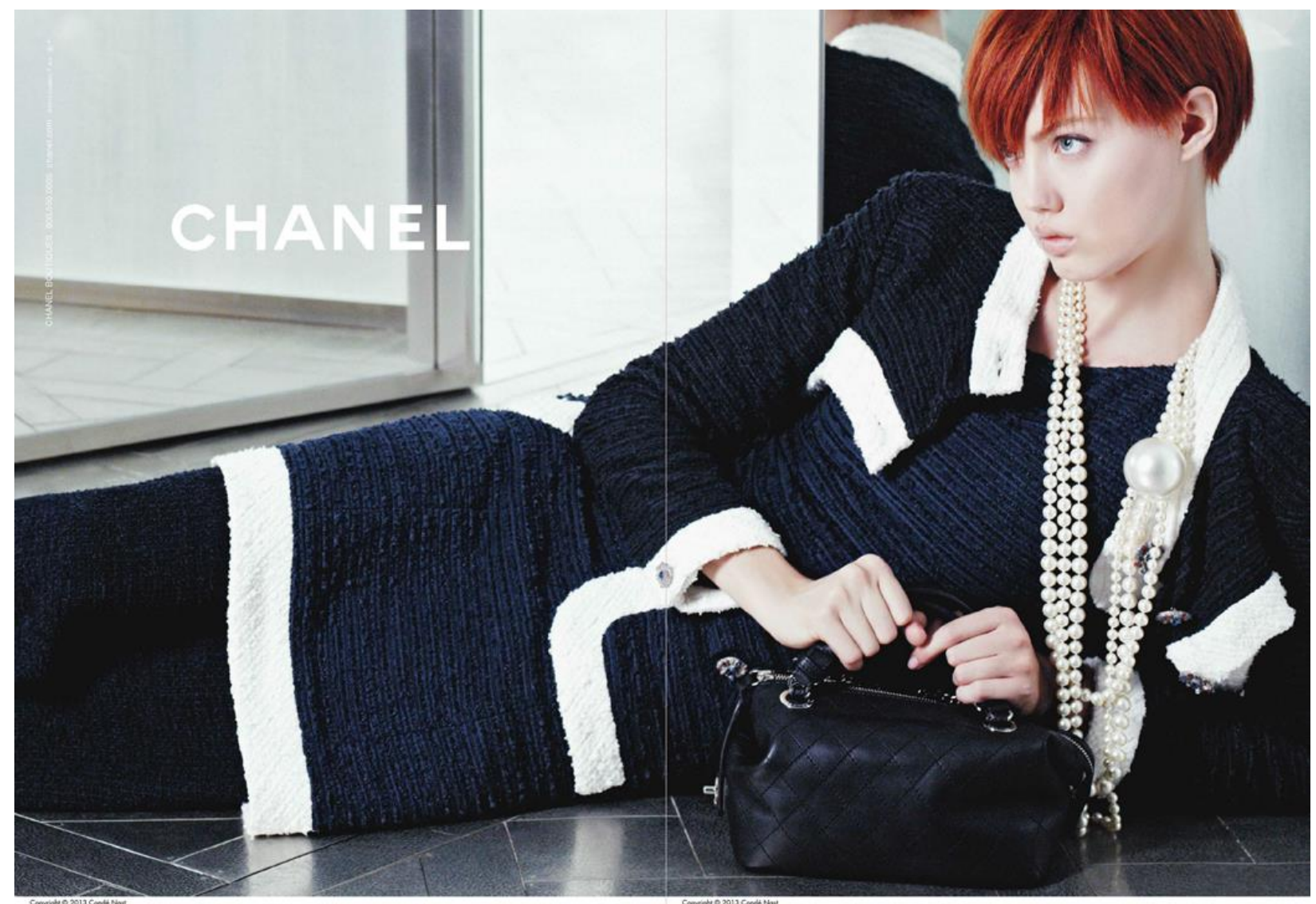

Figure 111: Chanel Print Advertisement from Vogue 204.2 (Feb 1, 2014): 2, 3.

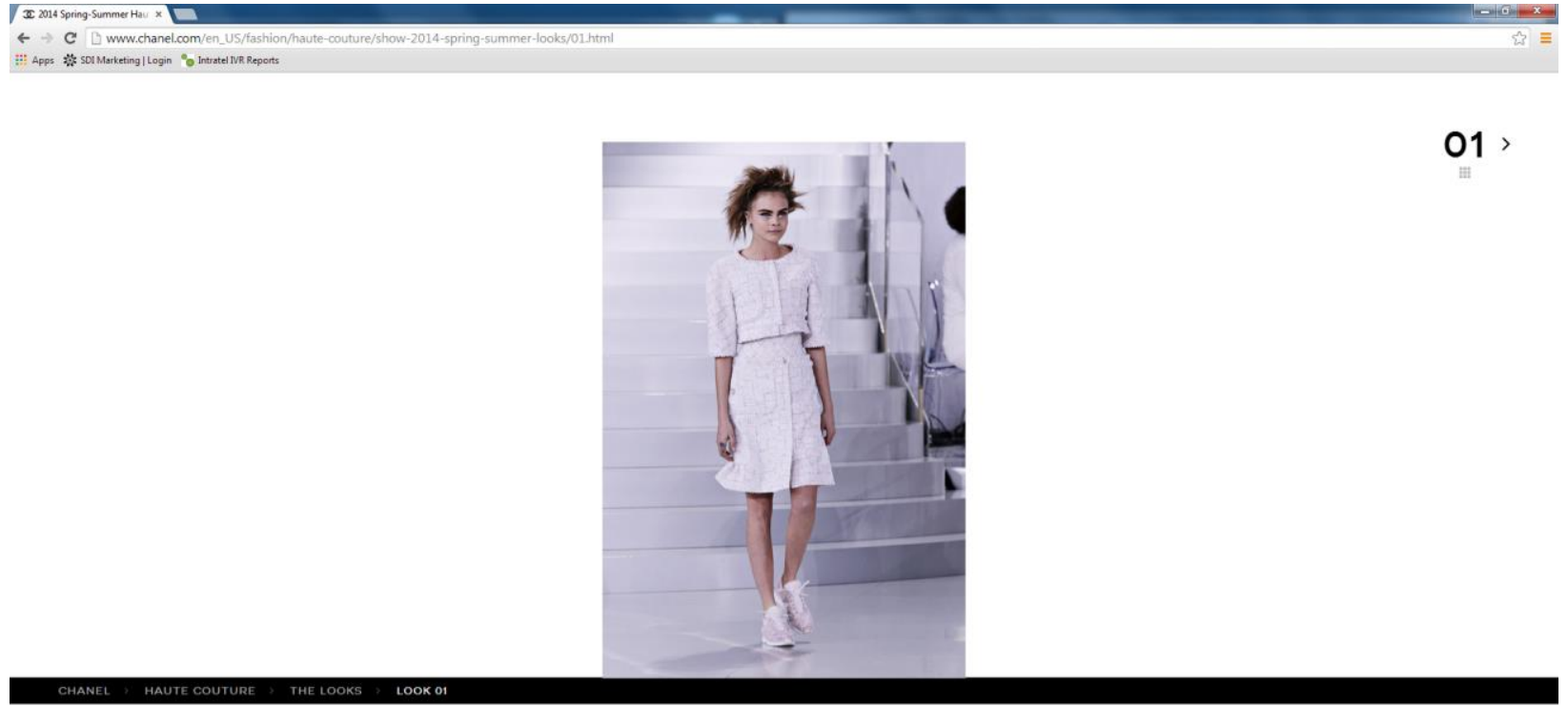

Figure 112: Chanel Official Website 


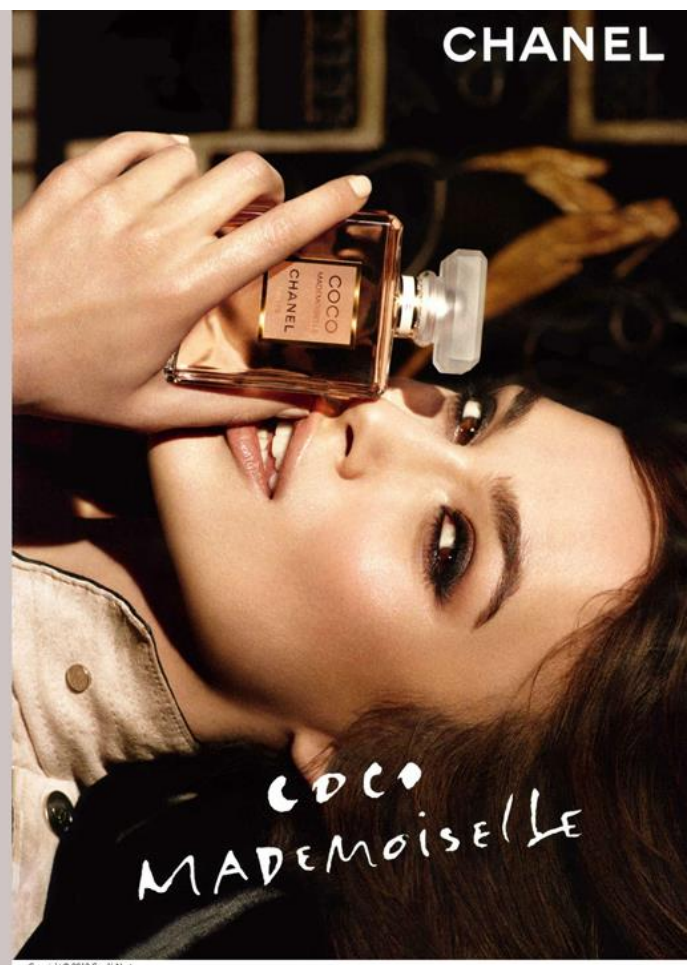

Figure 113 A: Chanel Print Advertisement from Vogue 204.2 (Feb 1, 2014): 93, 94.

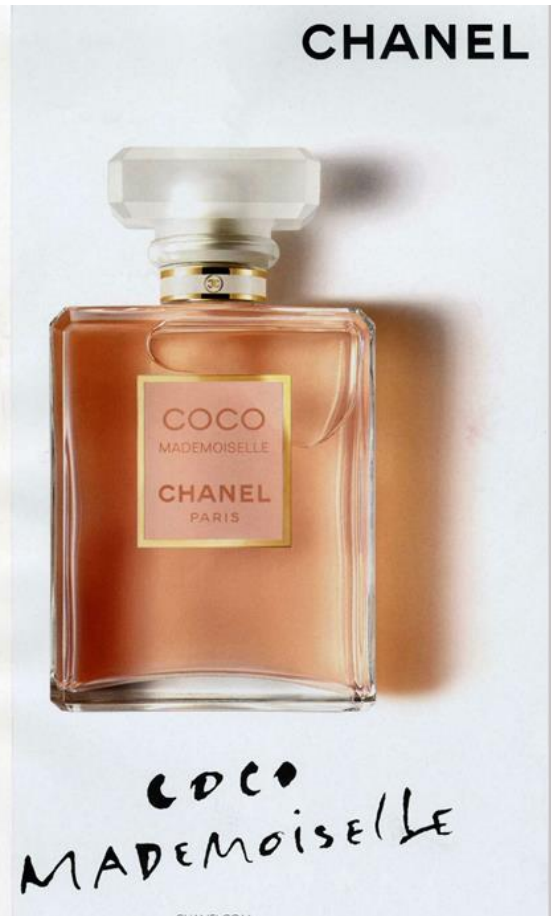

Figure 113 B: Chanel Print Advertisement from Vogue 204.2 (Feb 1, 2014): 93, 94. 


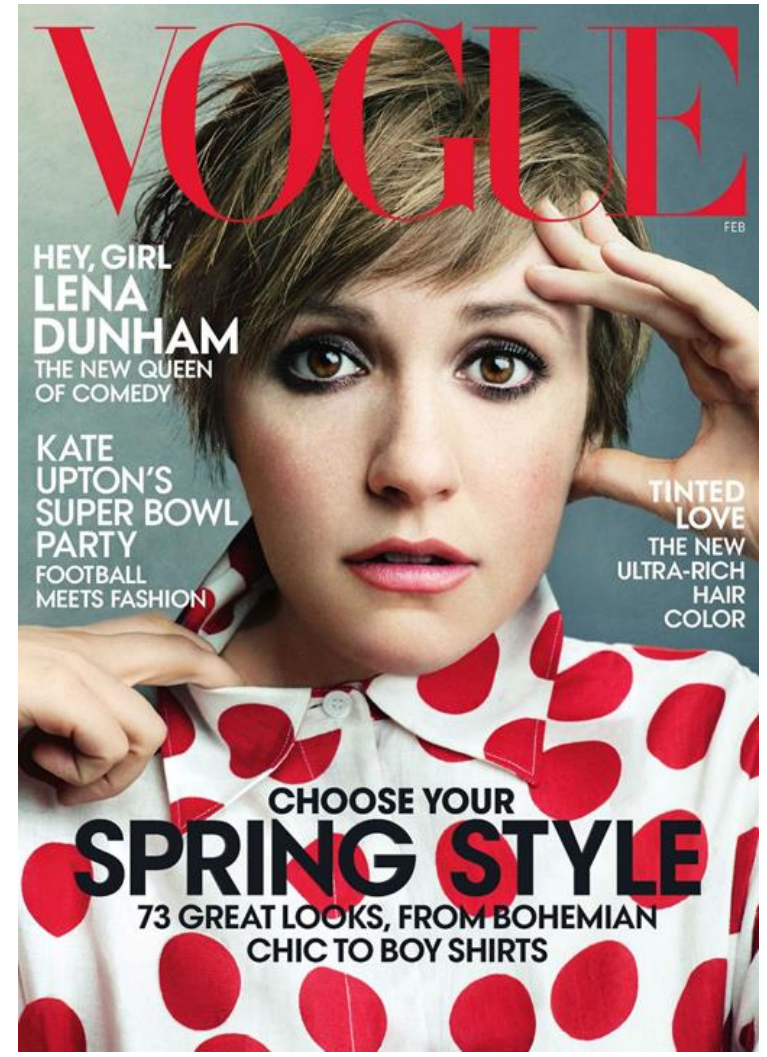

Figure 114: Front Page Cover - Advertising Burberry from Vogue 204.2 (Feb 1, 2014): C1.

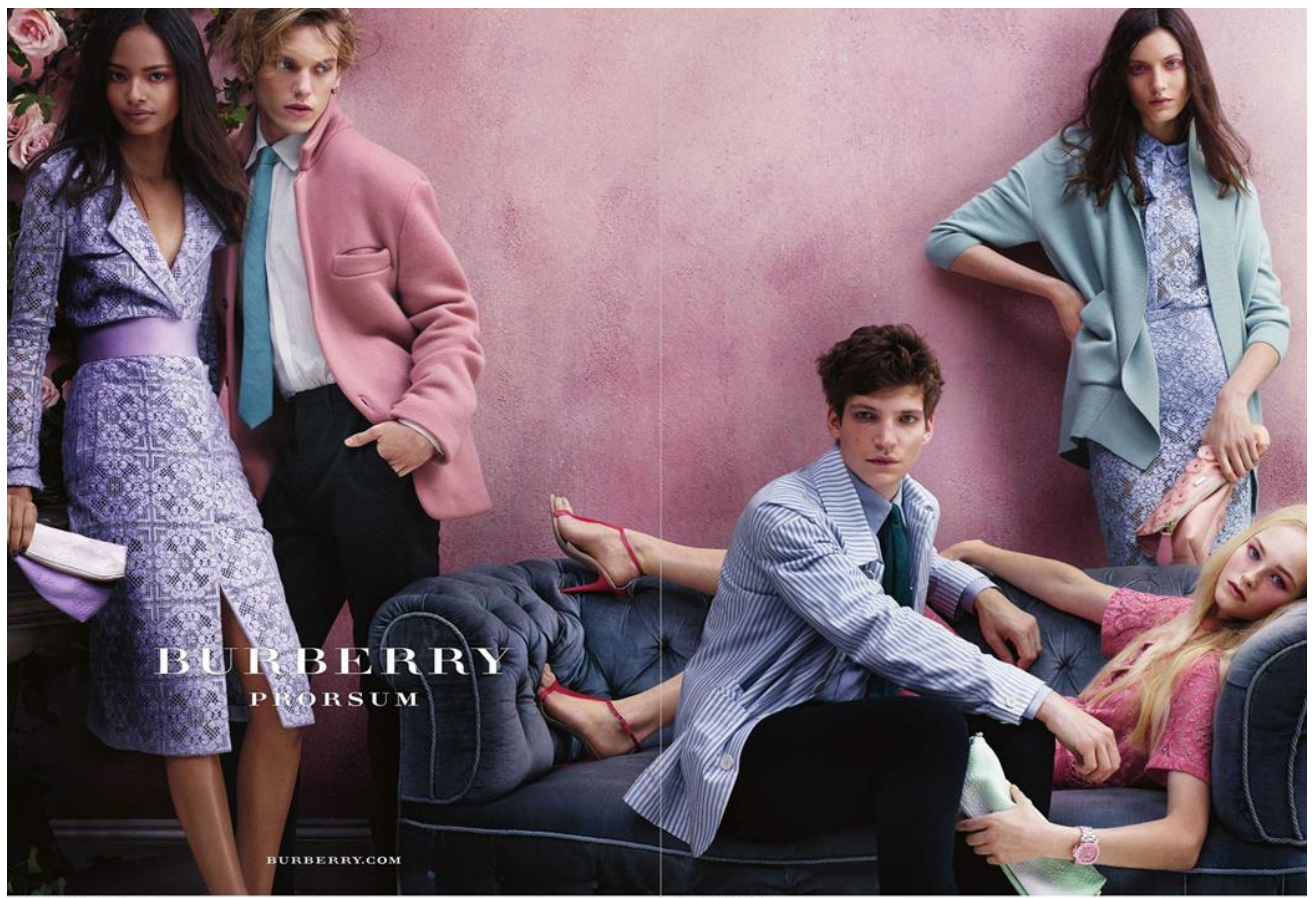

Figure 115: Burberry Prorsum Print Advertisement from Vogue 204.2 (Feb 1, 2014): 14, 15. 


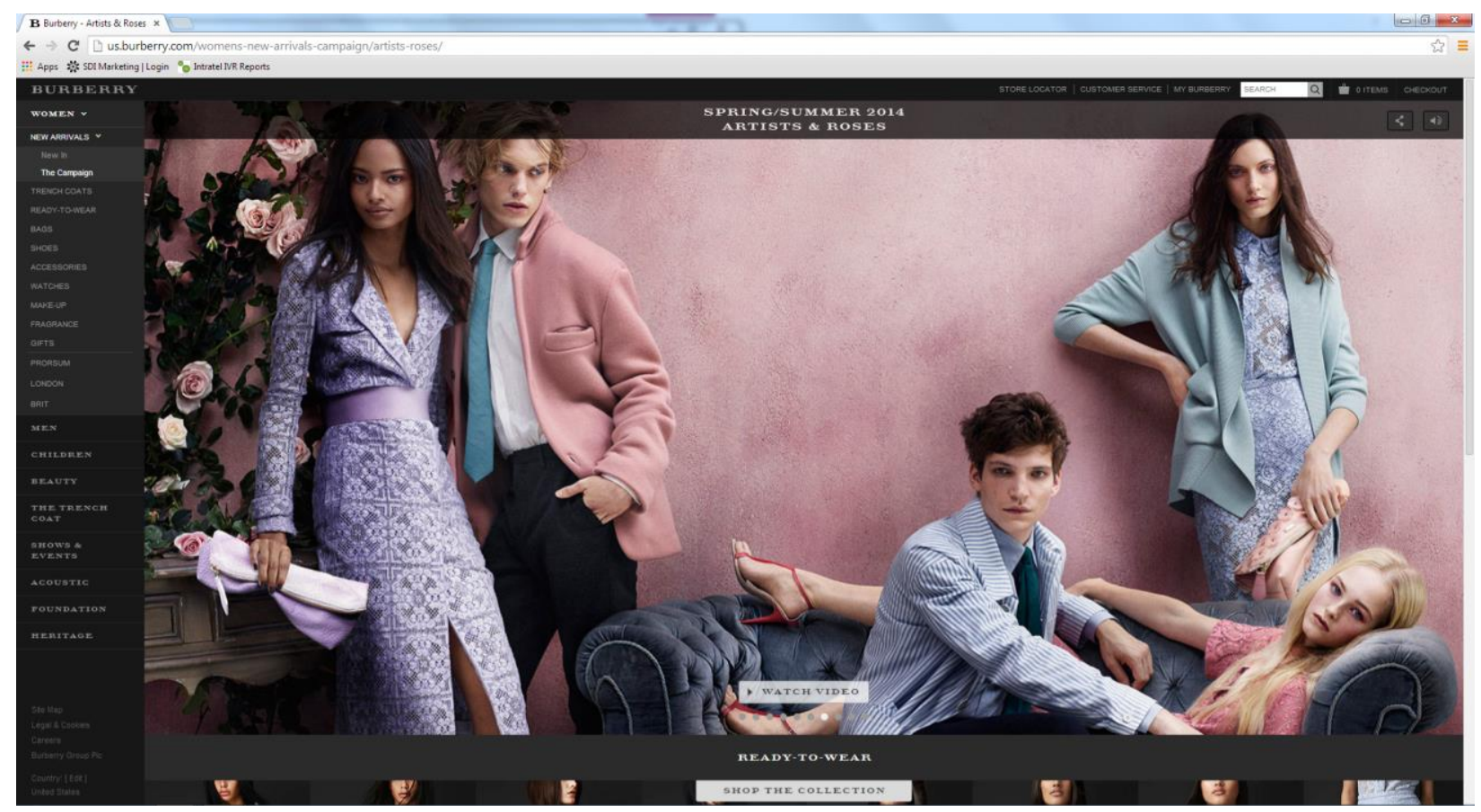

Figure 116: Burberry Prorsum Online Advertisement from Vogue 204.2 (Feb 1, 2014): 14, 15.

Ix CHANel Fashion Show $\times \square$

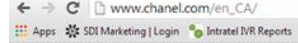

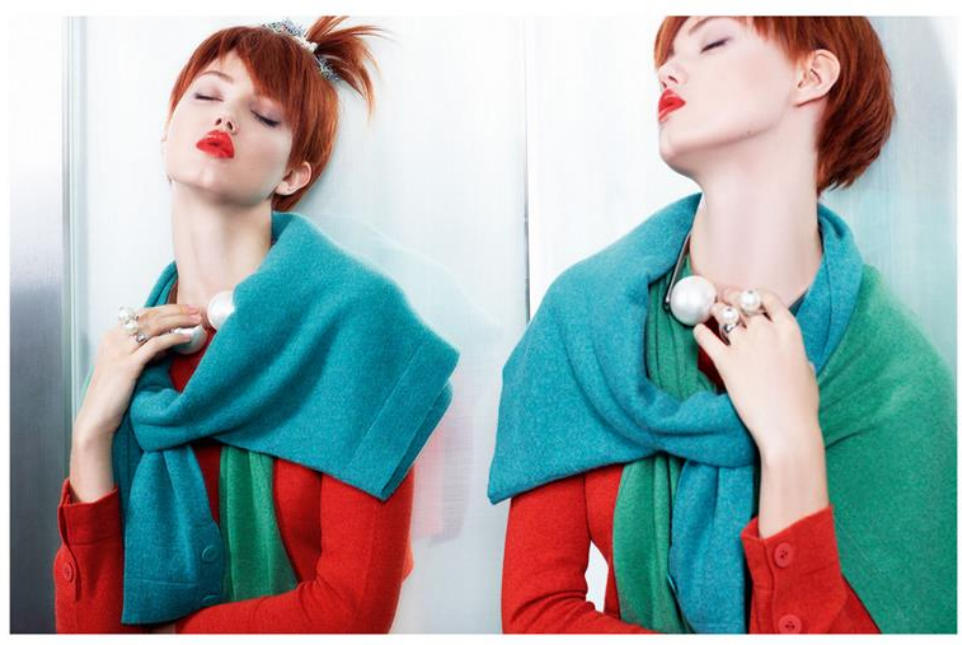

Figure 117 A: Chanel Official Website- Homepage Images 


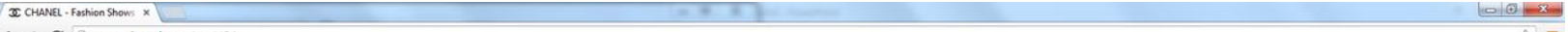

$\leftarrow \rightarrow C$ Q www.chanel.com/en_US

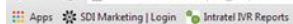

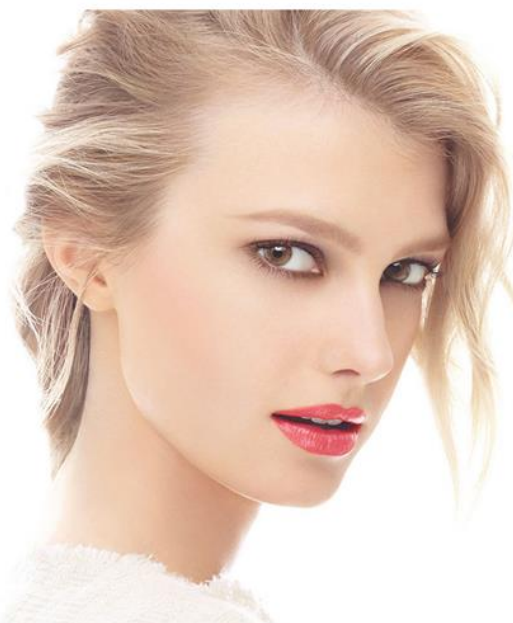

LE ROUGE CHANEL

Figure 117 B: Chanel Official Website- Homepage

$x$ CHankl - Fashion Show $\times \square$

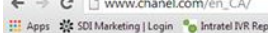

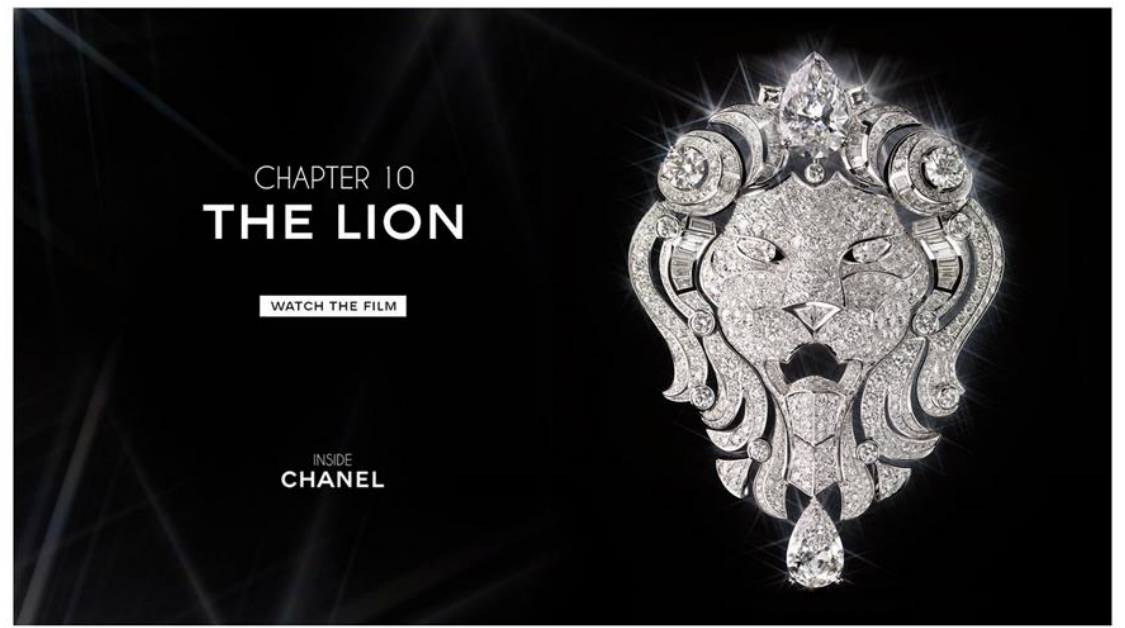

Figure 117 C: Chanel Official Website- Homepage 


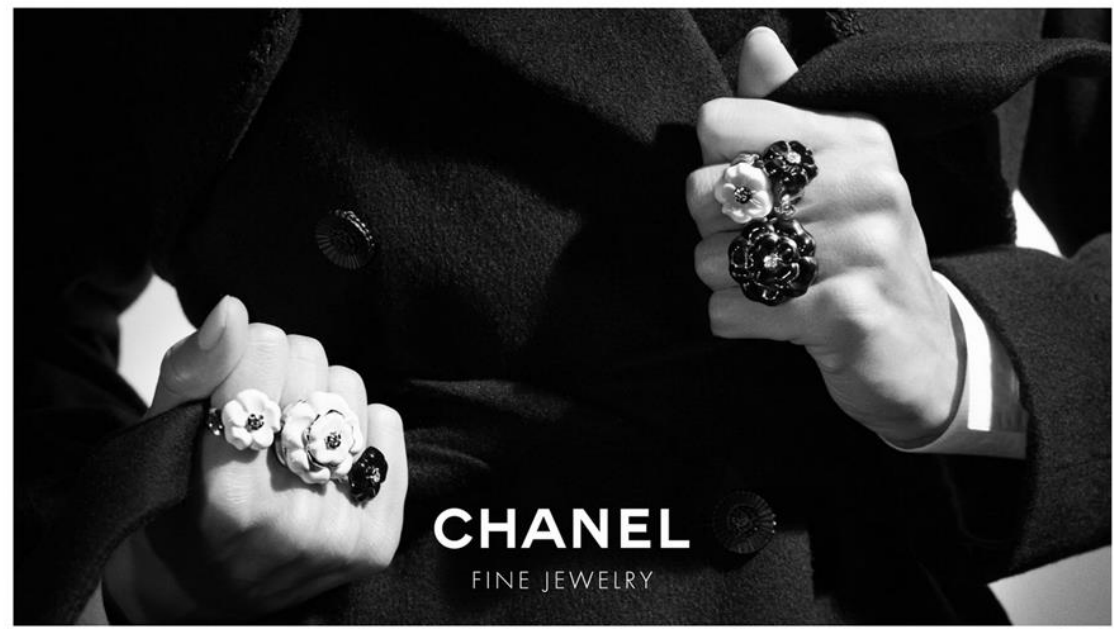

Figure 117 D: Chanel Official Website- Homepage

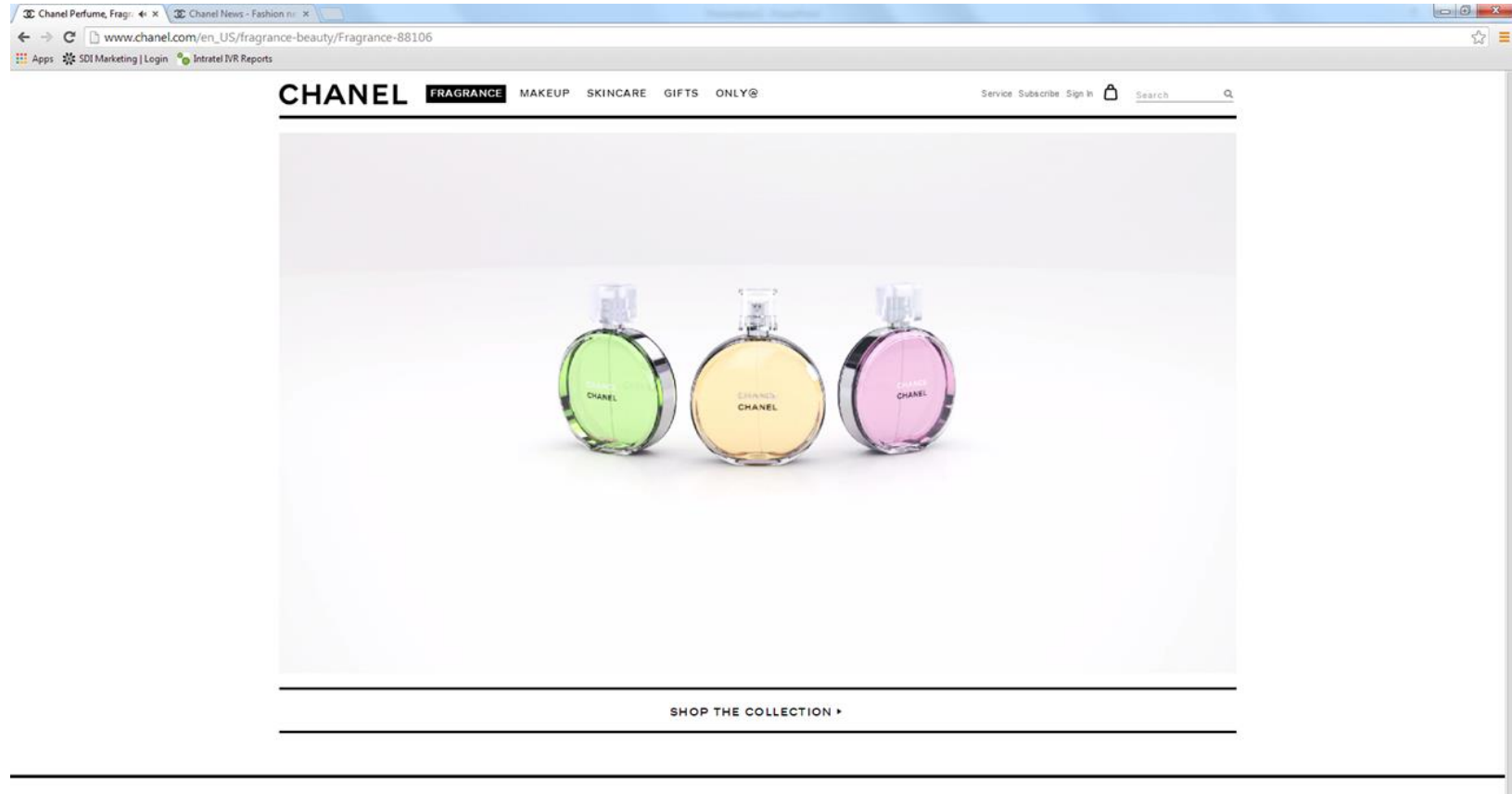

Figure 118: Chanel Official Website- Fragrance, Chanel Chance Homepage. 


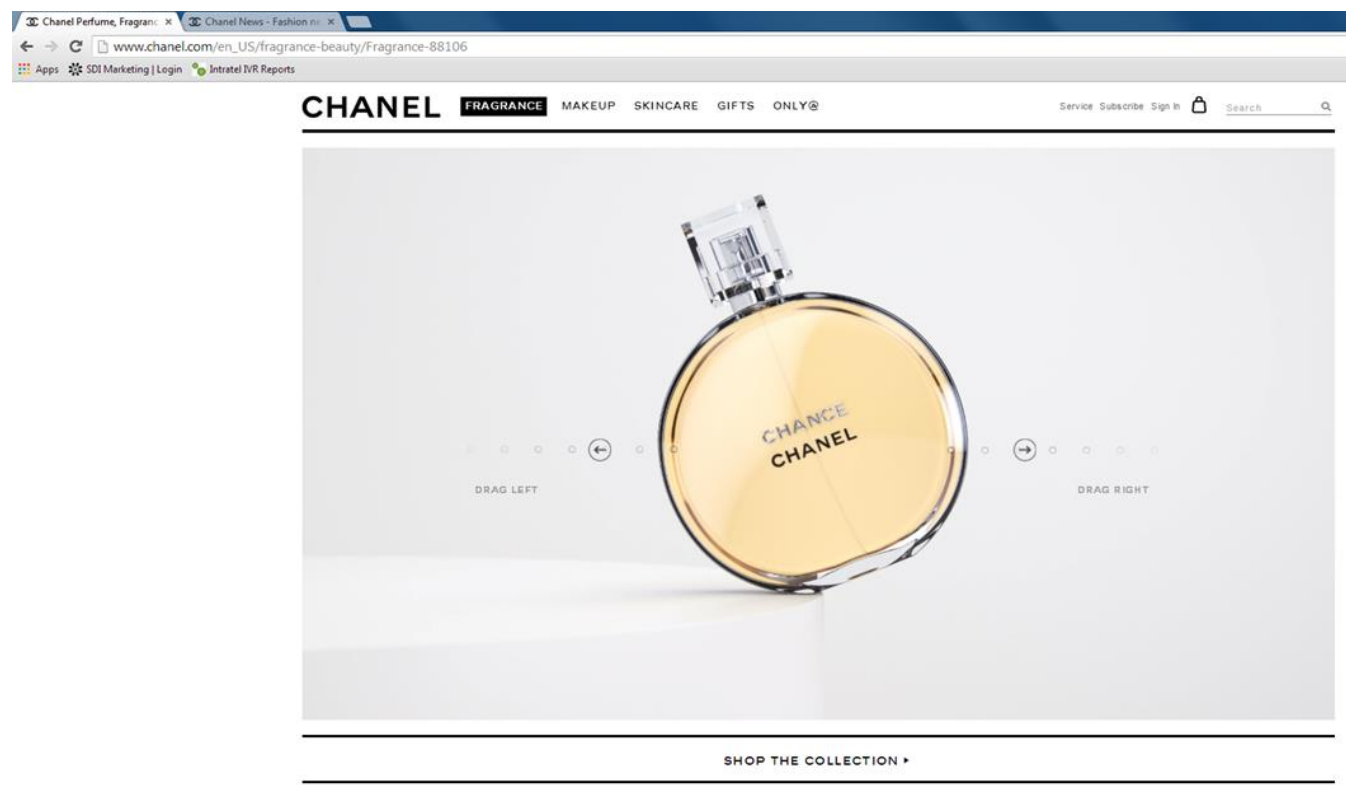

Mige chanel contact us complimentary shipping fá chanelcom.

Figure 119 A: Chanel Official Website- Fragrance, Chanel Chance Video.

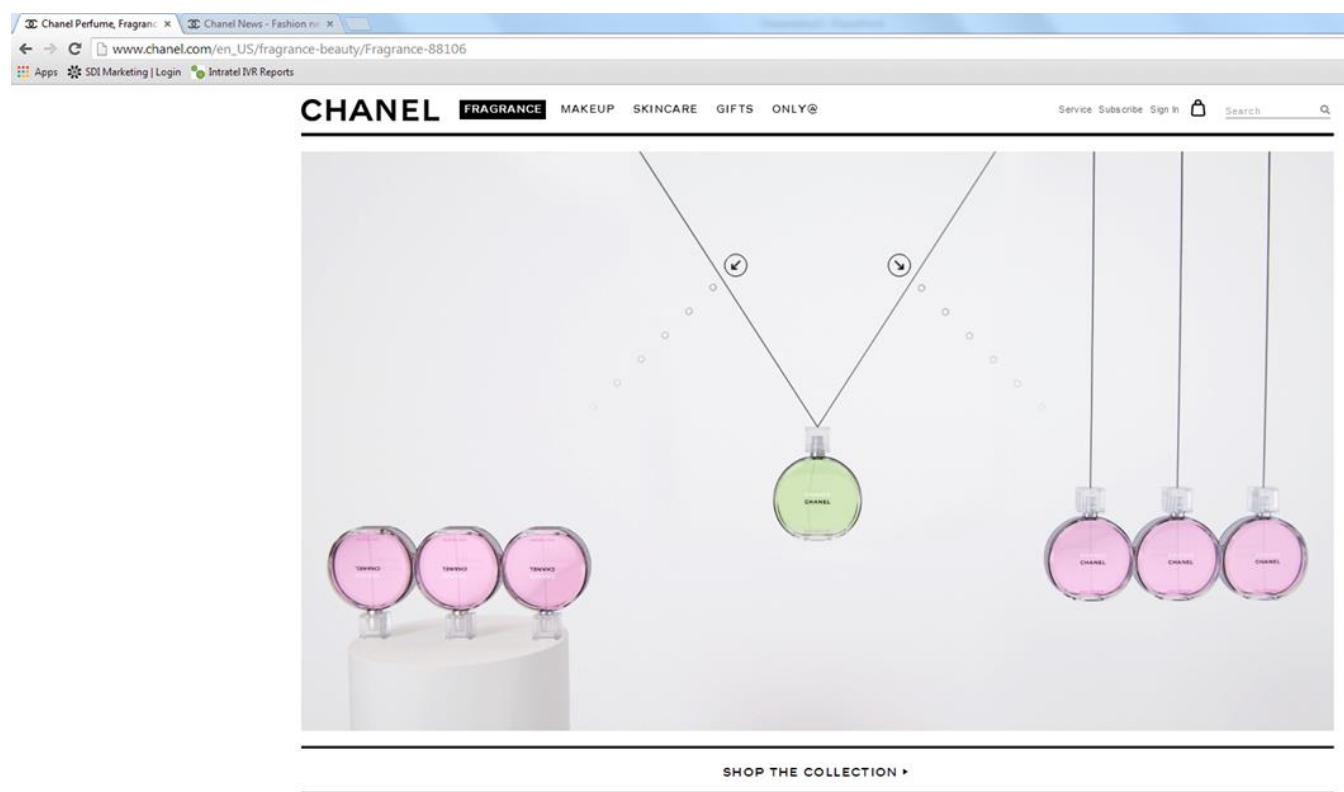

insioe chanel contact us complimentaky shipping fao chaneloom.

Figure 119 B: Chanel Official Website- Fragrance, Chanel Chance Video. 


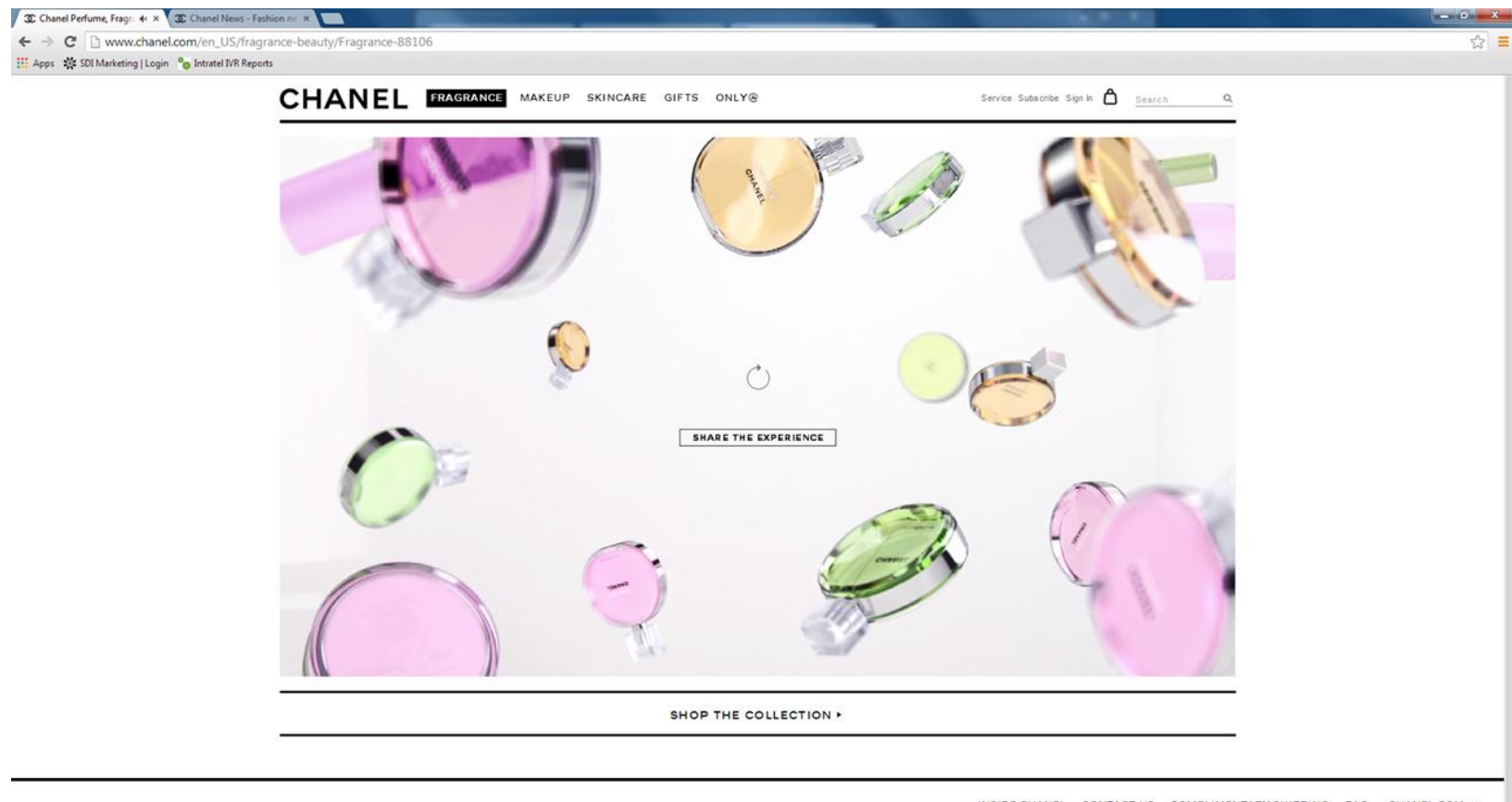

Figure 119 C: Chanel Official Website- Fragrance, Chanel Chance Video.

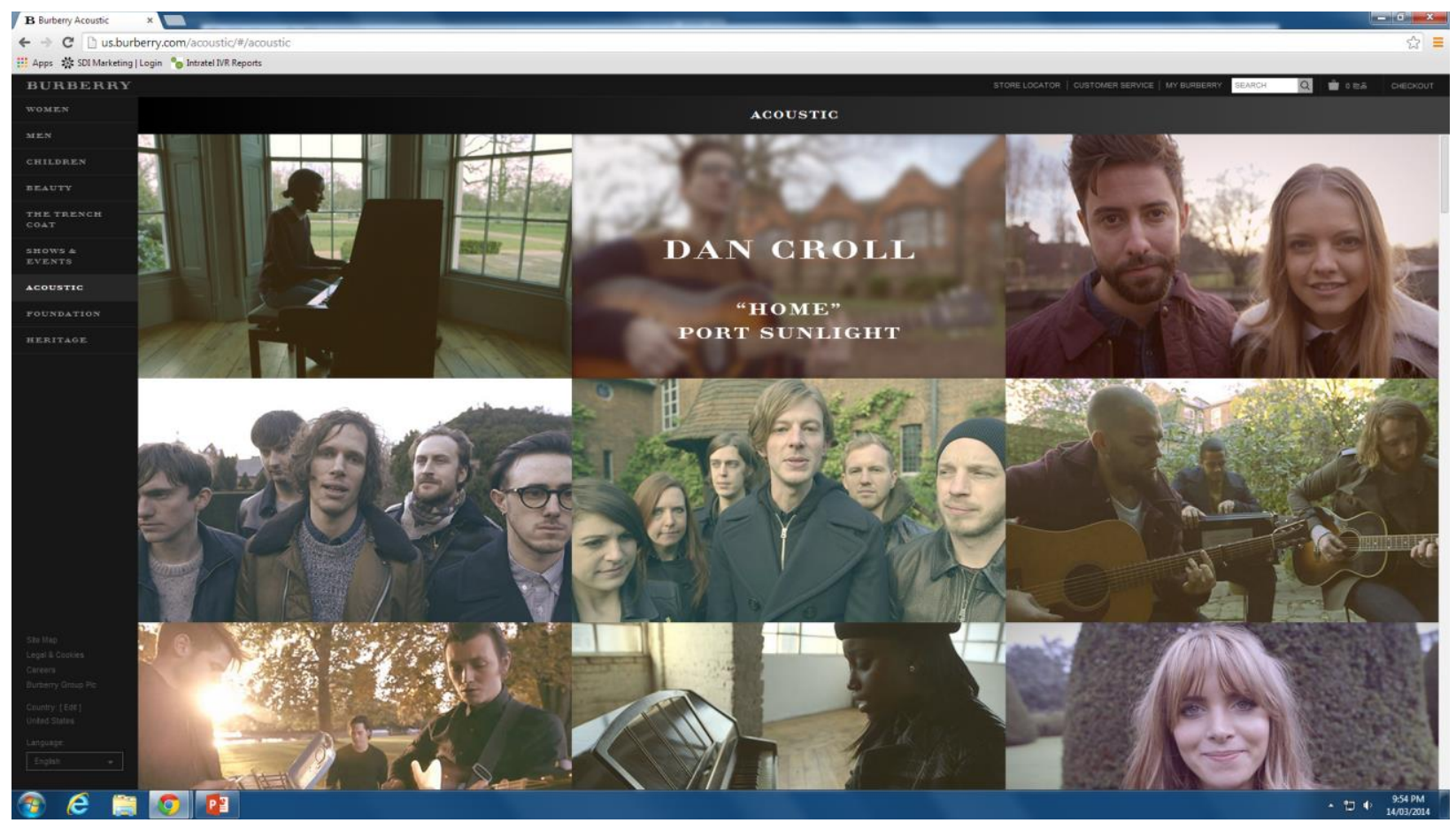

Figure 120: Burberry Official Website- "Acoustics" 


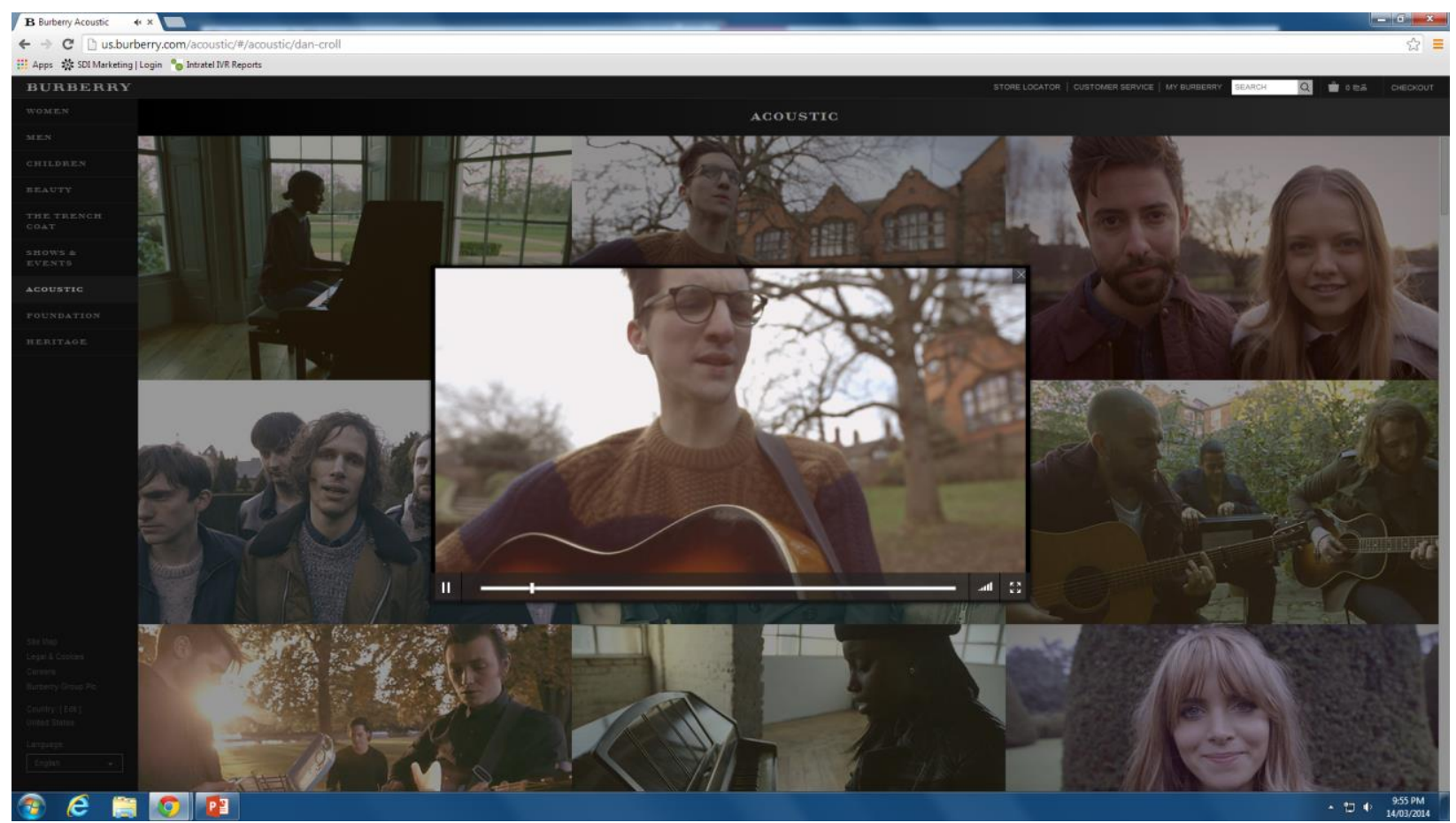

Figure 121: Burberry Official Website- "Acoustics"

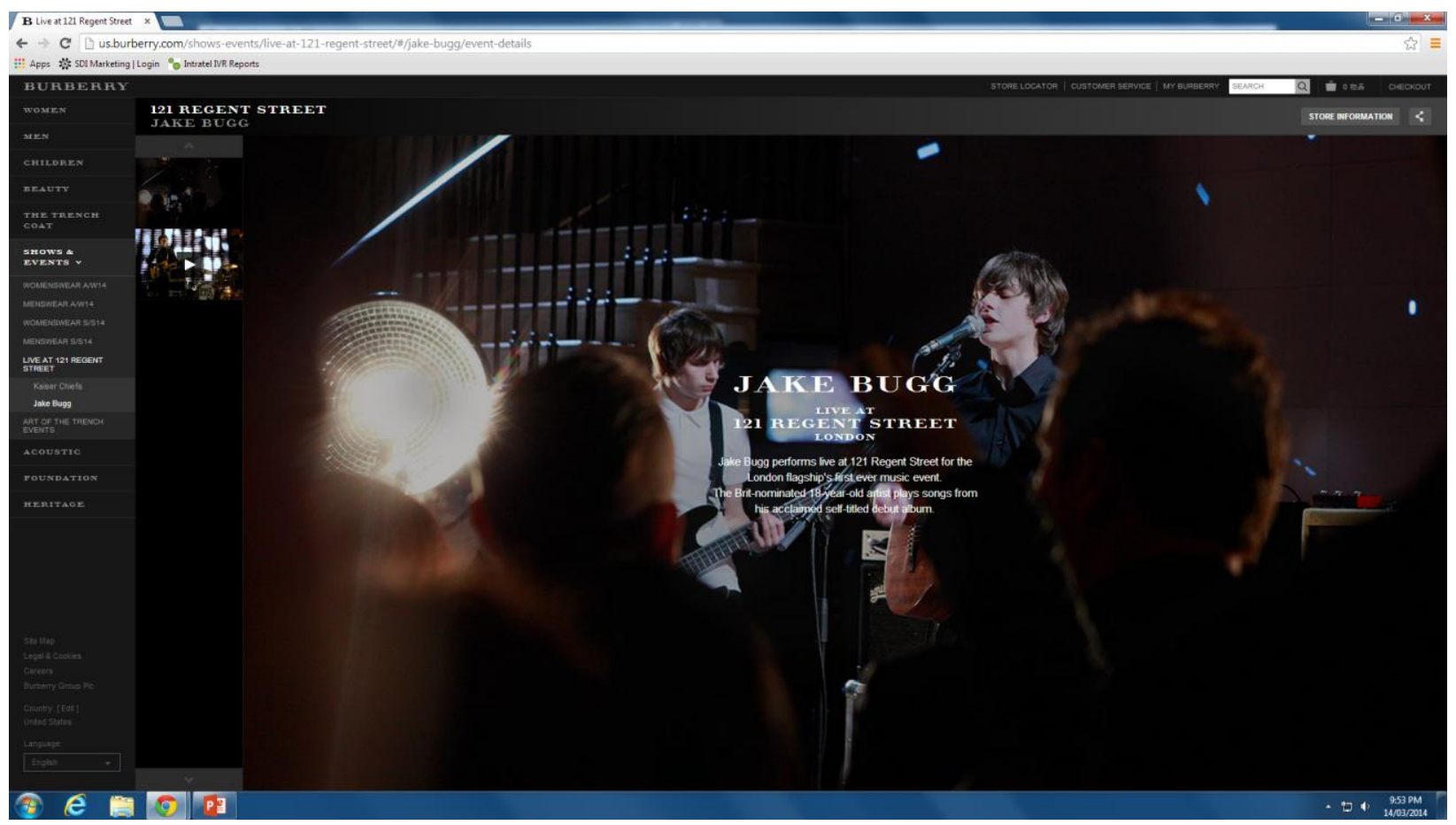

Figure 122: Burberry Official Website- "Live At 121 Regent Street"- Jake Bugg 


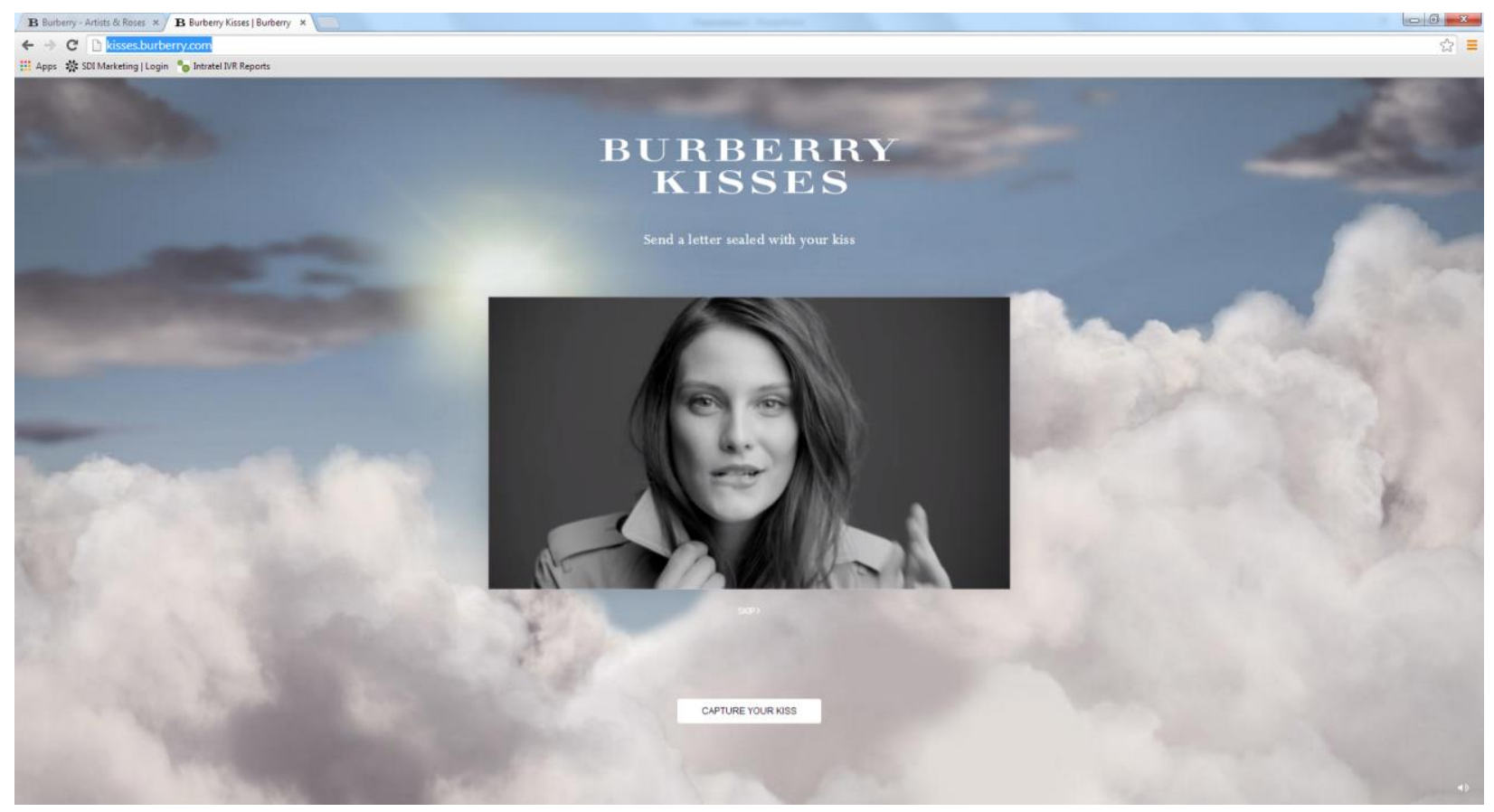

Figure 123 A: Burberry Online Website- Burberry Kisses Homepage

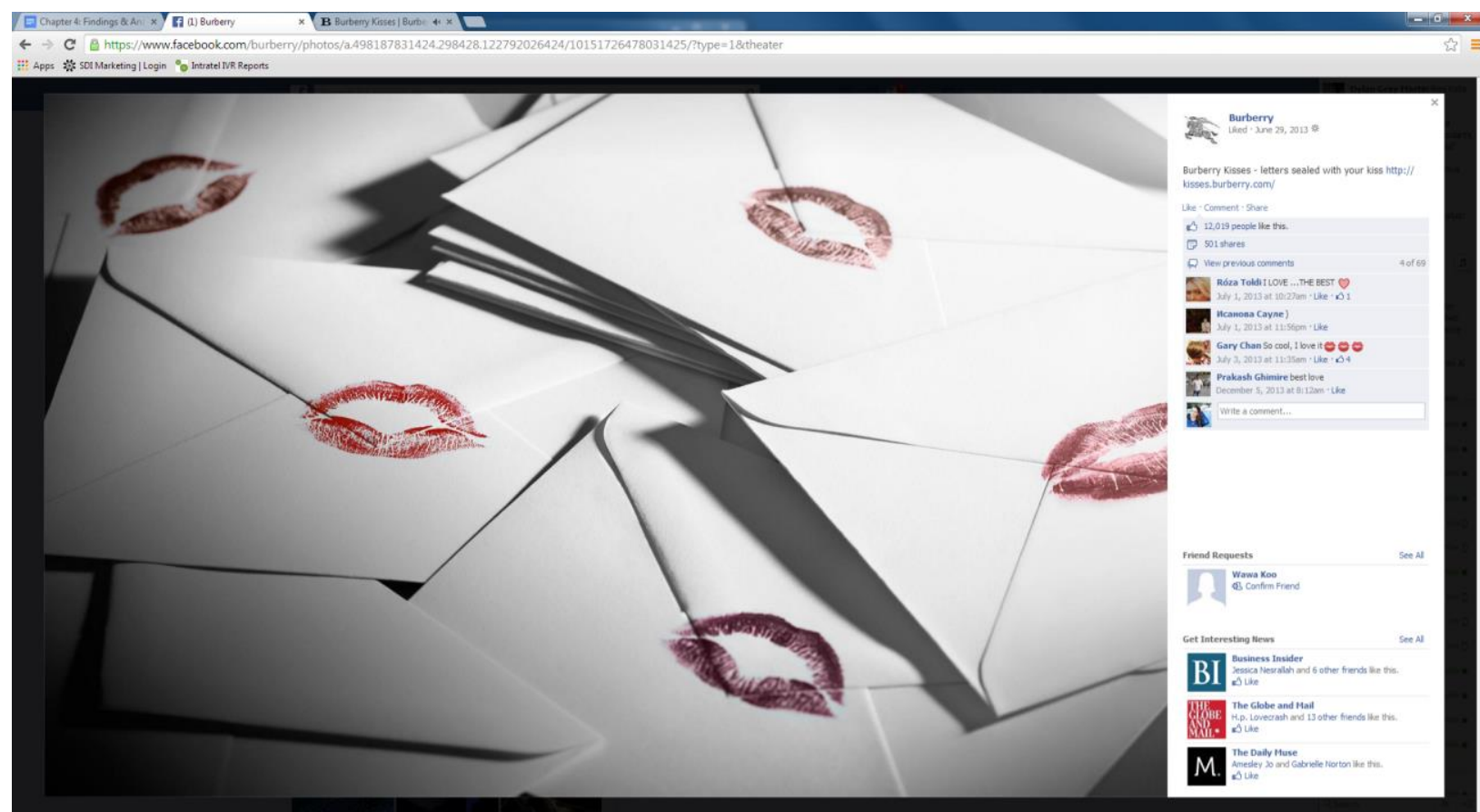

Figure 123 B: Burberry Facebook Page- Burberry Kisses Example 


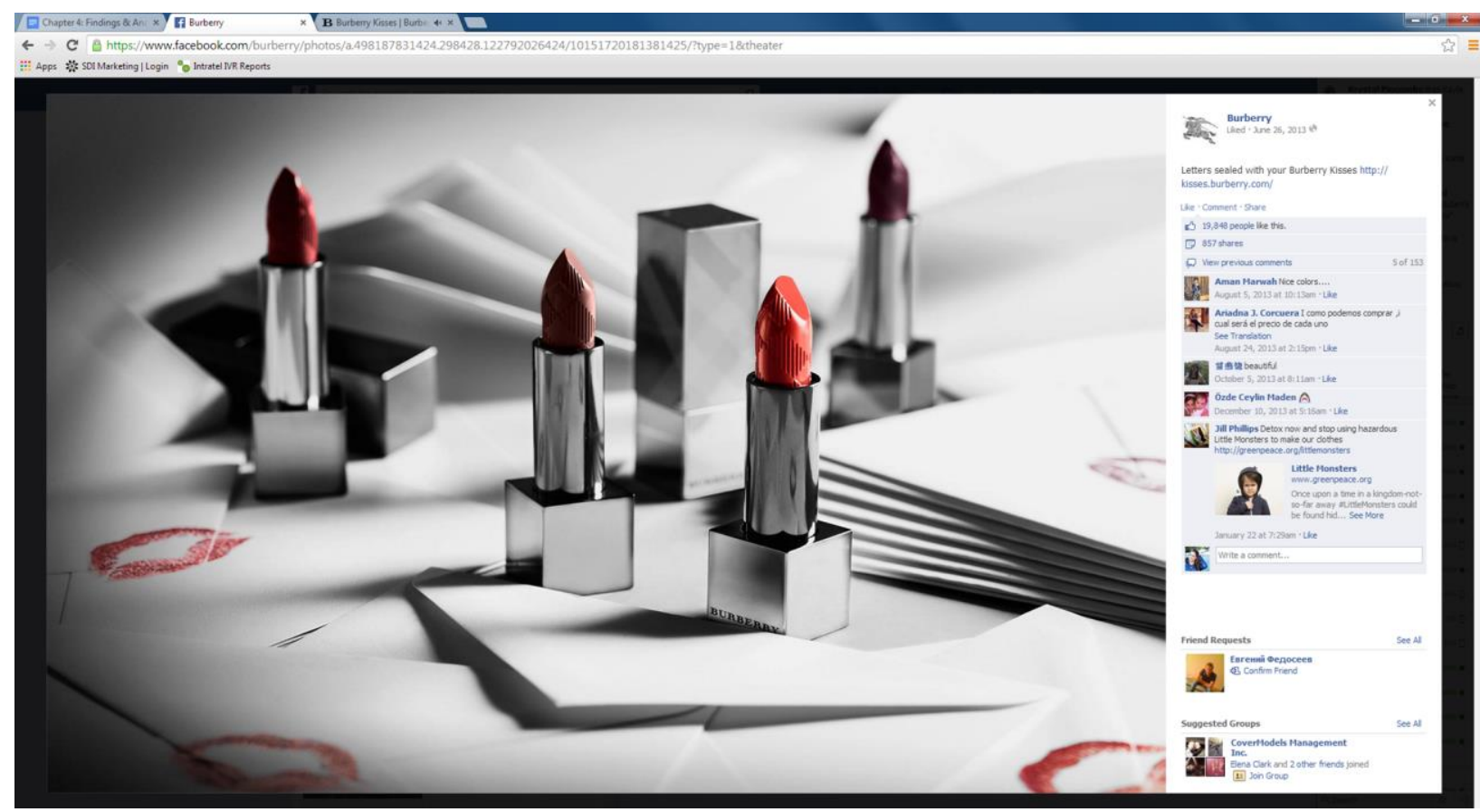

Figure 123 C: Burberry Facebook Page- Burberry Kisses Example

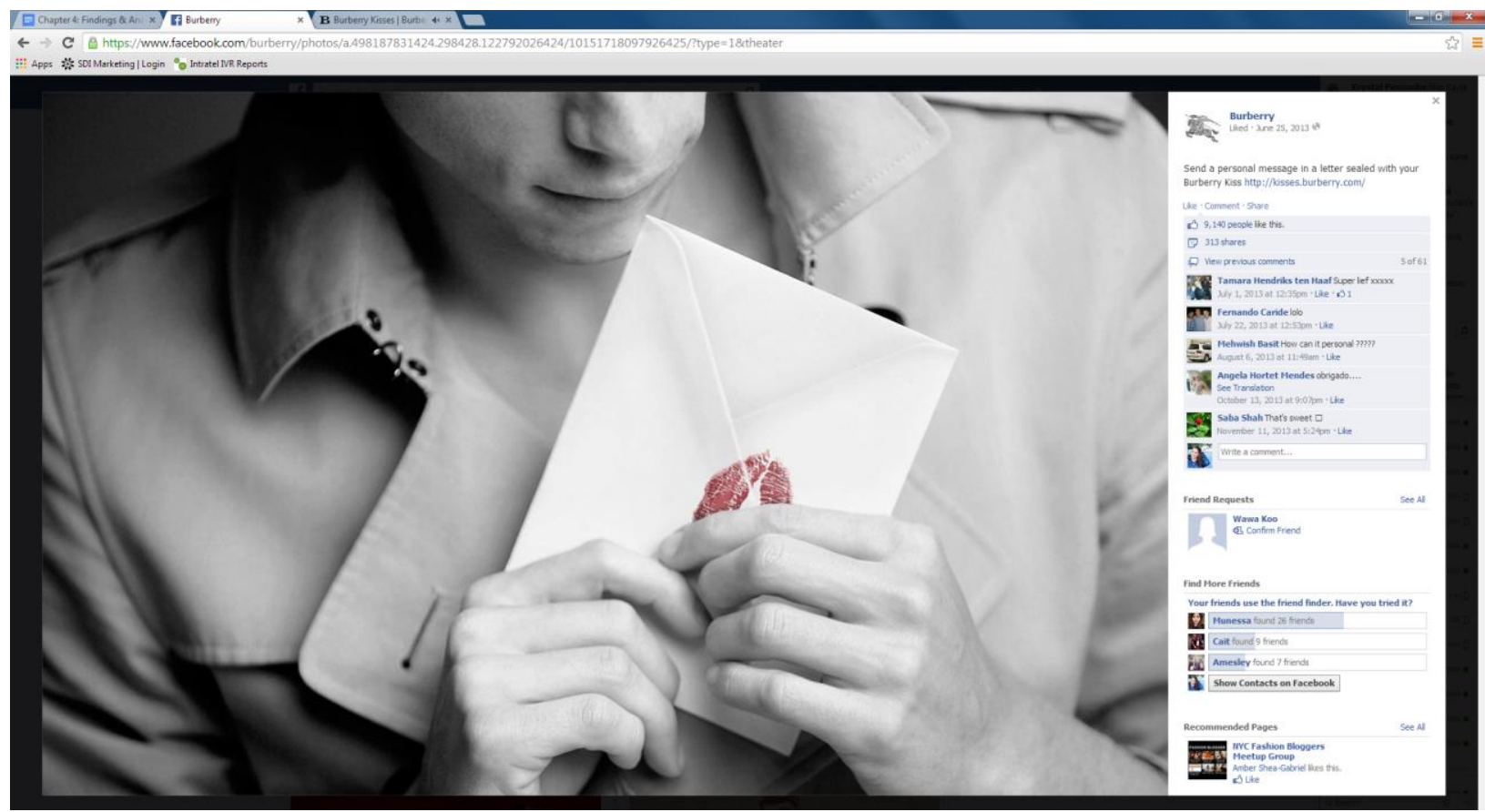

Figure 123 D: Burberry Facebook Page- Burberry Kisses Example 


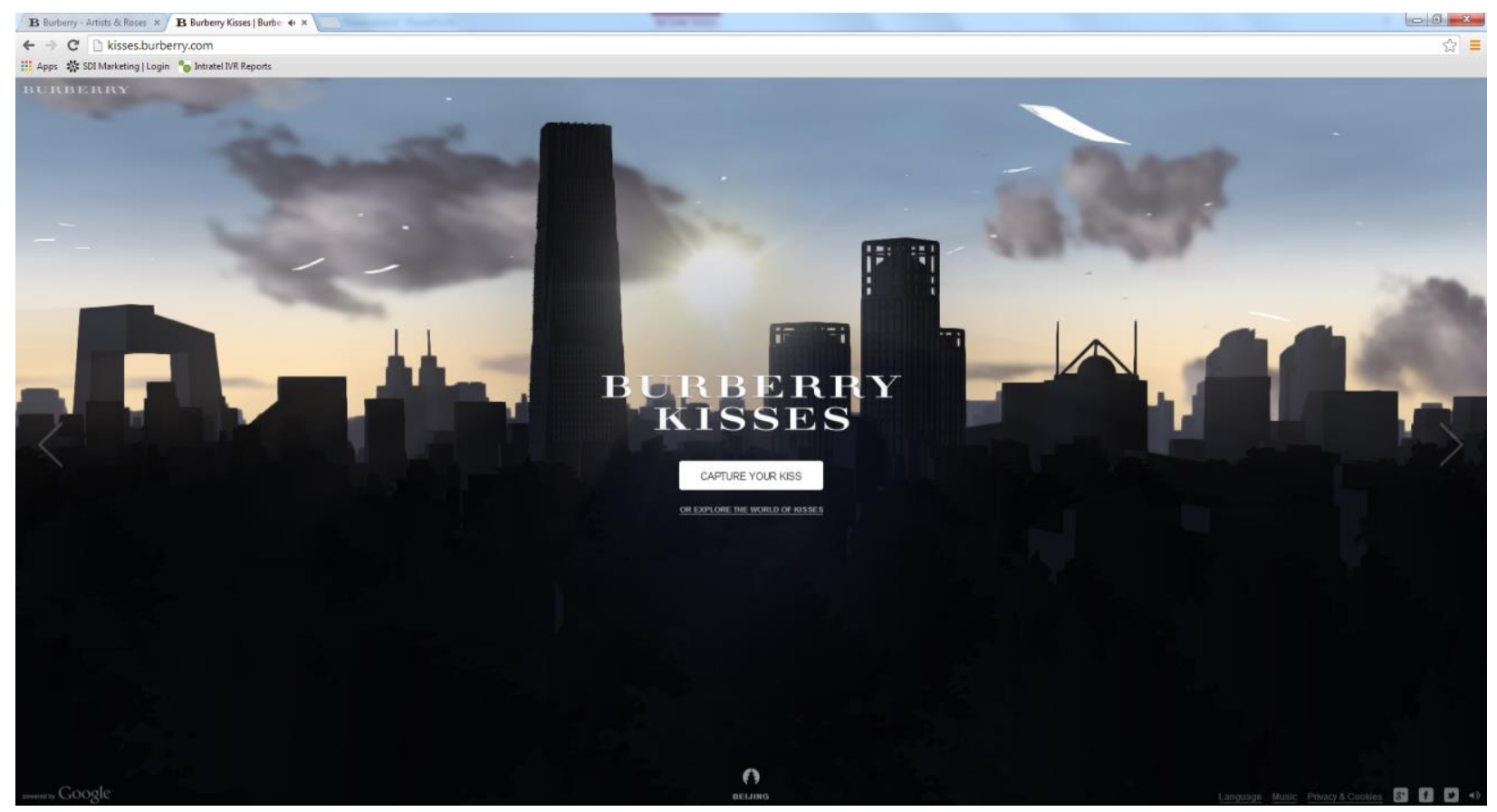

Figure 124: Burberry Online Website- Burberry Kisses (Capture Your Kisses)

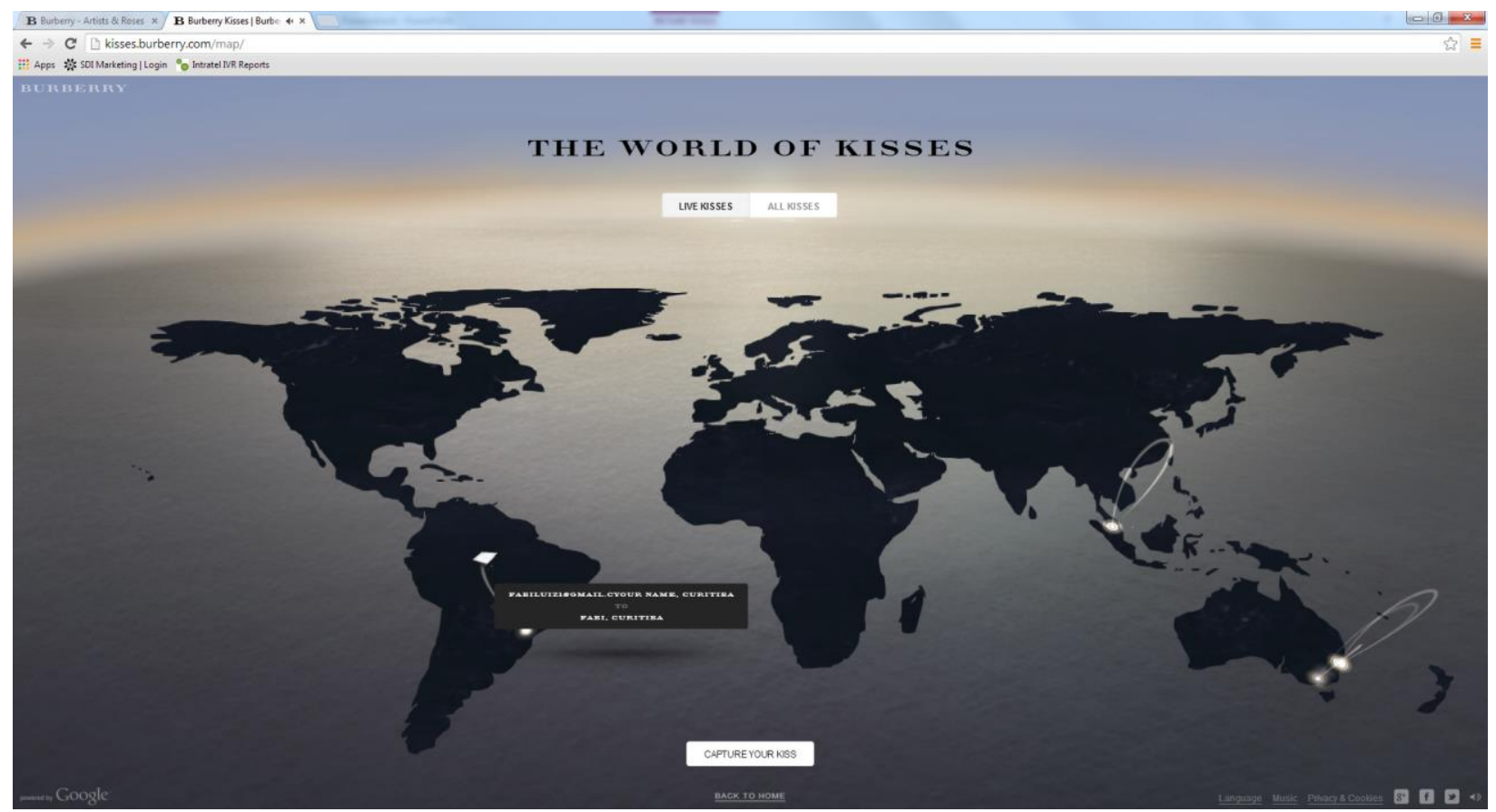

Figure 125: Burberry Online Website- Burberry Kisses (The World of Kisses) 


\section{Appendix 29: PHASE TWO: THIRD DIMENSION: PRODUCT INTEGRITY}

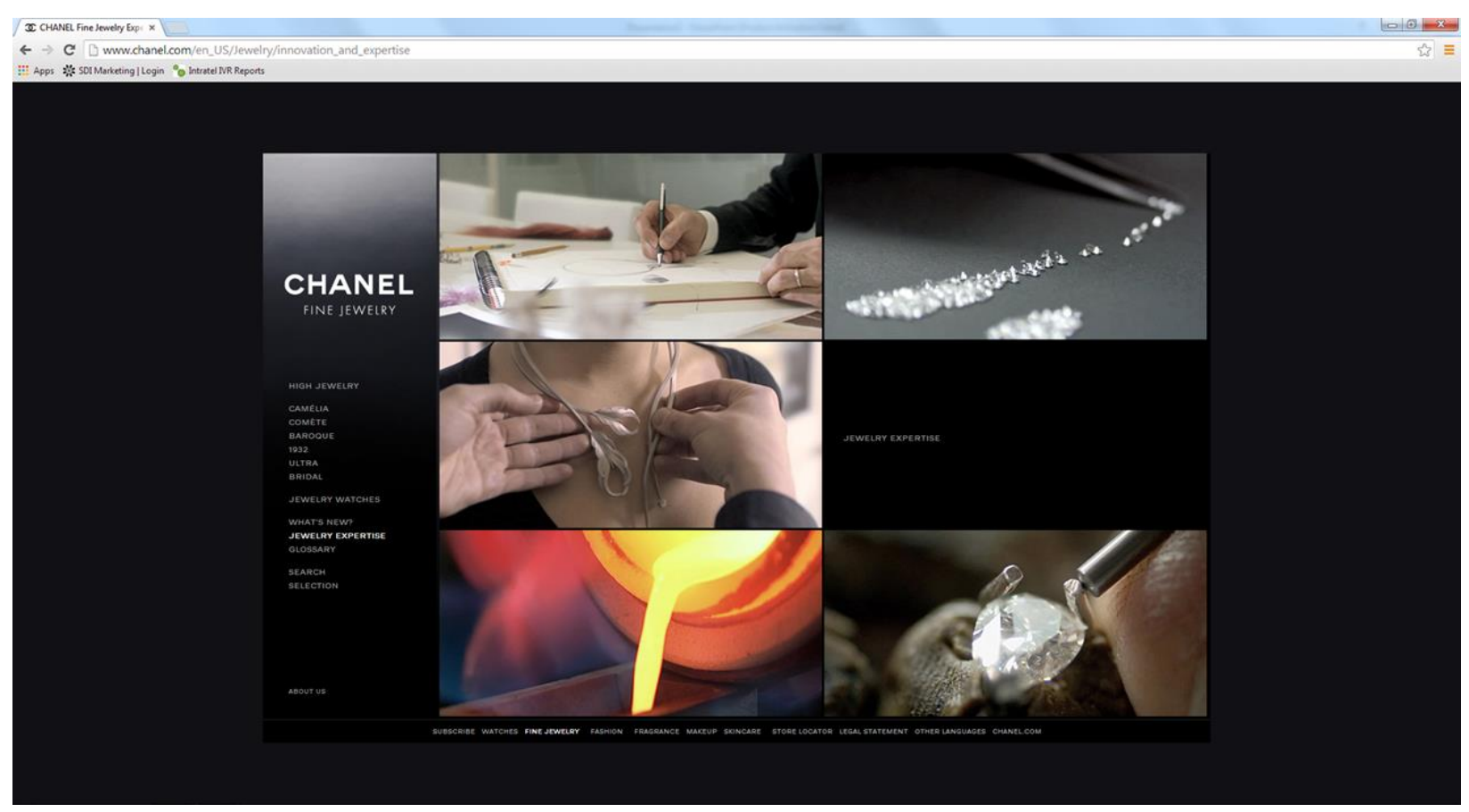

Figure 126 A: Chanel Jewelry Expertise: Setting the Stones, Selecting the Stones, The Creation, The Model, Casting

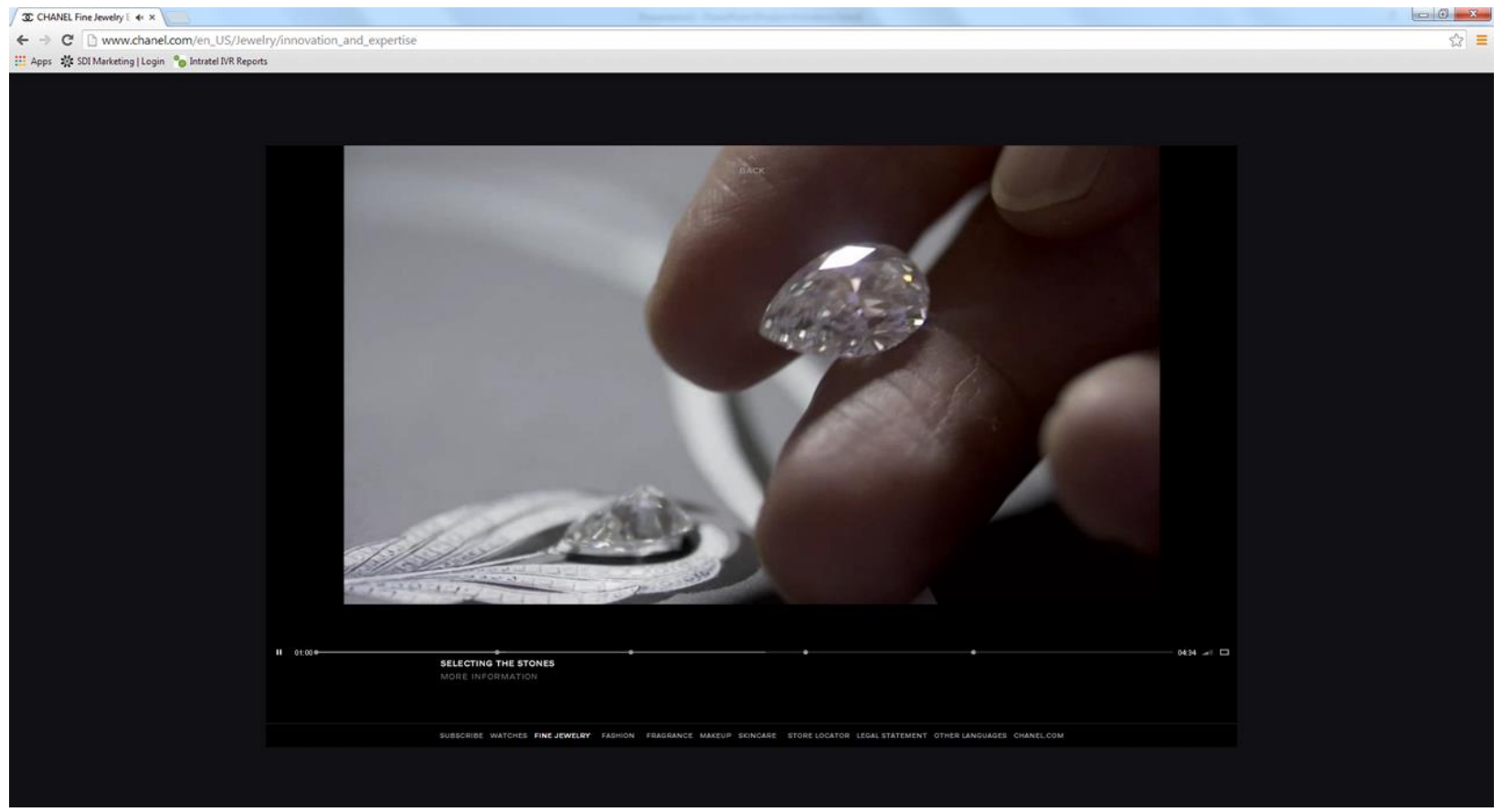

Figure 126 B: Chanel Jewelry Expertise Video: Setting the Stones, Selecting the Stones, The Creation, The Model, Casting 


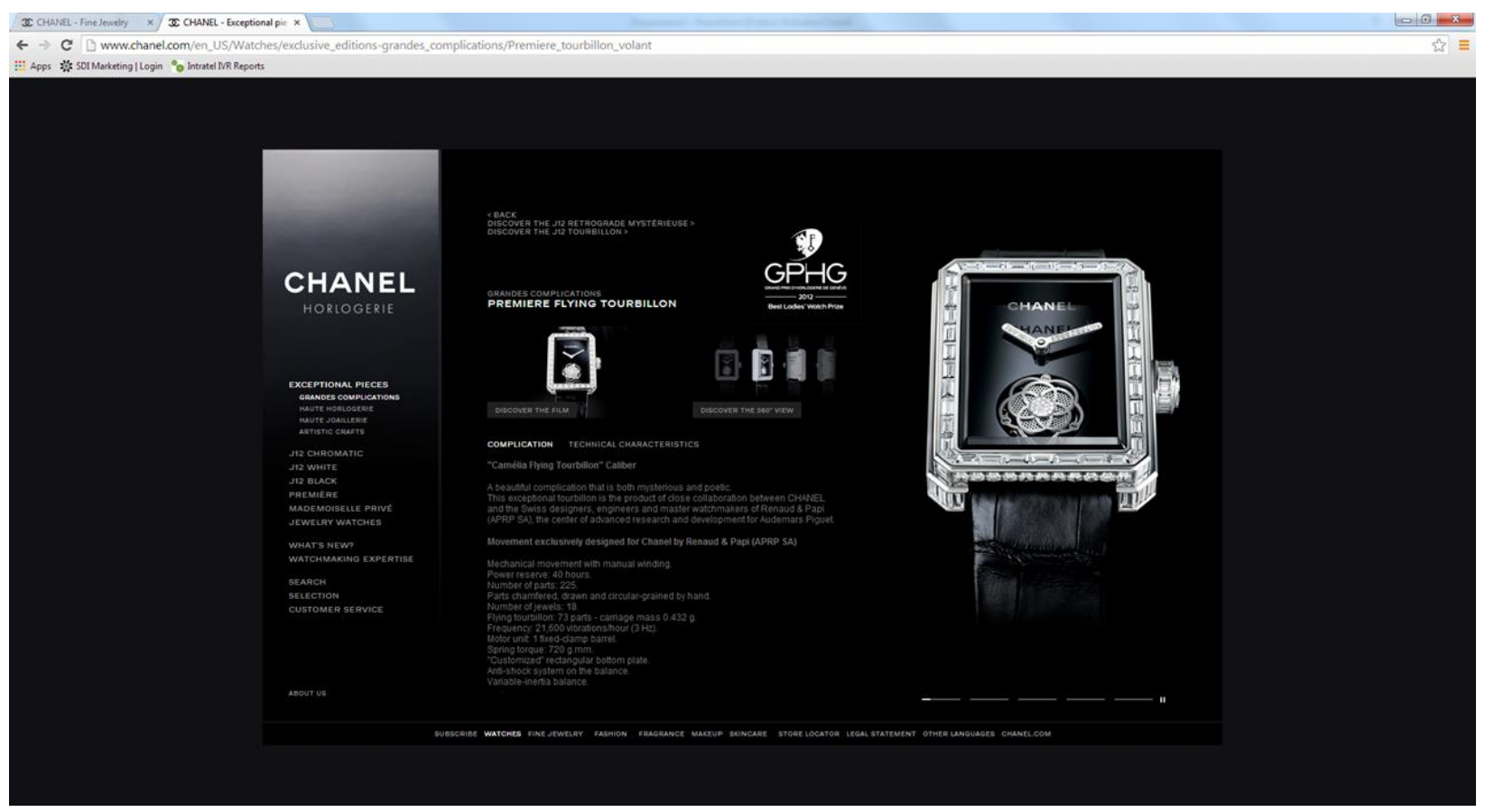

Figure 127 A: Chanel Horlogerie- Exceptional Pieces- 'Grandes Complications'

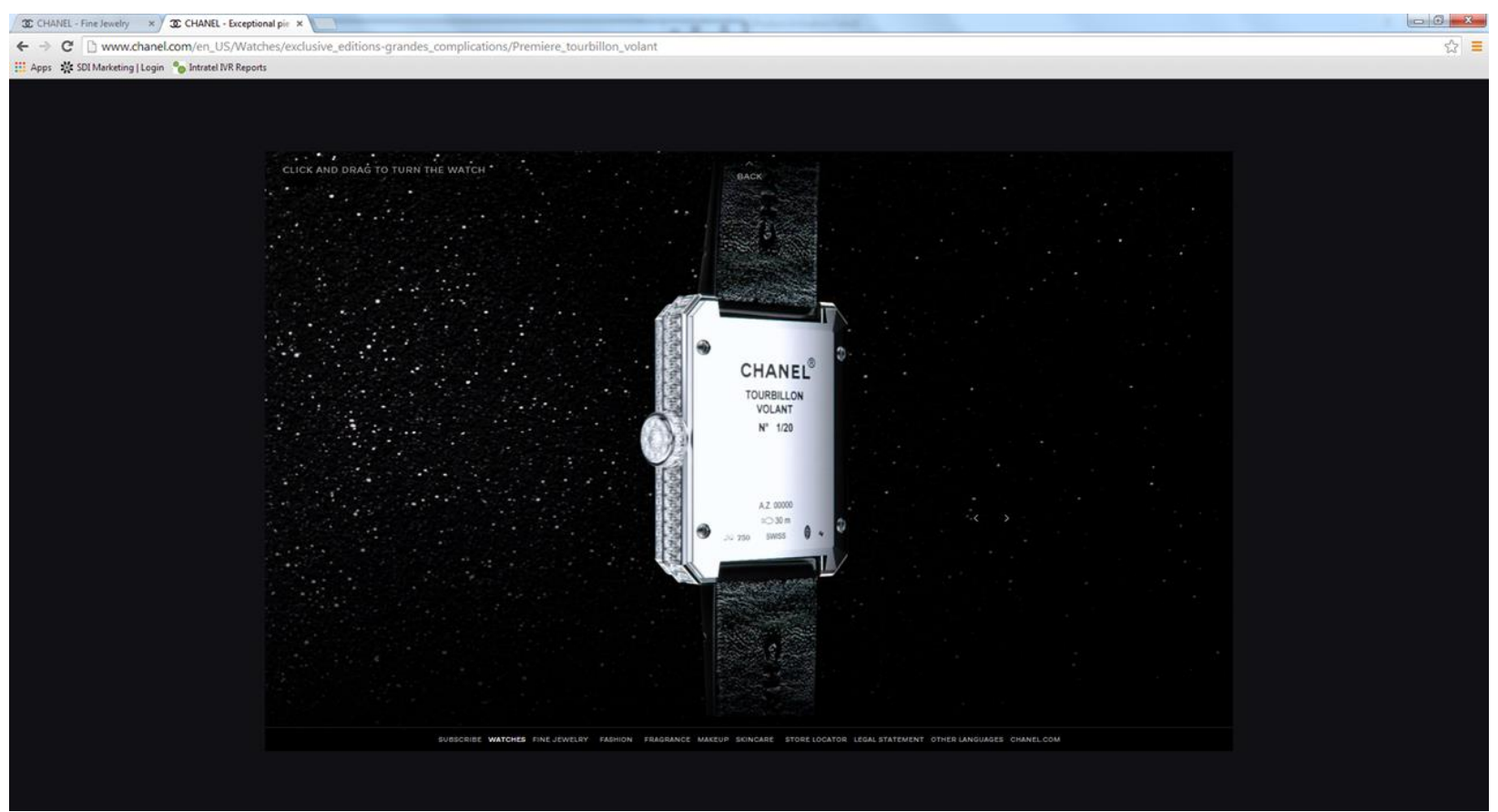

Figure 127 B: Chanel Horlogerie- Exceptional Pieces- 'Grandes Complications' (360 Degree View) 


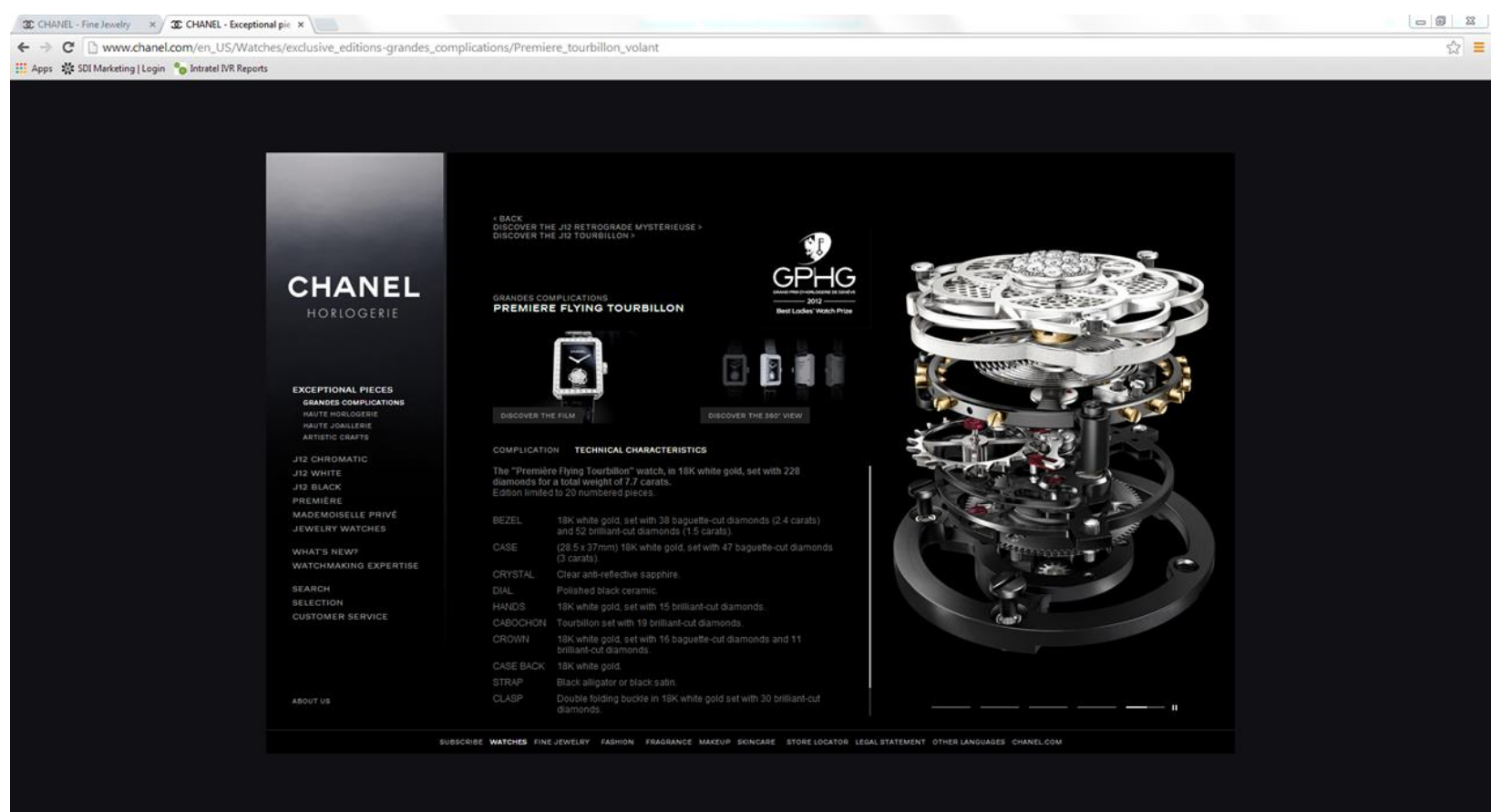

Figure 128 A: Chanel Horlogerie- Exceptional Pieces- 'Grandes Complications' (Description)

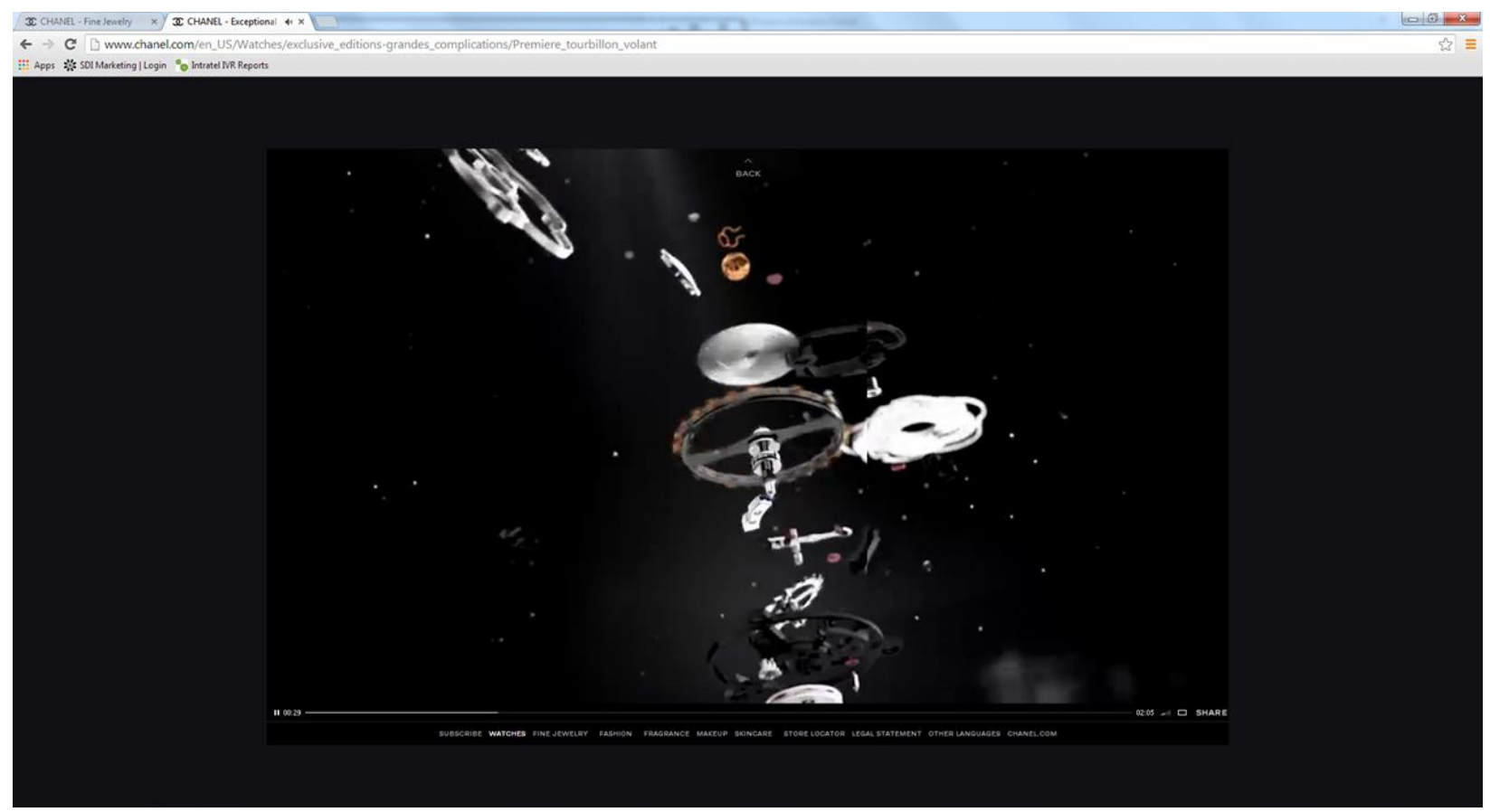

Figure 128 B: Chanel Horlogerie- Exceptional Pieces- 'Grandes Complications' (Video) 


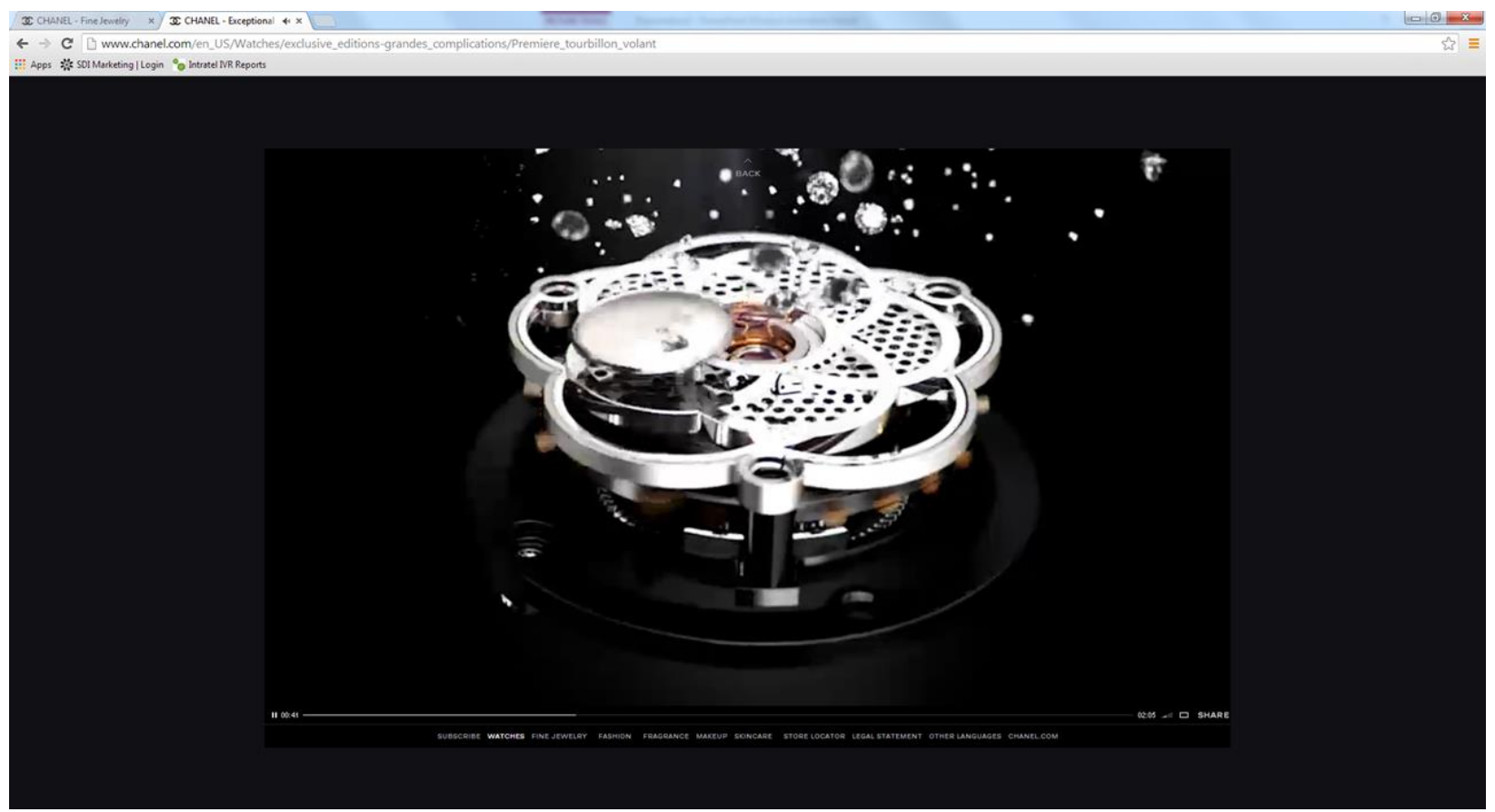

Figure 128 C: Chanel Horlogerie- Exceptional Pieces- 'Grandes Complications' (Video)

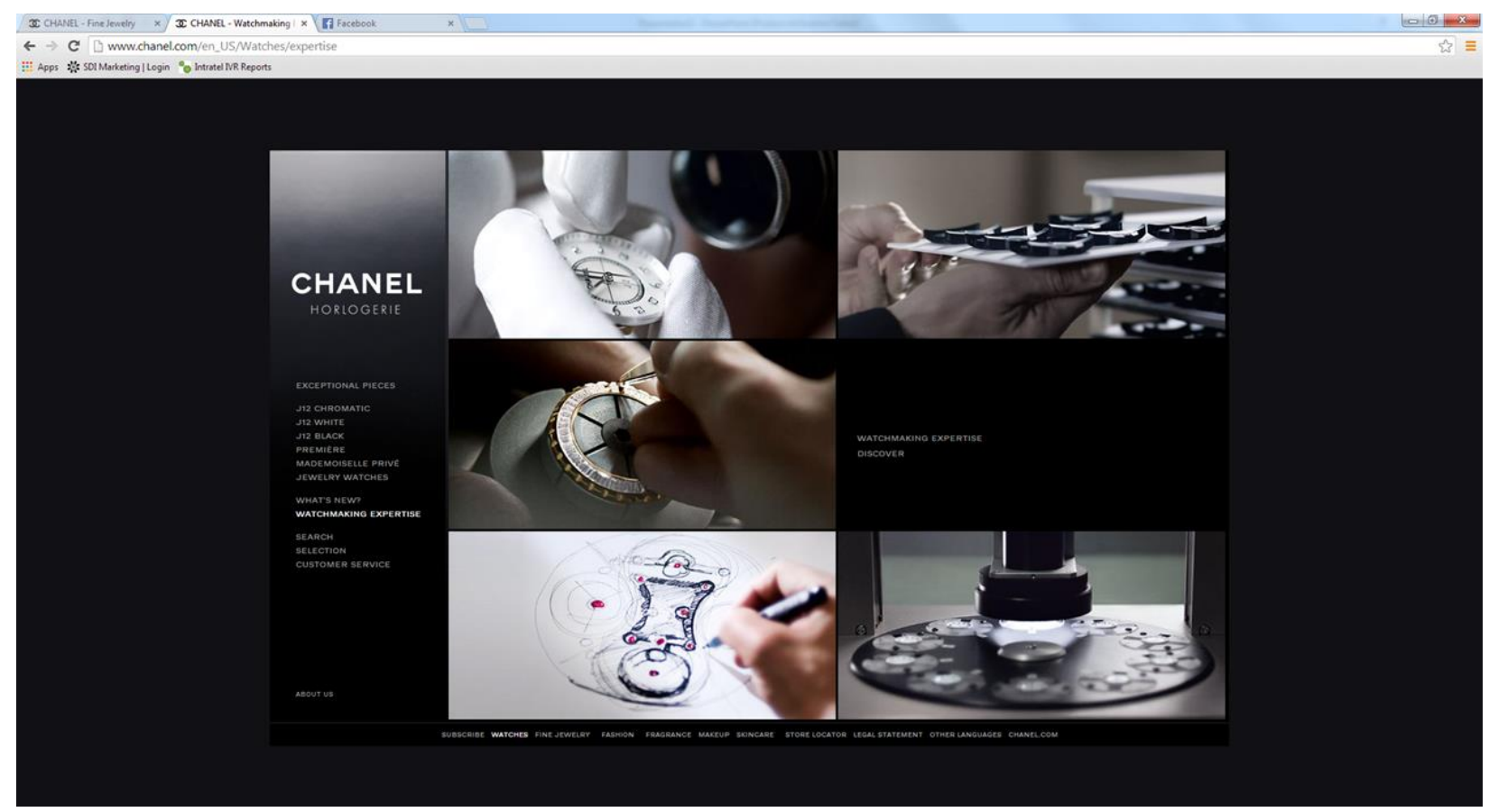

Figure 128 D: Chanel Horlogerie- Watchmaking Expertise Video: Manufacture of Watch Cases, The Precise Gestures of a Jeweler, The Ultimate Grande Complication, The Art and Mastery of Ceramic, How the Inspiration is Conveyed Through The Machine 


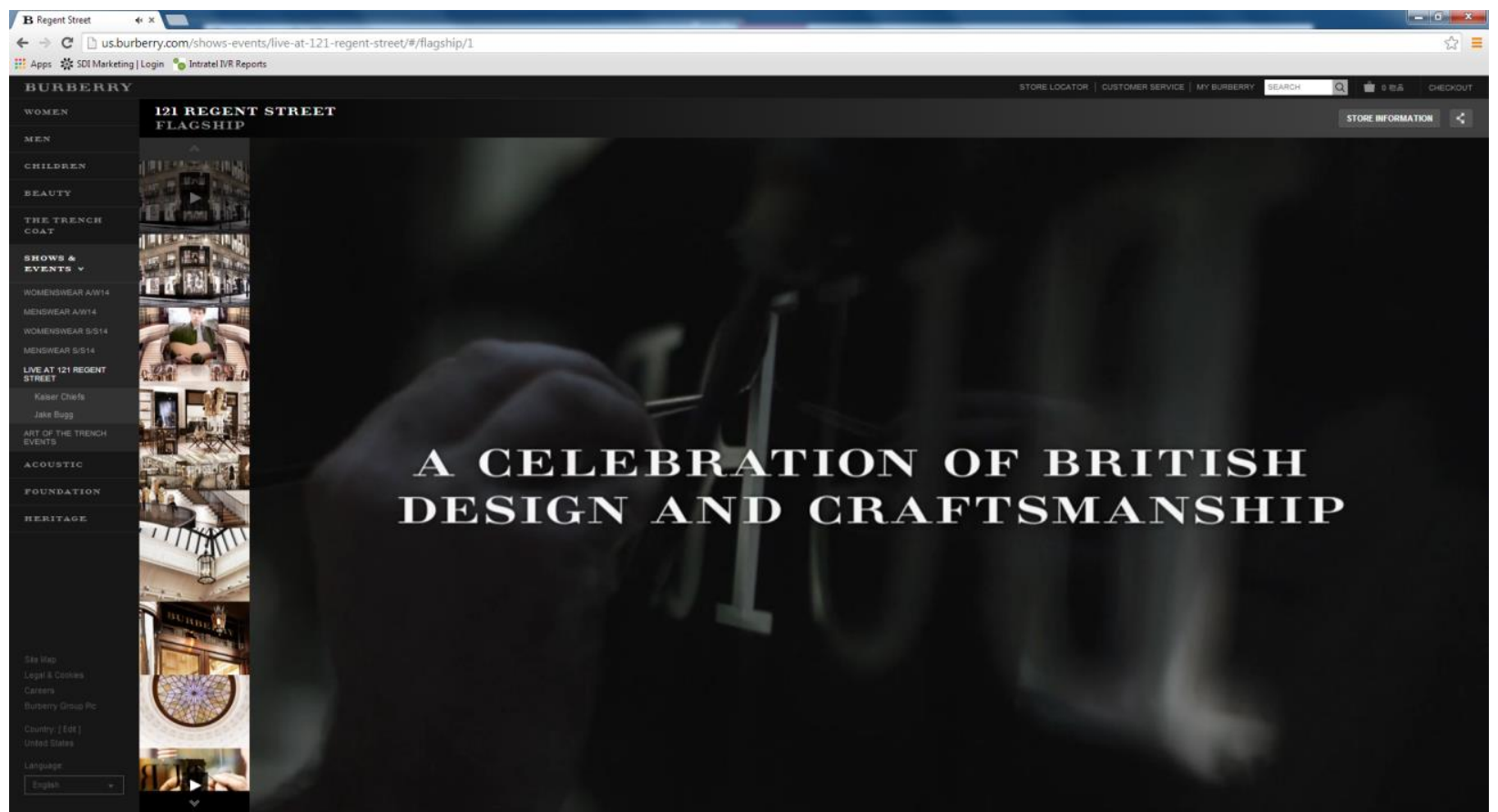

Figure 129 A: Burberry "Live at 121 Regent Street"- (Design \& Craftsmanship)

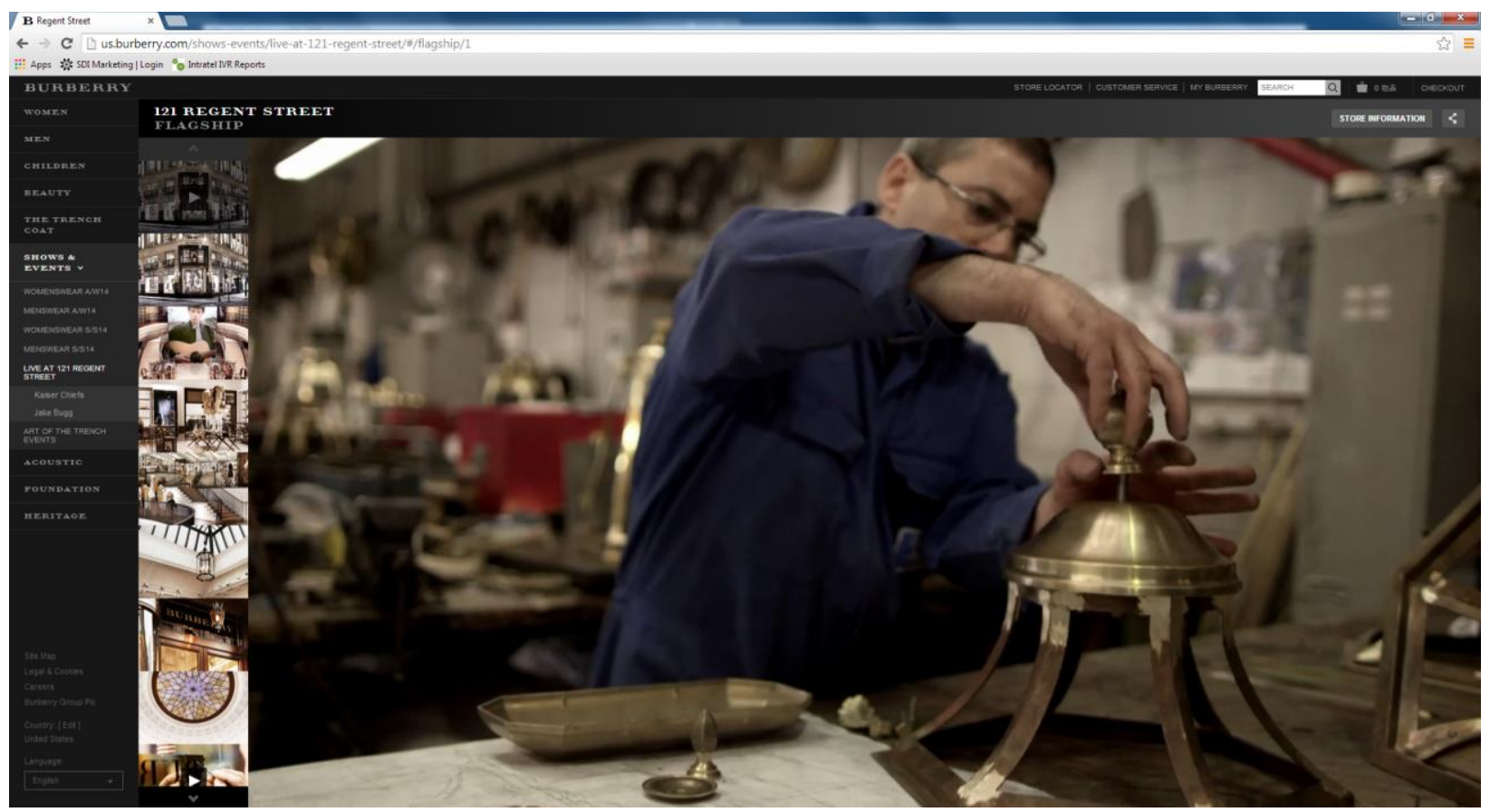

Figure 129 B: Burberry "Live at 121 Regent Street"- (Design \& Craftsmanship) 


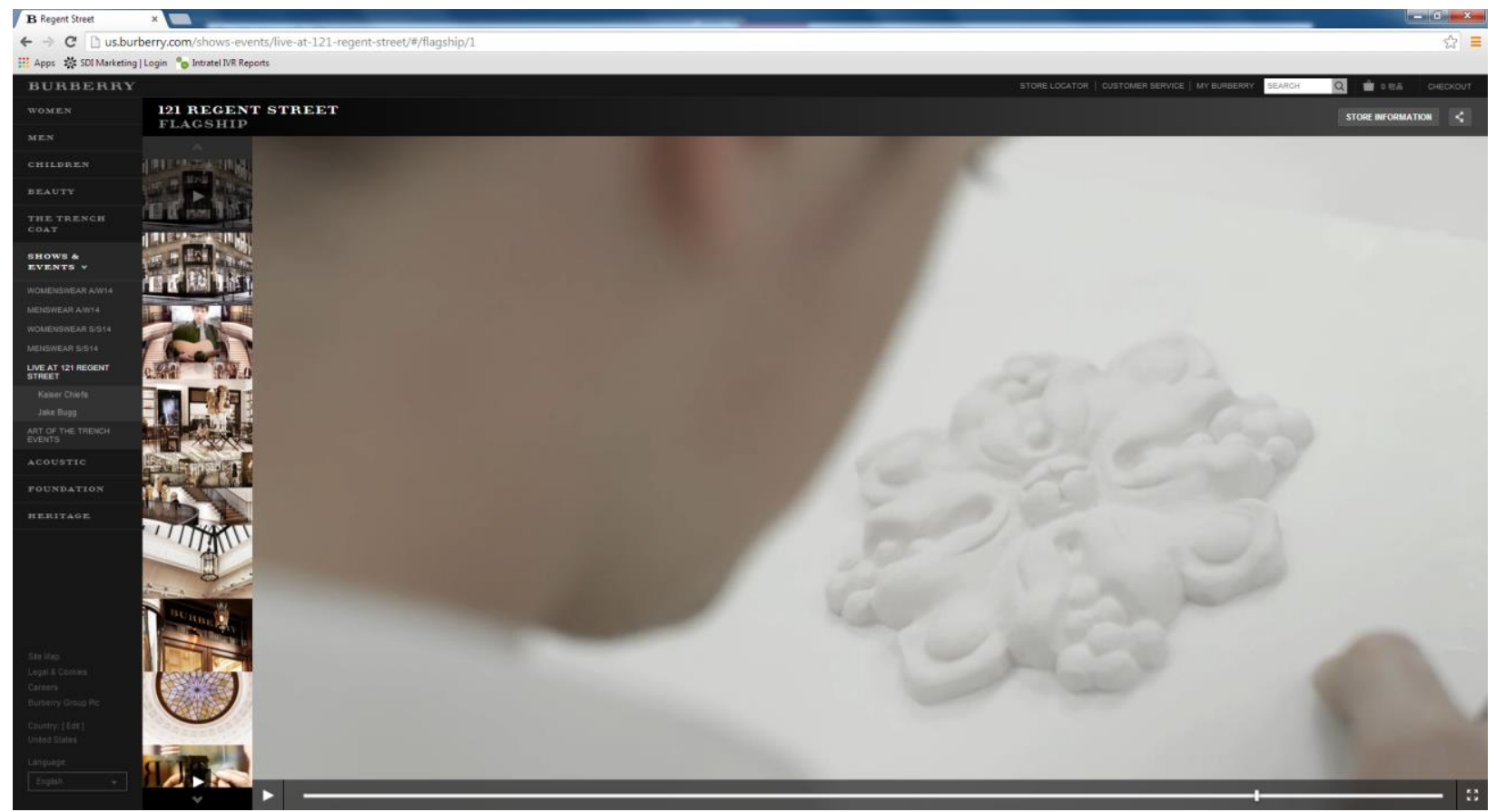

Figure 129 C: Burberry "Live at 121 Regent Street"- (Design \& Craftsmanship)

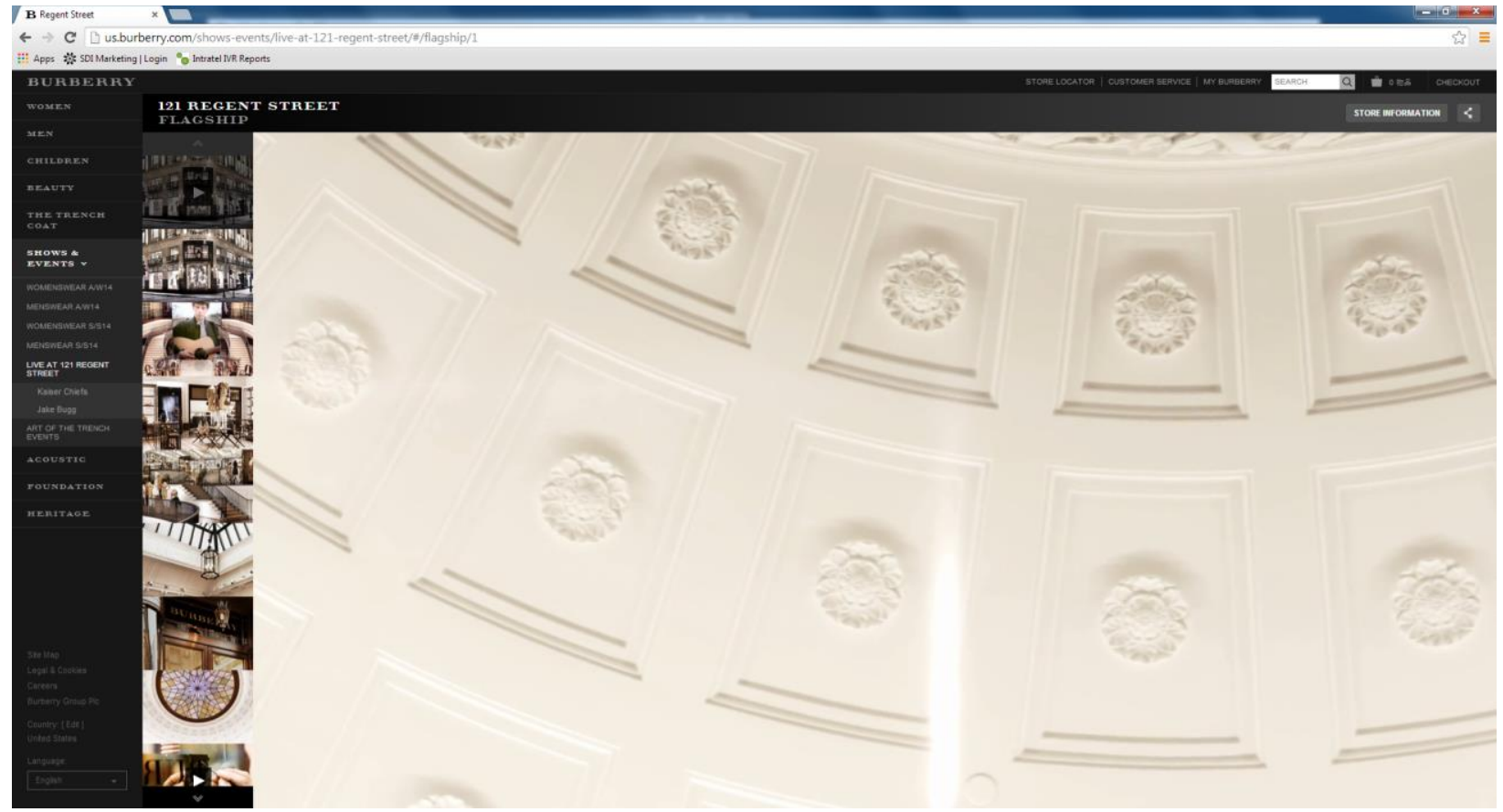

Figure 129 D: Burberry "Live at 121 Regent Street"- (Design \& Craftsmanship) 
Appendix 30: PHASE TWO: FOURTH DIMENSION: BRAND SIGNATURE

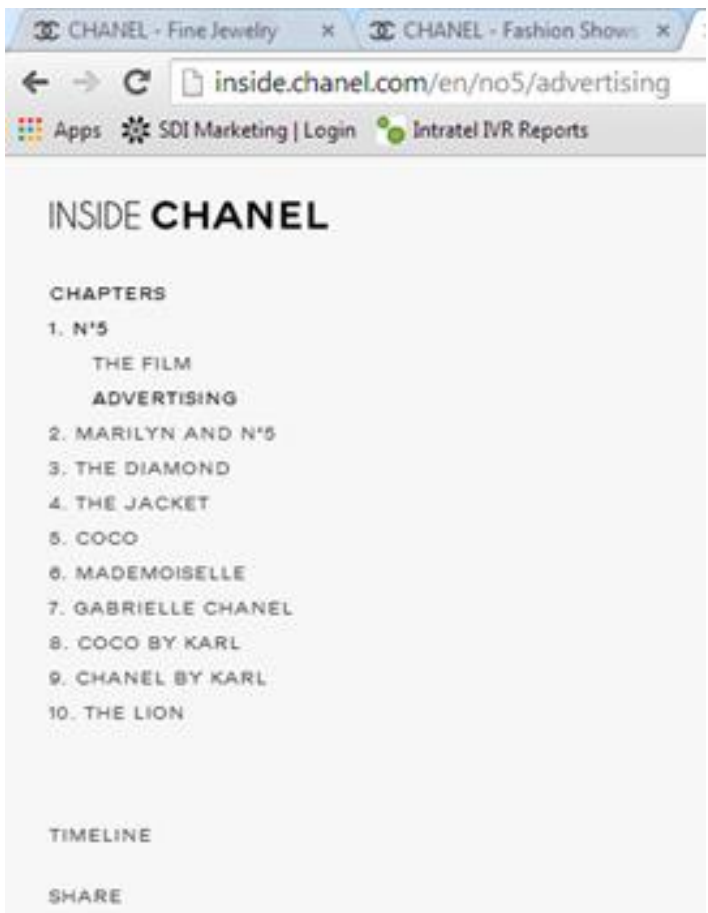

Figure 130: Chanel Official Website- "Inside Chanel- The Chapters"

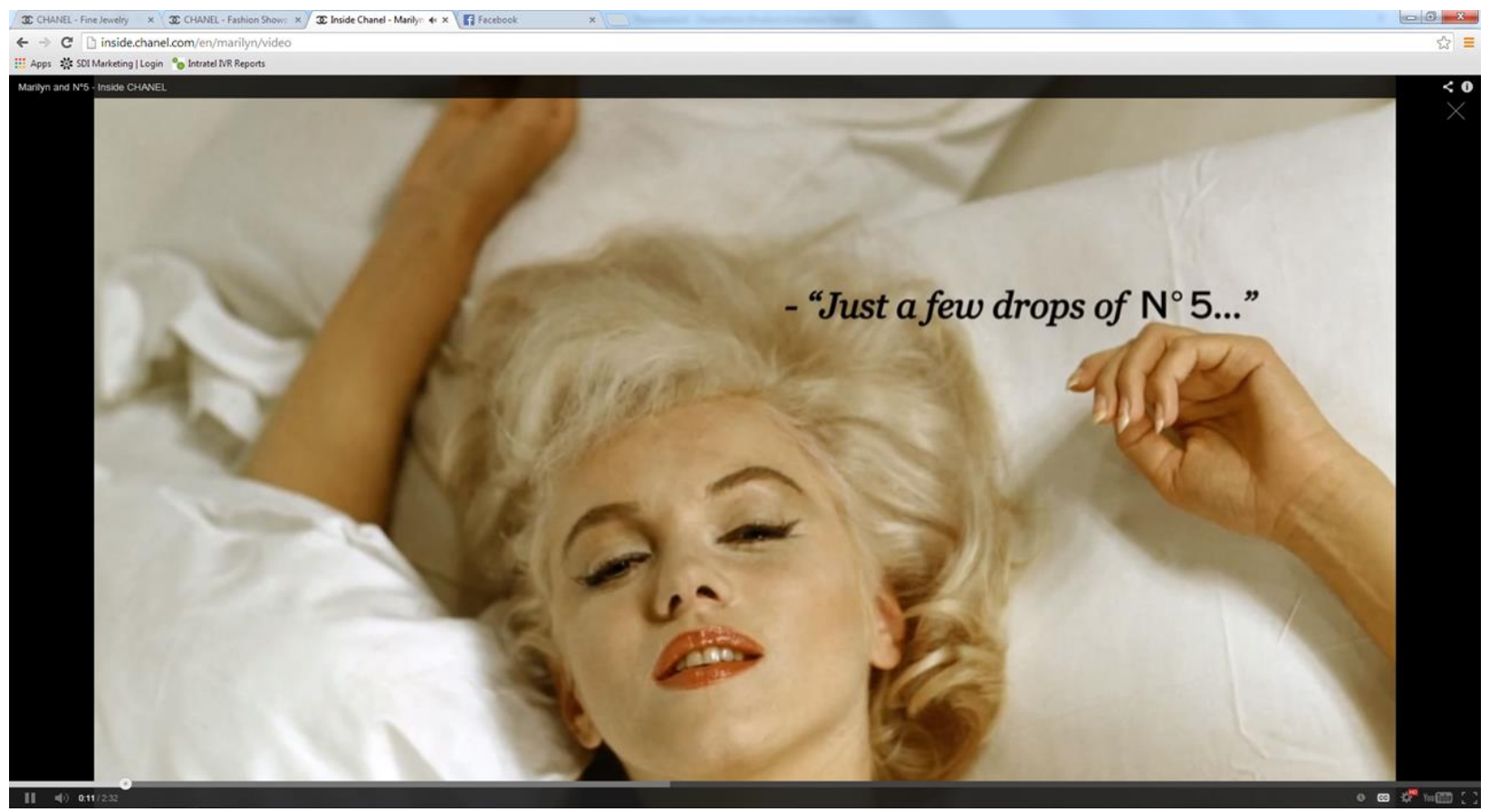

Figure 131: Chanel Official Website- "Inside Chanel"- "Chapter 2: Marilyn and No5" 


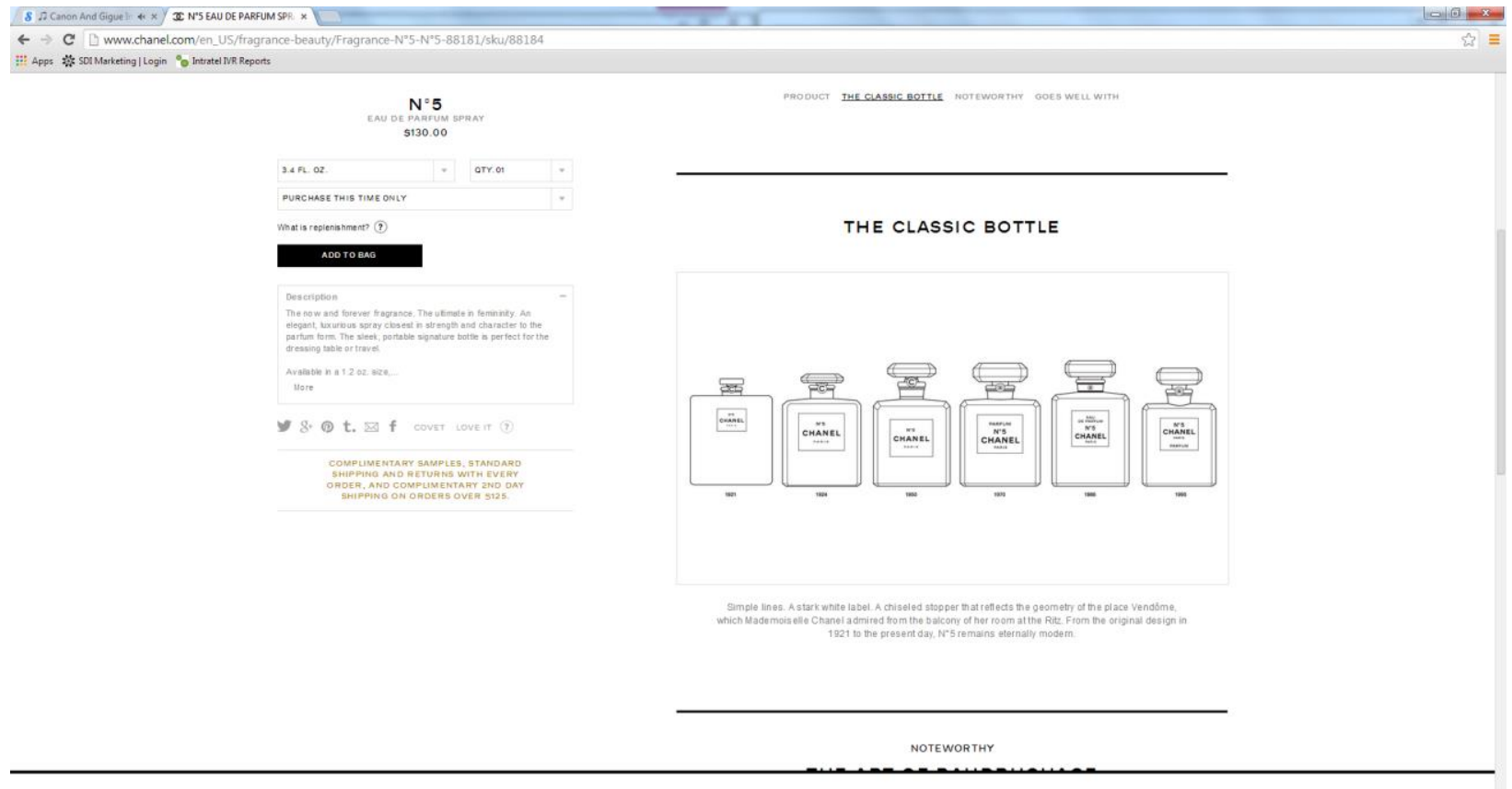

Figure 132: Chanel Official Website- The Classic Bottle- Chanel No5 Eau de Parfum Spray

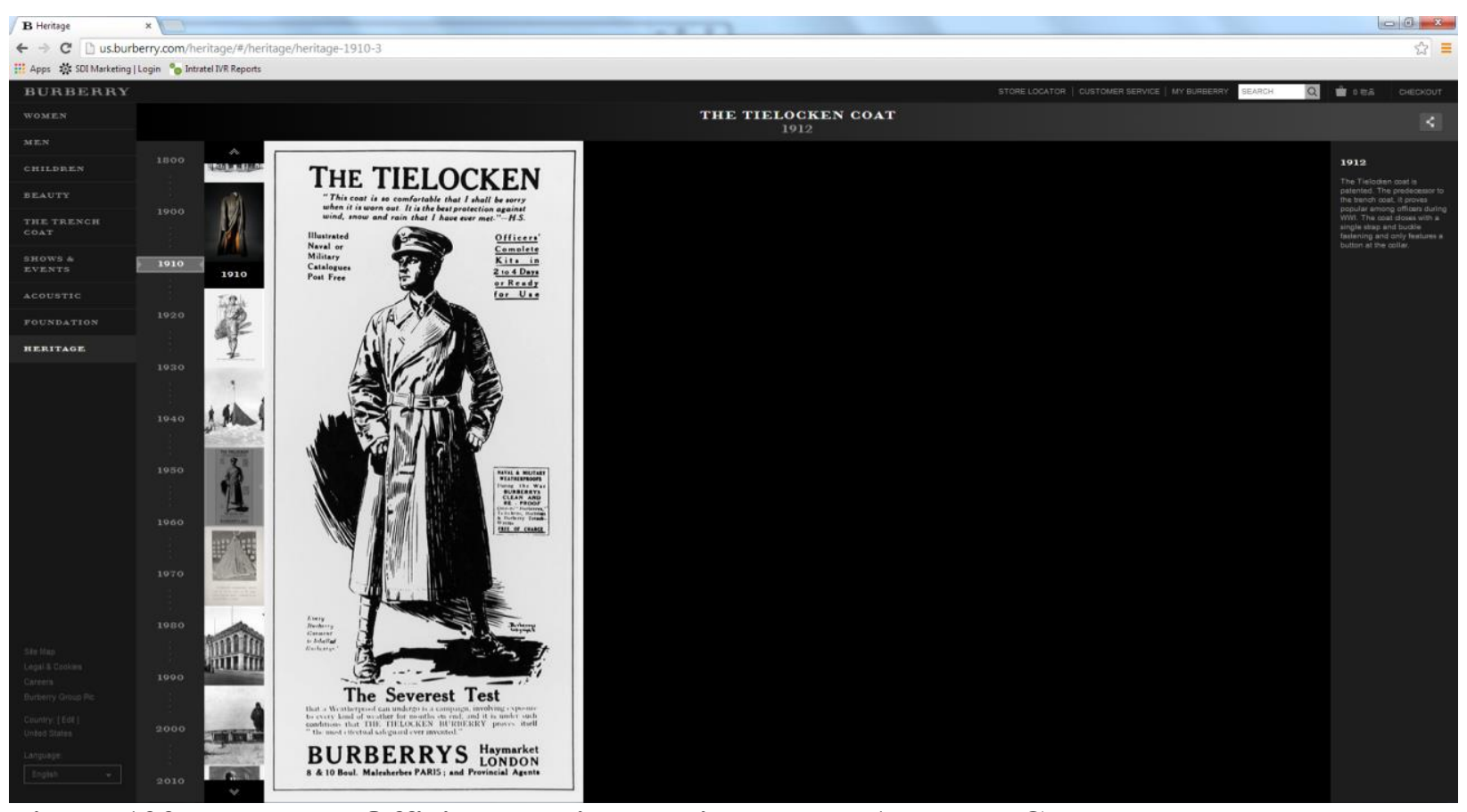

Figure 133: Burberry Official Website- Heritage- WW1 Trench Coat 


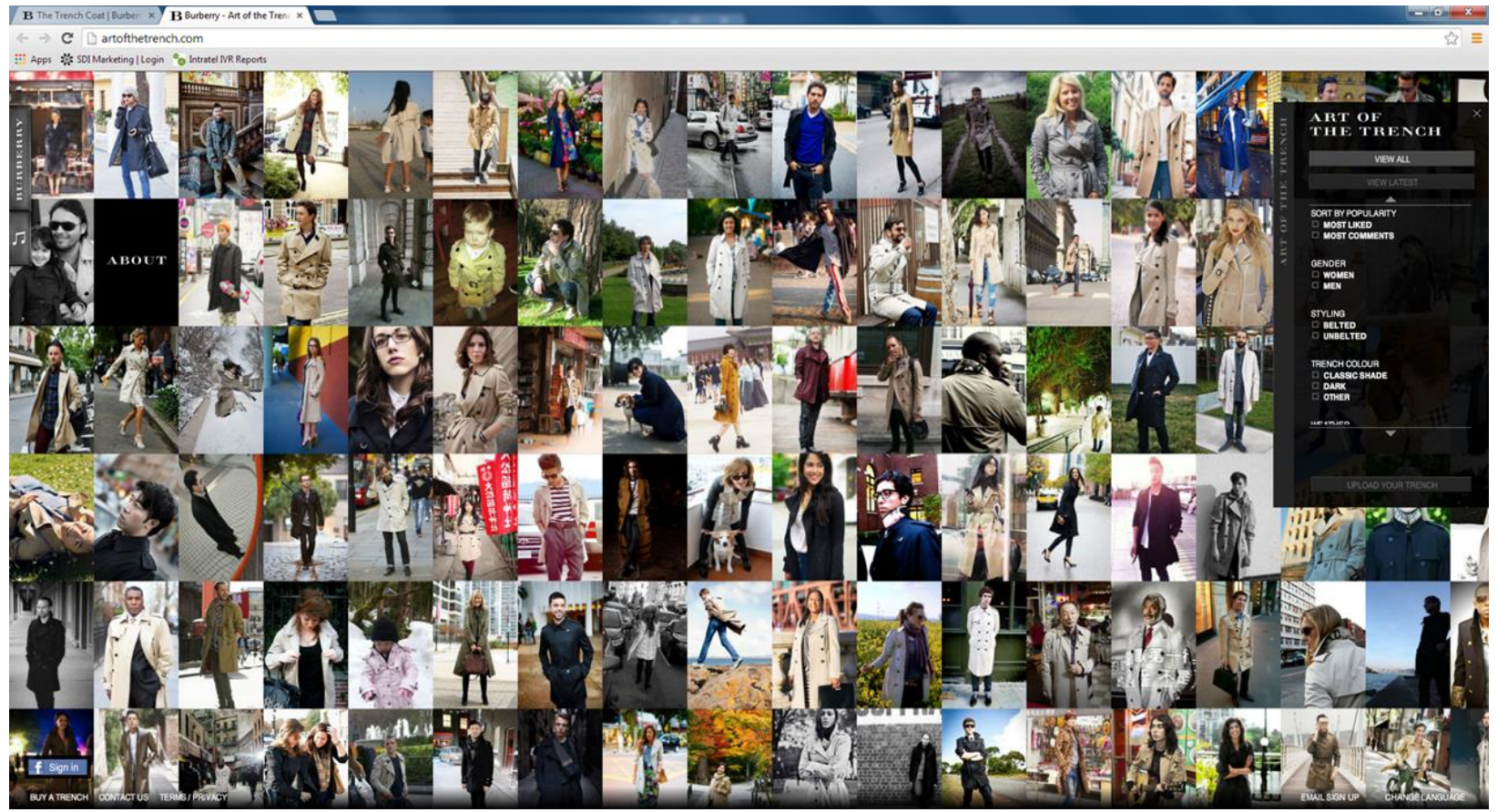

Figure 134 A: Burberry Art of The Trench Website

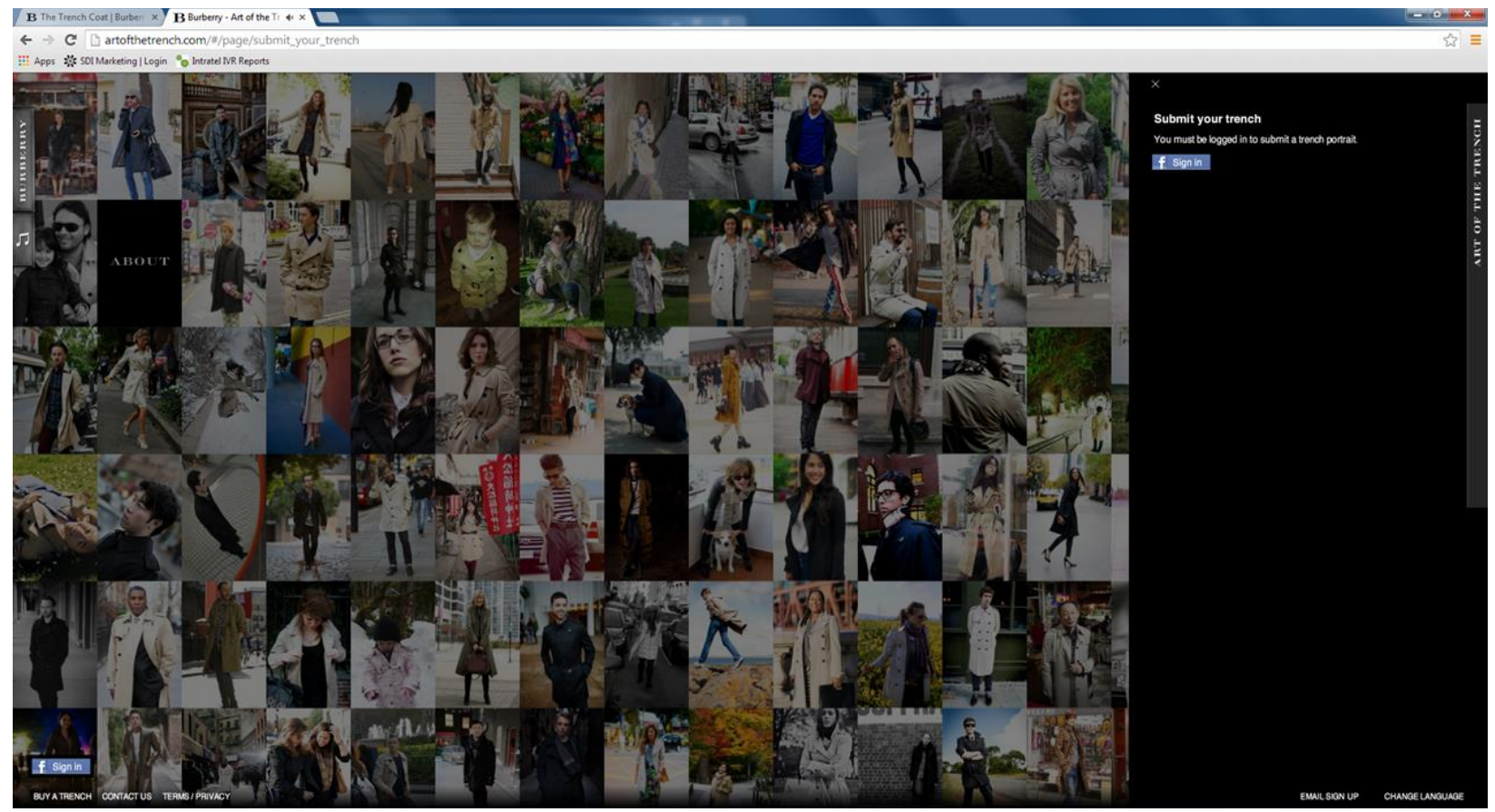

Figure 134 B: Burberry Art of The Trench Website 


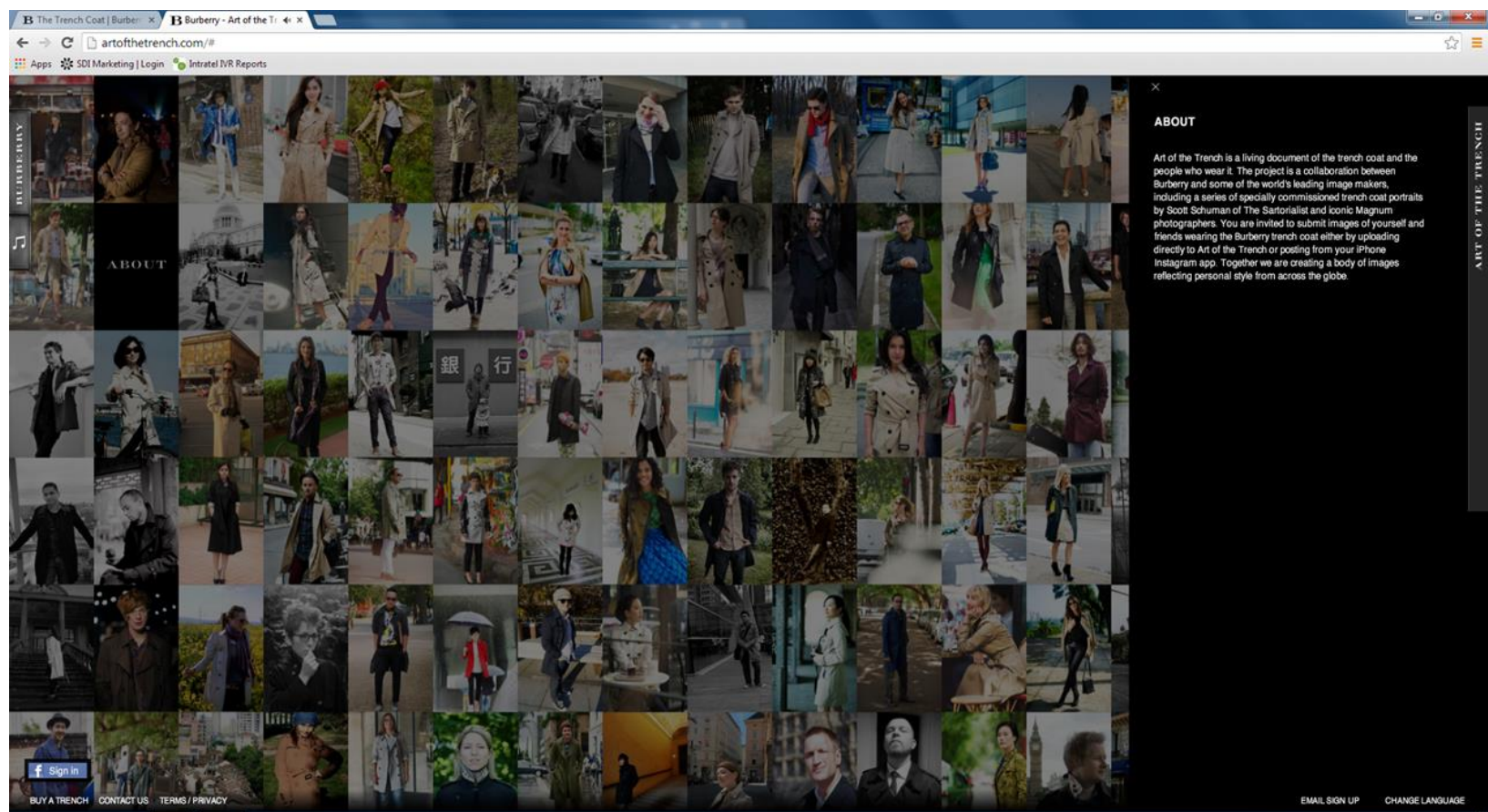

Figure 134 C: Burberry Art of The Trench Website

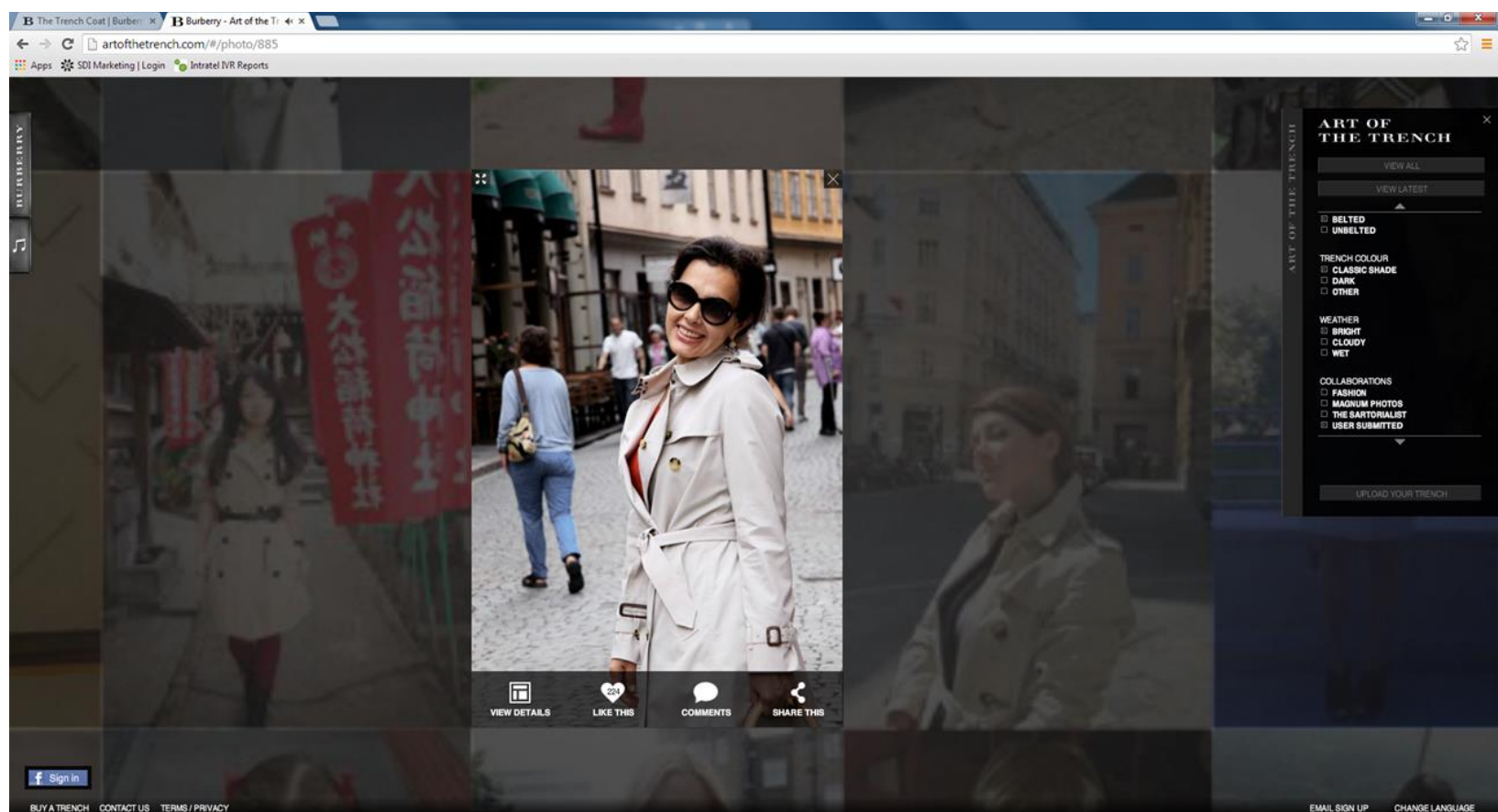

Figure 135 A: Burberry Art of The Trench Website 


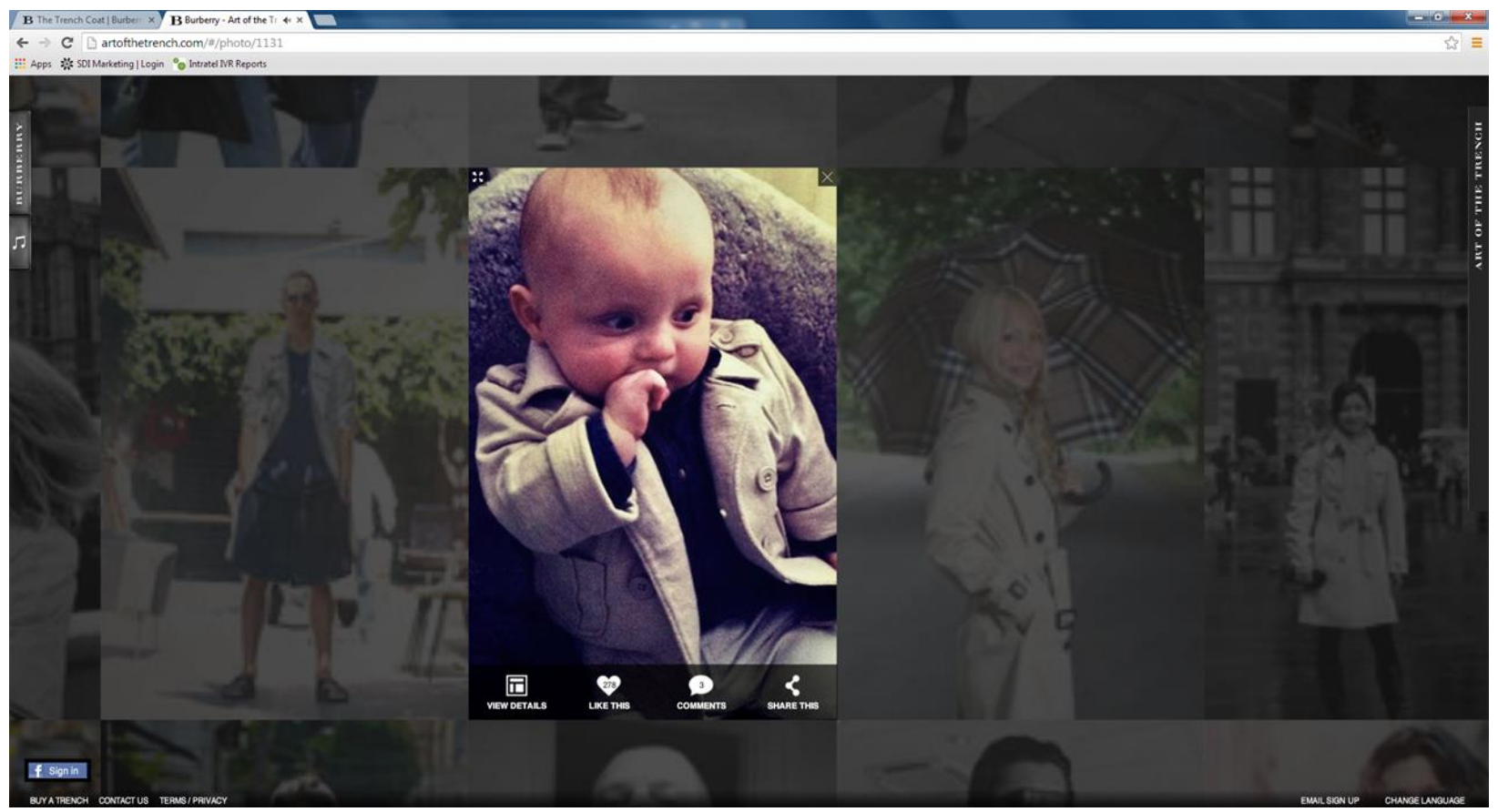

Figure 135 B: Burberry Art of The Trench Website

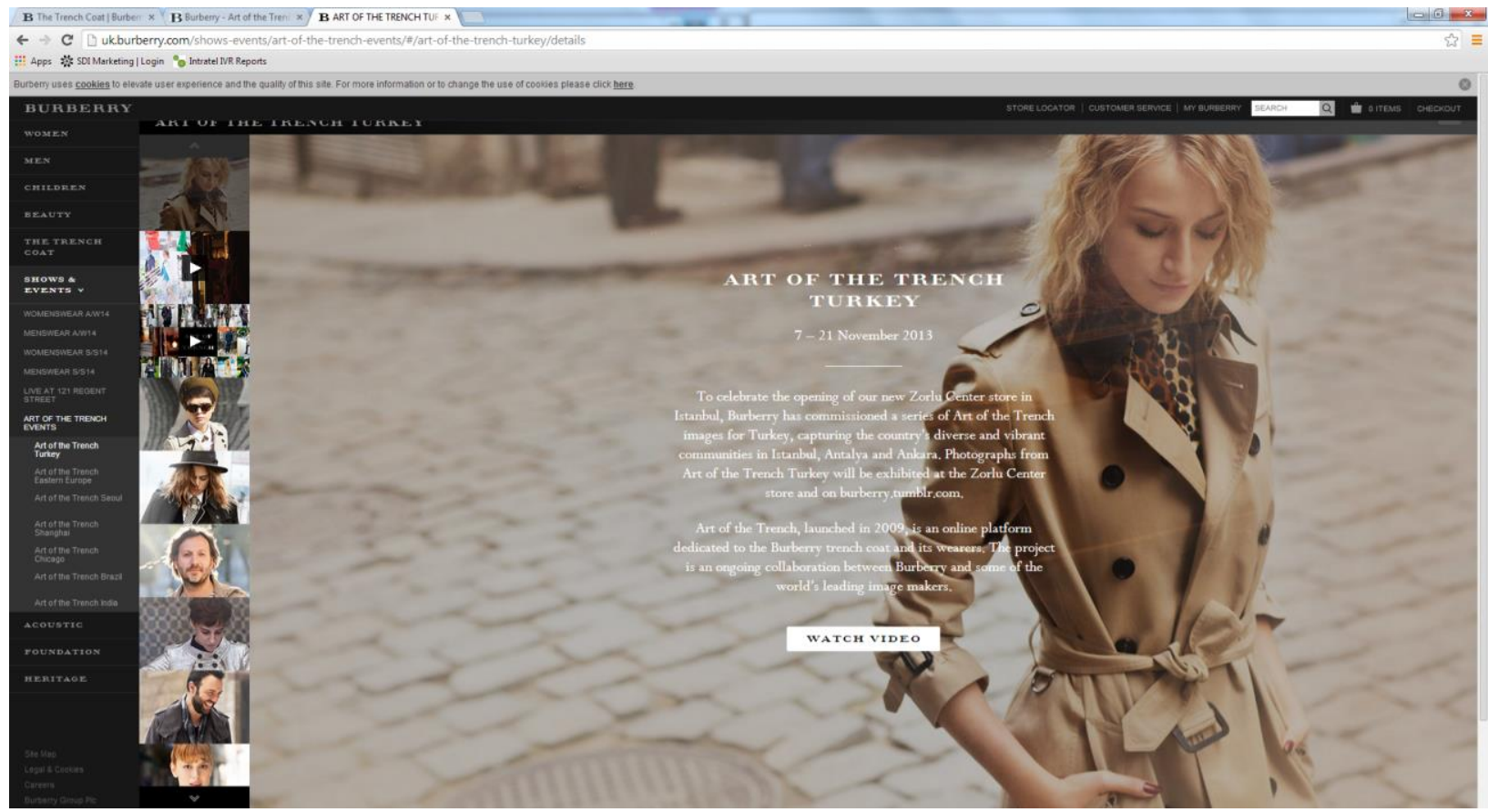

Figure 135 C: Burberry Art of The Trench Website - Focus on country of Turkey 


\section{Appendix 31: PHASE TWO: FIFTH DIMENSION: PREMIUM PRICES}
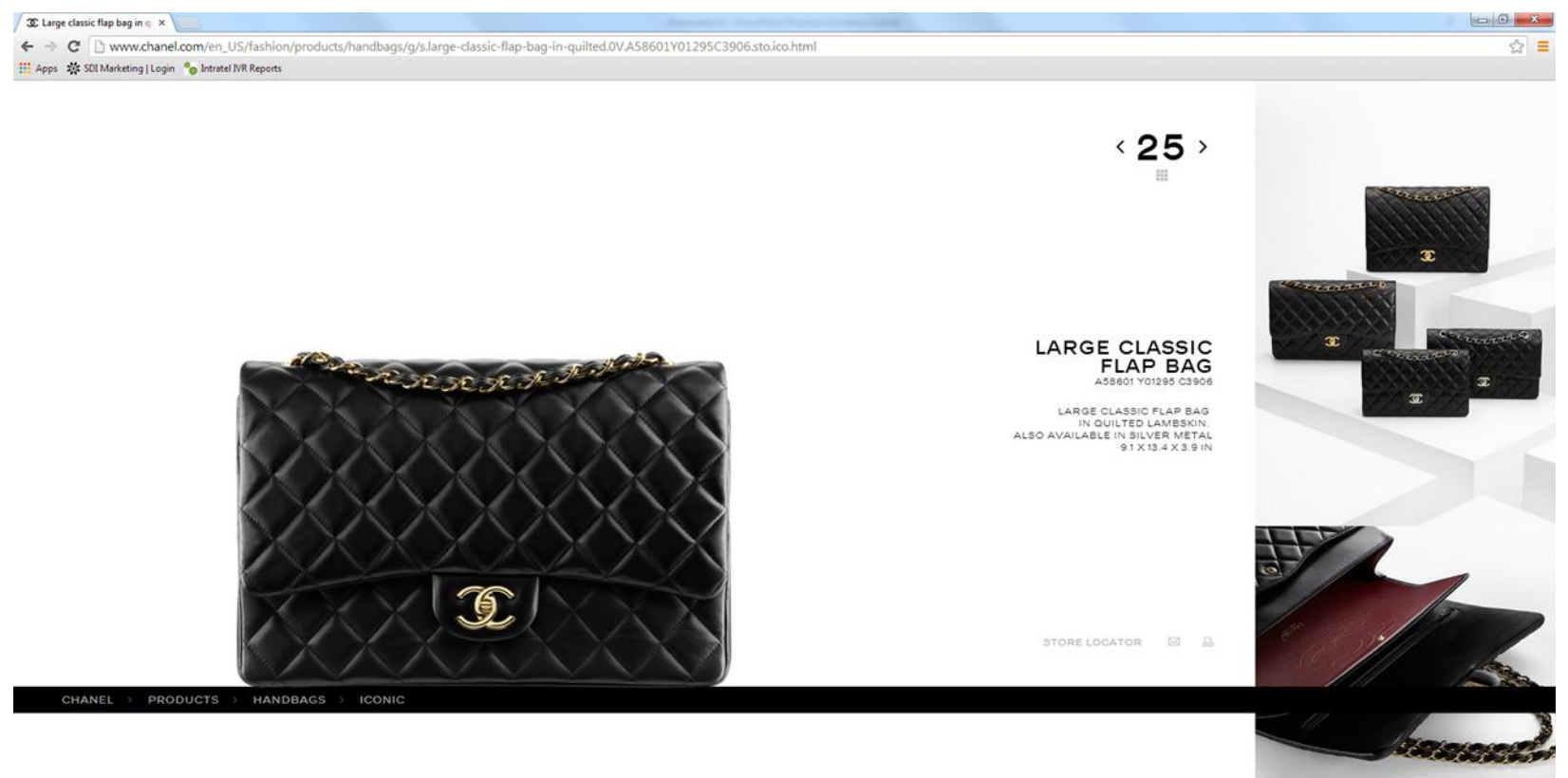

Figure 136 A: Chanel Official Website- Handbags

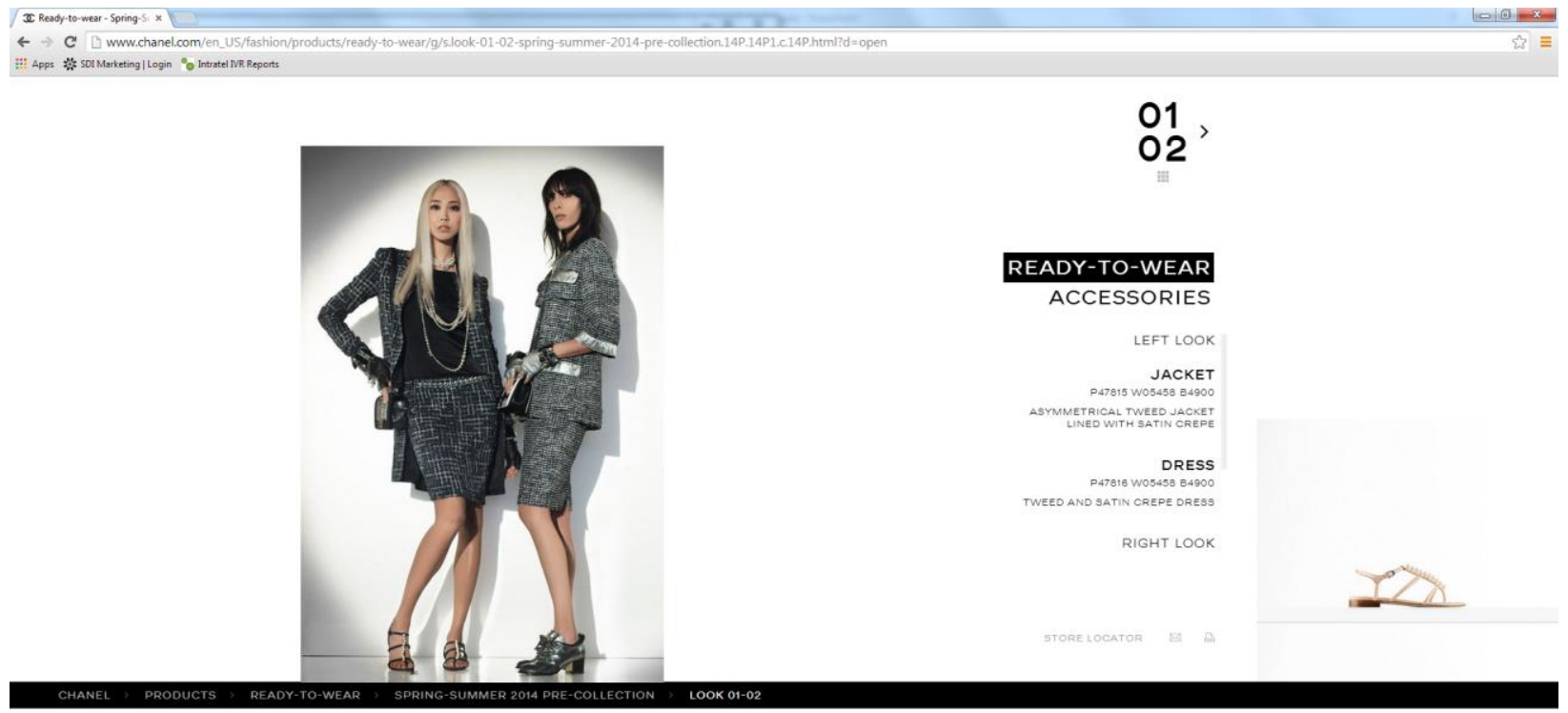

Figure 136 B: Chanel Official Website- Spring-Summer 2014 Pre-Collection Ready-ToWear 


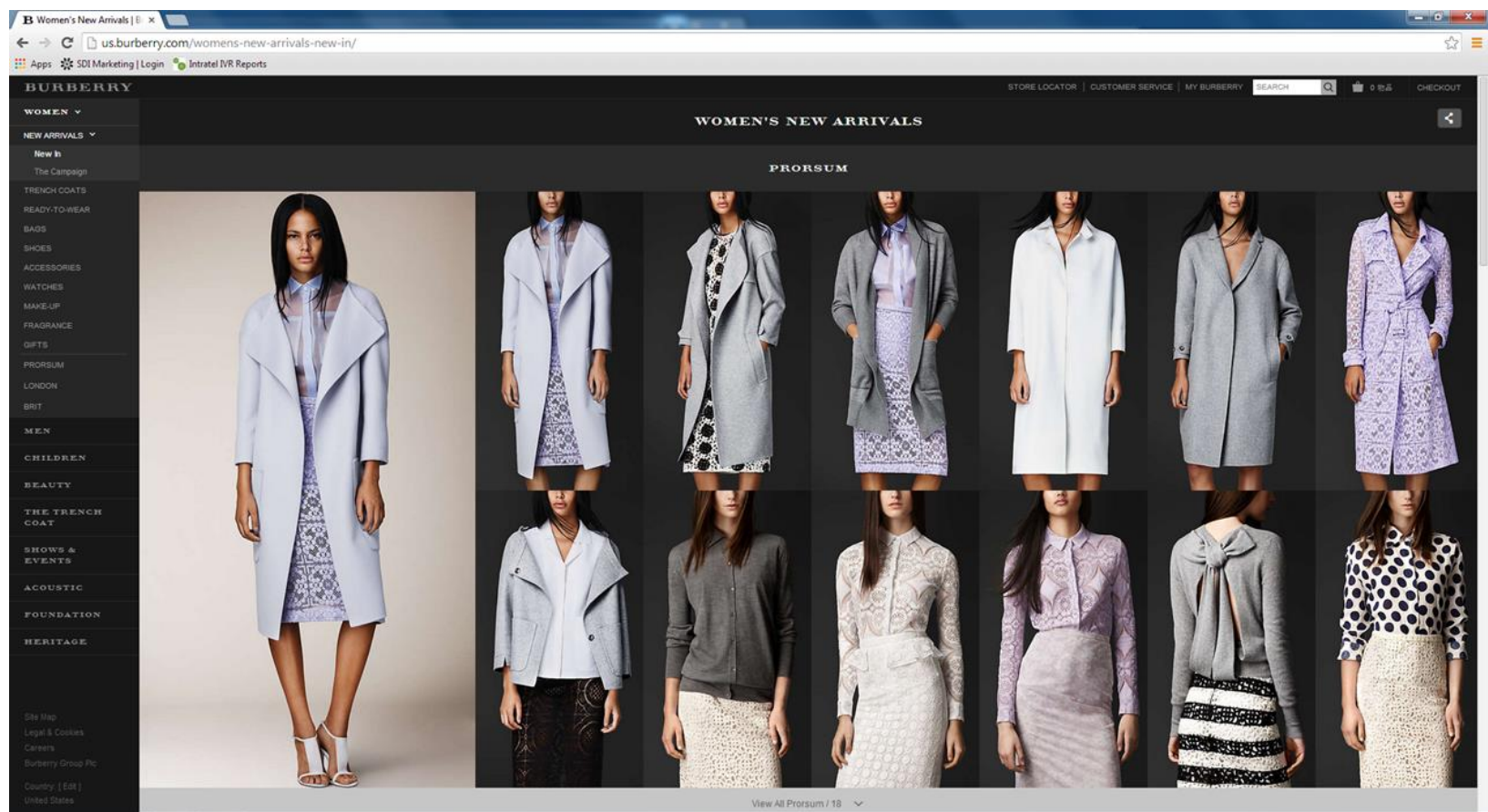

Figure 137 A: Burberry Official Website- Prorsum

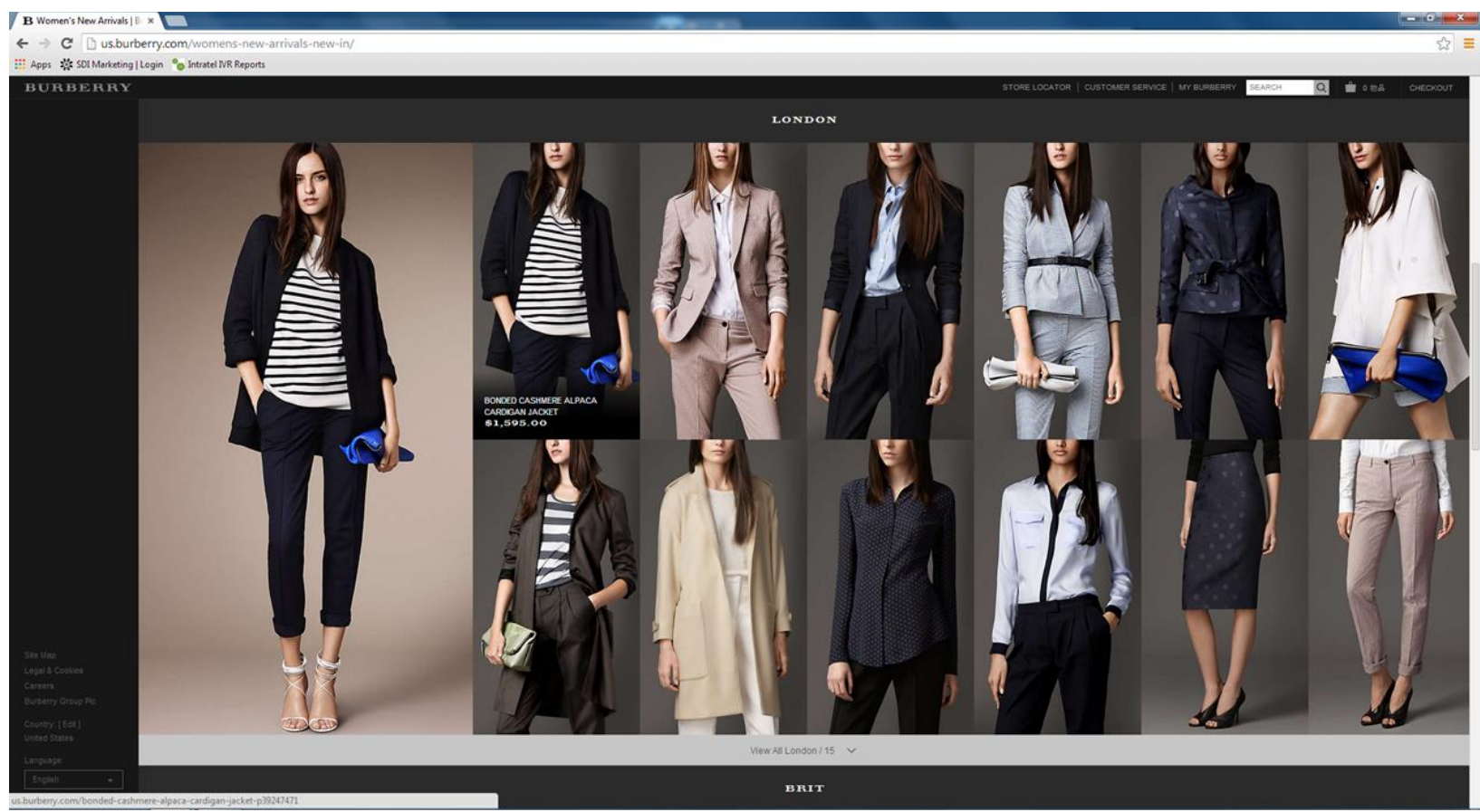

Figure 137 B: Burberry Official Website- London 


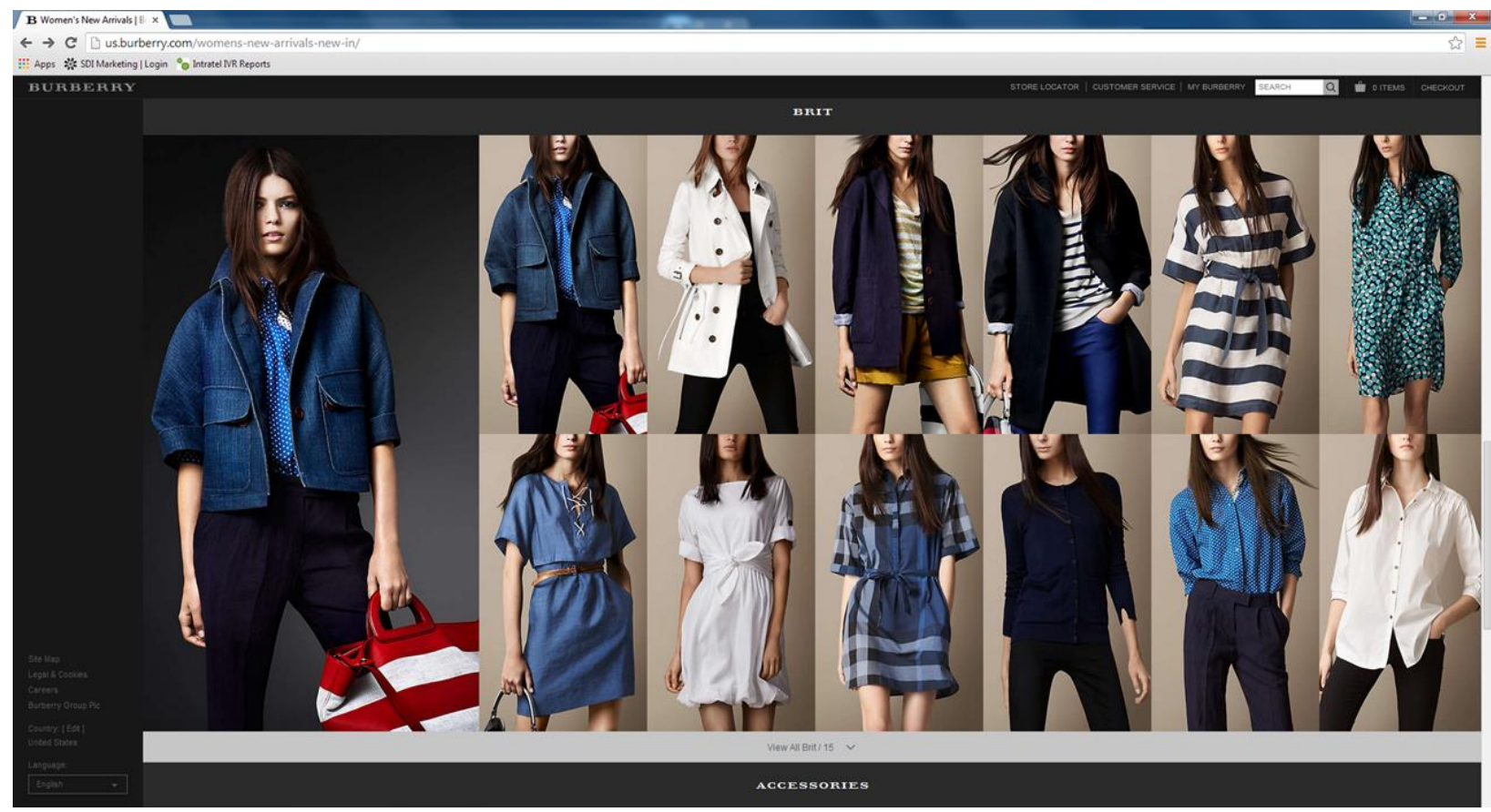

Figure 137 C: Burberry Official Website- Brit

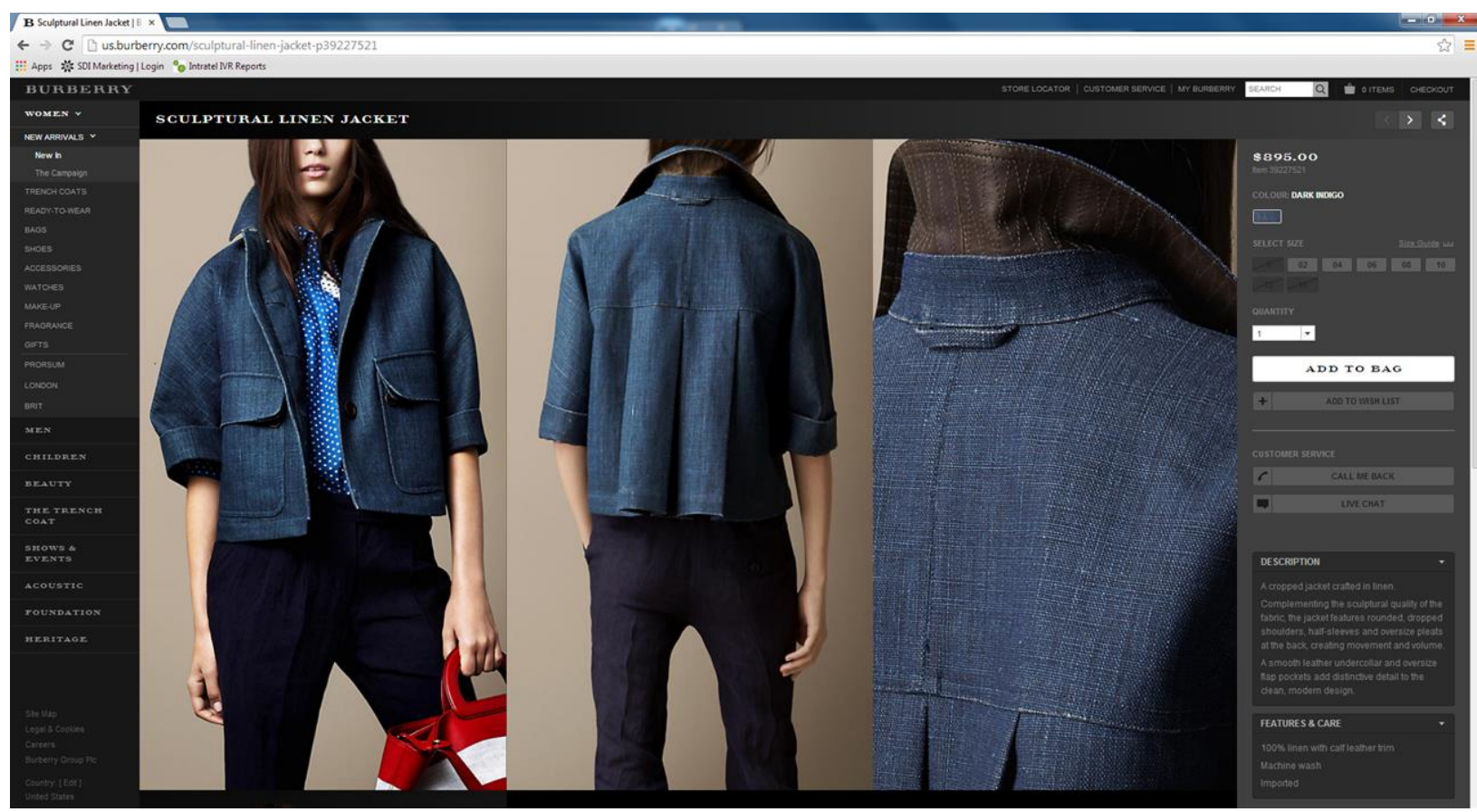

Figure 137 D: Burberry Official Website- Brit (Description) 


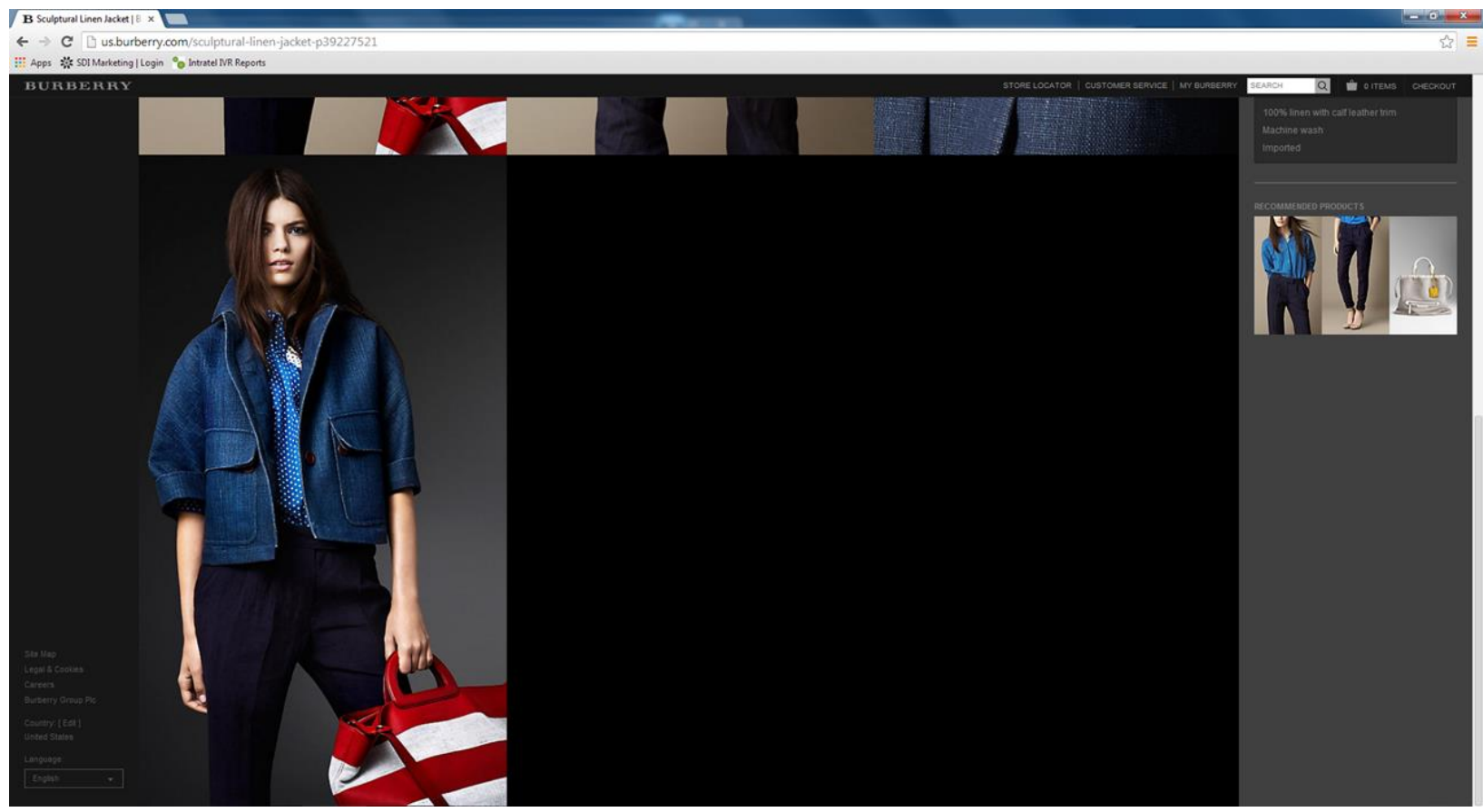

Figure 137 E: Burberry Official Website- Brit (Description)

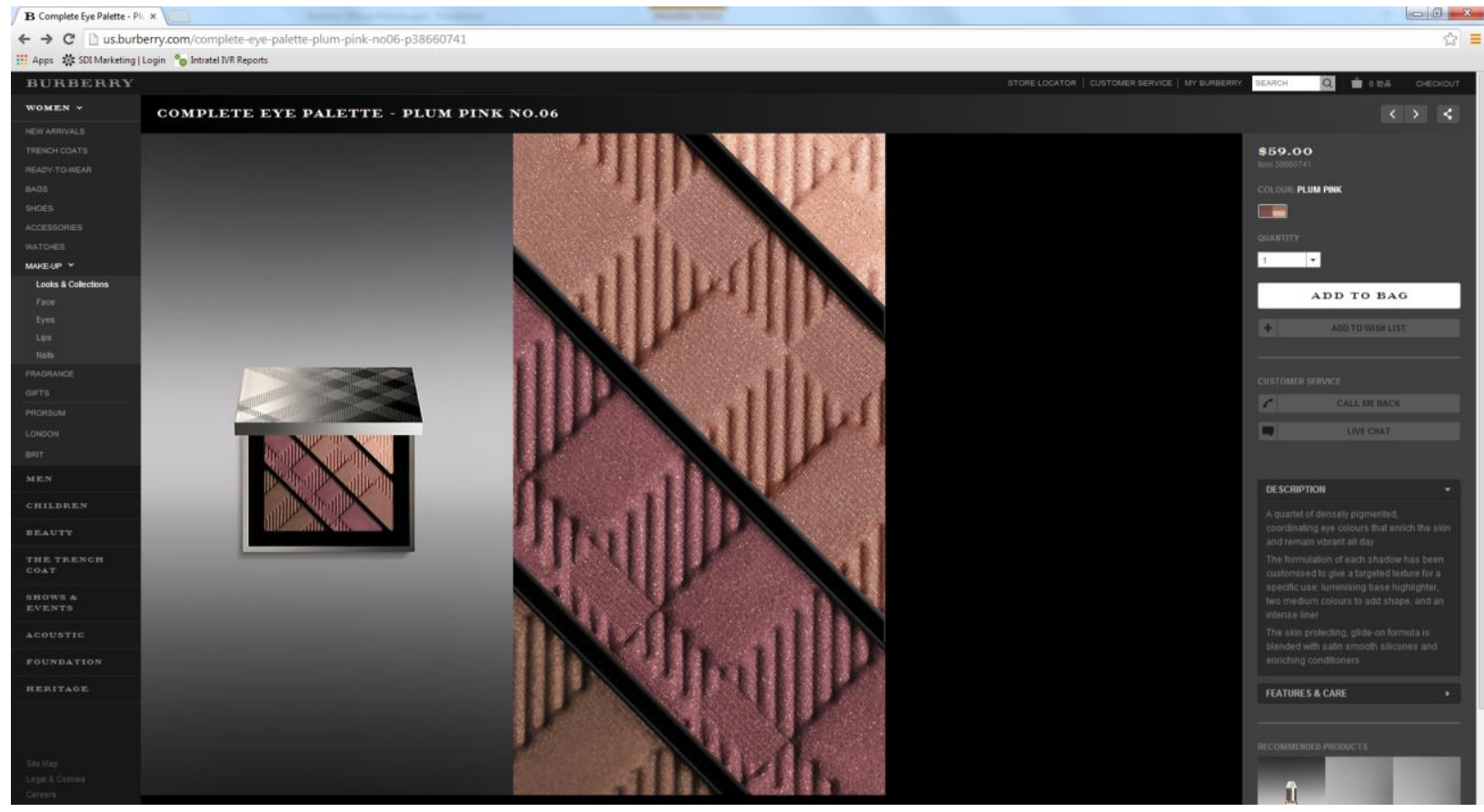

Figure 138 A: Burberry Official Website- Beauty 


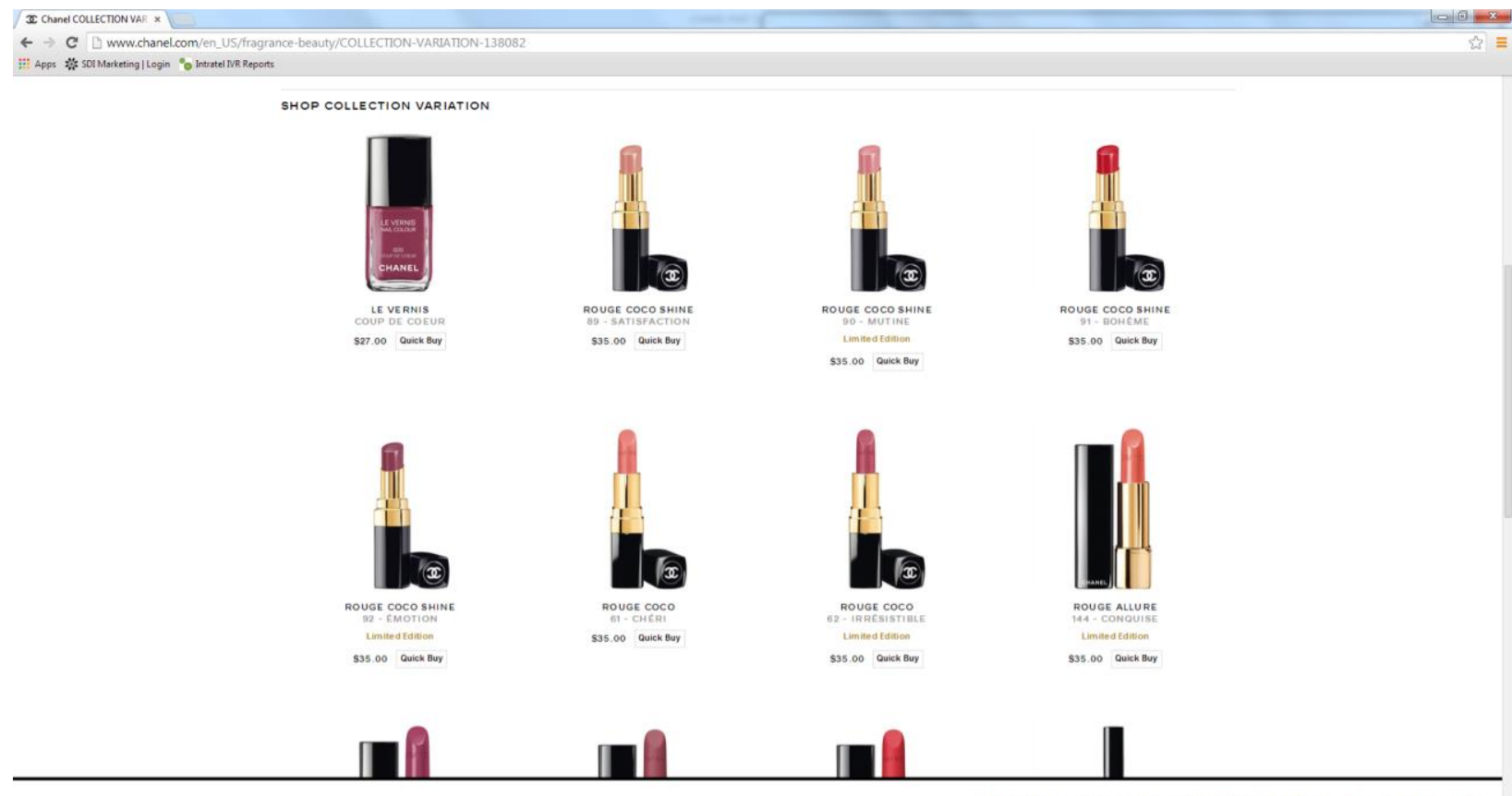

Figure 138 B: Chanel Official Website- Beauty 


\section{Appendix 32: PHASE TWO: SIXTH DIMENSION: EXCLUSIVITY}

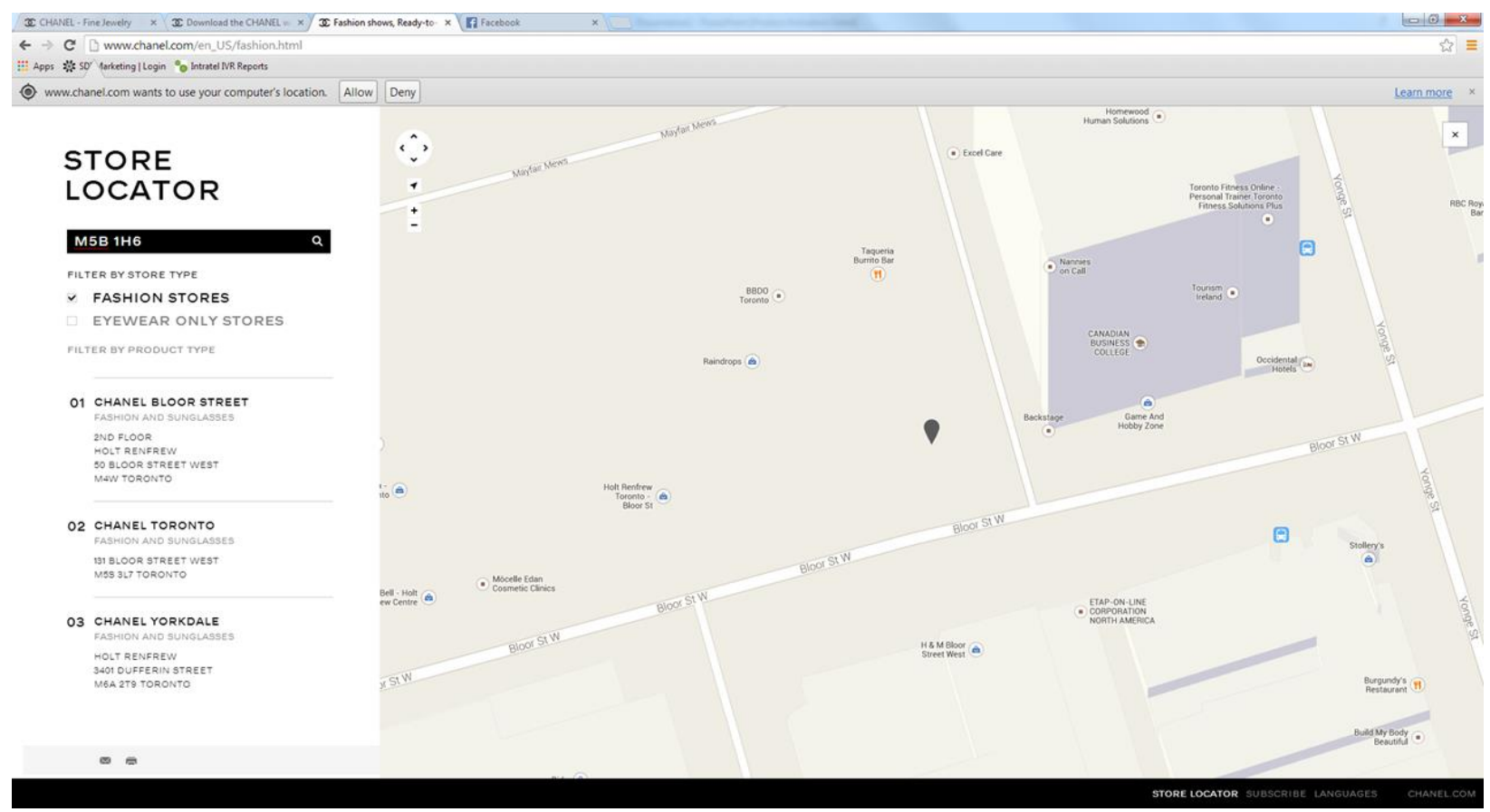

Figure 139: Chanel Official Website Store Locator

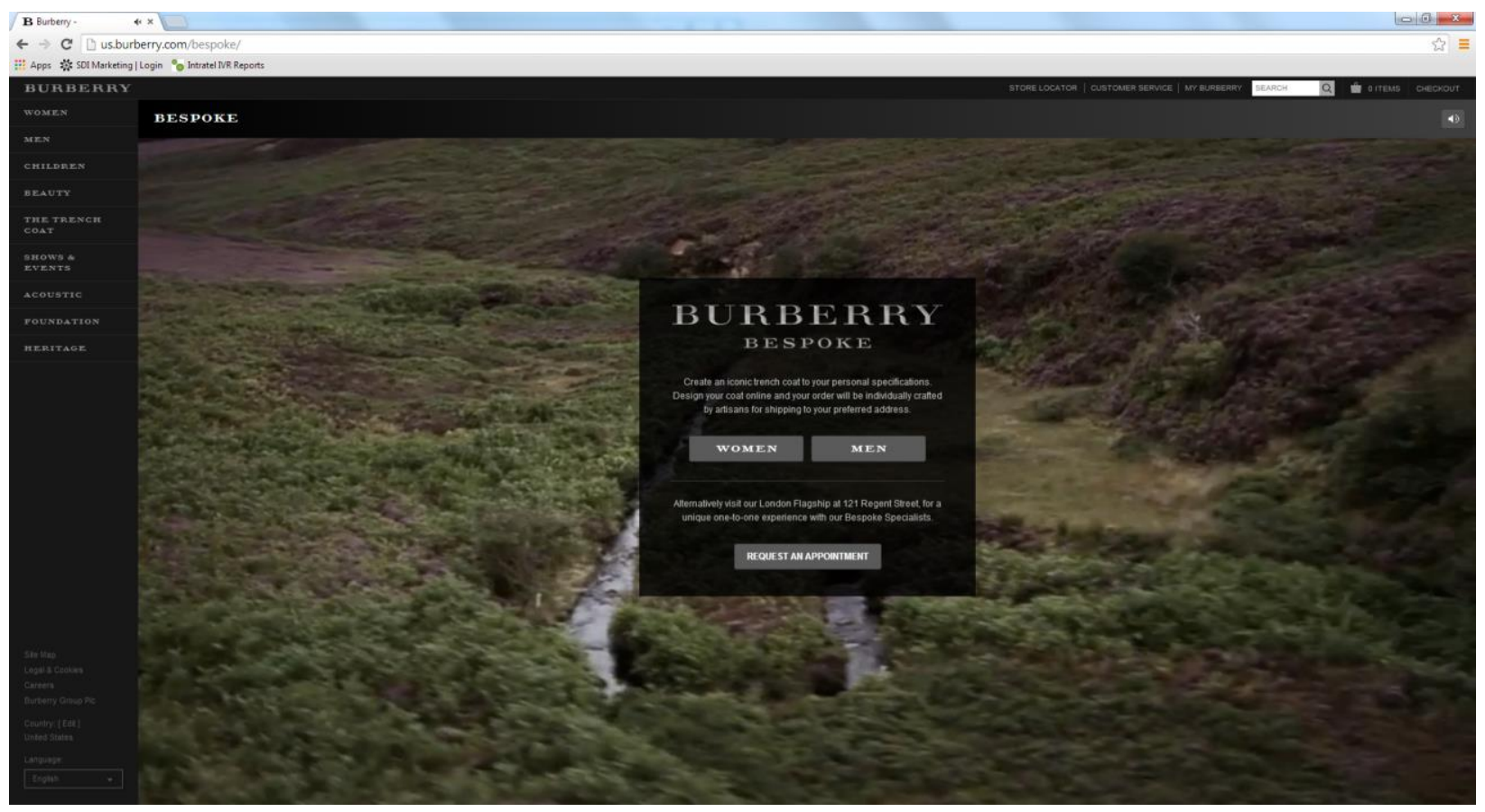

Figure 140: Burberry Official Website- Bespoke 


\section{Appendix 33: PHASE TWO: SEVENTH DIMENSION: HERITAGE}

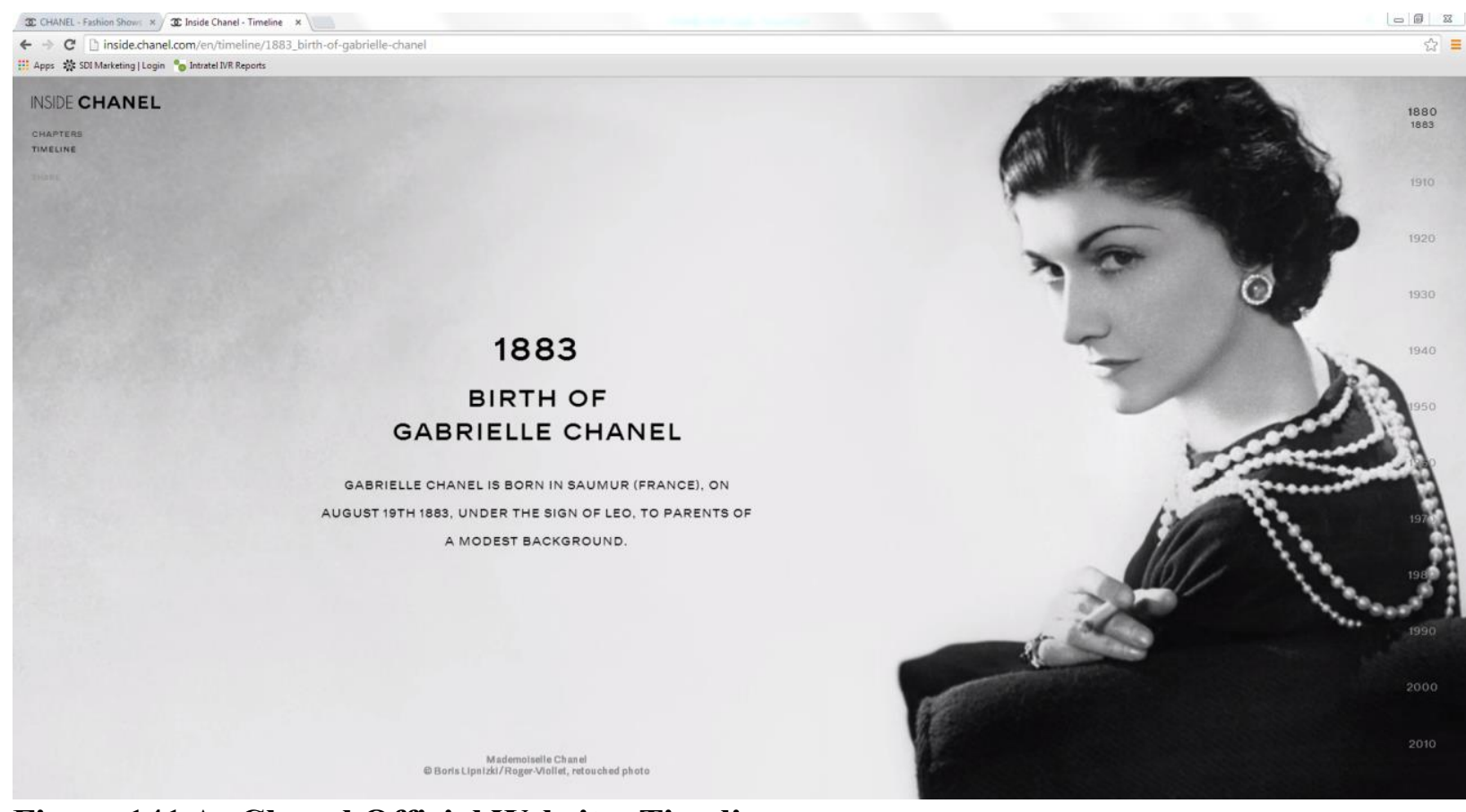

Figure 141 A: Chanel Official Website- Timeline

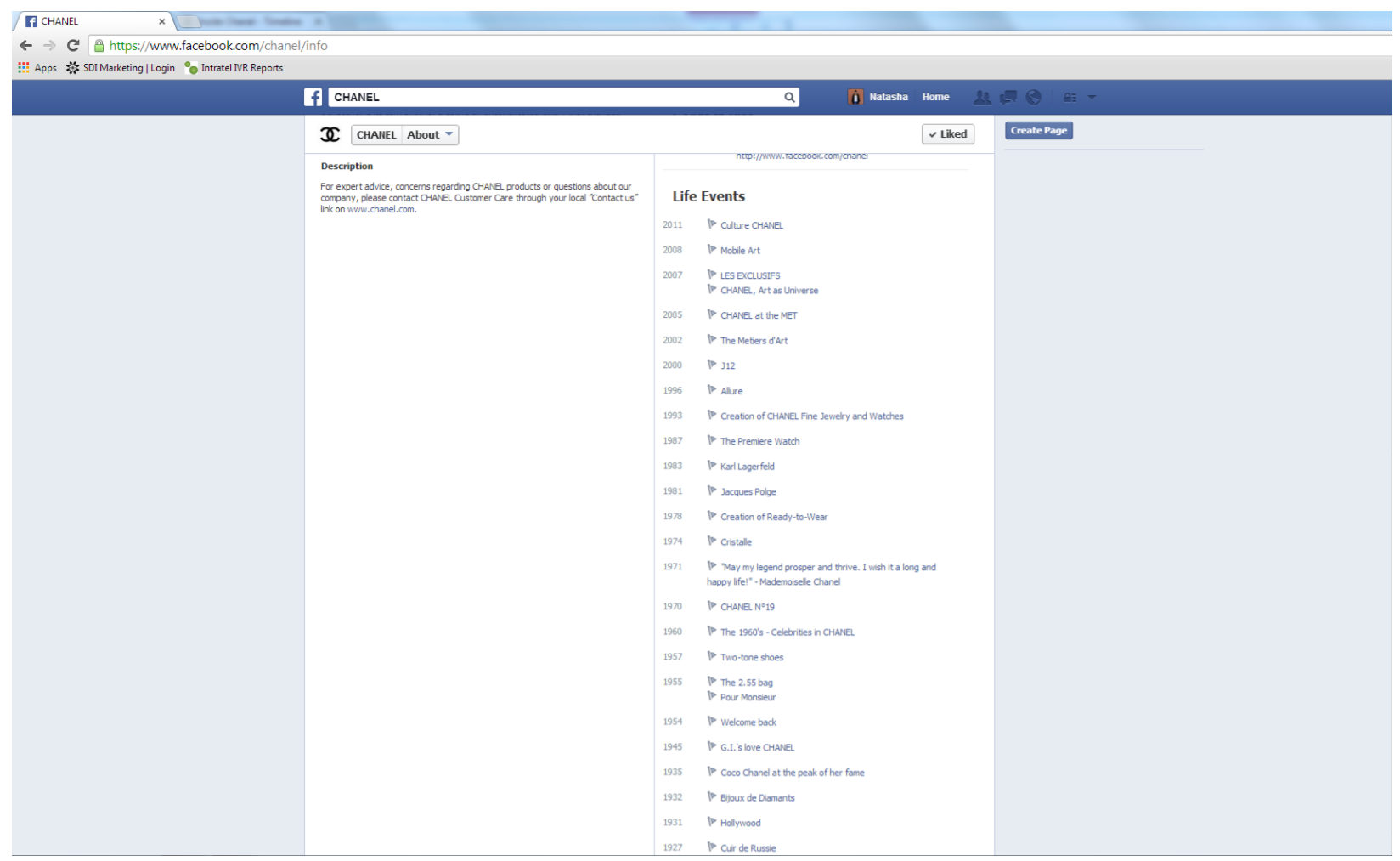

Figure 141 B: Chanel Official Facebook Page- Life Events 


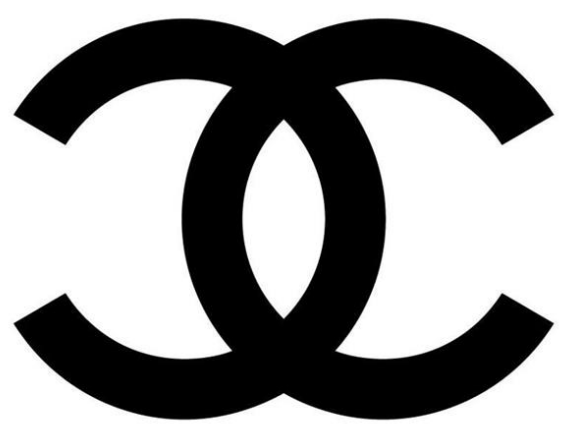

Figure 142: Chanel Icon Facebook Page

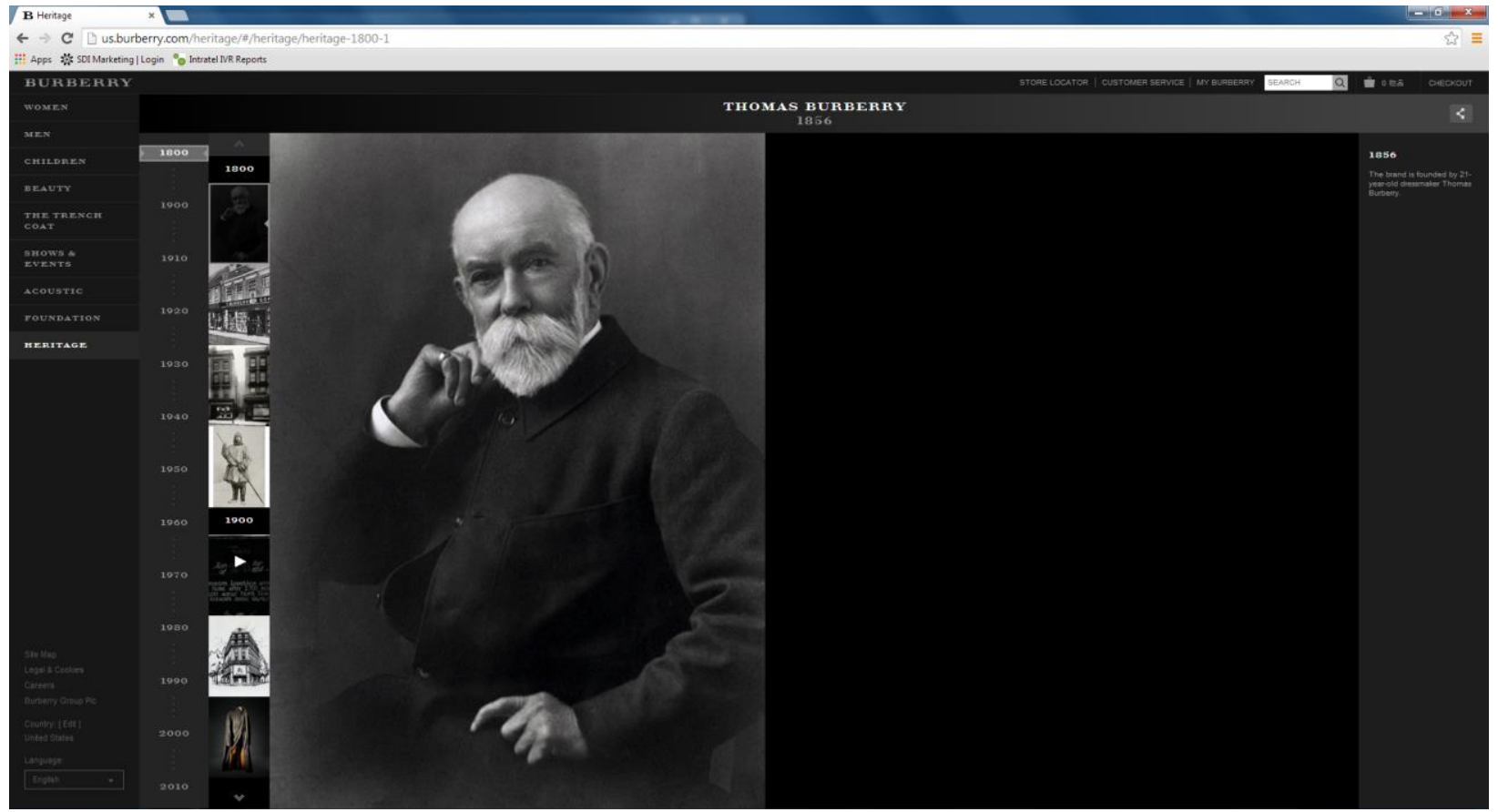

Figure 143 A: Burberry Official Website- Heritage 


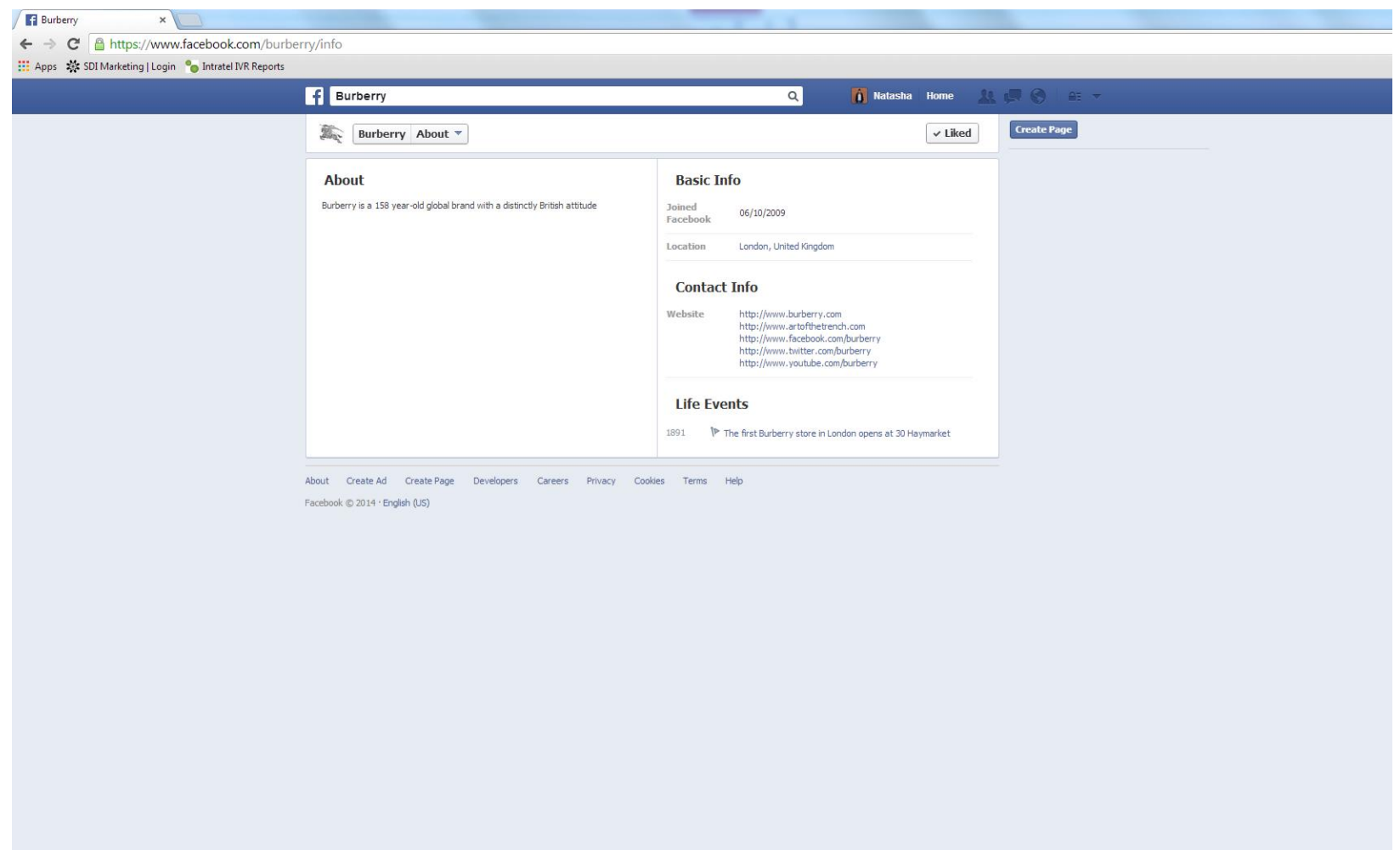

Figure 143 B: Burberry Official Facebook Page- Life Events

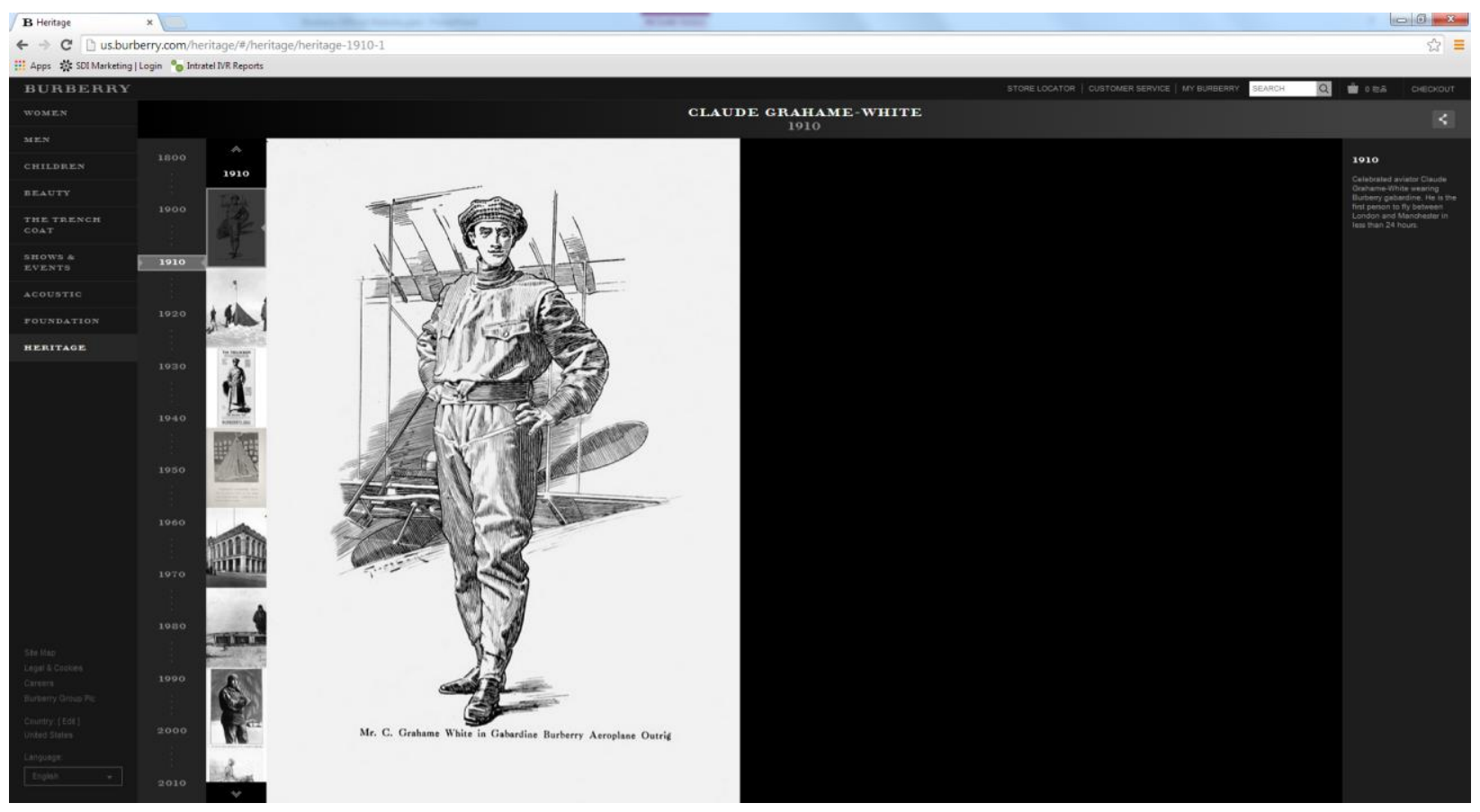

Figure 144: Burberry Official Website- Heritage- Gabardine 


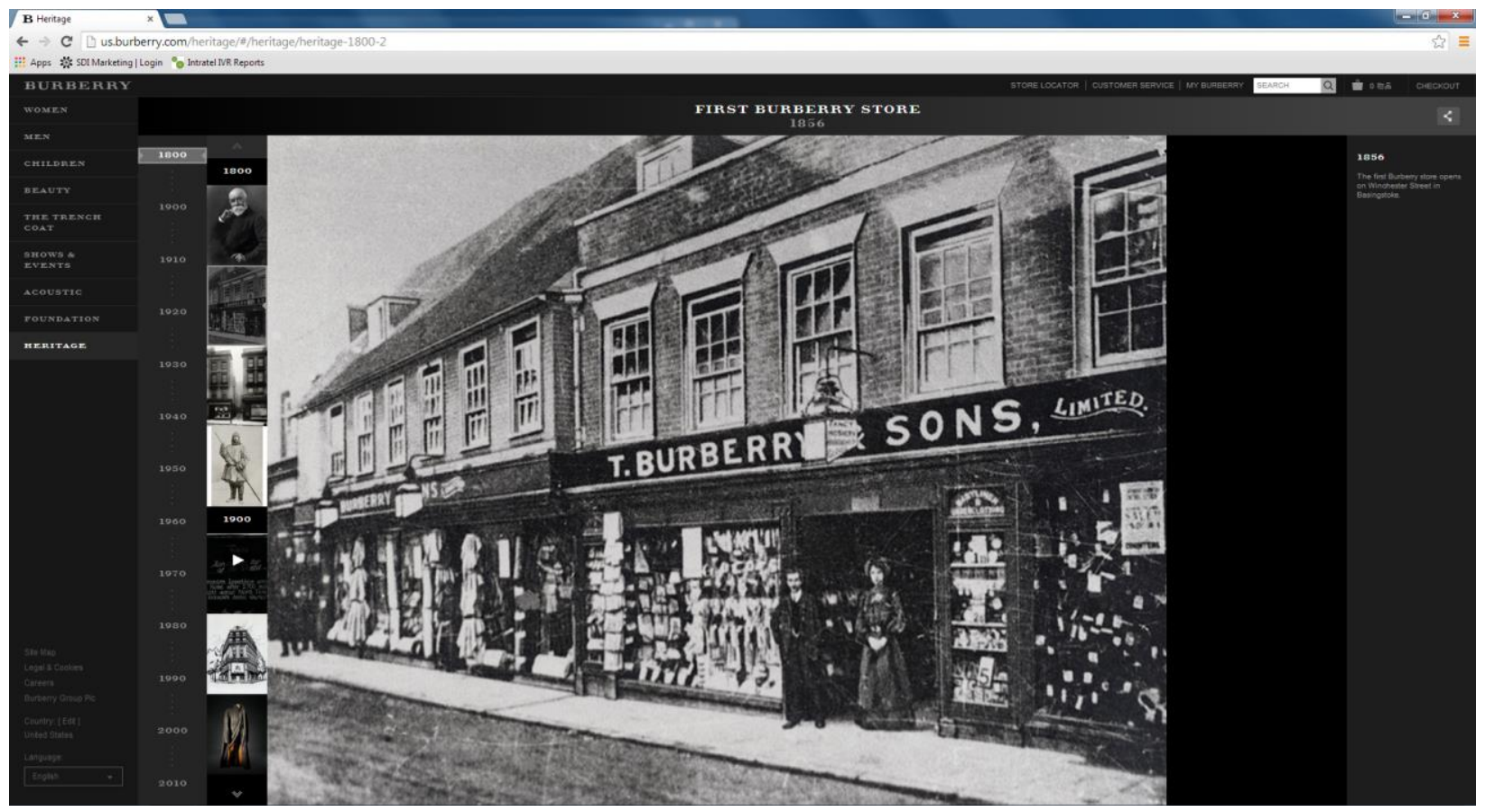

Figure 145: Burberry Official Website- First Burberry Store in 1856

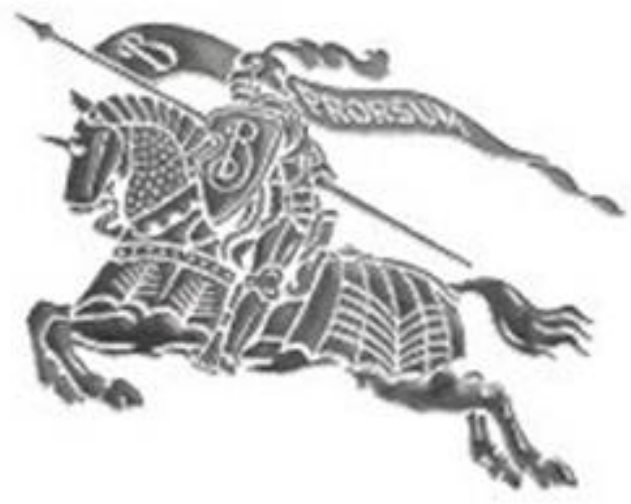

Figure 146: Burberry Facebook Page- Burberry Icon 


\section{Appendix 34: PHASE TWO: EIGHT DIMENSION: LUXURY ENVIRONMENT AND EXPENRIENCE}

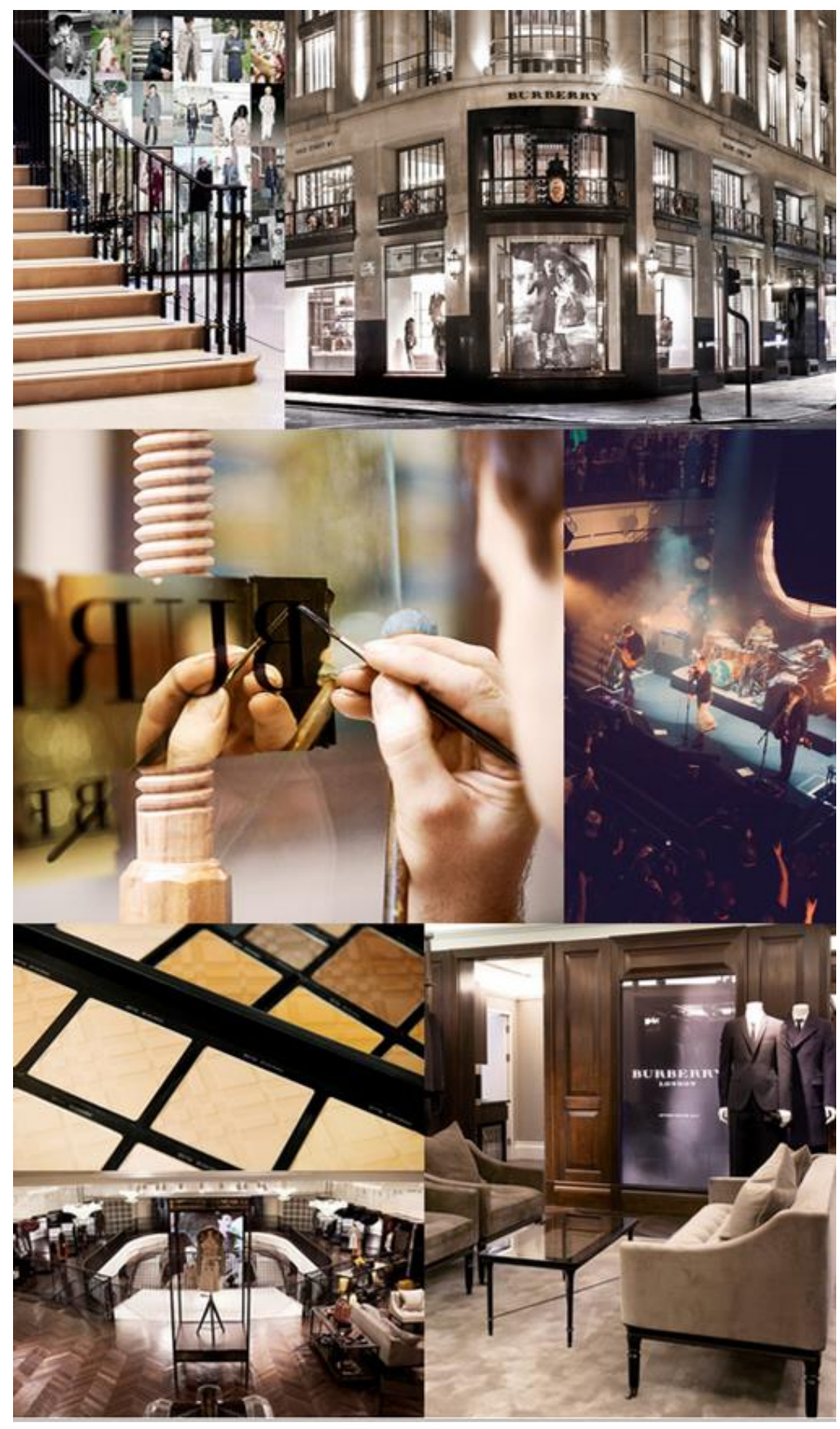

Figure 147: Burberry Official Website- London Flagship Store on Regent Street 


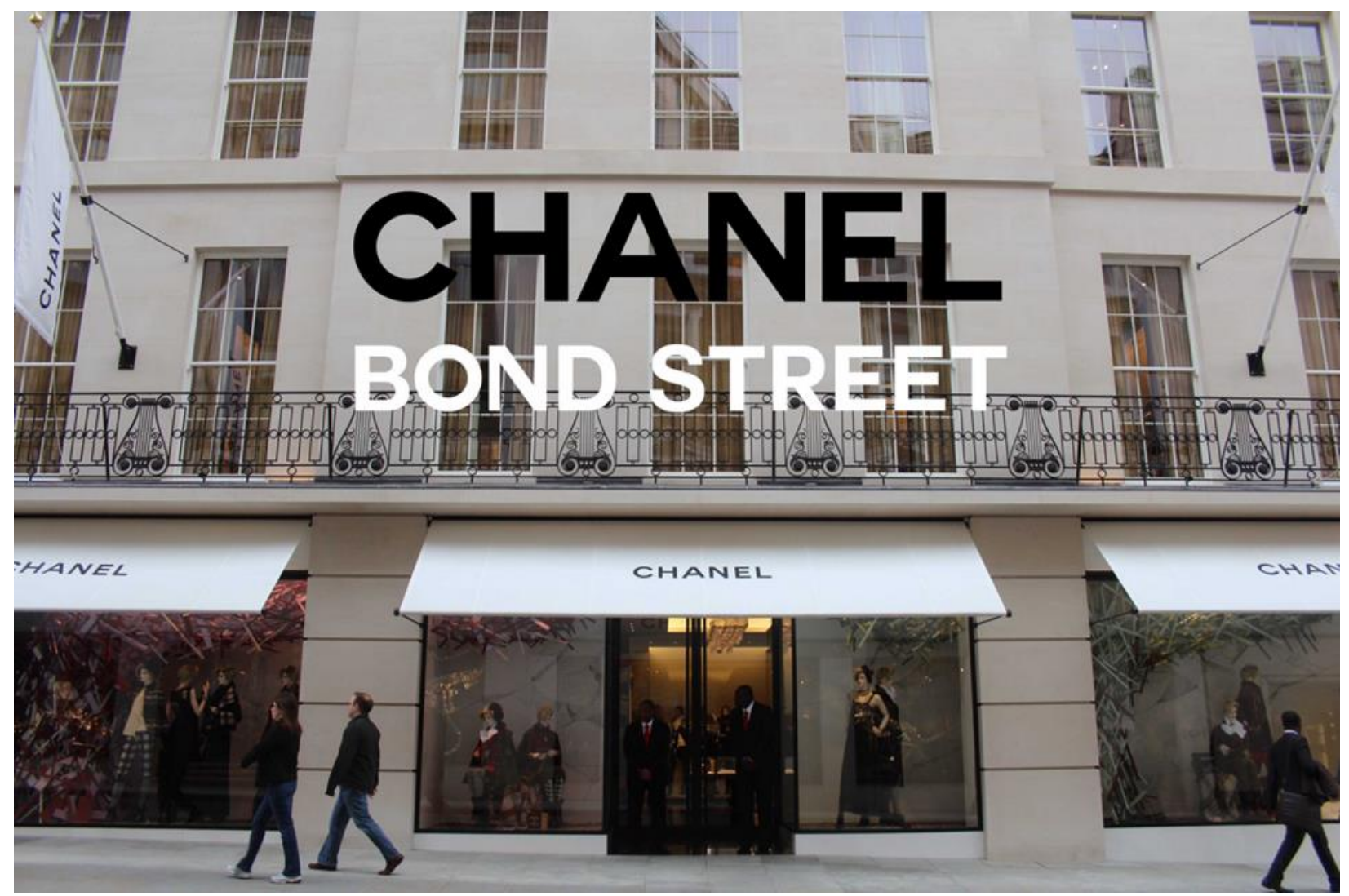

Figure 148: Chanel London Flagship Store on Bond Street

Source: Vanthournout, Alexandra. "First Look Inside Chanel's New Bond Street Flagship." Alex Loves. WPZOOM. Online. Web 5 March, 2014. 


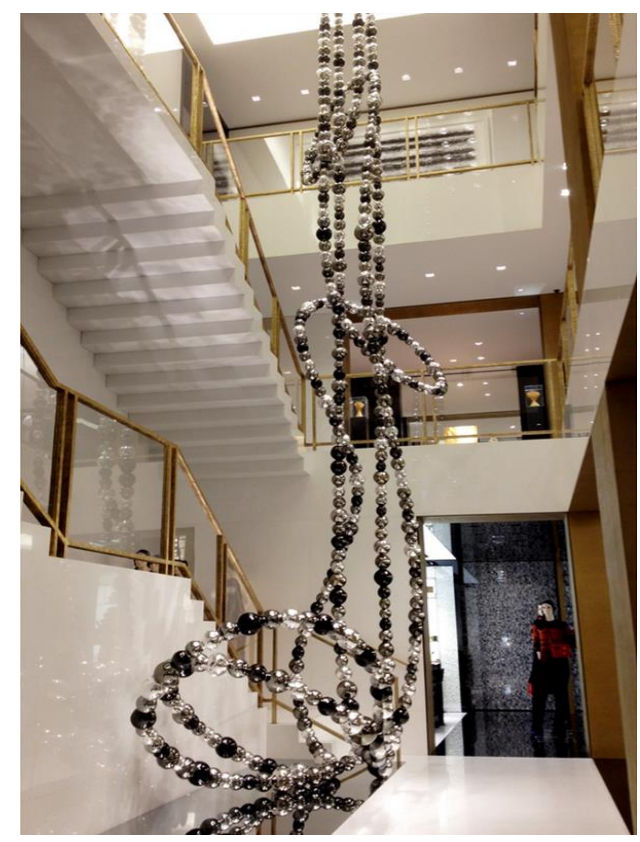

Figure 149: Chanel London Flagship Store on Bond Street- Sculpture

Source: Karmali, Sarah. Inside Chanel's New London Flagship. Vogue UK News, 10 June 2013. Web. 23 March 2014. Online.

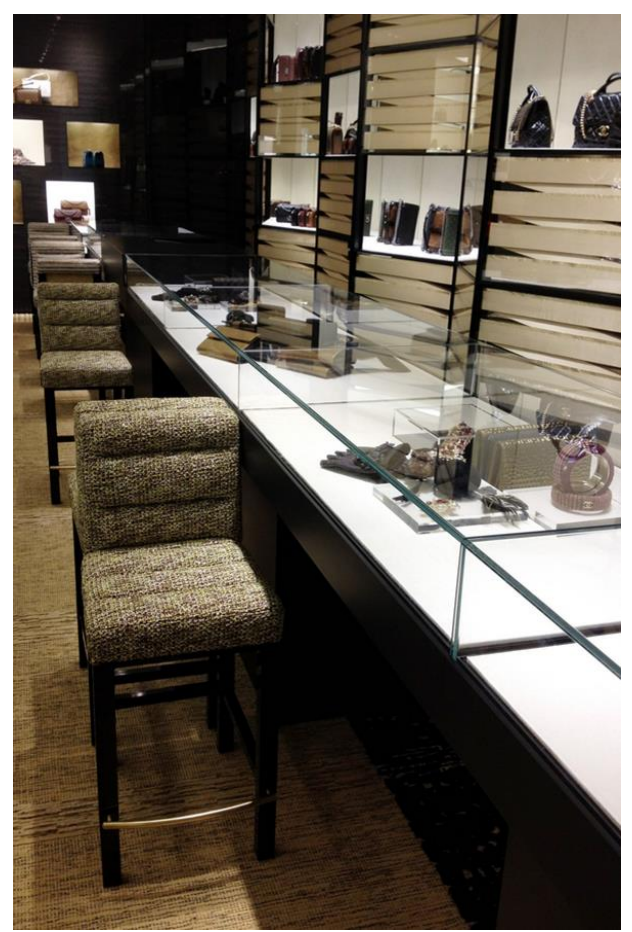

Figure 150 A: Chanel London Flagship Store on Bond Street- Bag Bar

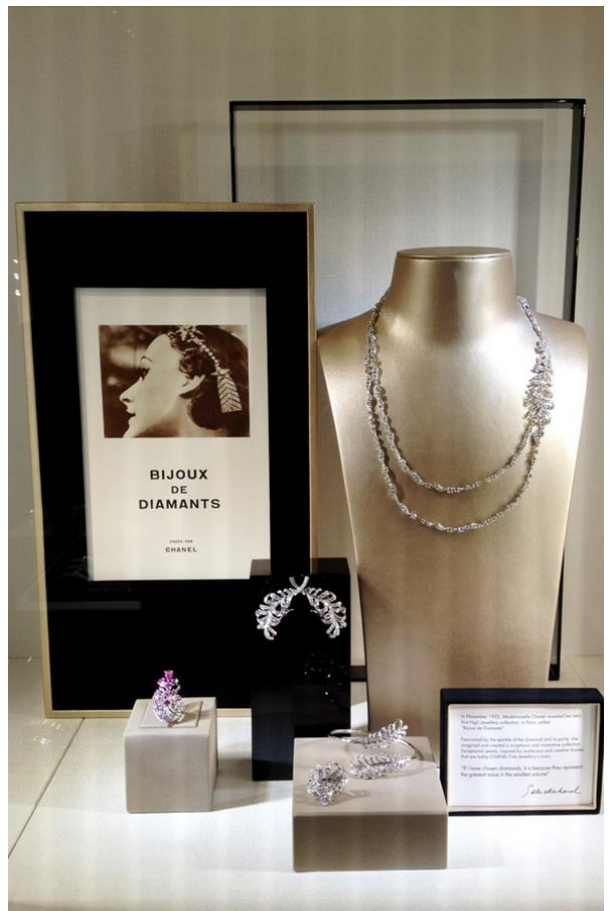

Figure 150 B: Chanel London Flagship Store on Bond Street- Fine Jewelry

Source: Karmali, Sarah. Inside Chanel's New London Flagship. Vogue UK News, 10 June 2013. Web. 23 March 2014. Online. 


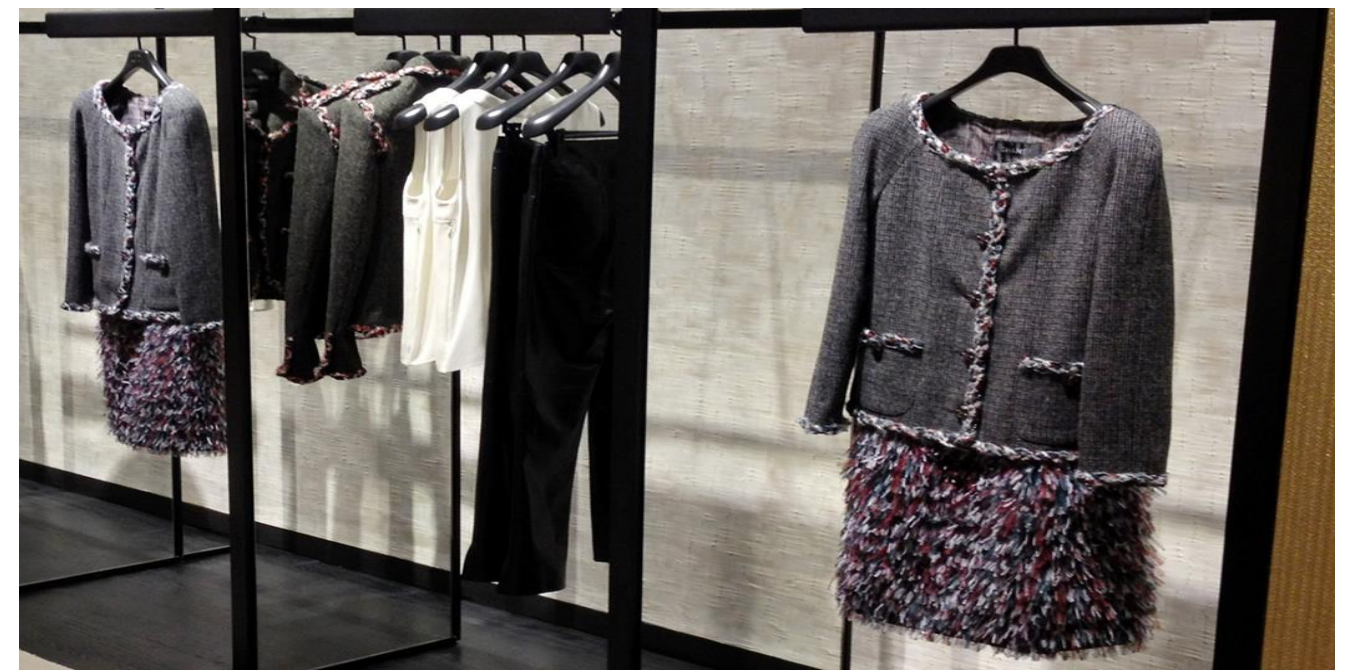

Figure 150 C: Chanel London Flagship Store on Bond Street- Ready-To-Wear

Source: Karmali, Sarah. Inside Chanel's New London Flagship. Vogue UK News, 10 June 2013. Web. 23 March 2014. Online.

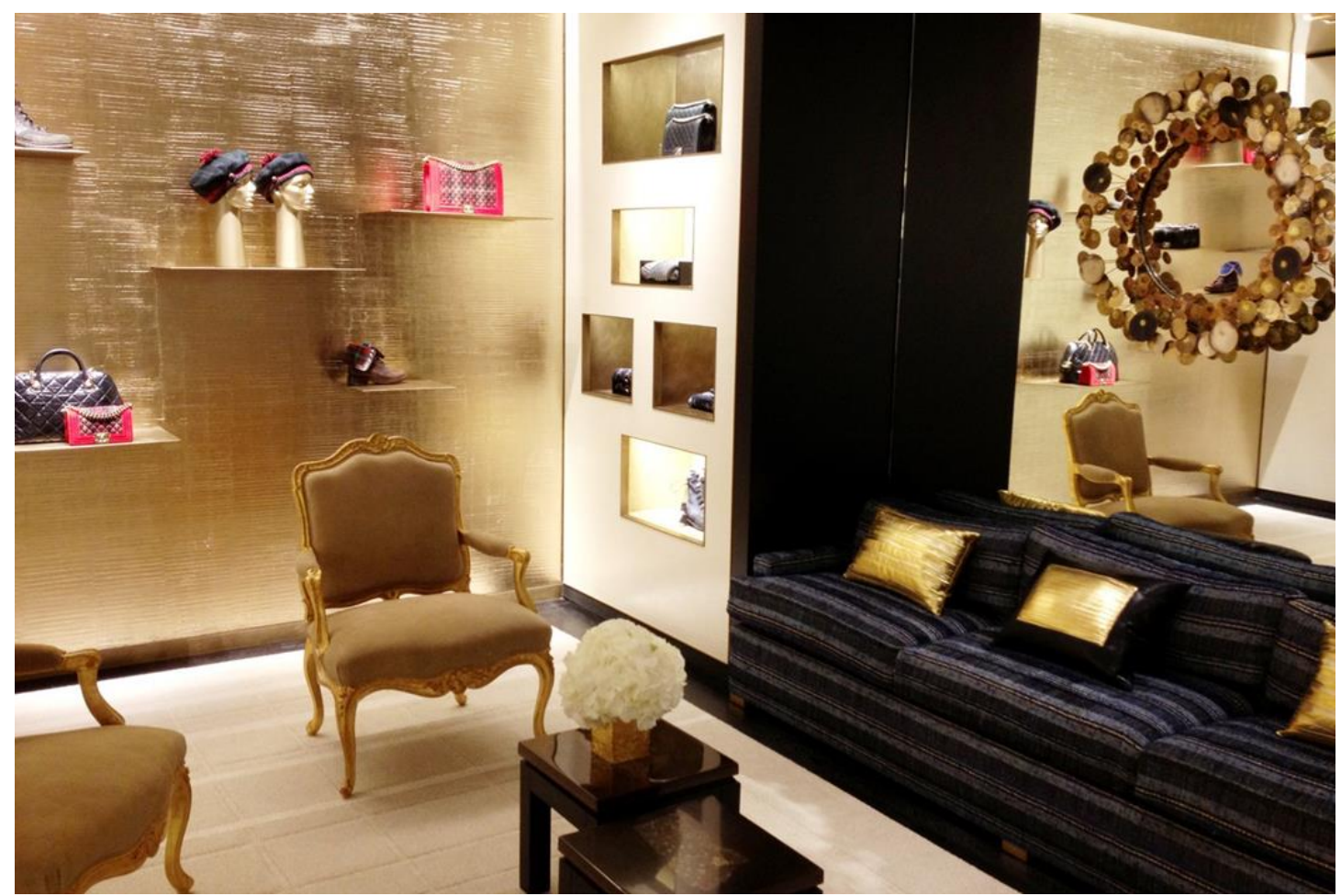

Figure 150 D: Chanel London Flagship Store on Bond Street- Gold Room

Source: Karmali, Sarah. Inside Chanel's New London Flagship. Vogue UK News, 10 June 2013. Web. 23 March 2014. Online. 


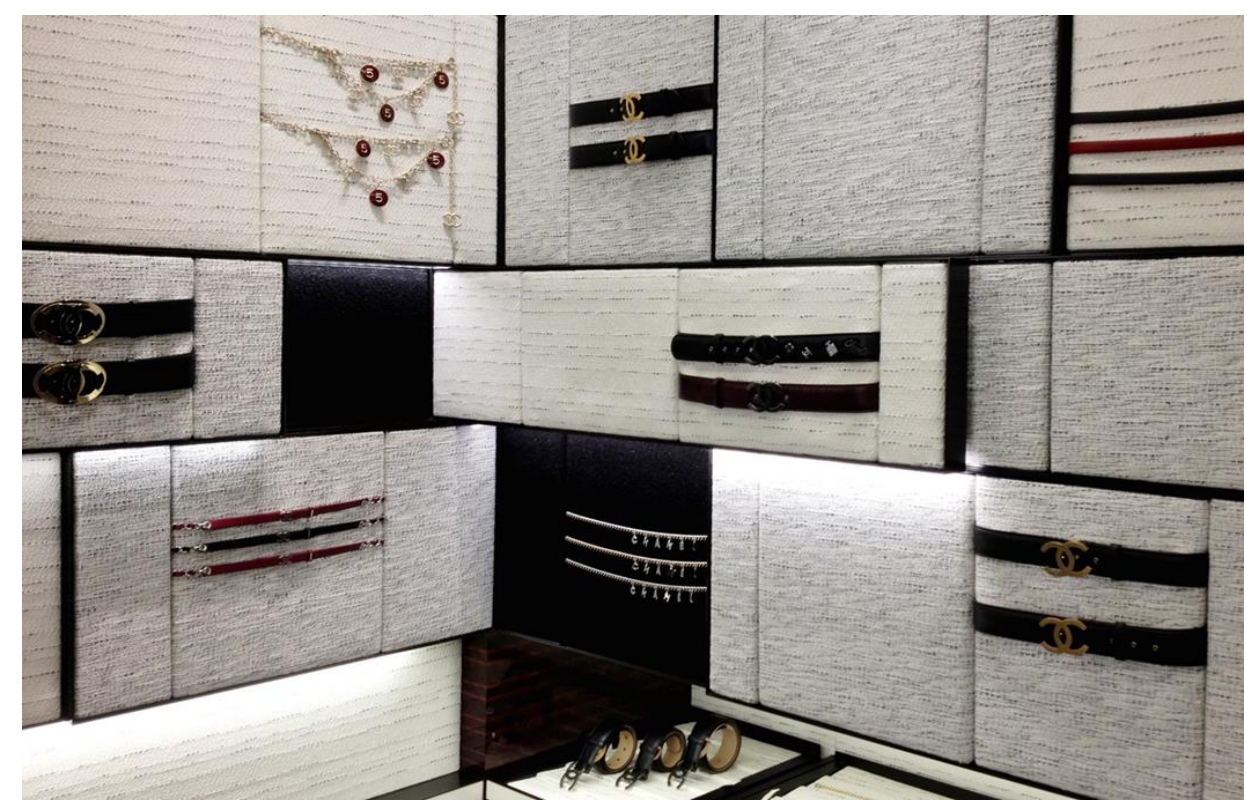

Figure 150 E: Chanel London Flagship Store on Bond Street- Accessories, Belts

Source: Karmali, Sarah. Inside Chanel's New London Flagship. Vogue UK News, 10 June 2013. Web. 23 March 2014. Online.

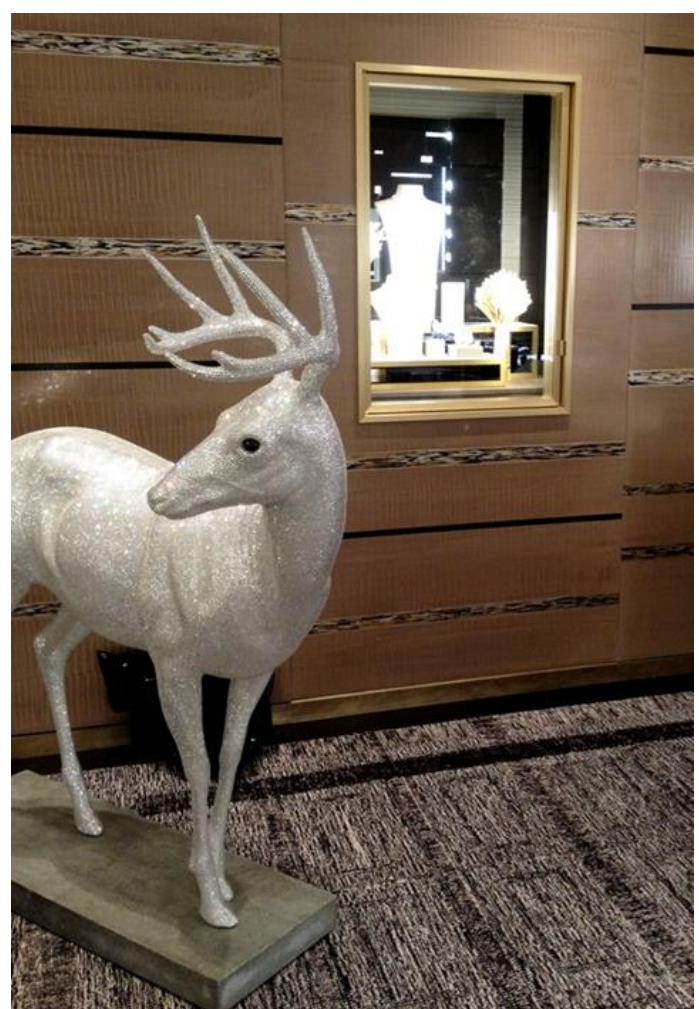

Figure 151: Chanel London Flagship Store on Bond Street- Mark Swanson Rhinestone Deer Deer

Source: Karmali, Sarah. Inside Chanel's New London Flagship. Vogue UK News, 10 June 2013. Web. 23 March 2014. Online. 


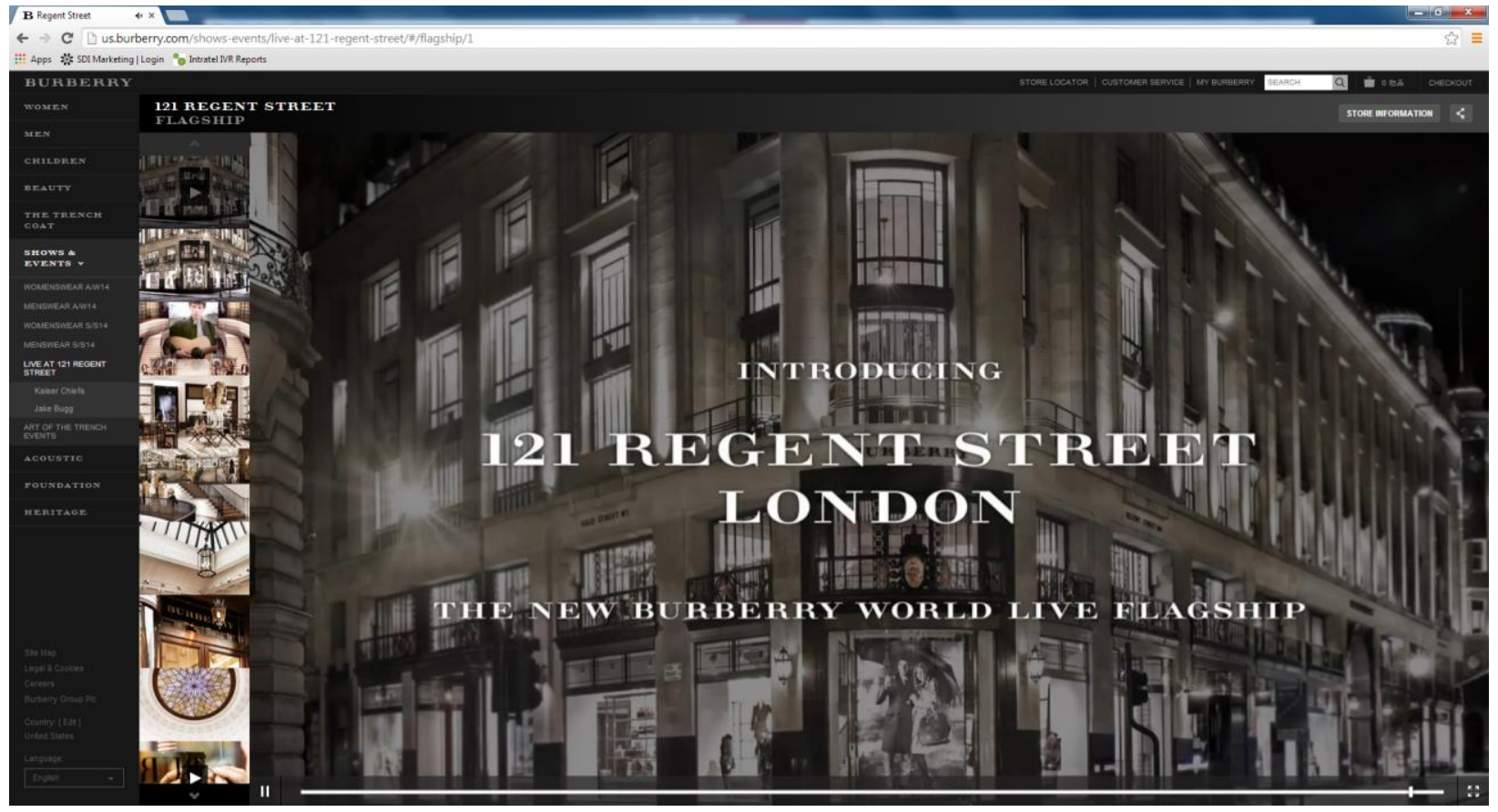

Figure 152 A: Burberry Official Website- London Burberry Regent Street Flagship Store

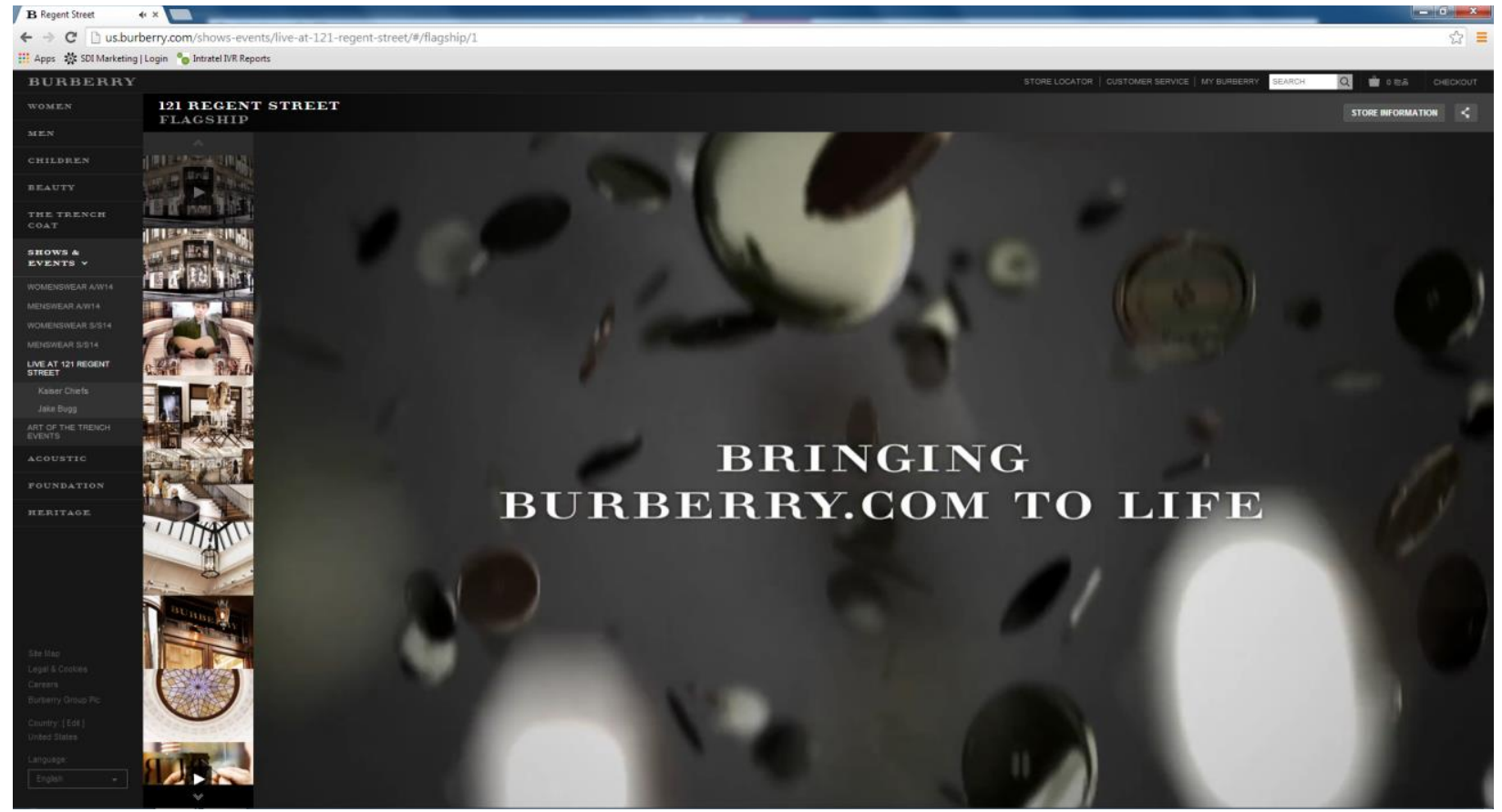

Figure 152 B: Burberry Official Website- London Burberry Regent Street Flagship Store 


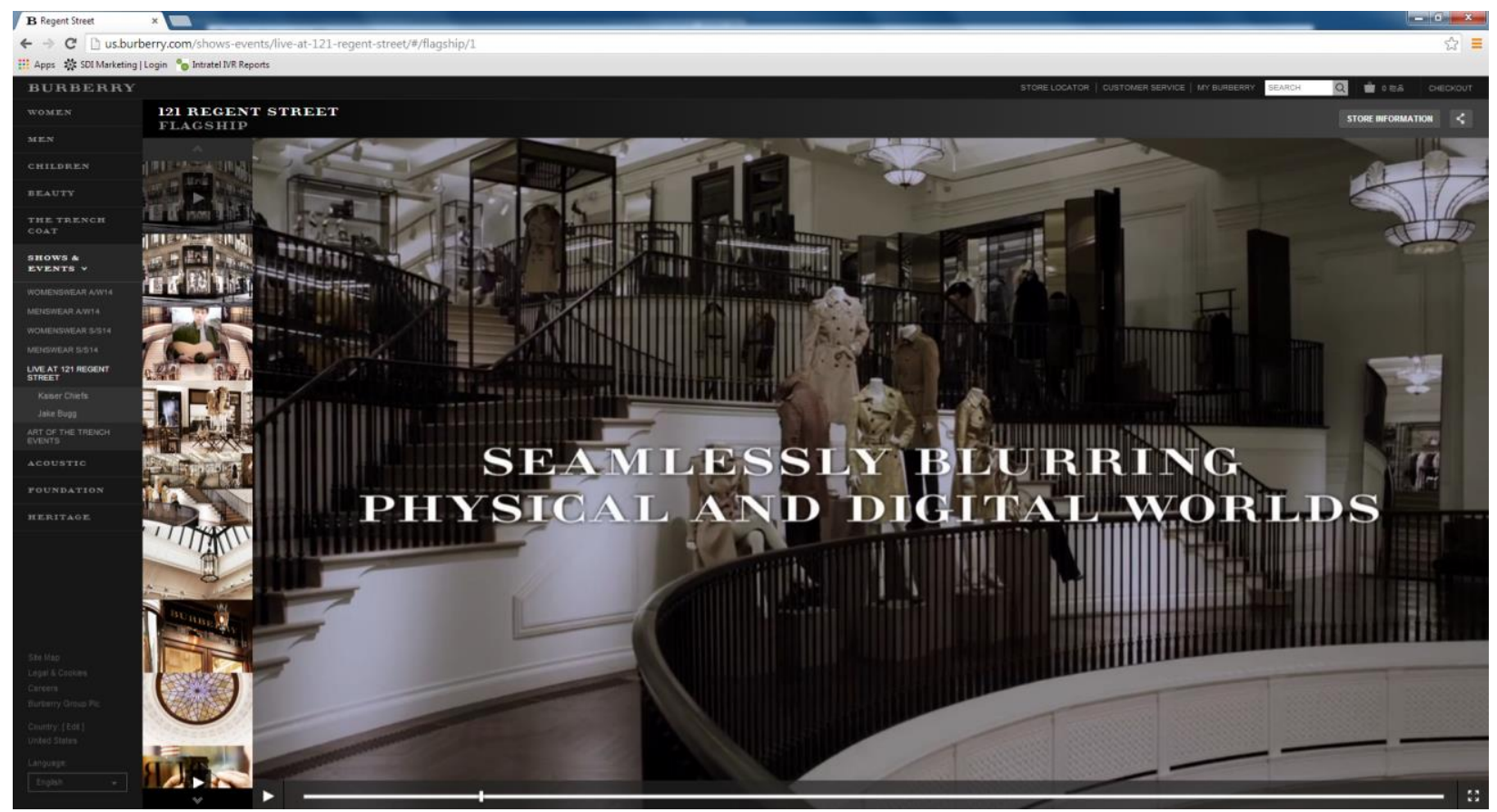

Figure 152 C: Burberry Official Website- London Burberry Regent Street Flagship Store

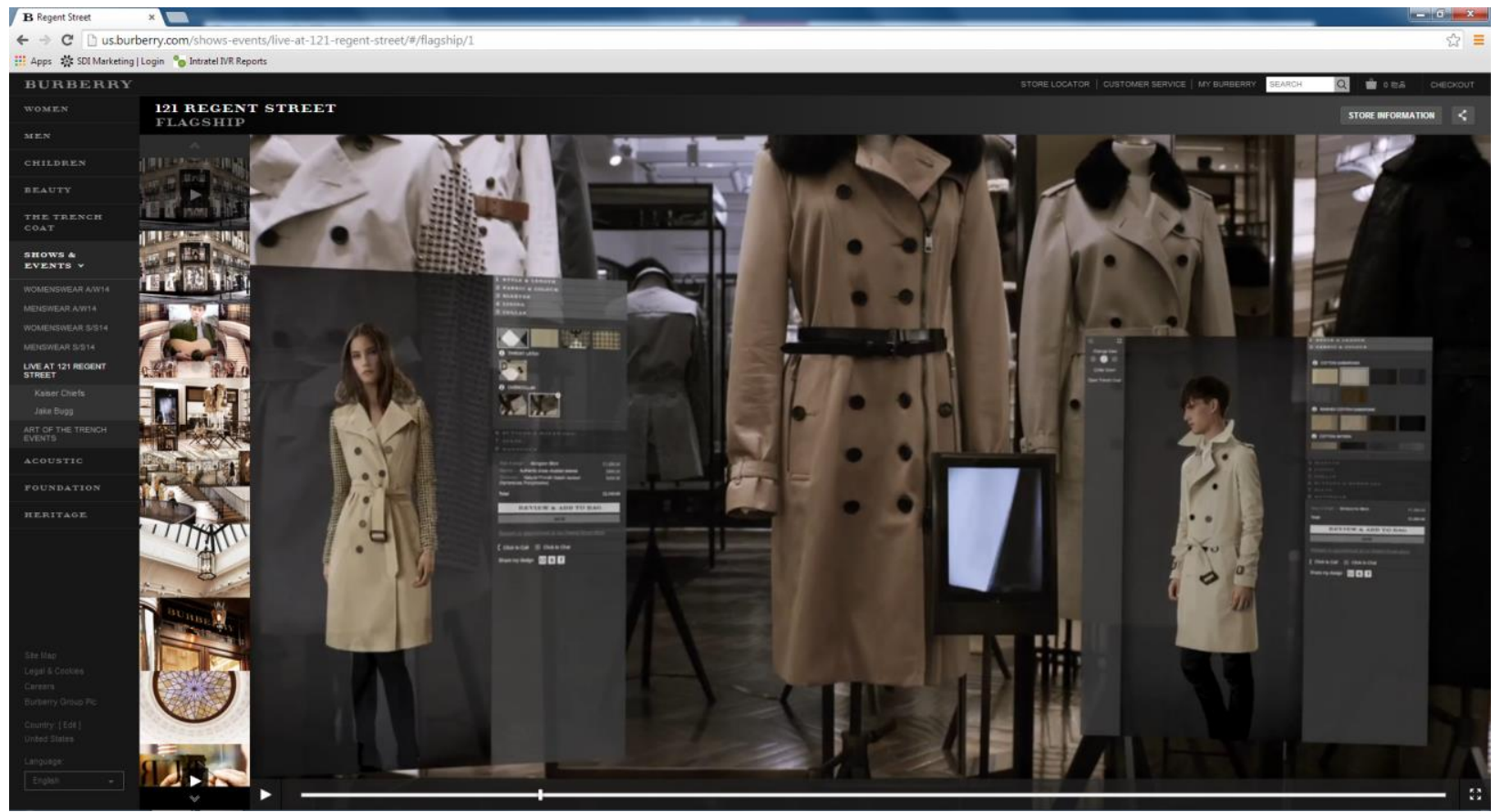

Figure 152 D: Burberry Official Website- London Burberry Regent Street Flagship Store 


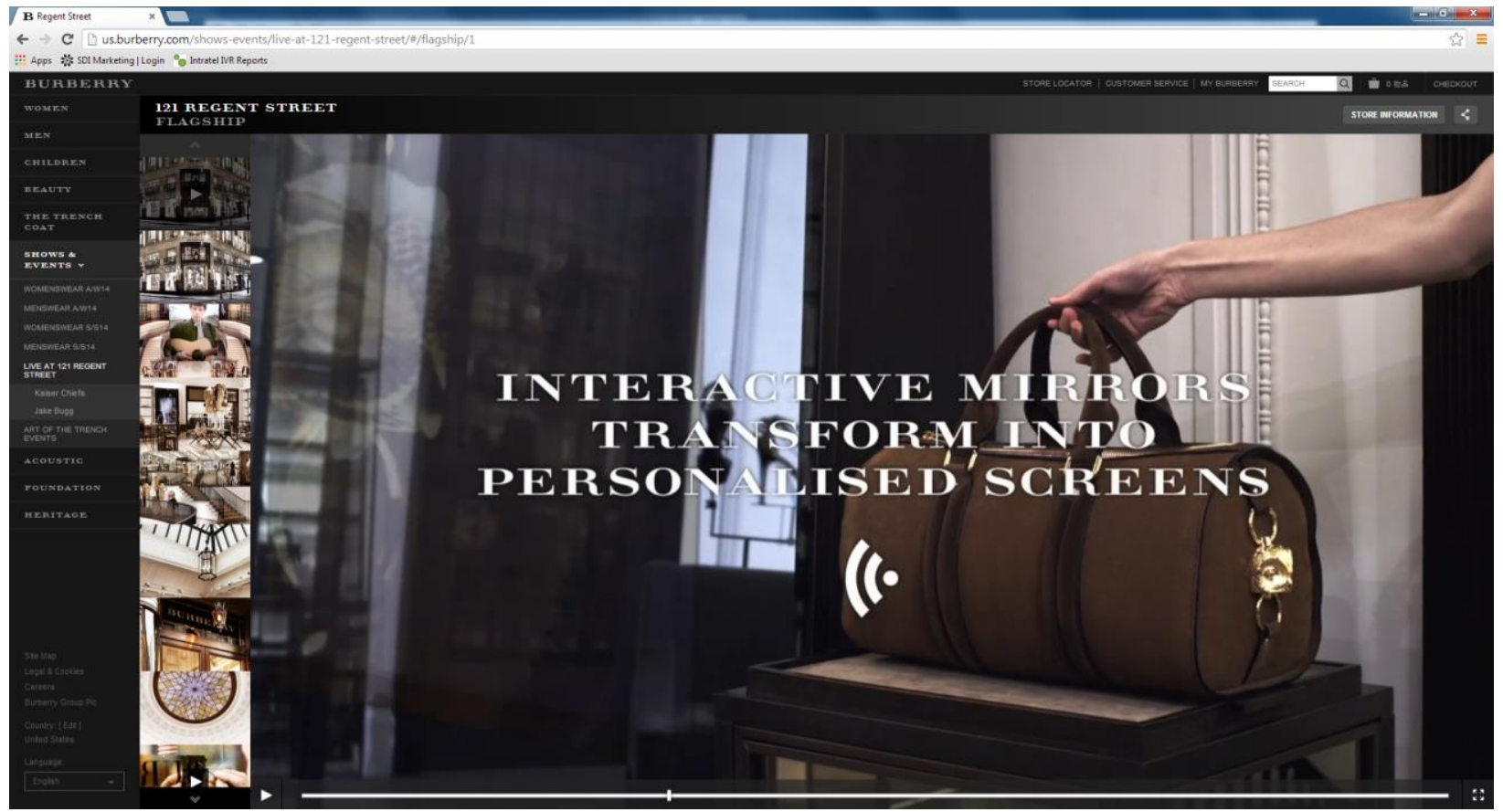

Figure 152 E: Burberry Official Website- London Burberry Regent Street Flagship Store

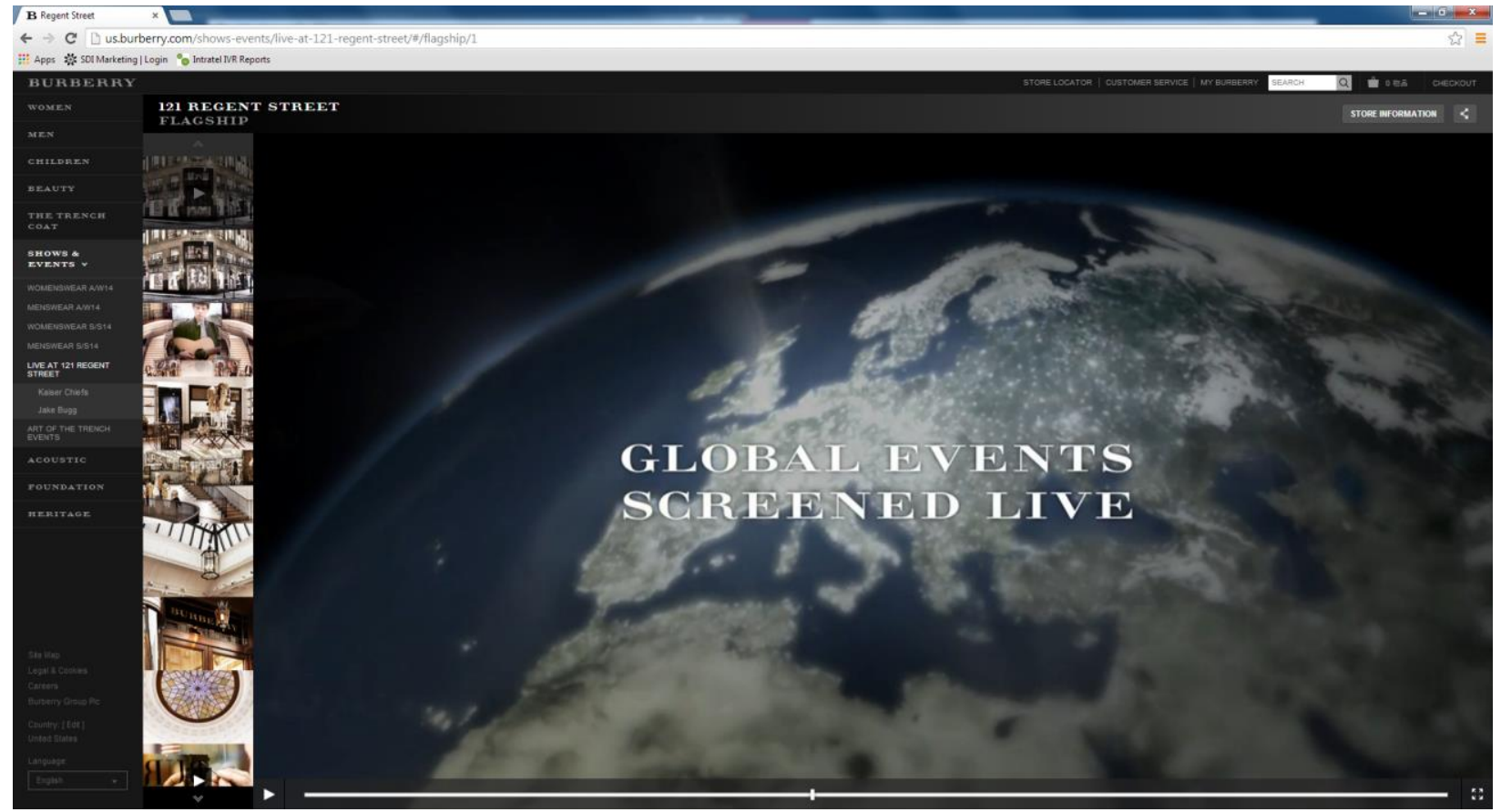

Figure 152 F: Burberry Official Website- London Burberry Regent Street Flagship Store 


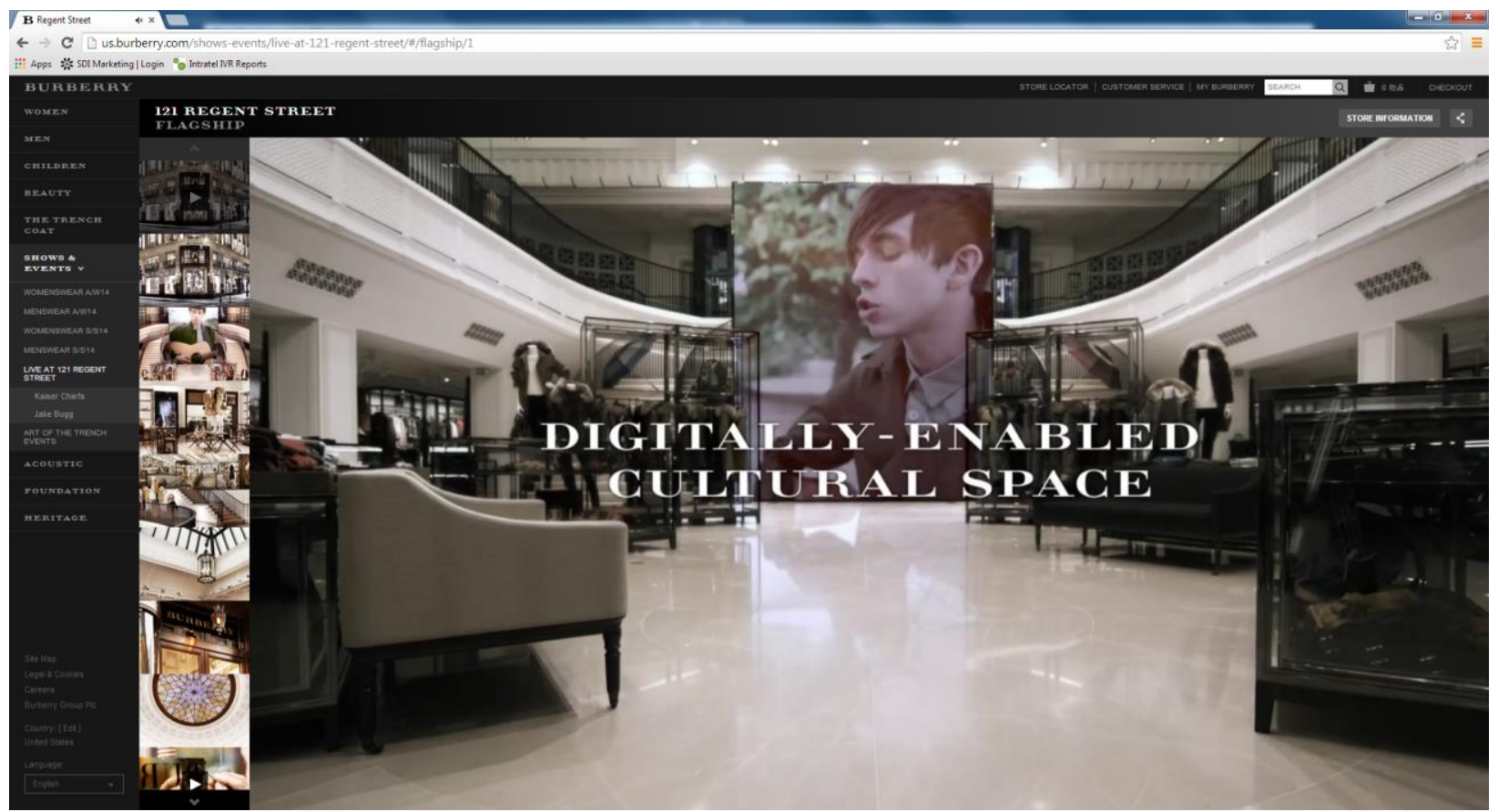

Figure 152 G: Burberry Official Website- London Burberry Regent Street Flagship Store

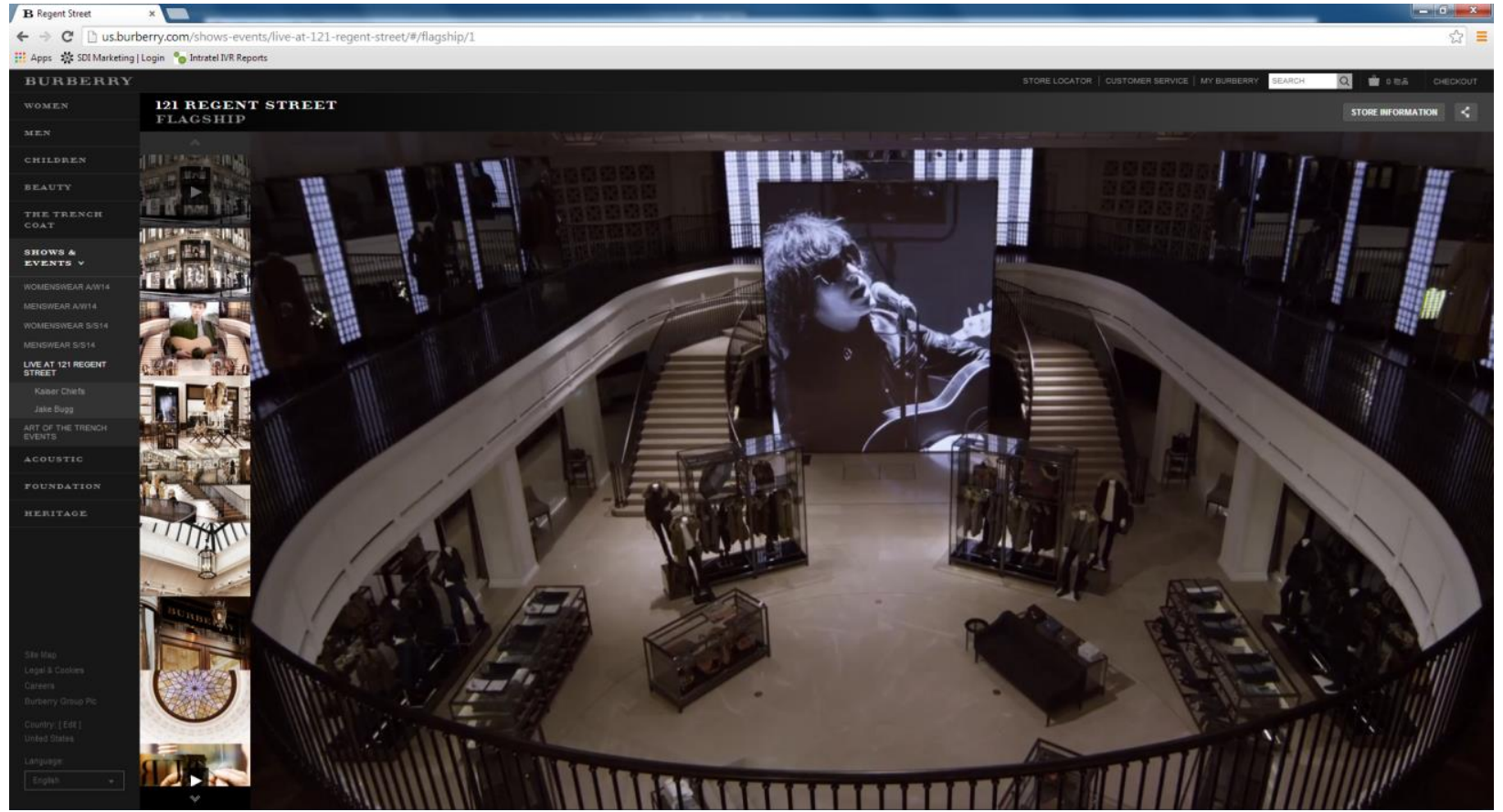

Figure 152 H: Burberry Official Website- London Burberry Regent Street Flagship Store 


\section{Appendix 35: PHASE TWO: NINTH DIMENSION: CULTURE}

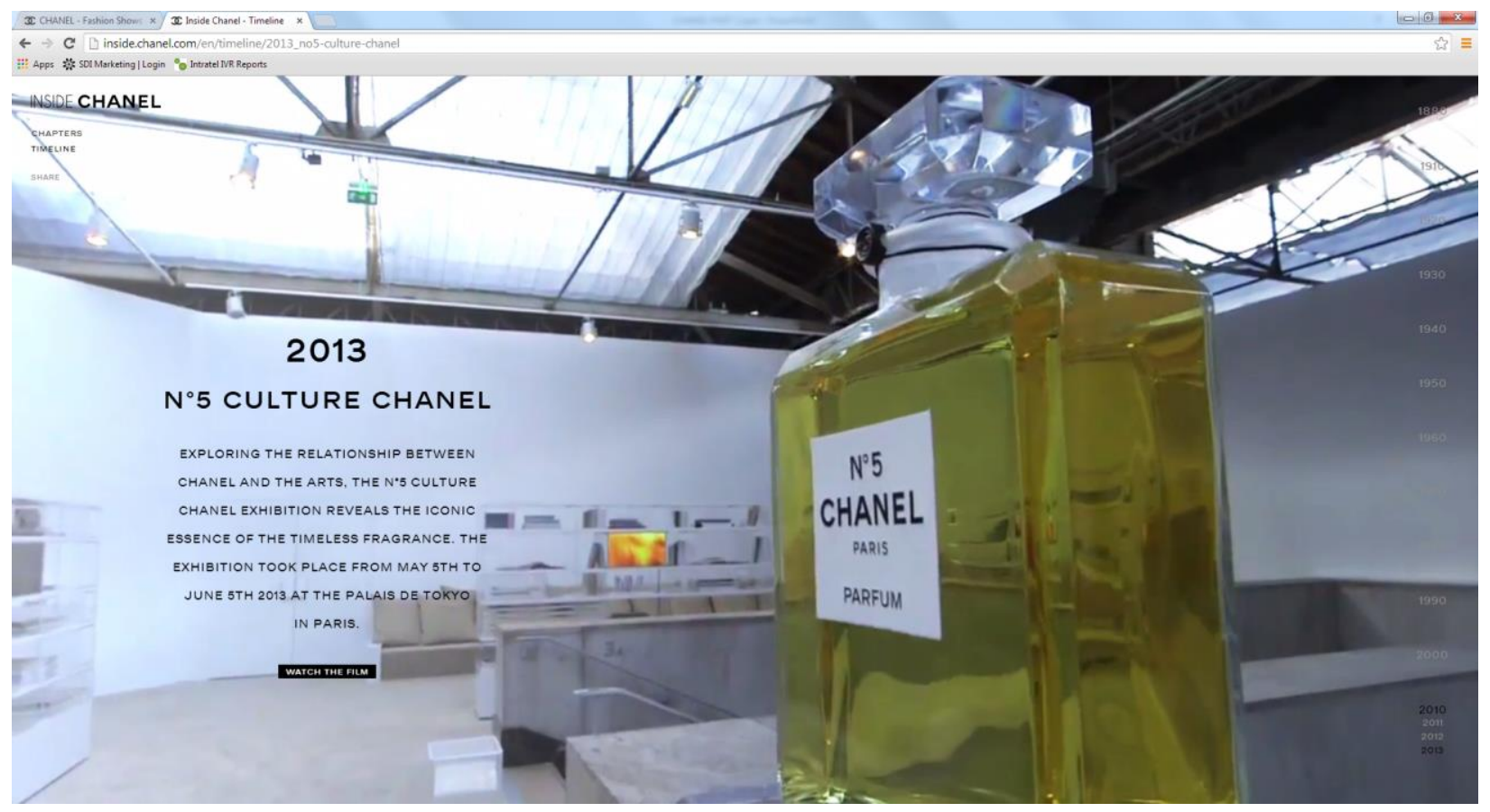

Figure 153: Chanel Official Website- N5 Culture Chanel Exhibit

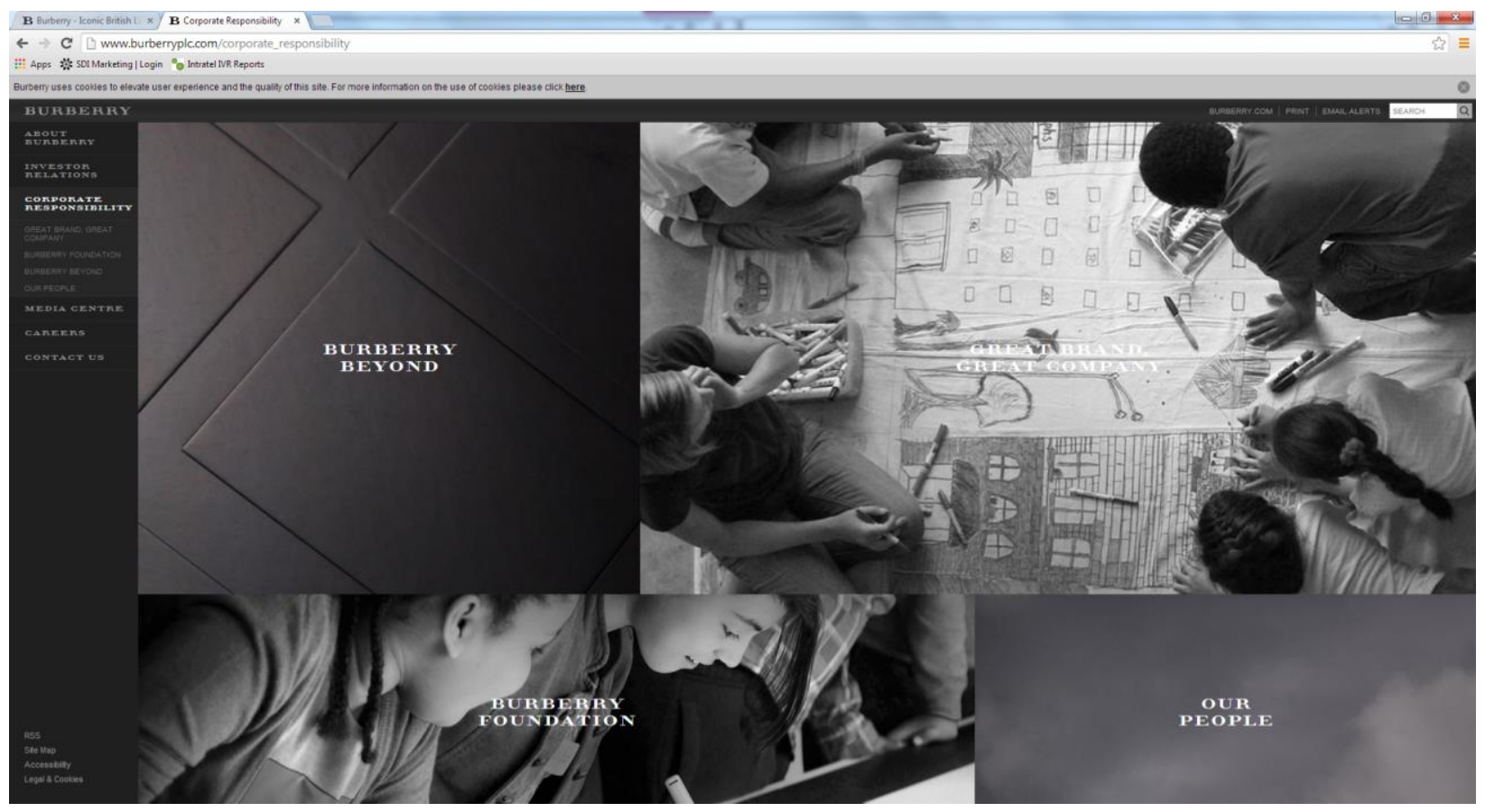

Figure 154: Burberry Official Website- Corporate Responsibility 